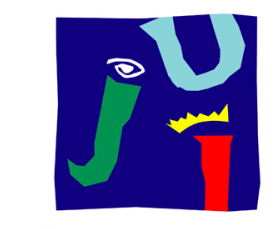

UNIVERSITAT

JAUME•I

\title{
Development of High Temperature Heat Pumps for Industrial Waste Heat Recovery
}

A dissertation presented by Carlos Mateu-Royo for the Degree of Doctor of Philosophy

DOCTORAL THESIS

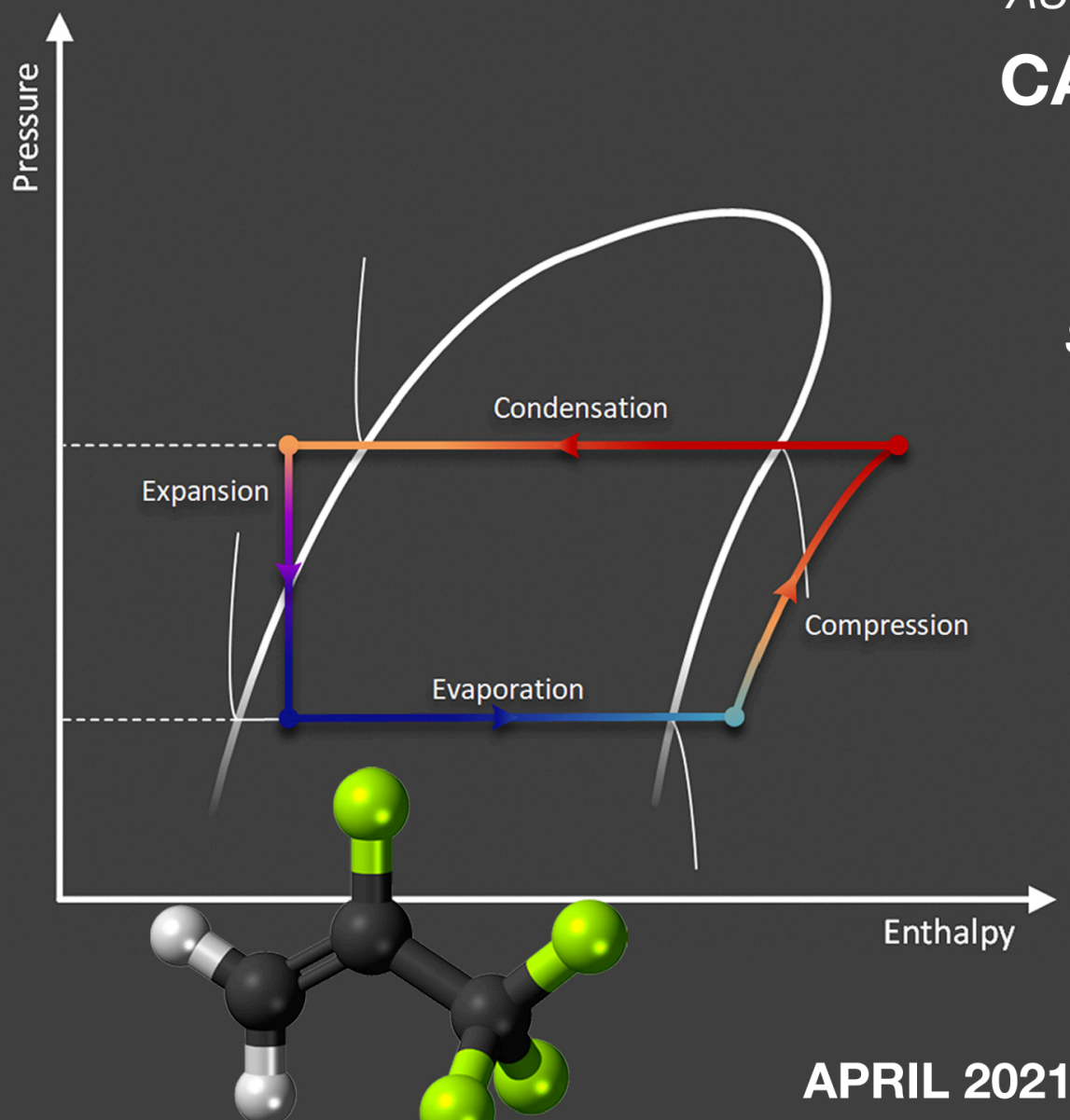

AUTHOR:

CARLOS MATEU ROYO

SUPERVISORS:

DR. JOAQUÍN NAVARRO ESBRÍ

DR. ADRIÁN MOTA BABILONI

APRIL 2021 



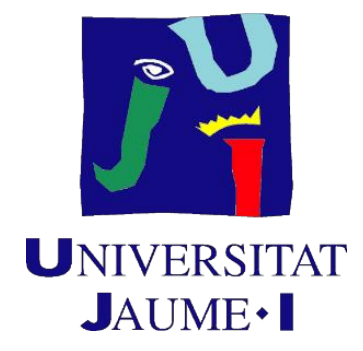

TESIS DOCTORAL

ESCUELA DE DOCTORADO DE LA UNIVERSITAT JAUME I

PROGRAMA DE DOCTORADO EN TECNOLOGÍAS INDUSTRIALES Y MATERIALES

\section{Desarrollo de Bombas de Calor de Alta Temperatura para la Recuperación de Calor Residual Industrial}

Memoria presentada por Carlos Mateu-Royo para optar al grado de doctor por la Universiat Jaume I

AUTOR:

CARLOS MATEU ROYO
DIRECTORES:

DR. JOAQUÍN NAVARRO ESBRÍ

DR. ADRIÁN MOTA BABILONI 



\section{FINNANCIAL SUPPORT}

This thesis has been realised with the financial support of the following institutions and projects:

\section{$\underline{\text { Research contract: }}$}

- Full-time temporal researcher at the project: "Desarrollo sistema híbrido bomba de calor de alta temperatura/ciclo Rankine orgánico para mejorar aprovechamiento de fuentes térmicas residuales y renovable". Financed by the Spanish Government (Ref. ENE2015-70610-R and RTC-2015-4193-3) 16 ${ }^{\text {st }}$ June $2017-30^{\text {th }}$ September 2018

\section{Predoctoral contract:}

- Ayuda predoctoral para la formación de personal investigador FPI - UJI, dentro del Plan de Promoción de la Investigación de la UJI 2017 (Ref. PREDOC/2017/41). Universitat Jaume I. $1^{\text {st }}$ October $2018-30^{\text {th }}$ September 2020

\section{Research stay:}

- Royal Institute of Technology (KTH), Stockholm, Sweden $\left(2^{\text {nd }}\right.$ September $2019-1^{\text {st }}$ November 2019). Financed by Beca para realizar estancias temporales en otros centros de investigación, para el personal docente e investigador de la Universidad del Plan de Promoción de la Investigación de la UJI 2019 (Ref. E-2019-28).

- Royal Institute of Technology (KTH), Stockholm, Sweden (14 $4^{\text {st }}$ July $2020-14^{\text {st }}$ August 2020). Online research stay. 



\section{COMPENDIUM OF PUBLICATIONS}

- Mateu-Royo, C., Navarro-Esbrí, J., Mota-Babiloni, A., Amat-Albuixech, M., Molés, F. Stateof-the-art of high-temperature heat pumps for low-grade waste heat recovery. Presented at 11th National and 2nd International Engineering Thermodynamics Congress (11CNIT) (2019).

- Mateu-Royo, C., Navarro-Esbrí, J., Mota-Babiloni, A., Amat-Albuixech, M., Molés, F. Theoretical evaluation of different high-temperature heat pump configurations for low-grade waste heat recovery. International Journal of Refrigeration 90, 229 - 237 (2018).

DOI: $\underline{10.1016 / j . i j r e f r i g .2018 .04 .017}$

CiteScore: 6.1 - Impact Factor: 3.461

- Mateu-Royo, C., Navarro-Esbrí, J., Mota-Babiloni, A., Amat-Albuixech, M., Molés, F. Thermodynamic analysis of low GWP alternatives to HFC-245fa in high-temperature heat pumps: HCFO-1224yd(Z), HCFO-1233zd(E) and HFO-1336mzz(Z). Applied Thermal Engineering 152, 762 - 777 (2019).

DOI: 10.1016/j.applthermaleng.2019.02.047

CiteScore: 8.8 - Impact Factor: 4.725

- Mateu-Royo, C., Navarro-Esbrí, J., Mota-Babiloni, A., Molés, F., Amat-Albuixech, M. Experimental exergy and energy analysis of a novel high-temperature heat pump with scroll compressor for waste heat recovery. Applied Energy 253, 113504 (2019).

DOI: $10.1016 /$ j.apenergy.2019.113504

CiteScore: 16.4 - Impact Factor: 8.848

- $\quad$ Mateu-Royo, C., Mota-Babiloni, A., Navarro-Esbrí, J. Semi-empirical and environmental assessment of the low GWP refrigerant HCFO-1224yd(Z) to replace HFC-245fa in high temperature heat pumps. International Journal of Refrigeration $(2021)^{*}$

DOI: $\underline{10.1016 / j . i j r e f r i g .2021 .02 .018}$

CiteScore: 6.1 - Impact Factor: 3.461

- Mateu-Royo, C., Mota-Babiloni, A., Navarro-Esbrí, J., Peris, B., Molés, F., Amat-Albuixech, M. Multi-objective optimisation of a novel reversible High-Temperature Heat Pump-Organic Rankine Cycle (HTHP-ORC) for industrial low-grade waste heat recovery. Energy Conversion and Management 197, 111908 (2019).

DOI: $10.1016 /$ j.enconman.2019.111908

CiteScore: 13.6 - Impact Factor: 8.208

\footnotetext{
* Extended version of the awarded study for the Best Paper by a Student Author on the Theme of Working Fluids at the IIR International Conference Rankine 2020 - Applications of Cooling, Heating and Power Generation, Glasgow, July 27-31, 2020.
} 
- Mateu-Royo, C., Sawalha, S., Mota-Babiloni, A., Navarro-Esbrí, J. High temperature heat pump integration into district heating network. Energy Conversion and Management 210, $112719(2020)$.

DOI: $10.1016 /$ j.enconman.2020.112719

CiteScore: 13.6 - Impact Factor: 8.208

"This thesis has been accepted by the co-authors of the publications listed above that have waved the right to present them as a part of another $\mathrm{PhD}$ thesis" 
Para mis padres y mi abuela, por darme siempre su incondicional apoyo y la libertad de elegir mi camino. 



\section{ACKNOWLEDGEMENTS}

First, I would like to thank my supervisors: Ximo, for his guidance, dedication, and mostly, I appreciate the confidence placed in me and for giving me the opportunity to start in the research world. Without your wise advice and patience, this thesis would not have been possible. I will always keep in mind the exciting and helpful conversations during the coffee hour and "Luxury" lunch. The other basic essential in this thesis is my other supervisor and colleague, Adrián, to who I am enormously grateful for being fundamental support in all of this journey. Your constant advice, revisions and teaching have achieved that this thesis becomes a reality. I will always be grateful for giving me incredible moral support, not only as a professional but also personal during these years. You are a fantastic person.

I would like to thank the rest of ISTENER research group for their collaboration during all these years. Because all the knowledge does not come from the literature, I would like to express my gratitude to Ángel for his extensive experience in real installations and funny anecdotes that has been made this process more realistic as well as enjoyable. Y por supuesto, quiero agradecer a Ángel (Padre de Ángel) por todos los momentos en el laboratorio y todo el conocimiento que me ha ido enseñando de su larga experiencia tratando con sistemas de compresión de vapor. Also, Fran, Bernardo, Javier and José Manuel, because of their help in some specific times, giving me the possibility to continue this thesis.

I want to thank the entities for the financial support that have been contributed to this thesis: the Universitat Jaume I for the predoctoral grant through the FPI-UJI program (PREDOC/2017/41), the research stay grant (E-2019-28) and the funding to the project (UJI-B2018-24).

Similarly, I would like to express my sincere gratitude to Samer Sawalha from the Royal Institute of Technology (KTH) for giving me the chance to go back to Stockholm during my research stay, this time as $\mathrm{PhD}$ candidate. It was a pleasure to work together with you during these months and obtain other research perspectives that I will keep in my mind. Also, my colleagues Sotiris and Mazyar for making me more enjoyable my research stay in Stockholm.

I would like to express my gratitude to the people at Universitat Jaume I, especially at the Department of Mechanical Engineering and Construction, where I realised this thesis and was a pleasure to share the lunches and meetings with all of you. Thanks to the administrative staff of the department (Marian and Rosa) to make me easier all the documentation processes.

Of course, I would like to thank my PhD colleagues Josep, Alexandra, Marta, Laura, Núria and Daniel for the shared conversations, laughs and anecdotes during the necessary coffee and lunches breaks. Castellón was a new place for me, but you made me feel at home. I will keep in my mind all the good moments during the dinners, parties and congresses that would not have been the same without you. Thank you very much.

Finalmente, quiero agradecer a mi familia todo su incondicional apoyo. A mi abuela, que desde bien pequeño me ha inculcado el trabajar duro para ser, según dice ella: "Un hombre de provecho el día de mañana". Y a mis padres, incombustibles en su empeño de apoyarme en todos y cada uno de mis proyectos, siendo como la luz de los faros, que guían siempre a los barcos, incluso en las más colosales tormentas. Muchas gracias por creer tanto en mí. 



\section{ABSTRACT}

One of the major challenges of this decade is developing more sustainable energy systems that contribute to environmental concern, especially climate change mitigation. Heat pump systems have received significant attention as a potential technology that can deal with this challenge thanks to their high energy efficiency and low carbon emissions compared to the conventional fossil fuel heating technology. However, this technology has temperature operating limitations that should be overcome in order to extend its applications and, above all, allow the integration of this technology in the industrial sector as sustainable heating and waste heat recovery systems.

Extending the operating conditions of the heat pump technology to higher temperatures will allow decarbonising the industrial sector from two slopes: recovering heat from waste heat sources that currently is being rejected to the ambient and produce heat at the required industrial thermal levels that become useful for the industrial processes. Both challenges will reduce the equivalent $\mathrm{CO}_{2}$ emissions of the industrial sector, contributing to sustainable development. These developments will represent a step forward of the heat pump technology, making possible their operation at high temperatures. Hence, these systems obtained a different classification known as high temperature heat pumps (HTHPs).

This thesis is intended to deal with the development of high temperature heat pumps through a comprehensive theoretical and experimental analysis to overcome different technology challenge: architecture, refrigerants, experimental prototype, advanced applications and system integration, providing new knowledge that represents a step forward in high temperature heat pump technology and sustainable industrial development.

The main results obtained in this study show that HFC-245fa becomes the most used refrigerant in HTHPs, but due to its high global warming potential of 848 , it should be replaced with alternative sustainable refrigerants. HC-601 (Pentane), HC-600 (Butane), R-514A, HFO-1336mzz(Z), HCFO$1233 z d(E)$ and HCFO-1224yd(Z) become a potential low GWP alternative refrigerant to replace HFC-245fa, being the last three refrigerants the most promising candidates. These candidates present material compatibility with the most common elastomers and oil lubricants (POE). Moreover, singlestage and two-stage configurations are the most common architectures in commercial, research and development systems, including the use of an internal heat exchanger (IHX) in most of the configurations. Reciprocating and screw compressors are the most used technologies in this system, becoming scroll compressors an interesting research gap to be studied.

The HTHP prototype with scroll compressor provides significant performance improvements for lowgrade waste heat recovery. At a heat source temperature of $80{ }^{\circ} \mathrm{C}$ and heat sink temperature of 140 ${ }^{\circ} \mathrm{C}$, the COP was 2.23 . The highest COP was 3.41 , achieved at heat source and sink temperatures of 80 and $110{ }^{\circ} \mathrm{C}$, respectively. The exergy analysis illustrated the areas of potential performance improvements. The compressor is the cycle component with the highest irreversibility and therefore, has the highest margin of improvement. Mechanical design and lubrication improvements in this component could increase the overall system efficiency. The semi-empirical computational evaluation showed that either HCFO-1233zd(E) or HCFO-1224yd(Z) could be used as a possible drop-in replacement HFC-245fa in high-temperature heat pumps. 



\section{RESUMEN}

Uno de los mayores desafíos de esta década recae en el desarrollo de sistemas energéticos más sostenibles que contribuyan a la preocupación medioambiental, especialmente a la mitigación del cambio climático. Los sistemas de bombas de calor han recibido especial atención como una potencial tecnología capaz de lidiar con este desafío, gracias a su alta eficiencia energética y las bajas emisiones de carbono, comparado con las tecnologías convencionales de calefacción basadas en combustibles fósiles. Sin embargo, esta tecnología tiene unas limitaciones térmicas de temperatura que conviene superar para poder extender sus aplicaciones y, sobre todo, permitir la integración de esta tecnología en el sector industrial como sistemas sostenibles de calefacción y recuperación de calor residual.

Extender las condiciones de funcionamiento de la tecnología de bomba de calor a temperaturas más elevadas permitirá descarbonizar el sector industrial desde dos vertientes: recuperar calor de fuentes de calor residual, que actualmente está siendo disipado al ambiente y producir calor a los niveles térmicos requeridos industrialmente, útiles para los procesos industriales. Ambas vertientes reducirán las emisiones de $\mathrm{CO}_{2}$ equivalentes del sector industrial, contribuyendo al desarrollo sostenible. Estos desarrollos supondrán un paso adelante en la tecnología de bomba de calor, haciendo posible su funcionamiento a altas temperaturas. Este avance tecnológico, supone una nueva clasificación en este tipo de sistemas, conociéndose como bombas de calor de alta temperatura (BCAT).

Esta tesis pretende abordar el desarrollo de bombas de calor de alta temperatura a través de un análisis teórico y experimental integral, para superar los diferentes desafíos tecnológicos: arquitectura, refrigerantes, prototipo experimental, aplicaciones avanzadas e integración de sistemas, generando nuevos conocimientos que representan un paso adelante en la tecnología de bombas de calor de alta temperatura y desarrollo industrial sostenible.

Los principales resultados obtenidos en este estudio muestran que el HFC-245fa se convierte en el refrigerante más utilizado en las BCAT, pero debido a su alto potencial de calentamiento atmosférico (PCA) de 848, debe ser reemplazado por refrigerantes más sostenibles. HC-601 (Pentano), HC-600 (Butano), R-514A, HFO-1336mzz (Z), HCFO-1233zd (E) y HCFO-1224yd (Z) se convierten en potenciales refrigerantes alternativos con bajo PCA para reemplazar al HFC-245fa, siendo estos tres últimos, los candidatos más prometedores. Estos refrigerantes presentan compatibilidad de material con la mayoría de los elastómeros y aceites lubricantes (POE). Además, las configuraciones de una y dos etapas son las arquitecturas más comunes en los sistemas comerciales, de investigación y desarrollo, incluyendo el uso de intercambiador de calor interno (IHX) en la mayoría de las configuraciones. Los compresores alternativos y de tornillo son las tecnologías más utilizadas en este tipo de sistemas, convirtiendo a los compresores tipo scroll en una interesante tecnología a investigar y desarrollar.

El prototipo de BCAT con compresor scroll proporciona importantes mejoras de rendimiento para la recuperación de calor residual. A una temperatura de la fuente de calor de $80^{\circ} \mathrm{C}$ y una temperatura del disipador de calor de $140{ }^{\circ} \mathrm{C}$, este sistema presenta un COP de 2.23 , llegando incluso a 3.41 a temperaturas de fuente de calor y sumidero de 80 y $110{ }^{\circ} \mathrm{C}$, respectivamente. El análisis de exergía muestra las áreas de posibles mejoras de rendimiento. El compresor es uno de los componentes del ciclo con mayor irreversibilidad y, por tanto, tiene un gran margen de mejora. Las mejoras en el diseño mecánico y la lubricación de este componente podrían aumentar la eficiencia general del 
sistema. Finalmente, la evaluación semi-empírica muestra que el HCFO-1233zd (E) o el HCFO$1224 y d(Z)$ podrían usarse como un posible reemplazo directo del HFC-245fa en bombas de calor de alta temperatura. 


\section{RESUM}

Un dels majors desafiaments d'aquesta dècada recau en el desenvolupament de sistemes energètics més sostenibles que contribueixen a la preocupació mediambiental, especialment a la mitigació del canvi climàtic. Els sistemes de bombes de calor han rebut especial atenció com una potencial tecnologia capaç de tractar aquest desafiament, gràcies a la seua alta eficiència energètica i les baixes emissions de carboni, comparat amb les tecnologies convencionals de calefacció basades en combustibles fòssils. No obstant això, aquesta tecnologia té unes limitacions tèrmiques de temperatura que convé superar per poder estendre les seues aplicacions i, sobretot, permetre la integració d'aquesta tecnologia en el sector industrial com a sistemes sostenibles de calefacció i recuperació de calor residual.

Estendre les condicions de funcionament de la tecnologia de bomba de calor a temperatures més elevades permetrà descarbonitzar el sector industrial des de dos vessants: recuperar calor de fonts de calor residual, que actualment està sent dissipat a l'ambient i produir calor als nivells tèrmics requerits, útils per als processos industrials. Les dues vessants reduiran les emissions de $\mathrm{CO} 2$ equivalents del sector industrial, i contribuiran al desenvolupament sostenible. Aquests desenvolupaments suposaran una millora en la tecnologia de bomba de calor, i faran possible el seu funcionament a altes temperatures amb una nova classificació, tot coneixent-se com bombes de calor d'alta temperatura (BCAT).

Aquesta tesi pretén abordar el desenvolupament de bombes de calor d'alta temperatura a través d'una anàlisi teòrica i experimental integral, per superar els diferents reptes tecnològics: arquitectura, refrigerants, prototip experimental, aplicacions avançades i integració de sistemes, tot generant nous coneixements que representen un pas endavant en la tecnologia de bombes de calor d'alta temperatura i desenvolupament industrial sostenible.

Els principals resultats obtinguts en aquest estudi mostren que el HFC-245fa es converteix en el refrigerant més utilitzat en les BCAT, però a causa del seu alt potencial d'escalfament atmosfèric (PEA) de 848, ha de ser reemplaçat per refrigerants més sostenibles. HC-601 (Pentà), HC-600 (Butà), R-514A, HFO-1336mzz (Z), HCFO-1233zd (E) i HCFO-1224yd (Z) es converteixen en potencials refrigerants alternatius amb baix PEA per reemplaçar el HFC-245fa, sent aquests tres últims, els candidats més prometedors. Aquests refrigerants presenten compatibilitat de material amb la majoria dels elastòmers i olis lubricants (POE). A més, les configuracions d'una i dues etapes són les arquitectures més comunes en els sistemes comercials, de recerca i desenvolupament, incloent l'ús d'intercanviador de calor intern (IHX) en la majoria de les configuracions. Els compressors alternatius i de cargol són les tecnologies més utilitzades en aquest tipus de sistemes, convertint els compressors tipus scroll en una interessant tecnologia a investigar i desenvolupar.

El prototip de BCAT amb compressor scroll proporciona importants millores de rendiment per a la recuperació de calor residual. A una temperatura de la font de calor de $80^{\circ} \mathrm{C}$ i una temperatura del dissipador de calor de $140{ }^{\circ} \mathrm{C}$, aquest sistema presenta un COP de 2.23, arribant fins i tot a 3.41 a temperatures de font de calor i dissipació de 80 i $110^{\circ} \mathrm{C}$, respectivament. L'anàlisi d'exergia mostra les àrees de possibles millores de rendiment. El compressor és un dels components del cicle amb major irreversibilitat i, per tant, té un gran marge de millora. Les millores en el disseny mecànic i la lubricació d'aquest component podrien augmentar l'eficiència general de sistema. Finalment, 
l'avaluació semi-empírica mostra que el HCFO-1233zd(E) o el HCFO-1224yd (Z) podrien usar-se com un possible reemplaçament directe del HFC-245fa en bombes de calor d'alta temperatura. 


\section{CONTENTS}

\begin{tabular}{|c|c|}
\hline 1.1 & Introduction ... \\
\hline 1.2 & Motivation.. \\
\hline 1.3 & Objectives............ \\
\hline 1.4 & Methodology ........................... \\
\hline 1.5 & Thesis organisation \\
\hline
\end{tabular}

Chapter 2 State-of-the-Art of High-Temperature Heat Pumps for Low-Grade Waste Heat

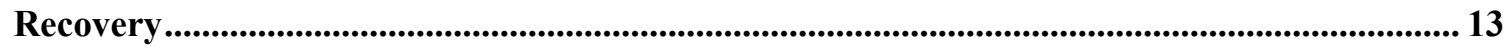

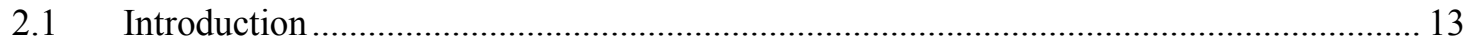

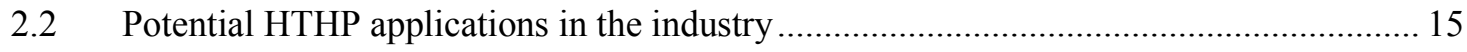

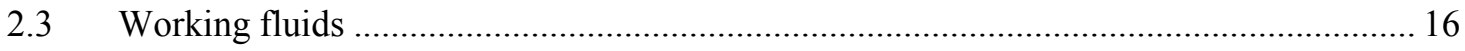

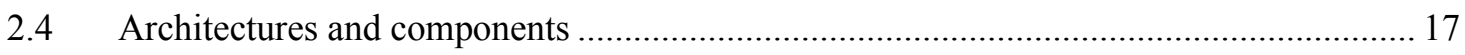

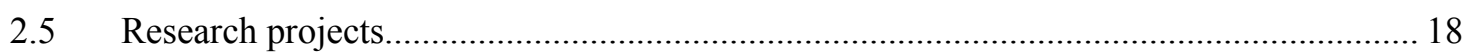

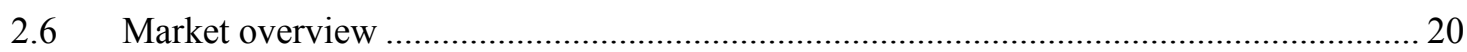

2.7 Research guidance for future potential research \& design of HTHPs............................... 21

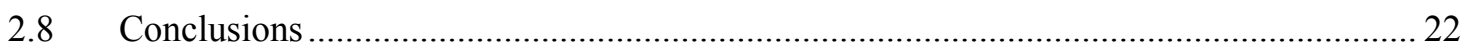

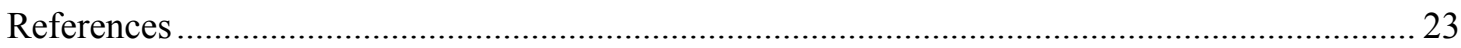

Chapter 3 Theoretical Evaluation of Different High-Temperature Heat Pump Configurations for Low-Grade Waste Heat Recovery .................................................................................................... 27

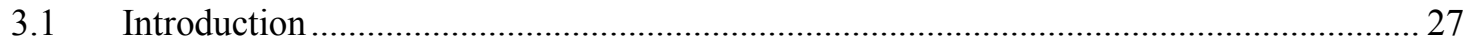

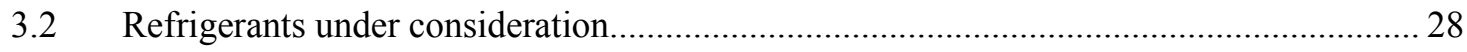

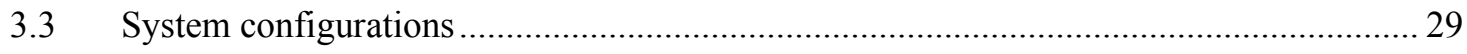

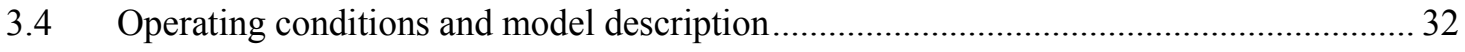

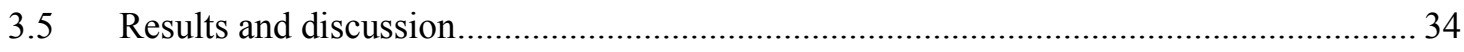

3.5.1 Comparison of low GWP alternatives to HFC-245fa in moderate-high temperature

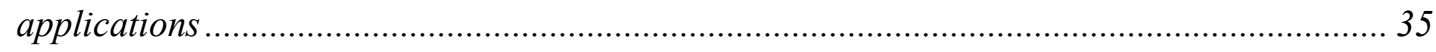

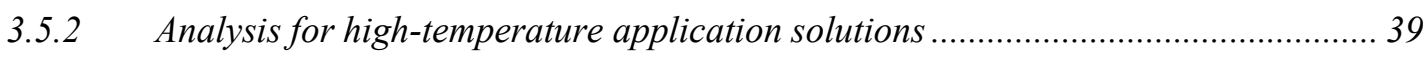

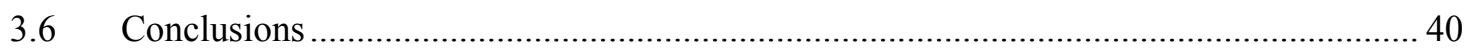

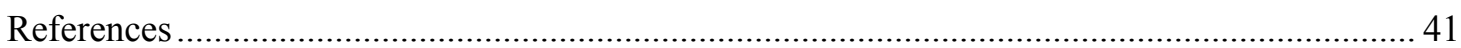

Chapter 4 Thermodynamic Analysis of Low GWP Alternatives to HFC-245fa in HighTemperature Heat Pumps: HCFO-1224yd(Z), HCFO-1233zd(E) and HFO-1336mzz(Z)...... 45

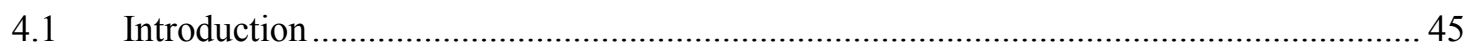


4.2 Properties Evaluation of the Proposed low GWP Refrigerants........................................ 48

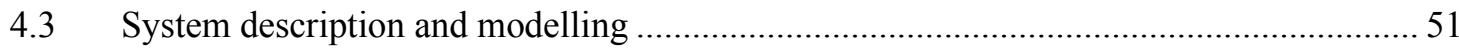

4.4 Superheat mapping and Internal Heat Exchanger (IHX) analysis......................................5 54

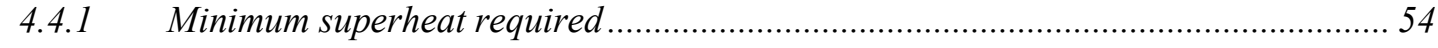

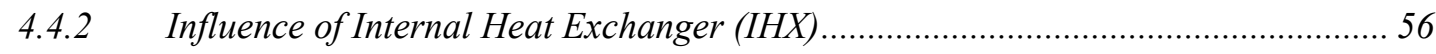

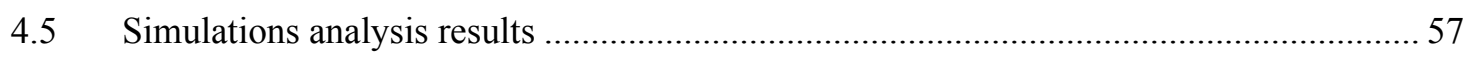

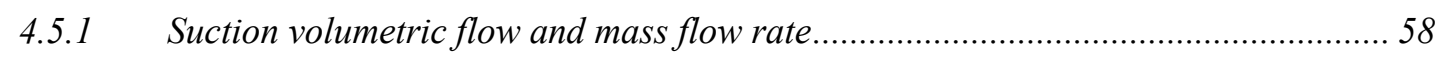

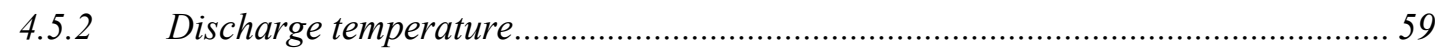

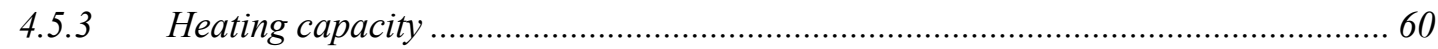

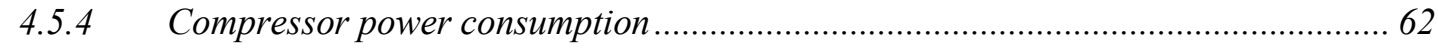

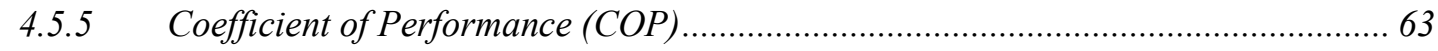

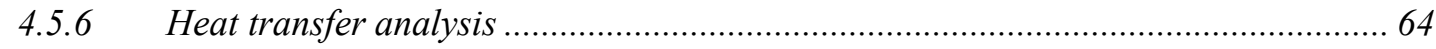

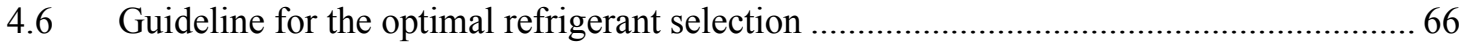

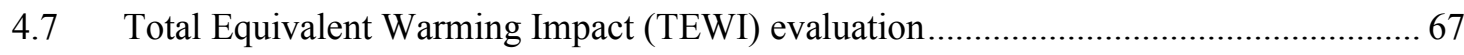

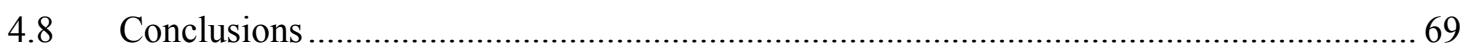

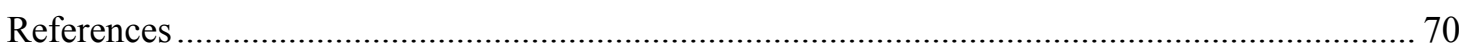

Chapter 5 Experimental Exergy and Energy Analysis of a Novel High-Temperature Heat Pump with Scroll Compressor for Waste Heat Recovery ................................................................. 73

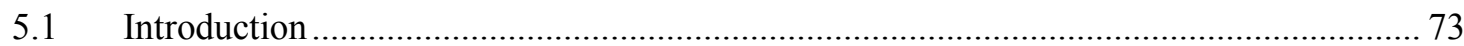

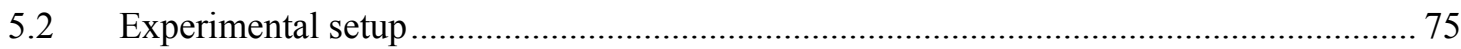

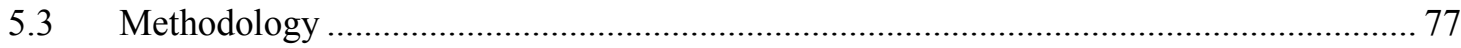

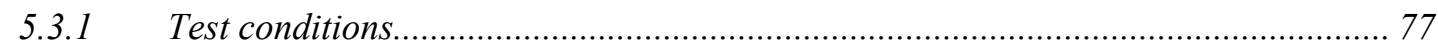

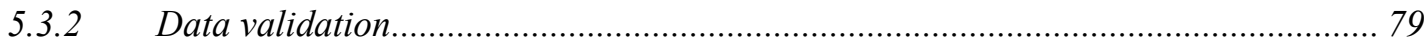

5.3.3 Propagation of errors in the estimated parameters ................................................ 80

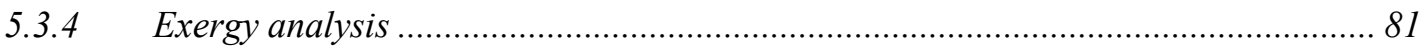

5.3.5 Prototype design, development and analysis process ........................................... 83

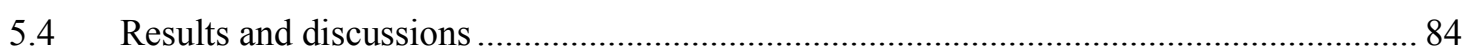

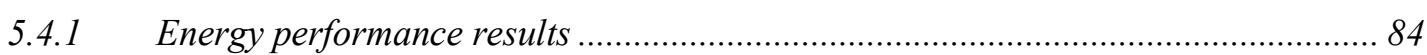

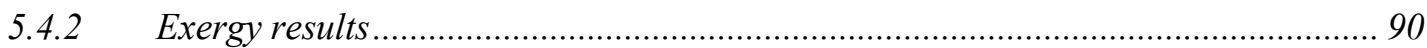

5.4.3 Semi-empirical low-GWP refrigerants assessment …......................................... 92

5.4.4 Environmental evaluation of HTHP integration as a waste heat recovery system ... 96

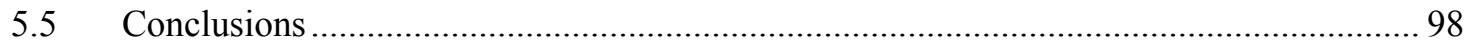

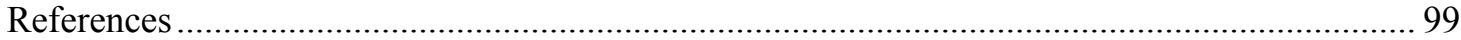


Chapter 6 Semi-Empirical and Environmental Assessment of the Low GWP Refrigerant HCFO-1224yd(Z) to Replace HFC-245fa in High Temperature Heat Pumps .......................... 103
6.1 Introduction 103

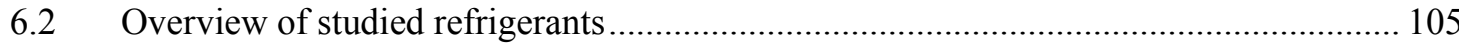

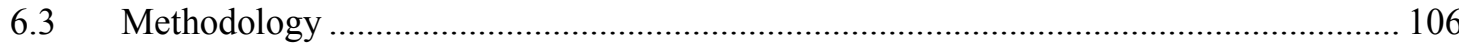

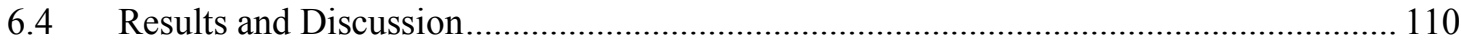

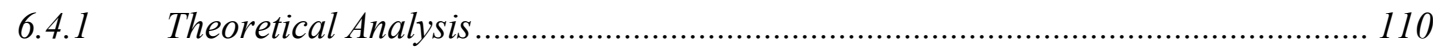

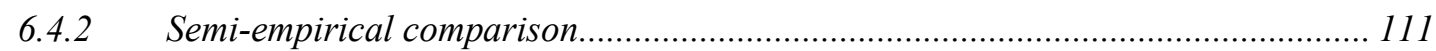

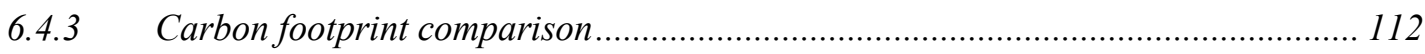

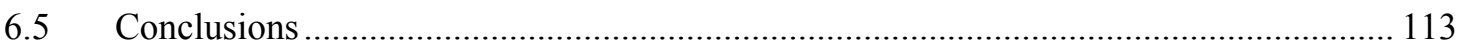

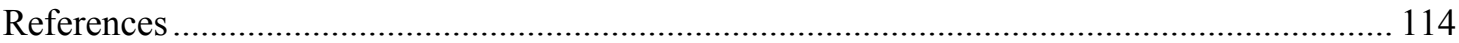

Chapter 7 Multi-Objective Optimization of a Novel Reversible High-Temperature Heat Pump - Organic Rankine Cycle (HTHP-ORC) for Industrial Low-Grade Waste Heat Recovery ... 117

7.1 Introduction 117

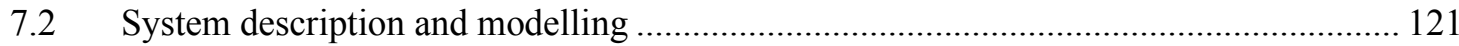

7.2.1 Description of the reversible HTHP-ORC system................................................ 121

7.2.2 Compressor-Expander modelling...................................................................... 123

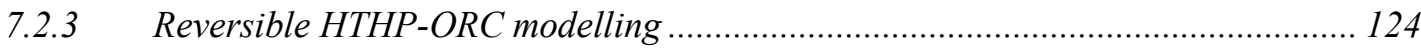

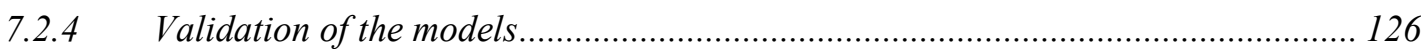

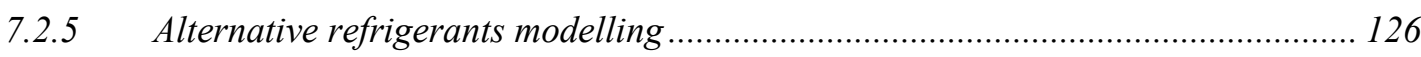

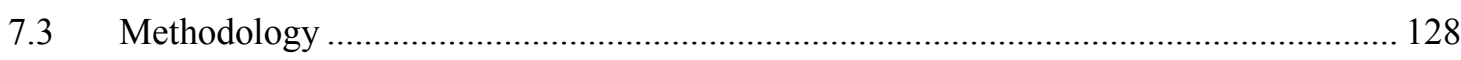

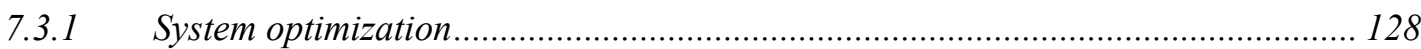

7.3.2 Simulation of the operating conditions .............................................................. 130

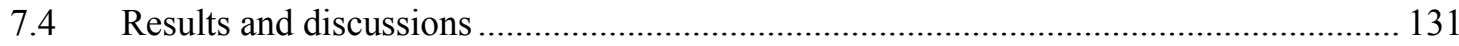

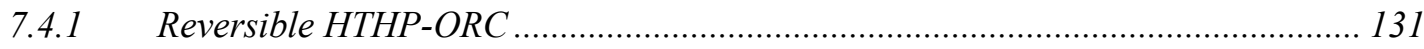

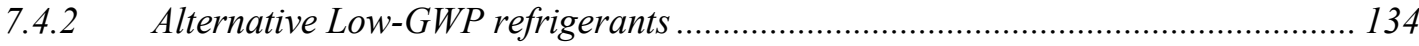

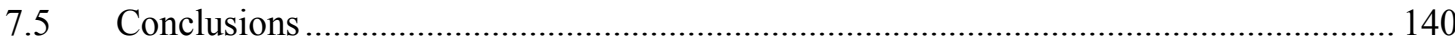

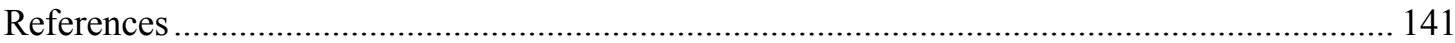

Chapter 8 High Temperature Heat Pump Integration into District Heating Networks......... 147

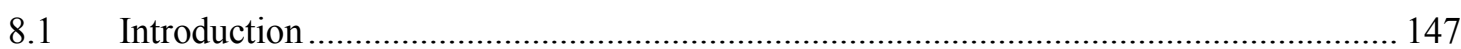

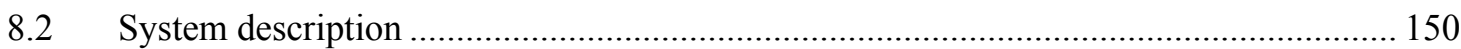

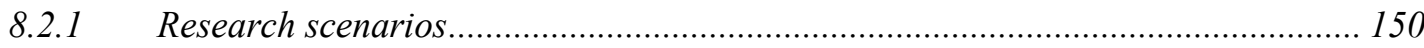

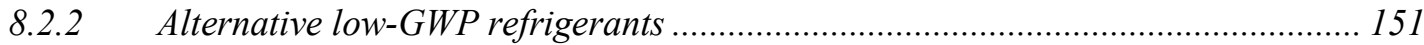

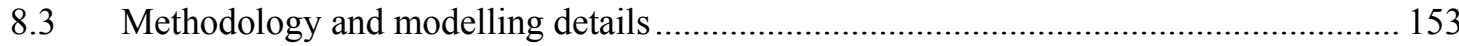


Contents

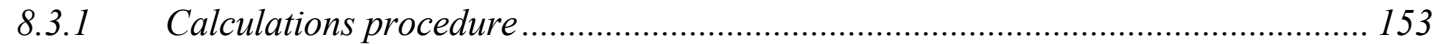

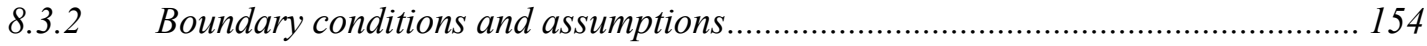

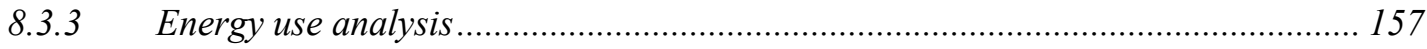

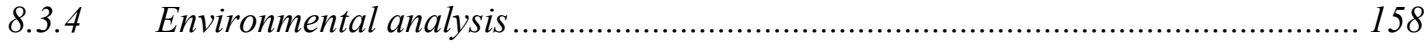

8.3.5 Total equivalent warming impact (TEWI) evaluation ……................................ 158

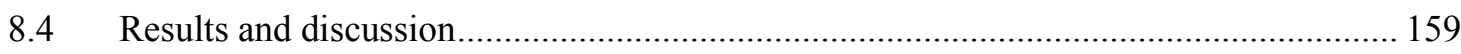

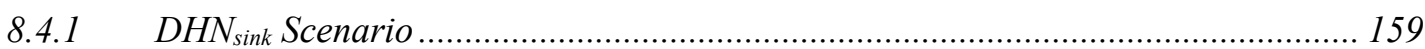

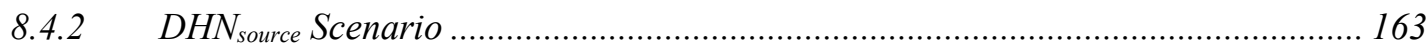

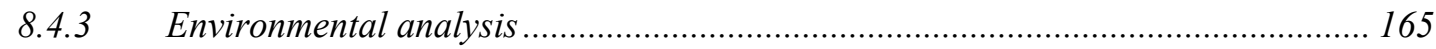

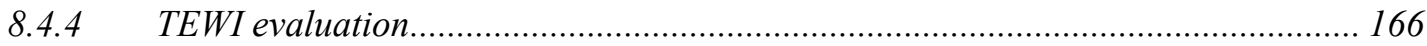

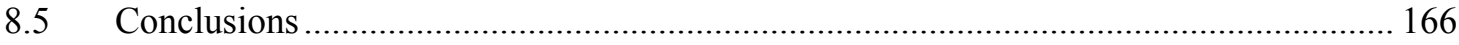

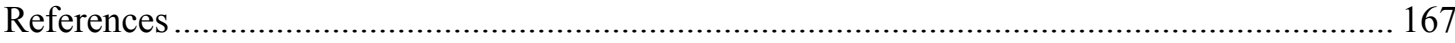

Chapter 9 Conclusions and Future Work................................................................................... 171

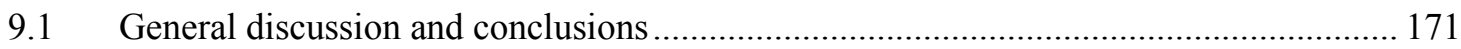

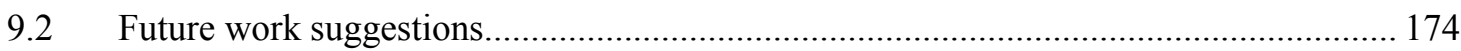

Chapter 10 Scientific Production ..................................................................................................... 177

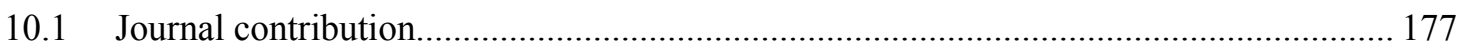

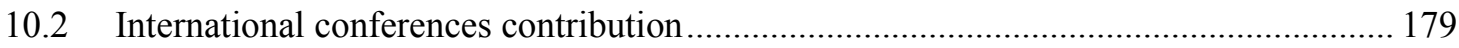

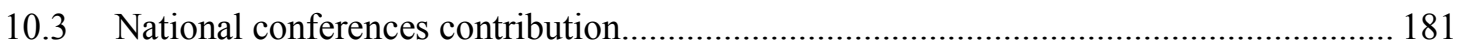

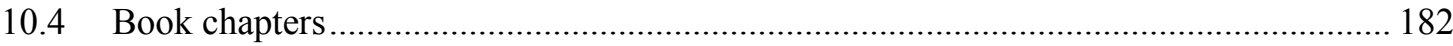




\section{LIST OF FIGURES}

Fig. 1.1. Global annual average temperature and carbon dioxide emissions evolution [2]. .............. 1

Fig. 1.2. Energy consumption breakdown and potential industrial low-grade waste heat [8] ........... 2

Fig. 1.3. Waste heat sources from different sectors, number of facilities and temperature ranges [9].

.

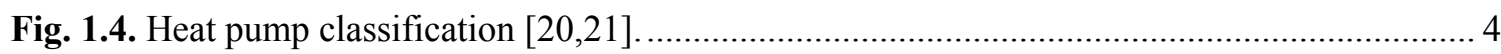

Fig. 1.5. Different industrial processes with the temperature range and the Technology Readiness Level (TRL) of the heat pump systems for each temperature range [18] ...................................... 5

Fig. 1.6. Impact of HFCs on the average global temperature between "business as usual" and the

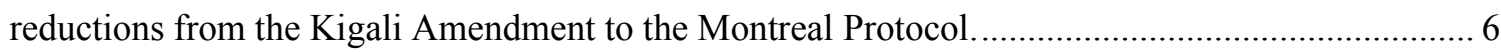

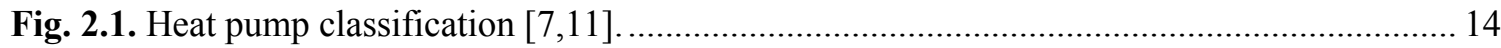

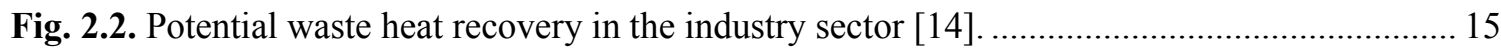

Fig. 2.3. COP for different HTHP working fluids with temperature lift of $60 \mathrm{~K}$. ............................ 17

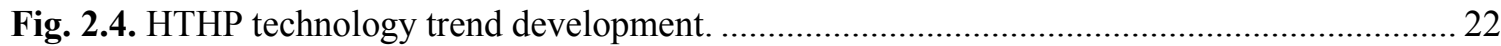

Fig. 3.1. Schematic and P-h diagram of single-stages configurations: a) single-stage cycle and b)

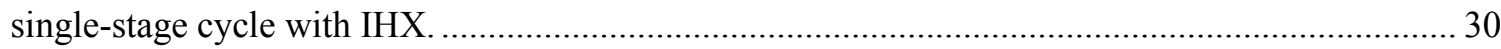

Fig. 3.2. Schematic and P-h diagram of two-stages configurations: a) two-stage cycle, b) two-stage

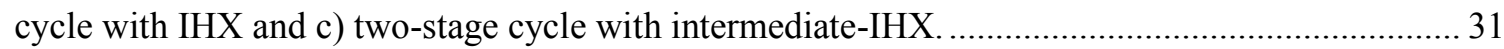

Fig. 3.3. Intermediate pressure and COP comparison analysis for different two-stage system

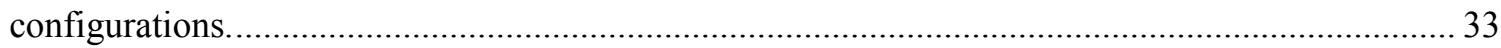

Fig. 3.4. Simulations results of $\%$ COP compared with single-stage cycle using HFC-245fa for

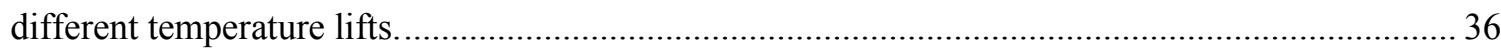

Fig. 3.5. Simulation relative results of $\mathrm{COP}$ and volumetric heating capacity for temperature lifts of 40 and $60 \mathrm{~K}$.

Fig. 3.6. Simulation relative results of $\mathrm{COP}$ and volumetric heating capacity for temperature lifts of 80 and $100 \mathrm{~K}$ 38

Fig. 3.7. Two-stage cycle with IHX simulations results of COP for heating production temperature of $150^{\circ} \mathrm{C}$.

Fig. 3.8. Two-stage cycle with IHX simulations results of volumetric heating capacity for heating production.

Fig. 4.1. Energy consumption breakdown and potential industrial low-grade waste heat [3] ......... 46 Fig. 4.2. a) T-s curves of the potential working fluids alternatives to HFC-245fa and b) Saturated vapour pressure over the operating range temperatures.

Fig. 4.3. Schematic and P-h diagram of single-stages configurations: a) single-stage cycle and $b$ ) single-stage cycle with IHX.

Fig. 4.4. Mapping of the minimum superheating required for: a) HFC-245fa, b) HCFO-1233zd(E), c) HCFO-1224yd(Z) and d) HFO-1336mzz(Z)...

Fig. 4.5. Influence the effectiveness of the IHX in: a) Discharge Temperature, b) COP, c) Volumetric Heating Capacity, d) Heating Capacity, e) Superheat and f) Sub-cooling.

Fig. 4.6. Relative differences of the suction volumetric flow varying the condensing temperature (a) without IHX, (b) with IHX; and the evaporating temperature (c) without IHX and (d) with IHX... 58 
Fig. 4.7. Relative differences of the mass flow rate varying the condensing temperature (a) without IHX, (b) with IHX; and the evaporating temperature (c) without IHX and (d) with IHX...............59

Fig. 4.8. Relative differences of the discharge temperature varying the condensing temperature (a) without IHX, (b) with IHX; and the evaporating temperature (c) without IHX and (d) with IHX... 60 Fig. 4.9. Relative differences of the heating capacity varying the condensing temperature (a) without IHX, (b) with IHX; and the evaporating temperature (c) without IHX and (d) with IHX.

Fig. 4.10. Relative differences of the compressor power consumption varying the condensing temperature (a) without IHX, (b) with IHX; and the evaporating temperature (c) without IHX and (d) with IHX.

Fig. 4.11. Relative differences of the COP varying the condensing temperature (a) without IHX, (b) with IHX; and the evaporating temperature (c) without IHX and (d) with IHX.

Fig. 4.12. Mapping of the guideline operating conditions of the alternative refrigerant: a) $\mathrm{COP} / \mathrm{COP}$ ref and b) $\mathrm{VHC} / \mathrm{VHC}_{\text {ref. }}$

Fig. 4.13. TEWI at a constant condensing temperature of $145^{\circ} \mathrm{C}$ and percentage reduction of the total equivalent $\mathrm{CO} 2$ emissions for the low GWP alternatives compared to the reference fluid HFC-245fa.

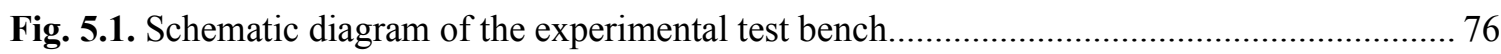

Fig. 5.2. Photo of the experimental prototype (ISTENER, Universitat Jaume I, Spain). (a) Start-up test without thermal insulation and (b) experimental campaign once thermally insulated. ............... 76

Fig. 5.3. Fluctuations of operating parameters of the highest heating production temperature steadystate test. (a) Evaporating pressure, (b) condensing pressure, (c) heat sink outlet temperature, (d)

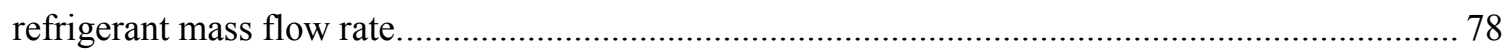

Fig. 5.4. T-s diagram of the highest heating production temperature steady-state test.................... 79

Fig. 5.5. Heating capacity at the condenser (comparing refrigerant and heat sink sides)................. 80

Fig. 5.6. Diagram methodology flow of the novel HTHP prototype design, development, and analysis.

Fig. 5.7. Experimental compressor power consumption variation as a function of the heat sink

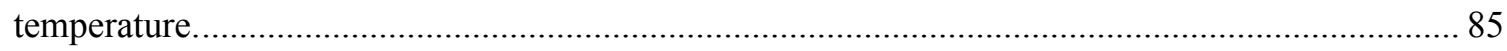

Fig. 5.8. Experimental mass flow rate variation regarding the heat sink temperature....................... 85

Fig. 5.9. Experimental discharge temperature as function of the heat sink temperature. ................. 86

Fig. 5.10. Experimental heating capacity at the tested conditions with the estimated uncertainty propagation.

Fig. 5.11. Experimental COP results at different operating points: (a) Experimental steady-state of the preliminary COP results and (b) COP mapping of the experimental results.............................. 87

Fig. 5.12. Experimental $\mathrm{COP}$ at the tested conditions with the estimated uncertainty propagation. 89

Fig. 5.13. Experimental IHX effectiveness in the different operating conditions............................. 89

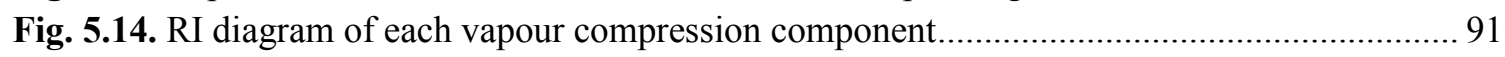

Fig. 5.15. Sankey diagram of the exergy flows in the HTHP system operating at heat sink temperature of $140{ }^{\circ} \mathrm{C}$ and heat source temperature of $80^{\circ} \mathrm{C}$.

Fig. 5.16. T-s diagram of the low-GWP refrigerants alternative to HFC-245fa: HCFO-1233zd(E),

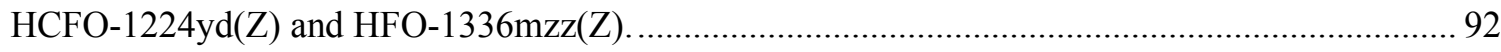

Fig. 5.17. Isentropic and volumetric corrected efficiencies of the alternative low-GWP refrigerants.

Fig. 5.18. Estimated COP versus pressure ratio for alternative low-GWP refrigerants. 
Fig. 5.19. Estimated performance parameters for alternative low-GWP refrigerants: a) Heating capacity and b) volumetric heating capacity (VHC).

Fig. 5.20. Estimated IHX influence in each refrigerant for different operating and performance parameters.

Fig. 5.21. Integration of HTHP as low-grade waste heat recovery system in CHP installations...... 97

Fig. 5.22. Equivalent $\mathrm{CO} 2$ emission reduction and values of HTHP as recovery system compared to conventional heating technology, natural gas boiler.

Fig. 6.1. Thermodynamic diagrams of a single-stage cycle with IHX, using HFC-245fa and HCFO$1224 y d(Z)$ as working fluids: a) Pressure-enthalpy and b) Temperature-entropy.

Fig. 6.2. Experimental setup: a) Schematic diagram of the experimental test bench and b) Photo of the HTHP prototype.

Fig. 6.3. Theoretical evaluation of single-stage cycle with IHX using HFC-245fa and HCFO$1224 \mathrm{yd}(\mathrm{Z})$ with a constant inlet heat sink temperature of $80^{\circ} \mathrm{C}$ : a) Volumetric heating capacity, b) compressor power consumption, c) heating capacity and d) COP.

Fig. 6.4. Semi-empirical results of HFC-245fa and HCFO-1224yd(Z) with a constant inlet heat source temperature of $80^{\circ} \mathrm{C}$ : a) Heating capacity, b) compressor power consumption, c) volumetric heating capacity and d) COP

Fig. 6.5. TEWI reduction using HCFO-1224yd(Z) instead of HFC-245fa......

Fig. 7.1. Schematic diagram of the reversible HTHP-ORC system, operating in: a) HTHP mode and b) ORC mode.

Fig. 7.2. T-s diagram of the reversible HTHP-ORC system at an evaporating temperature of $90{ }^{\circ} \mathrm{C}$ and HTHP and ORC condensing temperatures of 140 and $40{ }^{\circ} \mathrm{C}$, respectively.

Fig. 7.3. Schematic representation of semi-empirical models: a) Scroll compressor and b) Scroll expander.

Fig. 7.4. Over- and under-efficiency at different built-in volume ratio for compressor and expander [55]

Fig. 7.5. Built-in volume ratio optimisation process for HTHP-ORC models.

Fig. 7.6. Internal Heat Exchanger (IHX) optimisation process for HTHP-ORC models.

Fig. 7.7. Optimised values of built-in volume ratio for reversible system working in: a) HTHP mode and b) ORC mode.

Fig. 7.8. Optimum built-in volume ratio for different HTHP-ORC condensing temperatures with a fixed evaporating temperature of $85^{\circ} \mathrm{C}$.

Fig. 7.9. COP and net efficiency results of the semi-empirical reversible system modelling......... 133

Fig. 7.10. Compressor-expander isentropic and volumetric efficiencies from semi-empirical reversible modelling.

Fig. 7.11. Corrected isentropic efficiencies at different evaporating temperatures working as: a) Compressor and b) expander.

Fig. 7.12. Corrected volumetric efficiencies at different evaporating temperatures working as: a) Compressor and $b$ ) expander.

Fig. 7.13. Optimised built-in volume ratio for each alternative low-GWP refrigerant at different evaporating temperatures.

136

Fig. 7.14. Optimised effectiveness at different evaporating temperatures: a) IHX and b) Regenerator. 
List of Figures

Fig. 7.15. COP results for the alternative low-GWP refrigerants and HFC-245fa at different evaporating temperatures.

Fig. 7.16. Net efficiency results for the alternative low-GWP refrigerants and HFC-245fa at different evaporating temperatures.

Fig. 7.17. Electric power differences between the motor and generator capacities.

Fig. 7.18. Multi-objective evaluation of alternative low-GWP refrigerants in different scenarios, operating only in: a) HTHP mode and b) ORC mode.

Fig. 7.19. Multi-objective evaluation of alternative low-GWP refrigerants in different scenarios, operating as a reversible system.

Fig. 8.1. Breakdown of the thermal loads in a $\mathrm{CO} 2$ refrigeration system in average size supermarket based on the modelling proposed by Karampour et al. [8] and Sawalha [7]

Fig. 8.2. Schematic of the integration of HTHPs into DHN: DHNsink a) scenario with an HTHP heating production up to $90^{\circ} \mathrm{C}$ and b) DHNsource scenario with an HTHP heating production up to $130{ }^{\circ} \mathrm{C}$

Fig. 8.3. T-s diagram of the reference refrigerants and its potential low-GWP alternatives for a) DHNsink scenario (Ref. HFC-134a) and b) DHNsource scenario (Ref. HFC-245fa).

Fig. 8.4. Methodology flow diagram for the modelling scenarios, IHX optimisation and alternative low-GWP refrigerant analysis

Fig. 8.5. Cooling and space heating thermal load for the $\mathrm{CO} 2$ supermarket refrigeration system during the year.

Fig. 8.6. District heating network modelling assumptions: a) Selling prices and b) supply and return temperatures.

Fig. 8.7. Thermo-economic optimisation and economic benefits per operating hour of the HTHP integration into DHN as a heat source.

Fig. 8.8. COP of the different integrated system depending on the WHR exit and the ambient temperatures for a) $\mathrm{CO} 2$ refrigeration system, b) HTHP and c) Total integrated solution. 160

Fig. 8.9. Heating capacity of the HTHP system depending on the WHR exit and the ambient temperatures.

Fig. 8.10. Performance evaluation of the integrated system with the ambient temperature, using DHN as a heat source: a) COPs and b) relative difference in the operating cost.

Fig. 8.11. Alternative low-GWP refrigerants comparison to replace HFC-134a: a) COP and b) VHC.

Fig. 8.12. Performance analysis of integrating HTHP into DHN (scenario DHNsource): a) COPHTHP and $b$ ) heating capacity.

Fig. 8.13. Assessment for alternative low-GWP refrigerants to replace HFC-134a: a) COP and b) VHC.

Fig. 8.14. Environmental analysis of the $\mathrm{CO} 2$ equivalent emissions for the: a) DHNsink scenario and b) DHNsource scenario.

Fig. 8.15. Total equivalent warming impact (TEWI) evaluation for the: a) $D H N_{\text {sink }}$ scenario and $b$ ) $\mathrm{DHN}_{\text {source }}$ scenario. 


\section{LIST OF TABLES}

Table 2.1. Properties of the present and future HTHPs working fluids.............................................. 16

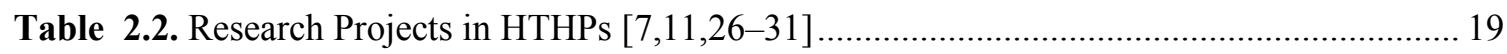

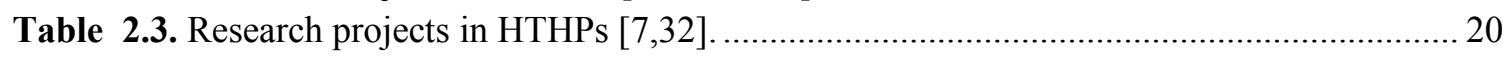

Table 2.4. Commercial Research and Development (R\&D) projects in HTHPs [7,33-35] .......... 21

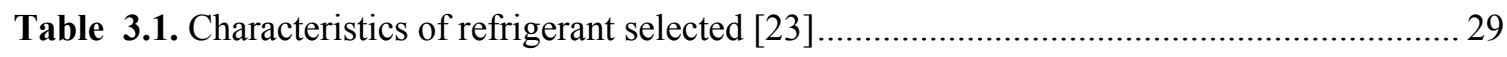

Table 4.1. Evolution of the main refrigerants used in high-temperature heat pumps...................... 47

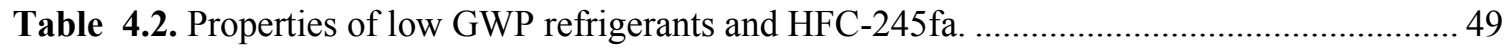

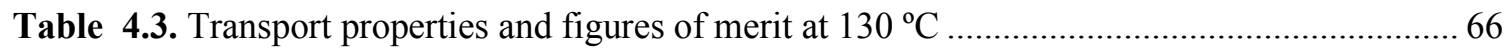

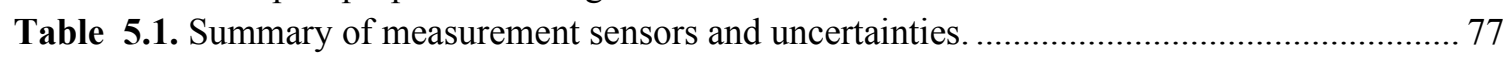

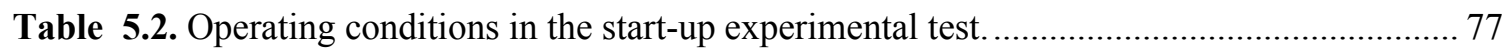

Table 5.3. Summary of the heating capacity values along with the absolute and relative uncertainties.

Table 5.4. Summary of the COP values along with the absolute and relative uncertainties........... 88

Table 5.5. Summary of the experimental exergy efficiency results. .............................................. 90

Table 5.6. Summary of the experimental exergy destruction and RI results................................... 90

Table 5.7. Properties of HFC-245fa and the alternative low GWP refrigerants.............................. 93

Table 6.1. Main thermodynamic and transport properties of HFC-245fa and HCFO-1224yd(Z). 105

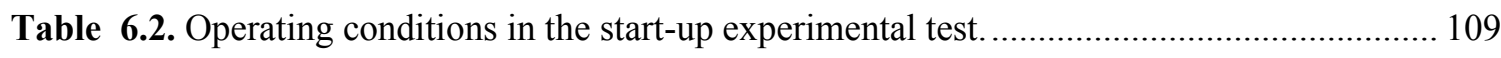

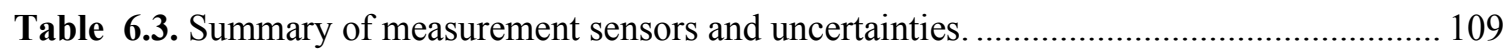

Table 7.1. Semi-empirical modelling coefficients for compressor and expander models............. 126

Table 7.2. Comparative refrigerant properties for HTHP/ORC application................................... 127

Table 7.3. Operating parameters of the reversible system modelling. ....................................... 131

Table 8.1. Selected properties of HFC-134a and its suggested low-GWP alternatives [37]........ 152

Table 8.2. Thermophysical properties of HFC-245fa and its alternative low-GWP refrigerants.. 152

Table 8.3. Emission factor associated with different system processes. .................................... 158 



\section{NOMENCLATURE}

$\begin{array}{ll}a, b, k_{e}, k_{s}, k_{1}, k_{2} & \text { Pierre's correlations constants } \\ \mathrm{AU} & \text { heat transfer coefficient }\left(\mathrm{W} \mathrm{K}^{-1}\right) \\ C & \text { coefficient } \\ \mathrm{COP} & \text { coefficient of performance }(-) \\ \mathrm{E}_{\mathrm{a}} & \text { annual energy consumption }(\mathrm{kWh}) \\ \dot{E} x & \text { rate of exergy }(\mathrm{kW}) \\ e x & \text { specific exergy }\left(\mathrm{kJ} \mathrm{kg}^{-1}\right) \\ h & \text { specific enthalpy }\left(\mathrm{kJ} \mathrm{kg}^{-1}\right) \\ \mathrm{L} & \text { annual refrigerant leakage rate }\left(\mathrm{kg} \mathrm{year}^{-1}\right) \\ M & \text { molecular weight }\left(\mathrm{g} \mathrm{mol}^{-1}\right) \\ m & \text { total refrigerant charge of the system }(\mathrm{kg}) \\ \dot{m} & \text { refrigerant mass flow rate }\left(\mathrm{kg} \mathrm{s}^{-1}\right) \\ \mathrm{n} & \text { lifespan of the vapour compression system (years) } \\ P & \text { pressure }(\mathrm{MPa}) \\ p & \text { price }\left(€ \text { MWh }{ }^{-1}\right) \\ P r & \text { Prandtl number }(-) \\ \dot{Q} & \text { thermal capacity }\left(\mathrm{kW}^{-1}\right) \\ r_{v} & \text { built-in volume ratio }(-) \\ \mathrm{RI} & \text { relative irreversibility }(-) \\ \mathrm{s} & \text { specific entropy }\left(\mathrm{kJ} \mathrm{kg} \mathrm{kg}^{-1} \mathrm{~K}^{-1}\right) \\ T & \text { temperature }\left({ }^{\circ} \mathrm{C}\right) \\ \mathrm{VHC} & \text { volumetric heating capacity }\left(\mathrm{kJ} \mathrm{m}{ }^{-3}\right) \\ v & \text { specific volume }\left(\mathrm{m}^{3} \mathrm{~kg}^{-1}\right) \\ \dot{V} & \text { volumetric flow rate }\left(\mathrm{m}^{3} \mathrm{~s}^{-1}\right) \\ \dot{W} & \text { electric power consumption }(\mathrm{kW}) \\ & \end{array}$

\section{Greek symbols}

$\alpha$

$\psi$

$\varepsilon$

$\eta$

$\Delta$

$\alpha$

$\beta$

\section{Subscripts}

0

ad

$\mathrm{amb}$ losses coefficient (-)

exergy efficiency (-)

effectiveness (-)

efficiency (-)

variation

recycling factor of the refrigerant (\%)

indirect emission factor $\left(\mathrm{kgCO}_{2} \mathrm{kWh}^{-1}\right)$

environment reference (dead state)

adapted

ambient 
Nomenclature

c

cond

crit

disch

em

ev

evap

ex

exp

HS

I

in

is

$\mathrm{k}$

$\operatorname{loss} 0$

LS

o

out

$\mathrm{pb}$

$r$

ref

reg

$\mathrm{S}$

sec

$\operatorname{sink}$

suc

source

temp

vol

\section{Abbreviations}

AEL

CFC

$\mathrm{DHN}$

EES

FOM

GHG

GWP

$\mathrm{HC}$

$\mathrm{HCFO}$

HFC

$\mathrm{HFO}$

HP

HR compressor

condensation

critical

compressor discharge temperature

electromechanical

expansion valve

evaporation

machine discharge

expander

high stage

intermediate

inlet

isentropic

condenser

constant losses

low stage

evaporator

outlet

pool boiling

reduced

reference working fluid

regenerator

installation size

secondary circuit

heat sink

suction

heat source

temperature

volumetric

atmospheric exposure level

chlorofluorocarbon

district heating network

engineering equation solver

figure of merit

greenhouse gas

global warming potential

hydrocarbon

hydrochlorofluoroolefin

hydrofluorocarbon

hydrofluoroolefin

heat pump

heat recovery 
HTHP

IHX

LT

MT

NBP

ODP

ORC

PR

SPHT

TEWI

WHR high-temperature heat pump

internal heat exchanger

low temperature

medium temperature

normal boiling point

ozone depletion potential

organic Rankine cycle

pressure ratio

single-phase heat transfer

total equivalent warming impact

waste heat recovery 


\section{Chapter 1 Introduction}

\subsection{Introduction}

Climate change mitigation becomes one of the most significant challenges that humanity faces in this century. The concern for global warming has raised awareness about the importance of climate change mitigation during the last decades. This was evidenced in the Paris Agreement through which around 200 nations established the long-term objective of keeping the increase in global average temperature below $2{ }^{\circ} \mathrm{C}$ above pre-industrial levels by 2100. Moreover, the Parties noted the relevance of promoting the mitigation of greenhouse gas (GHG) emissions while fostering sustainable development [1]. According to the Fifth Assessment Report (AR5) of the Intergovernmental Panel on Climate Change (IPCC), the anthropogenic GHG emissions have increased from $27( \pm 3.2)$ to 49 $( \pm 4.5) \mathrm{GtCO} 2 \mathrm{eq} / \mathrm{yr}(+80 \%)$ between 1970 and 2010 [1], increasing the global temperature as shown in Fig. 1.1.

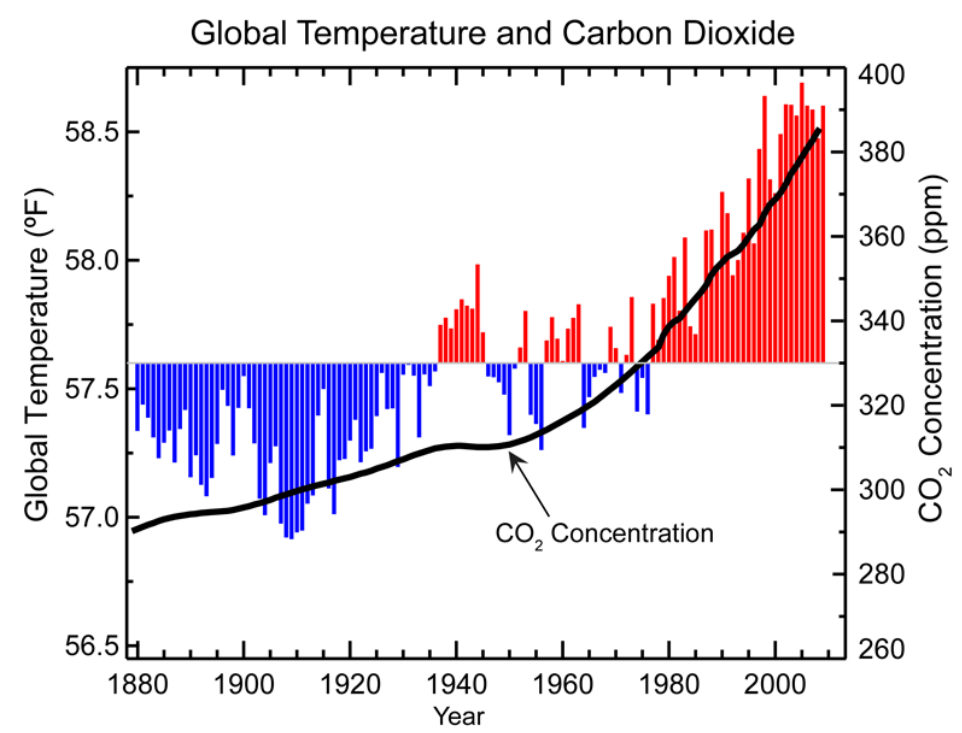

Fig. 1.1. Global annual average temperature and carbon dioxide emissions evolution [2].

Most of the energy consumption in the industrial sector is devoted to thermal processes at temperatures above $100{ }^{\circ} \mathrm{C}[3]$. This energy mainly comes from the combustion of fossil fuels, which present uncertain acquisition prices and have a severe environmental impact on the environment. Cullen and Allwood [4] estimate that $63 \%$ of the global primary energy is rejected during the combustion and heat transfer processes from the primary to final energy. Therefore, the primary energy losses considered waste heat must be recovered in order to improve the efficiency of the industrial processes [5]. Nevertheless, the availability and usability of this waste heat should be 
determined, taking into account different aspects such as the discontinuity, temperature ranges, the potential of each source, type and composition of the thermal effluent or even the distance between heat source and sink. Despite the above-mentioned aspects, there is a significant potential for waste heat sources in different energy uses throughout the world.

Among $20 \%$ to $50 \%$ of the total energy consumption of manufacturing processes is rejected as waste heat in the United States of America, becoming around $60 \%$ of the waste heat at temperatures below $230{ }^{\circ} \mathrm{C}[6]$. In Norway, $37 \%$ of the total waste heat comes with a temperature above $140{ }^{\circ} \mathrm{C}$, whereas around $32 \%$ is presented with temperatures between 40 and $60{ }^{\circ} \mathrm{C}$ [7]. Forman et al. [8] investigated the primary energy consumption breakdown, showing that a significant fraction (around 2.8\%) of the industrial energy consumption is rejected to the ambient as low-grade waste heat below $100{ }^{\circ} \mathrm{C}$, as shown in Fig. 1.2.

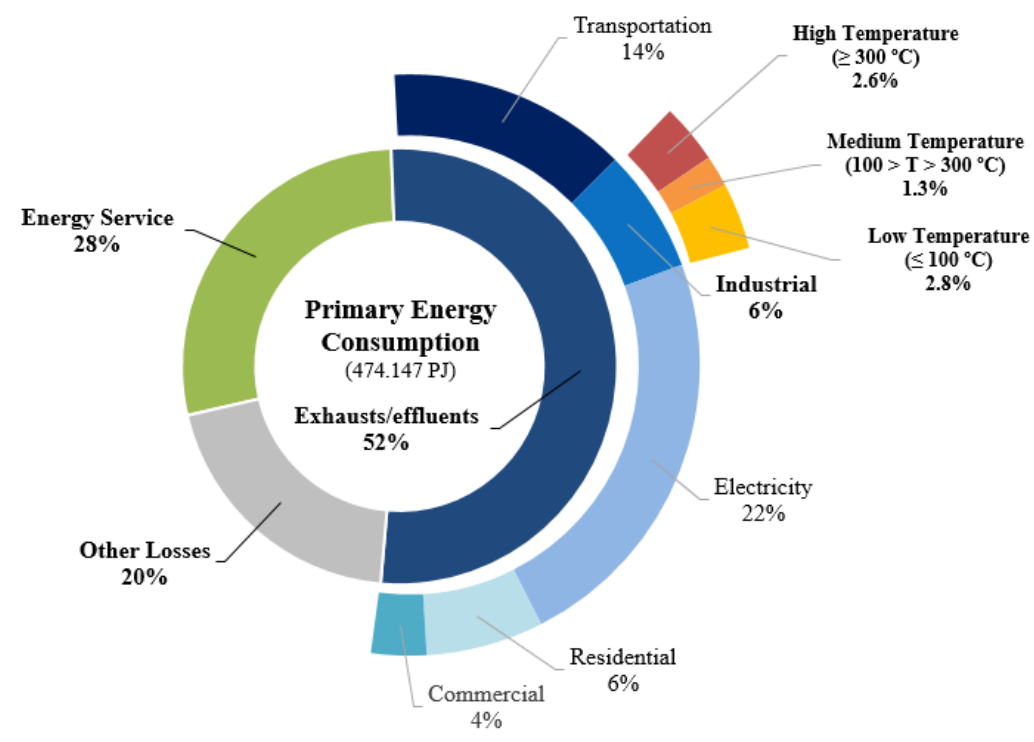

Fig. 1.2. Energy consumption breakdown and potential industrial low-grade waste heat [8].

Additionally, Elson et al. [9] quantified the potential waste heat sources in industrial sectors with different temperature ranges. There are many waste heat sources with low temperatures below 140 ${ }^{\circ} \mathrm{C}$, as shown in Fig. 1.3. These waste heat sources can be recovered with appropriate technologies in order to improve the energy efficiency of the industrial sector and reduce the equivalent $\mathrm{CO}_{2}$ emissions that will contribute to climate change mitigation.

There are different alternatives to take advantage of the waste heat through active or passive recovery processes. For waste heat sources with high thermal level, with temperatures above $230{ }^{\circ} \mathrm{C}$, passive recovery systems using heat exchangers become more appropriate. However, using an active recovery process becomes more convenient for waste heat sources with low thermal levels, especially for single sources with low thermal power. Two of the leading technologies for waste heat revalorisation are organic Rankine cycles (ORC) and vapour compression heat pumps. 


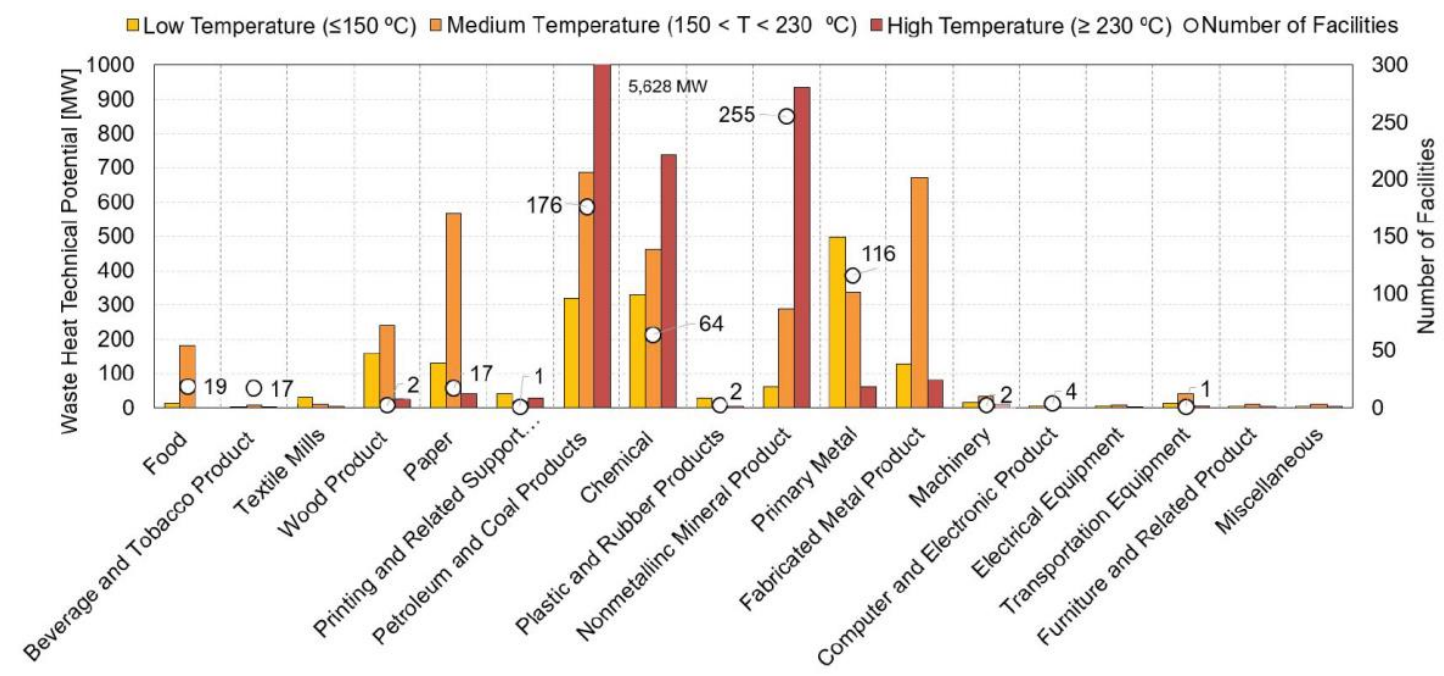

Fig. 1.3. Waste heat sources from different sectors, number of facilities and temperature ranges [9].

Focus on active recovery processes; it is possible to transform the low-grade waste heat into electricity with the use of organic Rankine, Kalina or flash-trilateral cycles [10]. Nevertheless, the waste heat can also be revalorised, upgrading the thermal level and becoming useful for industrial processes, especially for high temperature applications. Several heat pumps technologies can be used to elevate the required thermal level and overcome the heating demand, such as absorption, adsorption, vapour compression, and hybrid cycles (compression-resorption) [11,12].

Therefore, recovering the industrial waste heat below $100{ }^{\circ} \mathrm{C}$ and upgrading it into useful heat for the industrial thermal processes (above $100^{\circ} \mathrm{C}$ ) [13] through efficient energy technologies would increase the energy efficiency and reduce the GHG emissions of the industrial sector, which is, in fact, one of the three main energy-consuming sectors [14]. Approximately $3200 \mathrm{TWh}$ of the annual EU energy use corresponds to the industrial sector. On average, around $30 \%$ of the industrial energy consumption occurs in the form of electricity, and the remaining $70 \%$ corresponds to heating demands [15]. A potentially viable option could be the use of vapour compression systems, which can be integrated into different industrial processes due to the flexibility they offer in terms of operating temperatures and heating capacities.

Vapour compression heat pumps are systems based on the thermodynamics principles, which state that a relatively small amount of electrical or mechanical energy can revalorise a more significant amount of heat. Despite the environmental benefits of heat pumps in the industry, the current introduction of these systems in the industrial sector remains limited due to technological restrictions and the lower price of conventional boilers and fossil fuel. Hence, heat pumps designed to operate at temperatures above $140{ }^{\circ} \mathrm{C}$ must be studied and developed to increase the waste heat valorisation opportunities and energy efficiency of the industry [16].

This technological improvement modified the traditional classification of the heat pumps, becoming known as high temperature heat pumps (HTHPs) [17]. HTHPs represent a strategic tool to decarbonise different sectors since they can cover around 21.5 TWh per year in EU industries with heat consumption between 100 and $150{ }^{\circ} \mathrm{C}$. Non-metallic minerals, food, paper, and non-ferrous metal industries are the most promising industries for applying this technology [15]. 
According to their heat sink and heat source temperatures, the International Energy Agency [20] proposed a classification for heat pumps used in the industry, represented in Fig. 1.4. When the heating production temperature is above $80^{\circ} \mathrm{C}$, using a heat sink temperature above $40^{\circ} \mathrm{C}$, they can be considered HTHP systems. Note that the heating production temperature becomes an essential issue in this technology, and the heat source temperature does. HTHPs can produce heat at higher thermal levels than the industrial heat pumps and absorb heat from higher temperature sources. Several industrial processes in different sectors require a wide range of temperatures, where HTHP can cover this demand, as shown in Fig. 1.5.

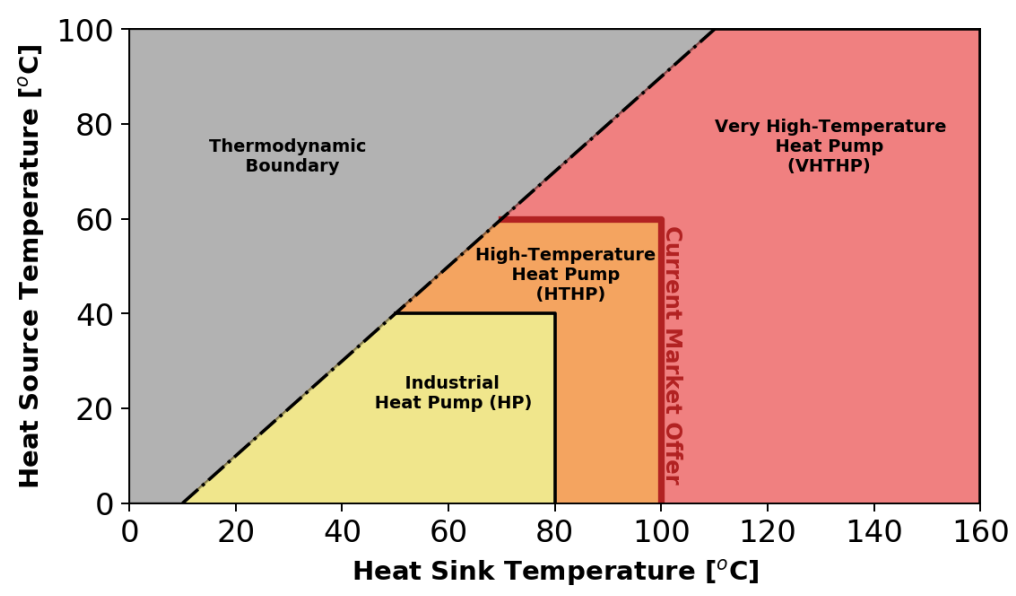

Fig. 1.4. Heat pump classification $[20,21]$.

The current market offers only heat pump systems that can produce at heat sink temperatures up to $100{ }^{\circ} \mathrm{C}$, using heat sources between $40-60^{\circ} \mathrm{C}$. However, there is a great potential to use waste heat sources with temperatures between $80-100^{\circ} \mathrm{C}$ and increase the production temperature above $100{ }^{\circ} \mathrm{C}$, as aforementioned. Thus, the development of HTHP that can reach these requirements becomes a step forward in the future of this technology. Nevertheless, several technical challenges should be overcome in order to achieve this ambitious objective.

The high level of evaporation temperatures of HTHPs systems involves higher compressor suction temperatures compared to the industrial heat pumps. Current commercial compressors do not resist that high suction temperature, and therefore, improvements in the electric motor or compressor design are required. Semi-hermetic compressors, magnetic joints or an improvement in the motor coil can allow operating at higher suction temperatures operating and higher thermal levels than the existing systems, improving the energy efficiency of these novel HTHPs [17].

Moreover, the lubrication of the compressor is another technical challenge to highlight. Due to the high temperatures, the viscosity of the lubricant oil should be higher than the typical lubricants used for refrigeration or heating applications. Furthermore, the oil lubricant should be miscible with the current refrigerants and the new low GWP alternatives in order to ensure the proper lubrication of the compressor. Polyester oil (POE) with high viscosity becomes the proper oil lubricant for HTHPs system that allows operating at higher temperatures with a compromise between the energy efficiency and system reliability [22]. 


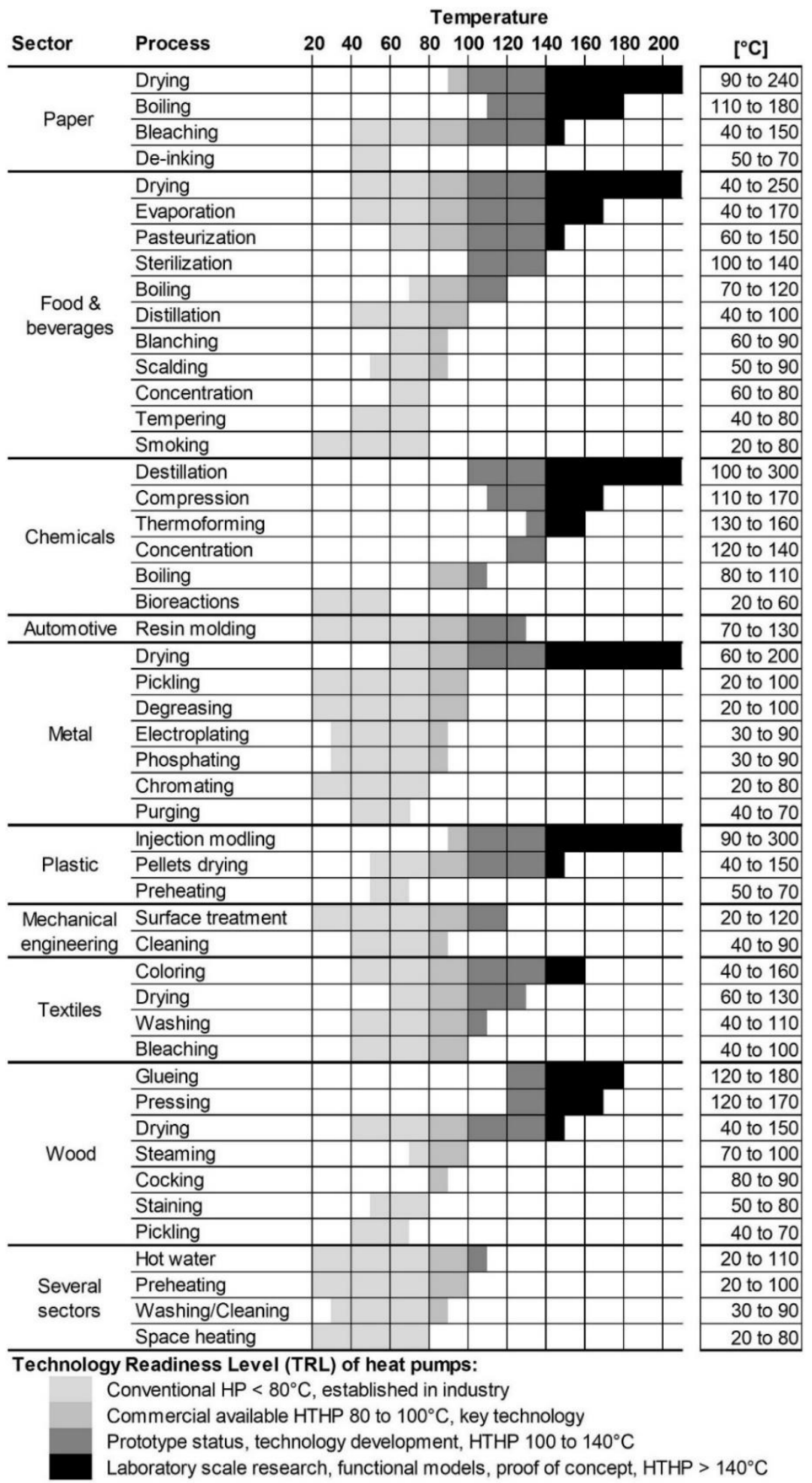

Fig. 1.5. Different industrial processes with the temperature range and the Technology Readiness Level (TRL) of the heat pump systems for each temperature range [18]. 
Moreover, the wide temperatures range, higher energy performance, and flexibility allow HTHPs to combine with other technologies in trigeneration systems [19] or integrated into district heating networks, achieving valuable economic and energy savings.

Thus, novel developments of HTHP can overcome most of these technical challenges and represent a step forward in heat pump technology and the sustainable development of heating technology. Moreover, using HTHPs in the industrial sector instead of fossil fuel heating technologies will reduce GHG emissions, supporting climate change mitigation.

Another important aspect of the HTHPs is the refrigerant or working fluid used in the thermodynamic cycle. The firstly developed HTHPs used CFC-114 [23] (chlorofluorocarbon), CFC-113 [24], and HCFC-123 [25] as refrigerants. Nevertheless, according to the Montreal Protocol, the substances that deplete the ozone layer must be phased out [26], and other chlorine-free refrigerants appeared to be used in these applications. Therefore, Brown [27] evaluated 56 potential CFC-114 replacement refrigerants for HTHP applications and identified HFC-245fa as potential candidate. HFC-245fa has zero ozone depletion potential (ODP) and high critical temperature $\left(154^{\circ} \mathrm{C}\right)$, allowing a wide use of high-temperature applications. HFC-245fa is the most common refrigerant for HTHPs today and is considered the reference fluid for high temperature for these applications [17].

However, in 2014, EU Regulation No. 517/2014 [28] gradually limited the acquisition and utilisation of HFCs, establishing market quotas to their consumption and limiting the maximum GWP in some applications in order to increase the share of low GWP refrigerants. In February 2017, the European Commission adopted a proposal to ratify the Kigali amendment to the Montreal Protocol to limit the HFCs production and use gradually. A drastic reduction of the consumption of these chemicals would potentially help to maintain global temperature rise well below $2{ }^{\circ} \mathrm{C}$ by 2100 [29]. It has been demonstrated that HFCs has a significant impact on the surface temperature, as shown in Fig. 1.6.

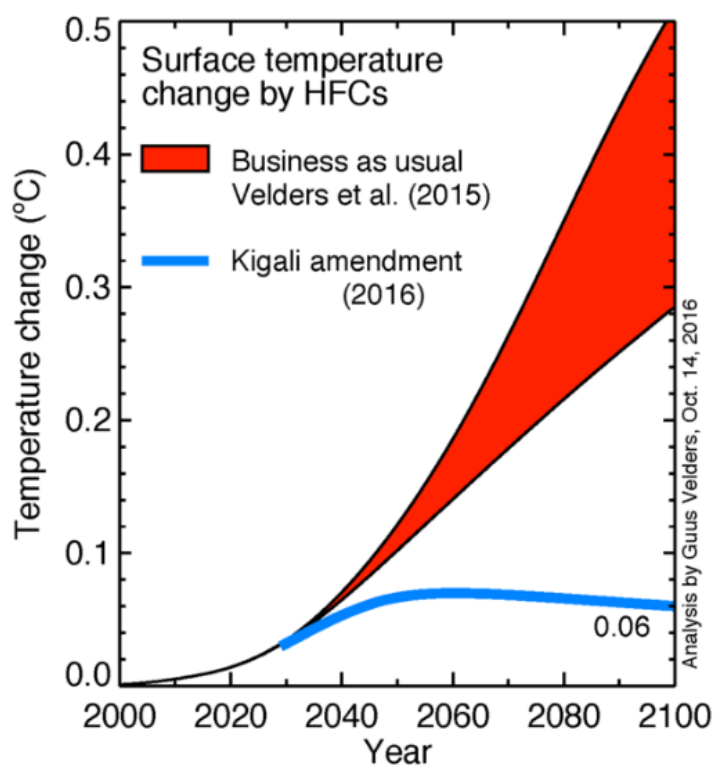

Fig. 1.6. Impact of HFCs on the average global temperature between "business as usual" and the reductions from the Kigali Amendment to the Montreal Protocol. 
Hence, low global warming potential (GWP) alternatives (named as fourth-generation refrigerants by Calm [30]) are necessary to replace HFC-245fa, which has a GWP value of 858. Natural refrigerants [31], hydrofluoroolefin (HFO) and hydrochlorofluorocarbon (HCFO) are becoming relevant for today HTHPs. Due to the thermodynamic similarity with HFC-245fa, low GWP organic refrigerants (HFOs and $\mathrm{HCFOs}$ ) receive more attention for high-temperature applications.

\subsection{Motivation}

Based on the aforementioned, research on high temperature heat pumps for industrial waste heat recovery acquires significant importance in promoting sustainable development in the industrial sector and contributing to climate change mitigation. The current technology and materials development allows to extend the operating limits of the vapour compression systems. Therefore, the interest of industrial heat pumps has increased significantly in recent years, and this is evidenced by the increasing number of publications on this topic. Nonetheless, a comprehensive study of these systems and prototypes development for experimental tests still becomes a research gap.

A comprehensive study of different system architectures and alternative low GWP refrigerants is needed to determine the proper system solution for each high temperature application. Moreover, alternative low GWP refrigerants for drop-in replacement should be found to replace HFC-245fa in existing designed components and systems.

The experimental development of functional HTHP prototypes that reach heating production temperatures up to $140{ }^{\circ} \mathrm{C}$ demonstrates the viability of this technology. Moreover, it represents a step forward in their development, providing guidelines for further design HTHPs for low-grade waste heat recovery in the industrial sector.

Finally, the combination of HTHPs with different technologies and integrating with district heating networks promote the utilisation of HTHPs, improving the flexibility, efficiency, and viability of these existing systems and introducing this technology as a potentially sustainable solution to heating demand instead of conventional fossil fuel technology.

Hence, this doctoral thesis becomes motivated by the development of the high temperature heat pump technology from different perspectives through the following objectives.

\subsection{Objectives}

The main objective of this doctoral thesis is to contribute in the high temperature heat pump technology development through a comprehensive theoretical and experimental analysis to overcome different technology challenges: architecture, refrigerants, experimental prototype, advanced applications and system integration, providing new knowledge that represents a step forward in high temperature heat pump technology and sustainable development.

To achieve this general objective, the following specific objectives are proposed:

- To perform a comprehensive analysis of the current development status of high temperature heat pump technology from research and commercial perspectives along with the most common architectures and refrigerants used in existing systems. 
- To evaluate different high temperature heat pump configurations for different temperature ranges, including the utilisation of an internal heat exchanger as a potential performance improvement.

- To compare potential alternative low GWP refrigerants that can replace HFC-245fa in high temperature heat pumps, including a complete thermodynamic assessment, to find possible drop-in replacements in these systems.

- To build an experimental prototype of high temperature heat pump in order to establish a baseline for future experimental tests with low GWP refrigerants that are intended to replace HFC-245fa.

- To characterise the performance of an experimental prototype, using HFC-245fa as baseline refrigerant, including and exergy, environmental, and low GWP refrigerants assessment.

- To study the low GWP refrigerant HCFO-1224yd(Z) as a potential drop-in replacement to HFC-245fa through a semi-empirical analysis based on experimental data and modelling analysis.

- To develop the concept of high temperature heat pump and organic Rankine cycle reversible system, optimising its design parameters to maximise the combined energy efficiency for different heat sources and applications.

- To promote the industrial heat pump integration, combining high temperature heat pumps with district heating networks and refrigeration systems from supermarkets.

\subsection{Methodology}

To accomplish these objectives, the investigation is conducted according to the following methodology.

Firstly, the state-of-the-art of high temperature heat pumps is reviewed to identify the current development status of this technology from a research and commercial perspective. This review has focused on the refrigerants, configurations and components developed in order to identify multiple research gaps that become interesting for the research community.

Secondly, potential configurations and low GWP refrigerants are theoretically evaluated in order to determine the most suitable solution for each application. These theoretical analyses are based on computational models programmed with the software Engineering Equation Solver (EES) [32], connected to the REFPROP refrigerants database [33].

Thirdly, a high temperature heat pump prototype was built and tested in order to demonstrate the technical viability, achieving heating production temperatures up to $140^{\circ} \mathrm{C}$ with $\mathrm{HFC}-245 \mathrm{fa}$ as the refrigerant. Moreover, the experimental data was used for developing a semi-empirical evaluation in order to study the low GWP candidate HCFO-1224yd(Z) as a drop-in replacement to HFC-245fa. The experimental data are analysed with Python and REFPROP together. 
Fourthly, a comprehensive analysis was proposed and realise for the concept of a single reversible system that can operate as high temperature heat pump or organic Rankine cycle, depending on the conditions and requirements.

Finally, the integration of high temperature heat pumps into district heating networks is investigated to promote the utilisation of industrial heat pumps as potential waste heat recovery systems.

\subsection{Thesis organisation}

Based on the established methodology, this doctoral thesis is organised as follows:

\section{$\underline{\text { State-of-the-art }}$}

- Chapter 2: State-of-the-art of high-temperature heat pumps for low-grade waste heat recovery.

This chapter provides a comprehensive analysis of the current status of the heat pump in the industry, comprising the advances of technological developments and the potential alternative refrigerants with low GWP to promote sustainable development. First, papers that analyse thermodynamic properties and performance of high-temperature working fluids are included; then, studies dealing with configurations and components are collected; and finally, research development and market situation are reviewed. Special attention is devoted to the comparison of existing research and commercial R\&D projects and commercially available systems.

\section{Theoretical analysis}

- Chapter 3: Theoretical evaluation of different high-temperature heat pump configurations for low-grade waste heat recovery.

In this chapter, a theoretical comparison is performed to evaluate the energy performance and the volumetric heating capacity of five vapour compression system configurations using $\mathrm{n}$ Pentane, Butane, HCFO-1233zd(E) and HFO-1336mzz(Z) as low GWP alternative fluids to HFC-245fa for heating production temperatures of 110 and $130{ }^{\circ} \mathrm{C}$. Moreover, this chapter evaluates optimum combinations of configuration and low GWP working fluid for heating production temperature up to $150{ }^{\circ} \mathrm{C}$. For this situation, the traditional refrigerant HFC-245fa cannot reach without degrading system energy efficiency.

- Chapter 4: Thermodynamic analysis of low GWP alternatives to HFC-245fa in hightemperature heat pumps: HCFO-1224yd(Z), HCFO-1233zd(E) and HFO-1336mzz(Z).

This chapter analyses and compares the operating and energetic performance of HFO1336mzz(Z), HCFO-1233zd(E) and HCFO-1224yd(Z) as potential low GWP alternatives to replace the commonly used HFC-245fa in high-temperature heat pumps (HTHPs). Besides, this chapter assesses the consequence of the HFC-245fa replacement, comparing the main thermodynamic and transport properties of the alternatives proposed and the influence of the internal heat exchanger (IHX). This chapter aims to provide comparative information on these recently developed working fluids. It can be used as a reference to decide the refrigerant to be used in particular HTHP applications, depending on the safety requirements, operating range of temperatures and pressures, and energy performance priorities. 
Chapter 1

\section{Experimental and semi-empirical evaluation}

- Chapter 5: Experimental exergy and energy analysis of a novel high-temperature heat pump with scroll compressor for waste heat recovery.

In this chapter, the first experimental results of a novel HTHP with scroll compressor for lowgrade waste heat recovery are presented. The prototype is designed to test low synthetic GWP refrigerants and reach heat sink temperatures of $140{ }^{\circ} \mathrm{C}$. Nevertheless, the first experimental results are obtained using HFC-245fa as a working fluid in order to establish the reference for future alternative refrigerant drop-in replacements.

- Chapter 6: Semi-empirical and environmental assessment of the low GWP refrigerant HCFO$1224 y d(Z)$ to replace HFC-245fa in high temperature heat pumps.

This chapter presents a semi-empirical evaluation of the alternative low-GWP refrigerant HCFO$1224 \mathrm{yd}(\mathrm{Z})$ as a replacement for HFC-245fa in high temperature heat pumps through a thermodynamic assessment and semi-empirical comparison. Single-stage cycle with IHX is used as the configuration in the test bench, operating with a fixed heat source inlet temperature of 80 ${ }^{\circ} \mathrm{C}$. In contrast, the heat sink outlet temperature varies from 110 to $140{ }^{\circ} \mathrm{C}$. The main parameters studied are the heating capacity, compressor power consumption, volumetric heating capacity and coefficient of performance (COP). Finally, the expected theoretical results and the semiempirical results are presented and discussed to comprehensively evaluate the potential of HCFO-1224yd(Z) as an alternative to HFC-245fa.

\section{$\underline{\text { Advanced applications and system integration }}$}

- Chapter 7: Multi-objective optimisation of a novel reversible High-Temperature Heat Pump-Organic Rankine Cycle (HTHP-ORC) for industrial low-grade waste heat recovery.

In this chapter, a novel reversible HTHP-ORC system for industrial low-grade waste heat recovery is presented. The focus is on the optimisation analysis and multi-objective low-GWP alternative refrigerant selection to provide guidelines for further design improvement and sustainable development.

- Chapter 8: High temperature heat pump integration into district heating network.

This chapter investigates the integration of HTHPs into DHN in two different scenarios, using the DHN as the heat sink or as the heat source. When the DHN is acting as the heat sink, the HTHP recovers, revalorises, and injects the heat rejected by the refrigeration system of a supermarket. A thermo-economic optimisation of the refrigeration system and HTHP has been done to maximise the benefits of this system integration. Moreover, the DHN is used as the heat source for HTHPs in the industrial sector to replace conventional natural gas boilers. Finally, alternative low-GWP refrigerants to HFC-134a and HFC-245fa are evaluated as sustainable candidates in HTHP systems. 


\section{References}

[1] IPCC. Climate Change 2014: Synthesis Report. Contribution of Working Groups I, II and III to the Fifth Assessment Report of the Intergovernmental Panel on Climate Change [Core Writing Team, R.K. Pachauri and L.A. Meyer (eds.)]. Geneva, Switzerland, 2014.

[2] NOAA/NCCC. Global Climate Change Indicators n.d.

[3] Hammond GP, Norman JB. Heat recovery opportunities in UK industry. Appl Energy 2014;116:387-97. doi:10.1016/j.apenergy.2013.11.008.

[4] Cullen JM, Allwood JM. Theoretical efficiency limits for energy conversion devices. Energy 2010;35:2059-69. doi:https://doi.org/10.1016/j.energy.2010.01.024.

[5] Semkov K, Mooney E, Connolly M, Adley C. Efficiency improvement through waste heat reduction. $\quad$ Appl Therm Eng 2014;70:716-22. doi:https://doi.org/10.1016/j.applthermaleng.2014.05.030.

[6] Johnson I, Choate WT, Davidson A. Waste Heat Recovery. Technology and Opportunities in U.S. Industry. 2008. doi:10.2172/1218716.

[7] SF E. Potensialstudie for utnyttelse av spillvarme fra norsk industri. Rapport. 2009.

[8] Forman C, Muritala IK, Pardemann R, Meyer B. Estimating the global waste heat potential. Renew Sustain Energy Rev 2016;57:1568-79. doi:10.1016/j.rser.2015.12.192.

[9] Elson A, Tidball R, Hampson A. Waste Heat to Power Market Assessment. Energy Transp Div US Dep Energy 2014.

[10] Lecompte S, Huisseune H, van den Broek M, Vanslambrouck B, De Paepe M. Review of organic Rankine cycle (ORC) architectures for waste heat recovery. Renew Sustain Energy Rev 2015;47:448-61. doi:https://doi.org/10.1016/j.rser.2015.03.089.

[11] Yang S, Yang S, Wang Y, Qian Y. Low grade waste heat recovery with a novel cascade absorption heat transformer. Energy 2017;130:461-72.

[12] Wang RZ, Wang LW, Hu B, Jiang L, Du S, Xu ZY, et al. Refrigerants and Heat Pumps for Efficient Use of Low Grade Thermal Energy. 5th IIR Int Conf Thermophys Prop Transder Process Refrig April 2017 Seoul, Korea 2017. doi:10.18462/iir.tptpr.2017.1001.

[13] Seck GS, Guerassimoff G, Maïzi N. Heat recovery using heat pumps in non-energy intensive industry: Are Energy Saving Certificates a solution for the food and drink industry in France? Appl Energy 2015;156:374-89.

[14] Brückner S, Liu S, Miró L, Radspieler M, Cabeza LF, Lävemann E. Industrial waste heat recovery technologies: An economic analysis of heat transformation technologies. Appl Energy 2015;151:157-67. doi:10.1016/j.apenergy.2015.01.147.

[15] Kosmadakis G. Estimating the potential of industrial (high-temperature) heat pumps for exploiting waste heat in EU industries. Appl Therm Eng 2019;156:287-98. doi:10.1016/J.APPLTHERMALENG.2019.04.082.

[16] Chua KJ, Chou SK, Yang WM. Advances in heat pump systems: A review. Appl Energy 2010;87:3611-24. doi:10.1016/j.apenergy.2010.06.014.

[17] Arpagaus C, Bless F, Uhlmann M, Schiffmann J, Bertsch SS. High temperature heat pumps: Market overview, state of the art, research status, refrigerants, and application potentials. 
Chapter 1

Energy 2018;152:985-1010. doi:10.1016/J.ENERGY.2018.03.166.

[18] Arpagaus C, Bless F, Uhlmann M, Schiffmann J, Bertsch SS. High temperature heat pumps: Market overview, state of the art, research status, refrigerants, and application potentials. Energy 2018;152:985-1010. doi:10.1016/j.energy.2018.03.166.

[19] Urbanucci L, Bruno JC, Testi D. Thermodynamic and economic analysis of the integration of high-temperature heat pumps in trigeneration systems. Appl Energy 2019;238:516-33. doi:10.1016/J.APENERGY.2019.01.115.

[20] International Energy Agency. Application of Industrial Heat Pumps, Final Report, Part 1, Report No. HPPAN35- 1 2014. doi:10.1017/CBO9781107415324.004.

[21] Jakobs R, Laue H-J. Application of Industrial Heat Pumps IEA HPP IETS Annex 35-13 IEA HPC. Work. Work. Regarding Heat Pumps IEA Proj. "Application Ind. Heat Pumps”, 4 May 2015, Aarhus, Denbark., 2015, p. 1-82.

[22] Cotter DF, Shah NN, Huang MJ, Hewitt NJ. Refrigerant Lubricant Interaction in HighTemperature Heat Pump and Organic Rankine Cycle Systems. IIR Int Rank 2020 Conf Heating, Cool Power Gener - 27-31 July 2020, Glas UK 2020.

[23] Eisa MAR, Best R, Holland FA. Working fluids for high temperature heat pumps. J Heat Recover Syst 1986;6:305-11. doi:10.1016/0198-7593(86)90116-5.

[24] Linton JW. Description and Test Results of a High Temperature Heat Pump Test Facility. Heat Pumps, 1990, p. 455-65. doi:10.1016/B978-0-08-040193-5.50055-9.

[25] Linton JW, Snelson WK. An Overview of Current High Temperature Heat Pump Technology. Heat Pumps Energy Effic. Environ. Prog., 1993, p. 217-27.

[26] United Nations. Montreal Protocol on Substances that Deplete the Ozone Layer. United Nations, New York, NY, USA 1987.

[27] Brown J. Potential R-114 replacement refrigerants. ASHRAE Trans 2008.

[28] The European Parliament and the Council of the European, Union. Regulation (EU) No 517/2014 of the European Parliament and the Council of 16 April 2014 on fluorinated greenhouse gases and repealing Regulation (EC). No 842/2006 Off J Eur Union 150, 195-230 2014.

[29] European Comission. Proposal for a Council Decision on the conclusion of the agreement to amend the Montreal Protocol on substances that deplete the ozone layer adopted in Kigali. Brussels, Belgium 2017.

[30] Calm JM. The next generation of refrigerants - Historical review, considerations, and outlook. Int J Refrig 2008;31:1123-33. doi:10.1016/j.ijrefrig.2008.01.013.

[31] Bamigbetan O, Eikevik TM, Nekså P, Bantle M. Review of vapour compression heat pumps for high temperature heating using natural working fluids. Int J Refrig 2017;80:197-211. doi:10.1016/j.ijrefrig.2017.04.021.

[32] Klein S. Engineering Equation Solver (EES) V10.6. Fchart Software, Madison, USA WwwFchartCom 2006.

[33] Lemmon EW, Bell IH, Huber ML, McLinden MO. NIST Standard Reference Database: Reference Fluid Thermodynamic and Transport Properties-REFPROP, Version 10. Natl Inst Stand Technol Stand Ref Data Program, Boulder, CO 2018. 


\section{Chapter 2 State-of-the-Art of High-Temperature Heat Pumps for Low-Grade Waste Heat Recovery}

High-temperature heat pumps (HTHPs) for low-grade waste heat recovery have been notoriously developed during the recent years to be installed in industrial applications. An improvement of the industrial energy efficiency would decarbonise this sector, and consequently, it would reduce the worldwide greenhouse gas emissions. To cover greater application and temperature ranges, the supply temperatures must be increased to levels where the integration of HTHPs in the industry become attractive. This paper gives a comprehensive overview of HTHPs technology to establish their state-of-the-art and future trends based on the working fluids, components and configurations, research projects development and market situation. This paper also includes an analysis of the research and commercially available and future HTHP systems. The commercially available systems are limited by a condensing temperature of $120^{\circ} \mathrm{C}$ and an evaporation temperature around $70^{\circ} \mathrm{C}$. Nevertheless, research projects are operating at higher condensing temperatures and absorbing heat from higher heat sources. Hence, the future trend in this technology lies in the development of HTHPS capable of supply increasing temperatures from higher heat sources. A satisfactory development of these prototypes can help to reach the target of greenhouse gas emissions reduction from industry.

\subsection{Introduction}

NASA expert team has measured an increase in global mean surface temperature on Earth [1]. If no additional actions are taken, the global temperature will increase by $4.8^{\circ} \mathrm{C}$ above pre-industrial levels by the end of this century. Therefore, the international Paris Agreement has planned a global reduction on greenhouse gasses (GHGs) emission to keep this temperature increase at a maximum of $2{ }^{\circ} \mathrm{C}$ [2]. The industrial sector is one of the three main energy consuming sectors worldwide, and in Europe, it represents $62 \%$ of the total energy consumption [3]. Hence, an improvement of the industrial energy efficiency would suppose a substantial reduction of GHGs emissions. The Intergovernmental Panel on Climate Change looks at industrial waste heat recovery as one of the possibilities to significantly reduce GHG emission [4]. At present, most of the heat below $100{ }^{\circ} \mathrm{C}$ has no interest for industrial purposes, and it is rejected to the ambient. To avoid this evident waste of profitable energy, it could be revalorised using the proper technology, including heat pumps. Instead of using conventional boilers, heat pumps.

The Intergovernmental Panel on Climate Change looks at industrial waste heat recovery as one of the possibilities to significantly reduce GHG emission [4]. At present, most of the heat below $100{ }^{\circ} \mathrm{C}$ has no interest for industrial purposes, and it is rejected to the ambient. To avoid this evident waste of profitable energy, it could be revalorised using the proper technology, including heat pumps [5]. 
Instead of using conventional boilers, heat pumps could be installed to reduce the fossil fuel dependence of the industry and help to decarbonise this sector.

Heat pumps present higher energy performance than boilers. Using the electrically activated compressor in a reverse Carnot cycle, heat pumps raise the heat from the industrial low-temperature waste heat source to high-temperature useful heat in the form of steam or pressurised water. However, the electrical energy consumed by the compressor strongly depends on the temperature lift, which quantifies the difference between the heat sink (condenser) and heat source (evaporator) temperatures. The heat sink temperature depends on the temperature level of the industrial requirements, and the heat source temperature depends on the sources available for waste heat recovery [6]. Given the different levels of the heat sink and source temperature, the classification of the types of heat pumps according to these operating parameters becomes necessary, since it is going to affect the analysis of the status of maturation of this technology.

International Energy Agency [7] proposed a classification for heat pumps used in the industry according to their heat sink and heat source temperatures, represented in Fig. 2.1. Therefore, while several studies mention high-temperature heat pumps (HTHPs) without establishing a specific operating range [8-10], only heat pumps operating at heat sink temperatures of between 80 and 100 ${ }^{\circ} \mathrm{C}$ and heat source temperatures of $40-60{ }^{\circ} \mathrm{C}$ could be mentioned in that way, according to IEA. Heat pumps below that temperatures range are called industrial heat pumps (IHP), and those above heat sink and source temperatures of 100 and $60^{\circ} \mathrm{C}$, very HTHPs.

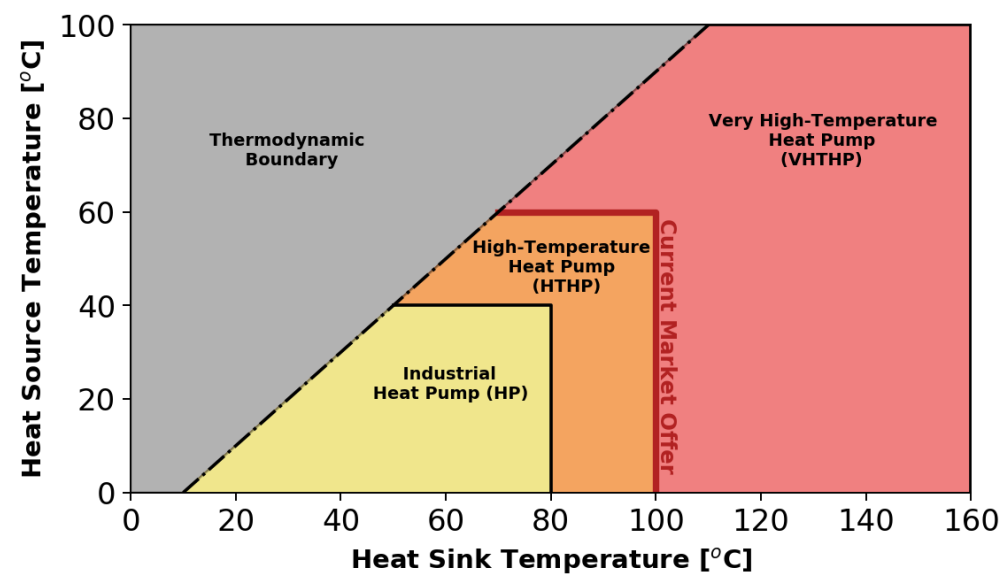

Fig. 2.1. Heat pump classification $[7,11]$.

Despite the environmental benefits of heat pumps in the industry, the present introduction of these systems is still limited due to technological restrictions and lower price of conventional boilers and fossil fuel. Hence, heat pumps that operate at temperatures above $140{ }^{\circ} \mathrm{C}$ must be studied and developed to increase the waste heat valorisation opportunities and energy efficiency of the industry [12].

Given the energy efficiency priority, within the past few years, several studies have been conducted to identify the adequate working fluids, components, and configurations for these systems. This paper aims to provide an analysis of the present status of the heat pump in the industry, comprising the advances of technological developments and the potential working fluids alternatives with low GWP 
to achieve a sustainable development. First, papers that analyse thermodynamic properties and performance of high-temperature working fluids are included; then, studies of configuration systems and components development are collected; and finally, research development and market situation are reviewed. Special attention is given to compare research projects, commercially available systems and commercial $R \& D$ projects.

\subsection{Potential HTHP applications in the industry}

Brückner, et al. [3] and Miró, et al. [4] analysed and presented the potential waste heat recovery opportunities in the European industry through different methods and technologies. Brückner, et al. [3] proposed a distinction between the theoretical, technical and economic potential for industrial waste heat. Moreover, Miró, et al. [4] reviewed and identified the industrial waste heat potential for 33 countries considering different sources. Additionally, Hammond and Norman [13] estimated the technical potential of various heat recovery technologies in the UK. Forman, et al. [14] concluded that $2.85 \%$ of the world primary energy consumption is lost as industrial waste heat below $100{ }^{\circ} \mathrm{C}$, as shown in Fig. 2.2. This section summarizes the conclusions achieved by several practical application cases of HTHPs in different industrial sectors.

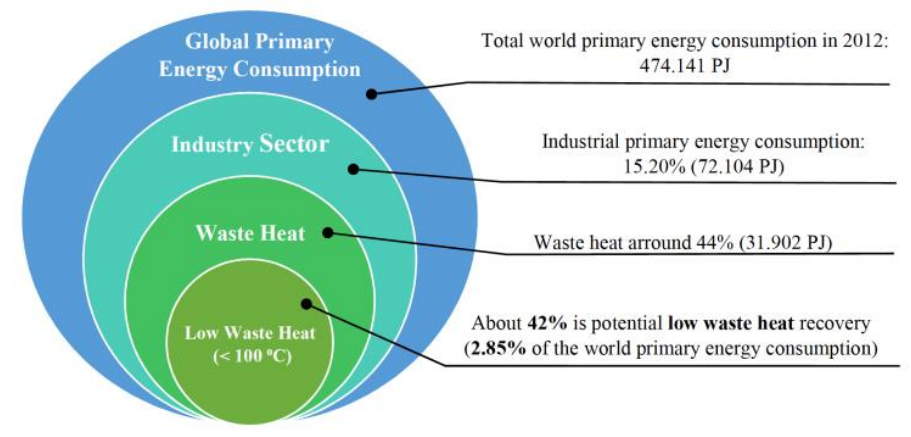

Fig. 2.2. Potential waste heat recovery in the industry sector [14].

Zhang, et al. [16] reviewed advances and applications of industrial heat pumps in China comparing different types of them. One of the conclusions is that some industrial processes like petrochemical need higher heating temperatures (above $100^{\circ} \mathrm{C}$ ) than available HTHPs can provide. Liu, et al. [17] analyzed HTHPs in marine diesel engines, in which around $7 \%$ of the input energy could be recovered from the cylinder cooling water. Then, this heat could be upgraded up to $120^{\circ} \mathrm{C}$ and satisfy the daily heating demand of steam-consuming equipment on ships.

Temperatures from 80 to $120{ }^{\circ} \mathrm{C}$ allow HTHPs in other applications that require steam or hightemperature heat. A recent potential application proposed by Sartor, et al. [18] is the integration of HTHPs in the low-temperature district heating network. Besides increasing the efficiency and flexibility of the system, it reduces the heat losses up to 1,900 MWh per year. Wilk, et al. [20] studied several integration cases of HTHPs into different applications. In the laundry industry, where heat can be recovered from humid exhaust gases to produce low-pressure steam, it reduces the primary $\mathrm{CO}_{2}$ emissions but also increases the operating cost. In the paper mill case, when an HTHP is integrated into the low-pressure steam grid, also reduces the amount of natural gas consumed. Finally, the case of expanded polystyrene production shows a highly efficient integration of HTHP with 
significant energy cost savings. In the same way, Lambauer, et al. [21] found that drying is an interesting sector to apply HTHPs. Firstly, the HTHP can absorb the heat and reduce humidity coming from the exhaust drying air, and secondly, it can reinject the required thermal heat to the drying process.

As it can be seen from the previous works, HTHP that works in the range of $75-140{ }^{\circ} \mathrm{C}$ of condensing temperature and $40-100{ }^{\circ} \mathrm{C}$ of evaporation temperature is essential for waste heat recovery in a great variety of industries. However, it requires an appropriate selection of the working fluid to enhance the HTHP energy performance and make them competitive.

\subsection{Working fluids}

After reviewing the most relevant working fluids used in HTHPs, further analysis of the potential alternatives become necessary to suggest the future trend. This section presents the different environmentally respectful possibilities considering the environmental protection regulations and objectives, and without losing sight of thermodynamic, safety and chemical stability requirements. Table 2.1 summarises the main thermodynamic properties of the fourth generation working fluids. Most of them have a high critical temperature $\left(\mathrm{T}_{\text {crit }}\right)$ and critical pressures $\left(\mathrm{P}_{\text {crit }}\right)$ between 2 and $4 \mathrm{MPa}$. They show differences in safety (toxicity and flammability) and this fact can involve discrepancies in their successful implementation.

Table 2.1. Properties of the present and future HTHPs working fluids.

\begin{tabular}{ccccccccc}
\hline Refrigerant & $\begin{array}{c}\text { Molar mass } \\
{\left[\mathbf{g ~ m o l}^{-1}\right]}\end{array}$ & $\begin{array}{c}\text { Normal } \\
\text { boiling } \\
\mathbf{p o i n t} \\
{\left[{ }^{\circ} \mathbf{C}\right]}\end{array}$ & ODP & $\mathbf{G W P}_{100}$ & $\begin{array}{c}\text { Lifetime } \\
\text { [years] }\end{array}$ & $\begin{array}{c}\text { Safety } \\
\text { classifica } \\
\text { tion }\end{array}$ & $\begin{array}{c}\mathbf{P}_{\text {crit }} \\
{[\mathbf{M P a}]}\end{array}$ & $\begin{array}{c}\mathbf{T}_{\text {crit }} \\
{\left[{ }^{\circ} \mathbf{C}\right]}\end{array}$ \\
\hline HFO-1234ze(E) & 114.04 & -19.0 & 0 & $<1$ & $16.4 \mathrm{~d}$ & $\mathrm{~A} 2 \mathrm{~L}$ & 3.64 & 109.4 \\
Ammonia & 17.03 & -33.3 & 0 & 0 & - & $\mathrm{B} 2 \mathrm{~L}$ & 11.28 & 132.4 \\
HFO-1234ze(Z) & 114.04 & 9.8 & 0 & $<1$ & $10 \mathrm{~d}$ & $\mathrm{~A} 2 \mathrm{~L}$ & 3.53 & 150.1 \\
Butane & 58.12 & -0.5 & 0 & 20 & 0.018 & $\mathrm{~A} 3$ & 3.80 & 152 \\
HFC-245fa & 134.04 & 15.1 & 0 & 858 & 7.6 & $\mathrm{~B} 1$ & 3.65 & 154.0 \\
HCFO-1224yd(Z) & 148.48 & 14.6 & negligible & $<1$ & $21 \mathrm{~d}$ & $\mathrm{~A} 1$ & 3.34 & 155.5 \\
HCFO-1233zd(E) & 130.49 & 18.3 & negligible & 1 & $26 \mathrm{~d}$ & $\mathrm{~A} 1$ & 3.77 & 165.6 \\
HFO-1336mzz(Z) & 164.05 & 33.4 & 0 & 2 & $26 \mathrm{~d}$ & $\mathrm{~A} 1$ & 2.90 & 171.3 \\
Pentane & 72.14 & 36.1 & 0 & 20 & 0.019 & $\mathrm{~A} 3$ & 3.37 & 196.6 \\
\hline
\end{tabular}

Attending to the environmental requirements, HFC-245fa, one of the most common refrigerants used in HTHPs, cannot be a future possibility due to their relatively high GWP. However, similar or higher COP than HFC-245fa is required to its potential replacement alternatives. A theoretical simulation illustrates the theoretical system performance of HTHPs that use alternative refrigerants, as shown in Fig. 2.3. The critical pressures and $\mathrm{COP}$ are calculated at typical operating parameters and condition of HTHPs: isentropic efficiency of 0.8 , sub-cooling degree of $5 \mathrm{~K}$, superheating degree of $15 \mathrm{~K}$, and temperature lift of $60 \mathrm{~K}$. 


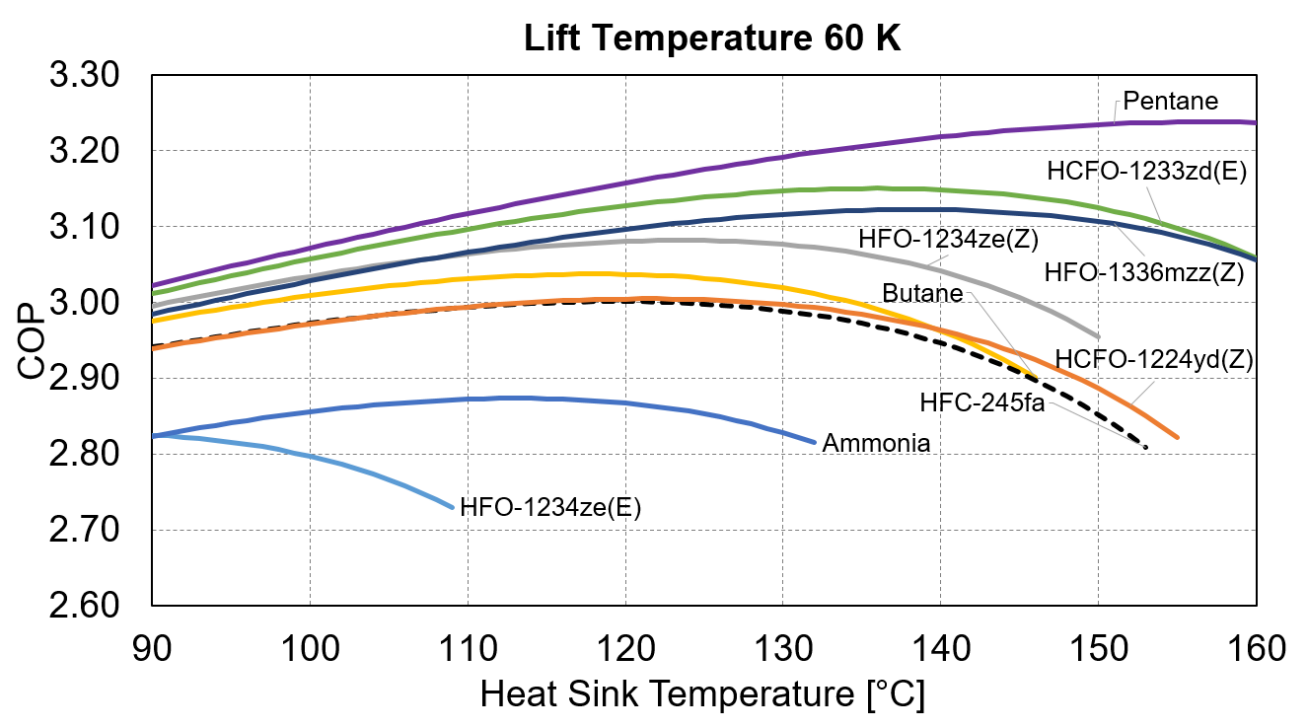

Fig. 2.3. COP for different HTHP working fluids with temperature lift of $60 \mathrm{~K}$.

While ammonia and HFO-1234ze(E) cannot be included as potential low GWP alternatives for HTHPs because of their lower COP than HFC-245fa, butane is an excellent alternative given its higher $\mathrm{COP}$ at some operating conditions. Hence, this hydrocarbon requires further detailed analysis for a clear conclusion about its potential. Nevertheless, the other refrigerants analysed could be potential working fluids for high-temperature heat pumps.

As a conclusion of the simulation results and the minimum established requirements (zero ODP, low GWP, non-toxic and non-flammable to be environmentally friendly and safe) for potential future alternatives in HTHPs, the most promising candidates are HFO-1234ze(Z), HCFO-1233zd(E), HCFO-1224yd(Z), HFO-1336mzz(Z), and pentane. Although water is also a potential candidate, it is not included in this paper because of the high properties difference with the other refrigerants. Finally, it should be noted that carbon dioxide has been excluded from this analysis because its proper HTHP application is closer to water heater applications than conventional boilers replacement or heat recovery applications.

\subsection{Architectures and components}

The component development and configuration are essential in order to go a step forward in the heat pump developing, especially for high-temperature applications. Therefore, this section presents the recent components developments for high-temperature applications, along with the configurations studied for this technology.

Compressor, as one of the main vapor compression components, is widely studied to improve system performance along with enlarging the operating boundaries. Hence, several studies are focused on extending the compressors temperature limits to enable their use in high-temperature applications. Bamigbetan, et al. [22] experimentally studied an HC-600 reciprocating compressor for hightemperature applications, showing that temperatures up $114{ }^{\circ} \mathrm{C}$ could be achieved. On the other hand, turbo-centrifugal compressors raise interest for installations using water as working fluid. Šarevski, 
et al. [23] conducted a theoretical study about the application of a turbo compressor with thermal vapour recompression and direct flash evaporation in industrial plants, which resulted in higher COP than conventional systems.

Another important component in HTHP is the Internal Heat Exchanger (IHX). Mota-Babiloni, et al. [8] studied several refrigerants in an HTHP cascade configuration paying particular attention to the low and high stages IHX optimisation. This study illustrates the importance of the IHX influence due to the notable behaviour differences in each refrigerant pair. Moreover, He, et al. [24] present an experimental study of a vapour injection economiser or IHX for HTHPs demonstrating that an injection below $1 \mathrm{MPa}$ increases the heating capacity while the opposite reduces the performance.

System configuration could provide a significant performance improvement in HTHP. Thus, MateuRoyo, et al. [9] analysed the energy performance of five different HTHP architectures with different environmentally-friendly working fluids. The results show that two-stage HTHPs with IHX achieve the highest performance. Similar conclusions are achieved by Cao, et al. [25], who analysed six different heat pump systems using HFC-152a as working fluid to produce up to $95^{\circ} \mathrm{C}$ hot water from waste heat recovery. The recent interest in HTHPs justifies the absence of experimental comparisons between different configurations. Future research developments would prove the theoretical results previously exposed.

To sum up, several studies consider improving the compressor efficiency, which is one of the main components in a heat pump system and the only one that consumes electrical energy for its operation. Hence, an increase in compressor efficiency directly benefits the system performance. The proper compressor technology is dependent on the heating power demand required and the pressure ratio. Screw and centrifugal compressors technology are present most of the research articles revised. Nevertheless, other compressor technology like scroll or reciprocating must be taken into account due to their significant presence in commercial systems. Other non-conventional components like ejectors or economizers are beginning to be experimentally studied.

As a result of the system configuration revision, it can be concluded that the optimum system configuration is strongly dependent on the temperature lift. While basic configuration (with or without IHX) is appropriate for low-temperature lifts, at higher ones, cascade or two-stage configurations seem the most appropriate. The system configuration research is absent at lowtemperature lifts since it does not represent a challenge. Hence, research studies are focused on advanced configuration, whereas commercial developments tend to improve system performance in simple configurations.

\subsection{Research projects}

The climate change mitigation has arisen interest in extending the operation limits of the heat pump technology to enable high temperatures applications. Thus, several research projects are a focus on developing high-temperature heat pumps with sustainable working fluids in order to contribute to society decarbonisation.

Table 2.2 shows the today main research projects that include HTHP prototypes. From this table, it can be extracted that the most common configurations are single-stages with or without IHX. Then, 
compressor technology selection strongly depends on the application of the HTHP and the heating capacity for those applications.

Table 2.2. Research Projects in HTHPs [7,11,26-31]

\begin{tabular}{|c|c|c|c|c|c|c|c|}
\hline Reference & Config. & Refrig. & Comp. type & $\begin{array}{l}Q_{\text {heat }} \\
{[\mathbf{k W}]}\end{array}$ & $\begin{array}{l}\text { THeat } \\
\text { Source } \\
{\left[{ }^{\circ} \mathrm{C}\right]}\end{array}$ & $\begin{array}{l}\text { THeat Sink } \\
{\left[{ }^{\circ} \mathrm{C}\right]}\end{array}$ & COP \\
\hline $\begin{array}{l}\text { Austrian } \\
\text { Institute of } \\
\text { Technology } \\
\text { (AIT) }\end{array}$ & $\begin{array}{l}\text { Single- } \\
\text { stage/IHX }\end{array}$ & $\begin{array}{l}\text { HFO- } \\
1336 \mathrm{mzz}(\mathrm{Z})\end{array}$ & Reciprocating & 12 & 90 & 160 & 2.5 \\
\hline $\begin{array}{l}\text { NTB } \\
\text { University, } \\
\text { Switzerland }\end{array}$ & $\begin{array}{l}\text { Single- } \\
\text { stage/IHX }\end{array}$ & $\begin{array}{l}\text { HCFO- } \\
1233 \mathrm{zd}(\mathrm{E})\end{array}$ & Reciprocating & 10 & $30-80$ & 151 & 1.1 \\
\hline $\begin{array}{l}\text { PACO, } \\
\text { University } \\
\text { Lyon EDF }\end{array}$ & Flash tank & Water & Twin screw & 300 & 95 & 145 & 3.6 \\
\hline $\begin{array}{l}\text { ISTENER, } \\
\text { Universitat } \\
\text { Jaume I, Spain }\end{array}$ & $\begin{array}{l}\text { Single- } \\
\text { stage/IHX }\end{array}$ & HFC-245fa & Scroll & 17 & $60-80$ & 140 & 2.2 \\
\hline $\begin{array}{l}\text { Alter ECO, } \\
\text { EDF }\end{array}$ & $\begin{array}{l}\text { IHX and sub- } \\
\text { cooler }\end{array}$ & HFC-245fa & Double scroll & $50-200$ & 60 & 140 & 2 \\
\hline $\begin{array}{l}\text { Austrian } \\
\text { Institute of } \\
\text { Technology } \\
\text { (AIT) }\end{array}$ & Economizer & HFC-245fa & Screw & $\begin{array}{l}250- \\
400\end{array}$ & 60 & 130 & 2.1 \\
\hline $\begin{array}{l}\text { Kysushu } \\
\text { University, } \\
\text { Japan }\end{array}$ & 1 -stage & $\begin{array}{l}\text { HFO- } \\
1234 \mathrm{ze}(\mathrm{Z})\end{array}$ & Twin screw & 1.8 & 90 & 125 & 5.4 \\
\hline $\begin{array}{l}\text { SmurfitKappa } \\
\text { Roermond, } \\
\text { Netherlands }\end{array}$ & $\begin{array}{l}\text { IHX and sub- } \\
\text { cooler }\end{array}$ & Butane & Reciprocating & 200 & 75 & 120 & 4.2 \\
\hline
\end{tabular}

In comparison with other compressor technologies, screw compressors are commonly used in hightemperature applications. The technological feasibility is demonstrated for heat sink temperatures between 125 and $140{ }^{\circ} \mathrm{C}$, but further developments are necessary to increase the efficiency of these technologies and their economic feasibility. The predominant working fluid is still HFC-245fa, which requires low GWP alternative replacements, as previously discussed. Therefore, low GWP refrigerants as HFO-1336mzz(Z), HCFO-1233zd(E), HFO-1234ze(Z), butane and water are only present in a few research projects. 


\subsection{Market overview}

Commercially available and the future systems are presented in different sections because several developed models are not still commercially available. This section investigates the commercially available HTHP technology to provide an overview of the operating conditions and working fluids used today by manufacturers as can be found in references [7,30,32]. A summary of the commercially available HTHPs is included in Table 2.2, and the conclusions are discussed in the following.

Table 2.3. Research projects in HTHPs [7,32].

\begin{tabular}{|c|c|c|c|c|c|c|c|c|}
\hline Reference & Model & Refrig. & $\begin{array}{l}\mathbf{T}_{\text {Sink }} \\
{\left[{ }^{\circ} \mathrm{C}\right]}\end{array}$ & $\begin{array}{l}\text { T source } \\
{\left[{ }^{\circ} \mathbf{C}\right]}\end{array}$ & $\begin{array}{l}\Delta T \\
{[K]}\end{array}$ & Comp. type & $Q_{\text {heat }}[\mathbf{k W}]$ & COP \\
\hline \multirow[b]{2}{*}{ Kobelco } & SGH 120 & HFC-245fa & 120 & 65 & 55 & \multirow[b]{2}{*}{ Twin screw } & $75-375$ & 3.5 \\
\hline & $\begin{array}{l}\text { HEM- } \\
\text { HR90 }\end{array}$ & $\begin{array}{l}\text { HFC-134a/ } \\
\text { HFC-245fa }\end{array}$ & 90 & 35 & 55 & & $75-235$ & 5.8 \\
\hline $\begin{array}{l}\text { Dürr } \\
\text { Thermea }\end{array}$ & Thermeco2 & Carbon dioxide & 110 & 20 & 90 & Screw & $50-2250$ & 4.2 \\
\hline Ochsner & IWHS ER3 & $\begin{array}{l}\text { HFC-134a/ } \\
\text { HFC-245fa }\end{array}$ & 95 & 45 & 45 & Screw & $190-745$ & 4.0 \\
\hline $\begin{array}{l}\text { GEA } \\
\text { Refrigeration }\end{array}$ & $\begin{array}{l}\text { GEA } \\
\text { Grasso FX } \\
\text { P } 63\end{array}$ & Ammonia & 90 & 45 & 45 & Twin screw & $2000-4500$ & 5.0 \\
\hline Mitsubishi & ETW-L & HFC-134a & 90 & 50 & 40 & $\begin{array}{l}\text { Turbo (2 } \\
\text { stage) }\end{array}$ & $345-610$ & 4.1 \\
\hline Viessmann & $\begin{array}{l}\text { Vitocal } \\
\text { 350-HT Pro }\end{array}$ & HFO-1234ze(E) & 90 & 50 & 40 & Reciprocating & $148-223$ & 3.4 \\
\hline
\end{tabular}

Similar to that drawn in the research projects analysis, screw compressor and HFC-245fa is the most common technology and working fluid, respectively. Nevertheless, Dürr Thermea highlights using $\mathrm{CO}_{2}$ as working fluid, which allows heat sink temperatures of $110^{\circ} \mathrm{C}$. Other manufacturers prefer ammonia or HFO-1234ze(Z). Although an accurate performance comparison would require comparable same high-temperature supply, Table 2.3 shows the COP of the commercially available technology to provide an overview of the current market situation. Most of the commercially available systems produce heat above $90^{\circ} \mathrm{C}$.

Nevertheless, higher heating production temperatures have been shown in commercial development projects that are not commercially available. Thus, these values establish the limit between the available commercial technology and future commercial HTHPs technology. Table 2.4 presents an overview of the present and future commercial HTHPs based on research \& development previously reviewed to make clearer the current trend. 
Table 2.4. Commercial Research and Development (R\&D) projects in HTHPs [7,33-35].

\begin{tabular}{|c|c|c|c|c|c|c|c|c|}
\hline Reference & Model & Refrig. & $\begin{array}{l}\mathrm{T}_{\text {Heat }} \\
\text { Sink } \\
\left.{ }^{\circ} \mathrm{C}\right]\end{array}$ & $\begin{array}{l}\mathbf{T}_{\text {Heat }} \\
\text { Source } \\
{\left[{ }^{\circ} \mathrm{C}\right]}\end{array}$ & $\begin{array}{l}\Delta \mathrm{T} \\
{[\mathrm{K}]}\end{array}$ & Comp. type & $\begin{array}{l}Q_{\text {heat }} \\
\text { [kW] }\end{array}$ & COP \\
\hline Kobelco & SGH 165 & HFC-245fa & 165 & 70 & 55 & $\begin{array}{l}\text { Twin screw + } \\
\text { steam } \\
\text { compressor }\end{array}$ & $70-660$ & 2.5 \\
\hline $\begin{array}{l}\text { Vickings } \\
\text { Heating } \\
\text { Engines AS }\end{array}$ & $\begin{array}{l}\text { Heat } \\
\text { Booster }\end{array}$ & HFO-1336mzz(Z) & 150 & 90 & 60 & Reciprocating & $28-188$ & 4.0 \\
\hline Rank & Rank ${ }^{\circledR} \mathrm{HP}$ & HCFO-1233zd(E) & 150 & 100 & 50 & Twin screw & $100-500$ & $4.17 *$ \\
\hline Hybrid Energy & $\begin{array}{l}\text { Hybrid Heat } \\
\text { Pump }\end{array}$ & Ammonia & 120 & 40 & 60 & Reciprocating & $250-2500$ & 4.5 \\
\hline Mayekawa & Eco Sirocco & Carbon dioxide & 120 & 25 & 95 & Screw & $65-90$ & 2.9 \\
\hline \multirow{2}{*}{ Ochsner } & IWWDS & $\begin{array}{l}\text { HFC-134a/HFC- } \\
245 \mathrm{fa}\end{array}$ & 130 & - & - & Screw & $170-750$ & - \\
\hline & $\begin{array}{l}\text { IWDS } 330 \\
\text { ER3 }\end{array}$ & $\begin{array}{l}\text { HFC-134a/HFC- } \\
245 \mathrm{fa}\end{array}$ & 105 & 50 & 55 & Screw & $100-350$ & 2.7 \\
\hline Combitherm & $\begin{array}{l}\text { Sonderanfer } \\
\text { tigung }\end{array}$ & HFC-245fa & 100 & 50 & 50 & Reciprocating & $20-300$ & 3.2 \\
\hline Friotherm & Unitop 22 & HFO-1234ze(E) & 95 & 34 & 60 & Turbo (2 stage) & $600-3600$ & 3.5 \\
\hline $\begin{array}{l}\text { Star } \\
\text { Refrigeration }\end{array}$ & Neatpump & Ammonia & 90 & 50 & 40 & Screw & $350-15000$ & 3.5 \\
\hline $\begin{array}{l}\text { Johnson } \\
\text { Controls }\end{array}$ & $\begin{array}{l}\text { HeatPAC } \\
\text { HPX }\end{array}$ & Ammonia & 90 & 30 & 51 & Reciprocating & $326-1324$ & 4.0 \\
\hline
\end{tabular}

${ }^{*} \mathrm{COP}$ at $90{ }^{\circ} \mathrm{C}$ of heat source and $120^{\circ} \mathrm{C}$ of heat sink

The common refrigerant for these projects is still the higher GWP refrigerant HFC-245fa, followed by the natural refrigerants ammonia and $\mathrm{CO}_{2}$. Then, two of the projects analysed use HFO$1336 \mathrm{mzz}(\mathrm{Z})$ and HFO-1234ze(E). Therefore, low GWP fluids are being slowly introduced in HTHPs. Screw is the most commonly selected compressor technology, and to a lesser extent, reciprocating models. The highest heat sink temperature is reached by the Kobelco model SGH 165 (a hybrid system HTHP), followed by the single HTHP Heat Booster produced by Vikings Heating Engines $\mathrm{AB}$, with a delivered temperature of $150^{\circ} \mathrm{C}$.

\subsection{Research guidance for future potential research \& design of HTHPs}

Fig. 2.4 provides a graphical overview of the status and future trends of HTHPs technology research, where the bubbles represent the heating capacity of each installation commercially available HTHP systems are located between 80 and $120^{\circ} \mathrm{C}$ of condensing temperature and evaporation temperatures below $70{ }^{\circ} \mathrm{C}$. Moreover, most of the R\&D HTHP commercial projects and commercially available systems are designed in the same operating range. Hence, the short-term trend of this technology will be inside the limits bounded by the commercially available technology. However, the analysed 
research projects are situated between 120 and $160{ }^{\circ} \mathrm{C}$ of heat sink temperatures and heat source temperatures above $70{ }^{\circ} \mathrm{C}$.

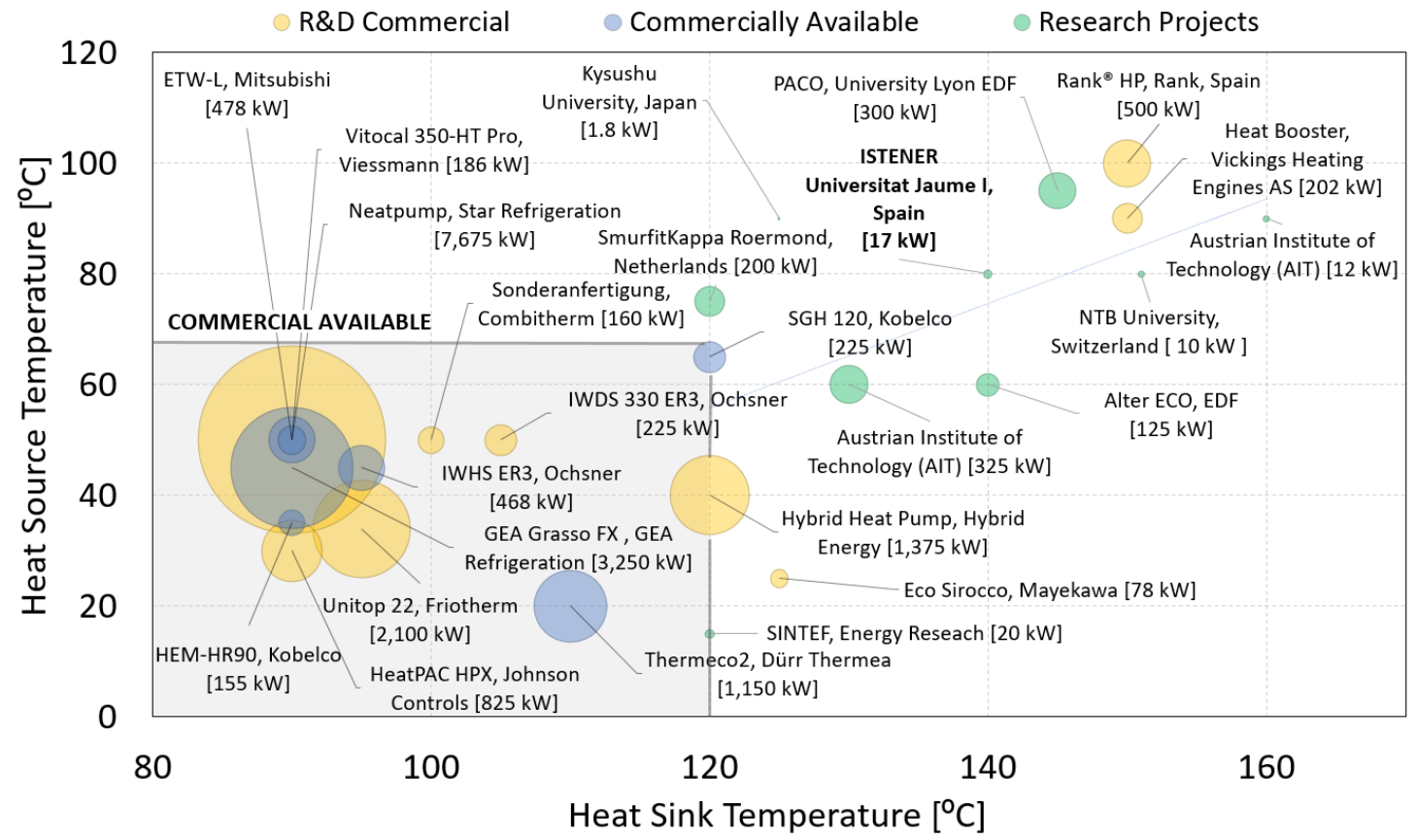

Fig. 2.4. HTHP technology trend development.

After a comprehensive revision of HTHP technology, it can be concluded that the research is focused on reaching higher condensing and evaporation temperatures due to the industrial interest of developing heat pumps for high-temperature applications. It means that the future trend of this technology lies in the development of HTHPs capable of supplying increasing temperatures from higher heat sources. Hence, the temperature limits exposed are increasing as the high-temperature technology improves.

\subsection{Conclusions}

HTHPs that recover low waste heat has been notoriously developed during recent years to benefit the industrial energy efficiency decarbonisation and reduce worldwide GHG emissions. To cover a broader application range, the supply temperatures must be increased to levels where the integration of HTHPs in the industry become attractive. This review paper gives a comprehensive overview of HTHPs technology to establish their state of the art and future trends based on the working fluids, components and configurations, research projects development and market situation.

The evolution in the primary HTHPs working fluids used from the 80 s to the present has been presented. The criteria considered for refrigerant selection are sustainability, commercial availability, safety, and performance. Moreover, a thermodynamic analysis has been performed to find the most proper alternative for high-temperature applications. HCFO-1233zd(E), HCFO-1224yd(Z) and HFO$1336 \mathrm{mzz}(\mathrm{Z})$ are those refrigerants that can be considered as future low GWP alternatives for HTHPs. 
These candidates present material compatibility with the most common elastomers and lubricants (POE).

Proposed system configurations, components and operational optimisation for HTHPs are reviewed to find the most appropriate architecture for this technology. Two-stage with IHX or flash tank configurations achieved higher performance than the other configurations. Several studies focus on screw compressor technology, which became interesting for small-scale installations.

This paper also includes an analysis of the research and commercially available and future HTHP systems to complete state of the art. A heat sink and heat source temperatures of 120 and $70{ }^{\circ} \mathrm{C}$, respectively, are the present boundaries of the commercially available systems. Nevertheless, research projects are extending the operating temperature limits for heat pump technology. Hence, the future trend in this field lies in the development of HTHPs capable of supplying higher temperatures from lower temperature sources. A satisfactory development of these prototypes can help the HTHP spread in the industry to reduce greenhouse gas emissions.

\section{References}

[1] GISTEMP TEAM. GISS Surface Temperature Analysis (GISTEMP). NASA Goddard Inst Sp Stud [Online] Available Https//DataGissNasaGov/Gistemp/ 2017.

[2] European Comission. Proposal for a Council Decision on the conclusion of the agreement to amend the Montreal Protocol on substances that deplete the ozone layer adopted in Kigali. Brussels, Belgium 2017.

[3] Brückner S, Liu S, Miró L, Radspieler M, Cabeza LF, Lävemann E. Industrial waste heat recovery technologies: An economic analysis of heat transformation technologies. Appl Energy 2015;151:157-67. doi:10.1016/j.apenergy.2015.01.147.

[4] Miró L, Brückner S, Cabeza LF. Mapping and discussing Industrial Waste Heat (IWH) potentials for different countries. Renew Sustain Energy Rev 2015;51:847-55. doi:10.1016/j.rser.2015.06.035.

[5] Langan M, O’Toole K. A new technology for cost effective low grade waste heat recovery. Energy Procedia 2017;123:188-95. doi:10.1016/j.egypro.2017.07.261.

[6] Arpagaus C, Bless F, Schiffmann J, Bertsch SS. Multi-temperature heat pumps: A literature review. Int J Refrig 2016;69:437-65. doi:10.1016/j.ijrefrig.2016.05.014.

[7] International Energy Agency. Application of Industrial Heat Pumps, Final Report, Part 1, Report No. HPPAN35- 1 2014. doi:10.1017/CBO9781107415324.004.

[8] Mota-Babiloni A, Mateu-Royo C, Navarro-Esbrí J, Molés F, Amat-Albuixech M, BarragánCervera Á. Optimisation of high-temperature heat pump cascades with internal heat exchangers using refrigerants with low global warming potential. Energy 2018;165:1248-58. doi:10.1016/j.energy.2018.09.188.

[9] Mateu-Royo C, Navarro-Esbrí J, Mota-Babiloni A, Amat-Albuixech M, Molés F. Theoretical evaluation of different high-temperature heat pump configurations for low-grade waste heat recovery. Int J Refrig 2018. doi:10.1016/j.ijrefrig.2018.04.017.

[10] Bamigbetan O, Eikevik TM, Nekså P, Bantle M. Review of vapour compression heat pumps for high temperature heating using natural working fluids. Int J Refrig 2017;80:197-211. 
Chapter 2

doi:10.1016/j.ijrefrig.2017.04.021.

[11] Jakobs R, Laue H-J. Application of Industrial Heat Pumps IEA HPP IETS Annex 35-13 IEA HPC. Work. Work. Regarding Heat Pumps IEA Proj. “Application Ind. Heat Pumps”, 4 May 2015, Aarhus, Denbark., 2015, p. 1-82.

[12] Chua KJ, Chou SK, Yang WM. Advances in heat pump systems: A review. Appl Energy 2010;87:3611-24. doi:10.1016/j.apenergy.2010.06.014.

[13] Hammond GP, Norman JB. Heat recovery opportunities in UK industry. Appl Energy 2014;116:387-97. doi:10.1016/j.apenergy.2013.11.008.

[14] Forman C, Muritala IK, Pardemann R, Meyer B. Estimating the global waste heat potential. Renew Sustain Energy Rev 2016;57:1568-79. doi:10.1016/j.rser.2015.12.192.

[15] Zhang J, Zhang H-H, He Y-L, Tao W-Q. A comprehensive review on advances and applications of industrial heat pumps based on the practices in China. Appl Energy 2016;178:800-25. doi:10.1016/j.apenergy.2016.06.049.

[16] Zhang J, Zhang H-H, He Y-L, Tao W-Q. A comprehensive review on advances and applications of industrial heat pumps based on the practices in China. Appl Energy 2016;178:800-25. doi:10.1016/j.apenergy.2016.06.049.

[17] Liu S, Chen W, Cai Z, Zheng C. Study on the Application of High Temperature Heat Pump to Recover Waste Heat of Marine Diesel Engine. 2009 Int. Conf. Energy Environ. Technol., IEEE; 2009, p. 361-4. doi:10.1109/ICEET.2009.93.

[18] Sartor K, Lemort V, Dewallef P. Improved District Heating Network Operation by the Integration of High Temperature Heat Pumps. Int J Sustain Energy 2017;0:1-15. doi:10.1080/14786451.2017.1383409.

[19] Wilk V, Windholz B, Jentsch R, Fleckl T, Fluch J, Grubbauer A, et al. Valorization of industrial waste heat by heat pumps based on case studies of the project EnPro. 12th IEA Heat Pumo Conf Rotterdam 2017.

[20] Wilk V, Windholz B, Jentsch R, Fleckl T, Fluch J, Grubbauer A, et al. Valorization of industrial waste heat by heat pumps based on case studies of the project EnPro n.d.

[21] Lambauer J, Wolf S, Fahl U, Blesl M, Voß A. IEA HPP - IETS Annex 35/13, The role of heat pumps for industrial processes, Current status and annex achievements. Appl. Ind. Heat Pumps Ger. Chill. Congr. 8 Oct. 2012., 2012.

[22] Bamigbetan O, Eikevik TM, Nekså P, Bantle M, Schlemminger C. Experimental investigation of a prototype R-600 compressor for high temperature heat pump. Energy 2019;169:730-8. doi:10.1016/J.ENERGY.2018.12.020.

[23] Šarevski MN, Šarevski VN. Thermal characteristics of high-temperature R718 heat pumps with turbo compressor thermal vapor recompression. Appl Therm Eng 2017;117:355-65. doi:10.1016/j.applthermaleng.2017.02.035.

[24] He Y, Cao F, Jin L, Wang X, Xing Z. Experimental study on the performance of a vapor injection high temperature heat pump. Int J Refrig 2015;60:1-8. doi:10.1016/j.ijrefrig.2015.08.012.

[25] Cao X-Q, Yang W-W, Zhou F, He Y-L. Performance analysis of different high-temperature heat pump systems for low-grade waste heat recovery. Appl Therm Eng 2014;71:291-300. 
doi:10.1016/j.applthermaleng.2014.06.049.

[26] Arpagaus C, Bless F, Uhlmann M, Büchel E, Frei S, Schiffmann J, et al. High temperature heat pump using HFO and HCFO refrigerants - System design , simulation, and first experimental results. 17th Int Refrig Air Cond Conf Purdue, July 9-12, 2018 2018:1-10.

[27] Helminger F, Kontomaris K, Pfaffl J, Hartl M, Fleckl T. Measured Performance of a High Temperature Heat Pump with HFO-1336mzz-Z as the Working Fluid. ASHRAE 2016 Annu. Conf. St. Louis, Missouri, 25-29 June 2016, 2016, p. 1-8.

[28] Hartl M, Lauermann M, Fleckl T, Rittenschober B, Kontomaris K. Hochtemperaturwärmepumpen für industrielle Produktionsprozesse mit simultaner Heiz- und Kühlanforderung, IV. Dtsch Kälte- Und Klimatagung 2015, 18-20 Novemb 2015, Dresden, Kurzfassungen 2015.

[29] Jakobs R, Cibis D, Laue H. Status And Outlook: Industrial Heat Pumps. Int Refrig Air Cond Conf 2010.

[30] Arpagaus C. Hochtemperatur Wärmepumpen Literaturstudie zum Stand der Technik, der Forschung, des Anwendungspotenzials und der Kältemittel. Interstaatliche Hochschule Für Teckhnik Buchs (NTB) Inst Für Energiesysteme 2017.

[31] Fleckl T, Hartl M, Helminger F, Kontomaris K, Pfaffl J. Performance testing of a lab-scale high temperature heat pump with HFO-1336mzz-Z as the working fluid. Eur Heat Pump Summit 2015 (EHPS), Nürnberg; 2015.

[32] European Heat Pump Association. Large scale heat pumps in Europe 2017.

[33] Zauner F. Hochtemperatur-Wärmepumpen zur energetischen Nutzung industrieller (Niedertemperatur-) Abwärme. Ochsner Energ Tech GmbH 2016:1-11.

[34] Suemitsu R, Miyoshi N, Hasegawa Y, Wajima K, Shirakata Y, Ueda K. Development of centrifugal chiller and heat pump using low GWP refrigerant. 12th IEA Heat Pump Conf 2017, Rotterdam 2017:1-10.

[35] Arpagaus C, Bless F, Uhlmann M, Schiffmann J, Bertsch SS. High temperature heat pumps: Market overview, state of the art, research status, refrigerants, and application potentials. Energy 2018;152:985-1010. doi:10.1016/J.ENERGY.2018.03.166. 
Chapter 2 


\title{
Chapter 3 Theoretical Evaluation of Different High-Temperature Heat Pump Configurations for Low-Grade Waste Heat Recovery
}

\begin{abstract}
The introduction of high-temperature heat pumps for waste heat recovery with low GWP refrigerants can reduce the greenhouse gas emissions in the industrial sector. This article evaluates the energy performance and the volumetric heating capacity of five vapour compression system configurations using n-Pentane, Butane, HCFO-1233zd(E) and HFO-1336mzz(Z) as HFC-245fa low GWP alternative fluids for heating production at temperatures of 110,130 and $150{ }^{\circ} \mathrm{C}$ and different temperature lifts. The selected architectures and the equations are presented, and the most appropriate method to calculate the intermediate pressure is selected. The results of the simulation show that single-stage cycle with an internal heat exchanger (IHX) becomes the most efficient configuration at lower temperature lifts whereas two-stage cycle with IHX at higher lifts. While nPentane provides the highest energy performance values, Butane (only up to $130^{\circ} \mathrm{C}$ ) and $\mathrm{HCFO}$ $1233 z d(E)$ highlight in the heating volumetric capacities. HFO-1336mzz(Z) provides intermediate values in both parameters. Consequently, the working fluid selection is highly dependent on the specifications and the energetic and installation costs.
\end{abstract}

\subsection{Introduction}

The mitigation of the climate change is one of the greatest challenges that humanity faces in this century. To address it, greenhouse gas emissions (GHG), which is the main cause of the global warming, need to be controlled. Therefore, the efforts to improve the energy efficiency has been intensified, especially in the industrial sector as being one of the three main energy consuming sectors [1]. Intergovernmental Panel on Climate Change considers the use of heat recovery technologies as a tool to improve the energy efficiency [2], decreasing the energy consumption of the industrial processes and therefore, the GHGs emissions.

Many industrial processes reject a significant amount of waste heat below $100{ }^{\circ} \mathrm{C}$ and hence, a substantial quantity of waste heat energy remain unused due to economic and technical barriers [3]. However, a higher range of temperature is required by some industrial processes, especially between 100 and $130^{\circ} \mathrm{C}[4,5]$. Thus, the attempts to introduce high-temperature heat pumps (HTHPs) have attracted significant attention for waste heat recovery in industrial processes [6]. In addition, the integration of HTHPs as a heat source for the industrial processes leads to a reduction of the fossil fuels dependence, promoting a decarbonised and sustainable industrial sector.

At present, HFC-245fa, with a global warming potential (GWP) of 858 , is widely used as a working fluid for HTHPs and Organic Rankine Cycles [7]. Nevertheless, the European Comission [8] has 
adopted a proposal to ratify the Kigali amendment to the Montreal Protocol to gradually limit the HFCs production and consumption to mitigate the global warming. Thus, the use of HTHPs for waste heat recovery using working fluids with low GWP becomes a solution to climate change mitigation by improving the industrial processes energy efficiency, using environmental friendly working fluids.

A few studies realised a fundamental performance analysis of different low GWP working fluids for HTHPs $[9,10]$. Moreover, vapour compression systems can use different configurations alternatives to basic cycle to improve the energy performance $[11,12]$. HTHPs can also use these variations to increase the temperature of the heat source to a higher and more useful temperature. Cao et al. [13] studied different heat pump systems configurations for waste heat recovery with an average temperature of $45^{\circ} \mathrm{C}$ and heating production temperature up to $95^{\circ} \mathrm{C}$. Similar system configurations than Cao et al. [13] are analysed by Antonijević et al. [14] for groundwater HTHPs. Nevertheless, studies that analyse HTHP configurations with low GWP working fluids at different operating heating production temperatures are not found in the literature.

Therefore, the aim of this article is to theoretically compare the energy performance and the volumetric heating capacity of five vapour compression system configurations using n-Pentane, Butane, HCFO-1233zd(E) and HFO-1336mzz(Z) as low GWP alternative fluids to HFC-245fa for heating production temperatures of 110 and $130{ }^{\circ} \mathrm{C}$. Moreover, this article evaluates the potential configuration and low GWP working fluid binomial for heating production temperature up to $150^{\circ} \mathrm{C}$, which is a situation not reachable by the traditional refrigerant HFC-245fa.

\subsection{Refrigerants under consideration}

Despite hydrofluorocarbons (HFCs) have been commonly used as refrigerants for HTHPs, the European Commission is gradually limiting the production and use of these chemicals. Hence, hydrofluoroolefins (HFO), hydrochlorofluoroolefin (HCFO) and natural refrigerants become potential alternatives. In addition, all the potential replacements must have comparable or higher critical temperature than HFC-245fa, as is the parameter that defines the possibility to achieve high heating production temperatures in a subcritical cycle.

HCFO-1233zd(E) and HFO-1336mzz(Z) are synthetic fluids widely used for organic Rankine cycle applications $[15,16]$ and, moreover, those refrigerants are being considered in HTHP applications $[17,18]$. Both fluids are considered non-flammable and non-toxic. Butane (R-600) is an commonly known hydrocarbon limited by its critical temperature to HTHP applications with heating production temperatures below $130^{\circ} \mathrm{C}[19,20]$, whereas n-Pentane (R-601), is only considered by Yamazaki and Kubo [21] and Jakobs et al. [22]. However, the higher critical temperature of n-Pentane compared with the other refrigerants makes it an interesting candidate. Both hydrocarbons are flammable but non-toxic refrigerants.

Table 3.1 provides a general overview of several relevant characteristics of these HTHP refrigerants. As it can be seen, the molar mass of the hydrocarbons is much lower than that of synthetic fluids (HFC, HFO and HCFO). From this initial comparison, the molecular weight difference can be highlighted, because of the influence of the density that can affect the HTHPs components design. 
Table 3.1. Characteristics of refrigerant selected [23]

\begin{tabular}{llllllll}
\hline Refrigerant & $\begin{array}{l}\text { ASHRAE } \\
\text { Safety } \\
\text { class. }\end{array}$ & $\begin{array}{l}\text { Molar } \\
\text { mass } \\
{\left[\mathbf{g ~ m o l}^{-1}\right]}\end{array}$ & $\begin{array}{l}\mathbf{P}_{\text {crit }} \\
{[\mathbf{M P a}]}\end{array}$ & $\begin{array}{l}\text { Normal } \\
\text { boiling point } \\
{\left[{ }^{\circ} \mathbf{C}\right]}\end{array}$ & $\begin{array}{l}\mathbf{T}_{\text {crit }} \\
{\left[{ }^{\circ} \mathbf{C}\right]}\end{array}$ & ODP & $\mathbf{G W P}_{\mathbf{1 0 0}}$ \\
\hline HFC-245fa & B1 & 134.05 & 3.65 & 15.18 & 154.01 & 0 & 858 \\
HCFO-1233zd(E) & A1 & 130.50 & 3.77 & 18.32 & 165.60 & 0 & $<1$ \\
HFO-1336mzz(Z) & A1 & 164.06 & 2.90 & 33.47 & 171.27 & 0 & 2 \\
Butane & A3 & 58.12 & 3.80 & -0.52 & 151.98 & 0 & 20 \\
n-Pentane & A3 & 72.15 & 3.37 & 35.87 & 196.54 & 0 & $<1$ \\
\hline
\end{tabular}

\subsection{System configurations}

In this paper, five vapor-compression architectures are considered to provide an adapted solution to provide useful heat from different grades of industrial waste heat: single-stage cycle (SS), singlestage cycle with internal heat exchanger (S-S IHX), two-stage cycle (T-S), two-stage cycle with IHX (T-S IHX) and two-stage cycle with intermediate-IHX (T-S I-IHX).

The first system configuration presented is a single-stage cycle, Fig. 3.1a. This basic configuration is composed of the following elements: compressor, condenser, expansion valve and evaporator.

This cycle is used as a reference for the system configuration analysis. Then, adding a heat exchanger between the suction and the liquid line to this basic configuration the single-stage cycle with IHX configuration is achieved Fig. 3.1b. The IHX reduces the liquid temperature before the expansion valve (sub-cooling) by means of heating the suction vapour (superheat). In contrast to refrigeration systems [12], the interest of IHX for HTHP lies more in heating this suction gas to increase the gas discharge temperature instead of increasing the sub-cooling degree of the system. Higher discharge temperature increases the performance of heat pump applications, considering the components temperature limits.

Two-stage cycles can be obtained by the division of the compression stage in two compression stages. The introduction of two-stage cycles, Fig. 3.2a, reports an increase in the cycle performance through a reduction of the pressure ratio of compression stages. In refrigeration applications, this system configuration has an inter-cooler or liquid injection between the compressors with the purpose of decrease the gas discharge temperature [24].

Nevertheless, in heating applications, it is interesting to increase the discharge temperature to enhance the useful heat transfer to the secondary fluid ( $\left.\mathrm{T}_{\mathrm{k}, \mathrm{sec}, \mathrm{out}}\right)$. Therefore, two modifications of the initial two-stage configuration are proposed for the analysis of the HTHPs performance. 
Chapter 3
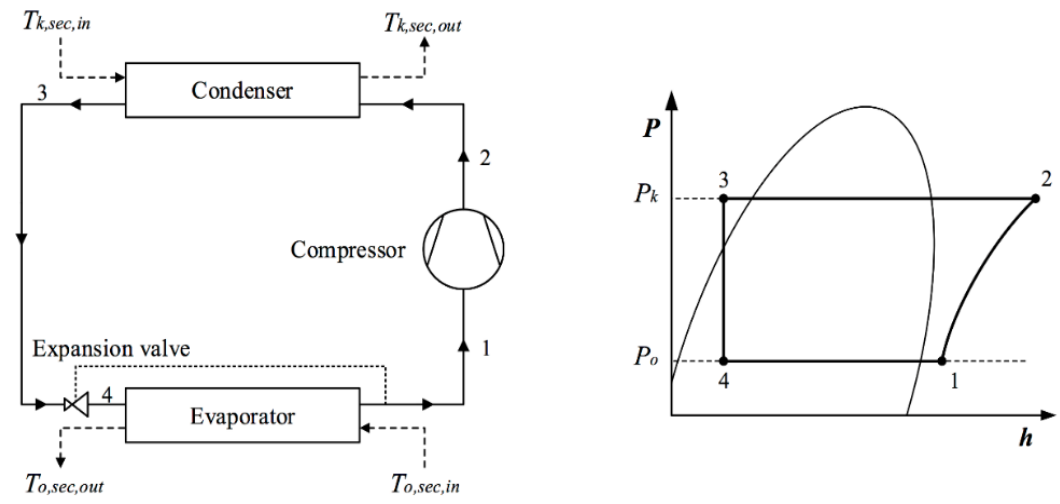

(a)
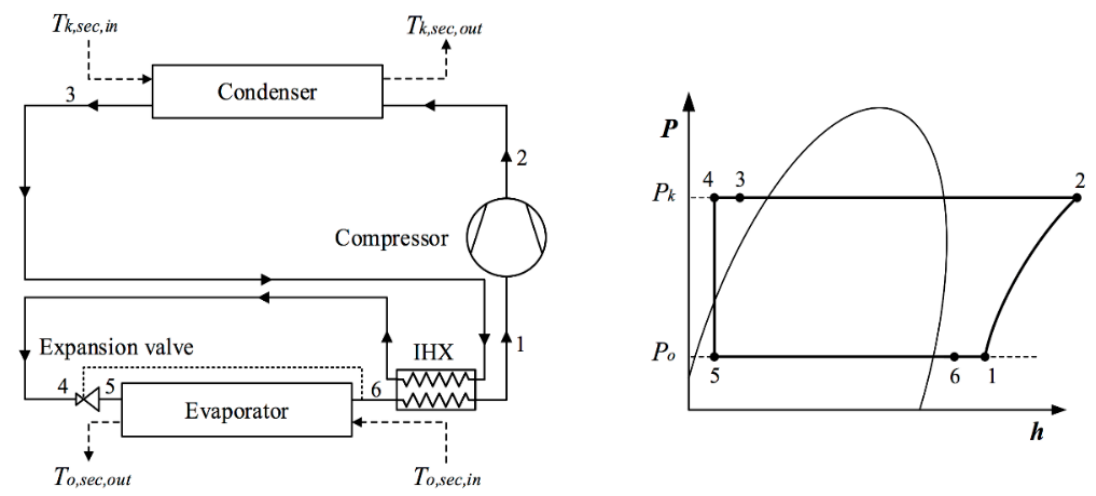

(b)

Fig. 3.1. Schematic and P-h diagram of single-stages configurations: a) single-stage cycle and b) single-stage cycle with IHX.

IHX can be added between the evaporator and the low stage (LS) compressor and hence two-stage cycle with IHX configuration is obtained, Fig. 3.2b. This configuration, similar to single-stage cycle with IHX, increases the superheat before the LS compressor at the expense of cooling the liquid before the expansion valve. It produces an increase of the gas discharge temperature of the LS compressor and consequently, an increase of the gas discharge pressure of the high stage (HS) compressor.

Finally, the IHX could be located between the LS compressor and the HS compressor, giving rise to the last configuration two-stage cycle with intermediate-IHX. In contrast to single-stage cycle with IHX, this configuration increases the vapour suction temperature of the HS compressor instead of the LS compressor, as shown in Fig. 3.2c. Hence, the gas discharge temperature of LS compressor remains similar to the two-stage cycle configuration, but the gas discharge temperature of the HS compressor increases. It can result interesting for the analysis because HS gas discharge temperature 
is a parameter relevant to the useful heat production. Nevertheless, a comprehensive analysis is required to find the proper system configuration and the appropriate working fluid.
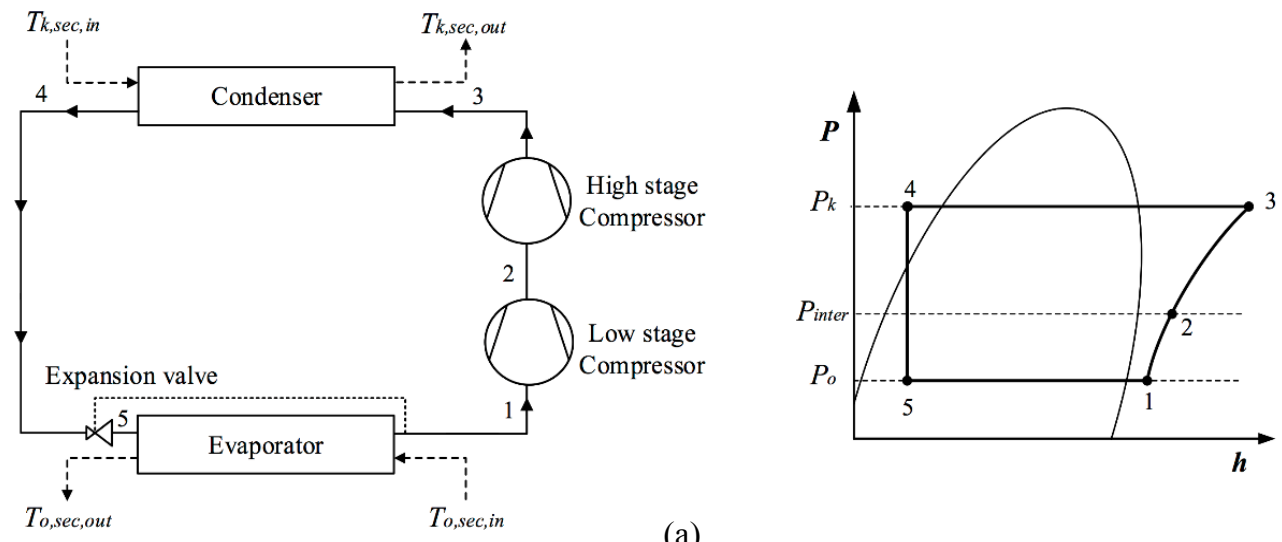

(a)
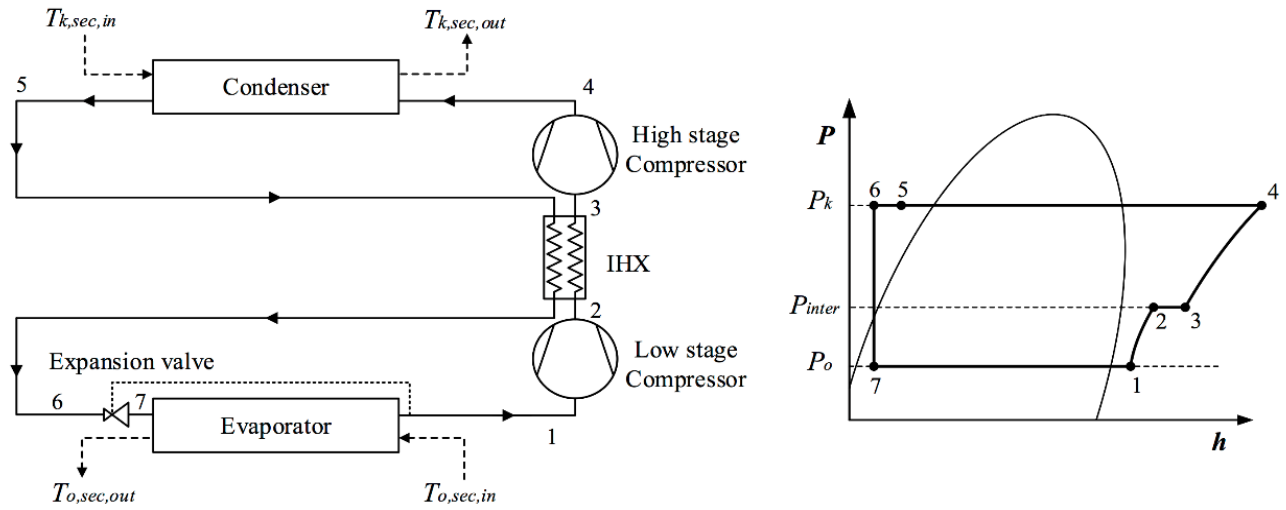

(b)
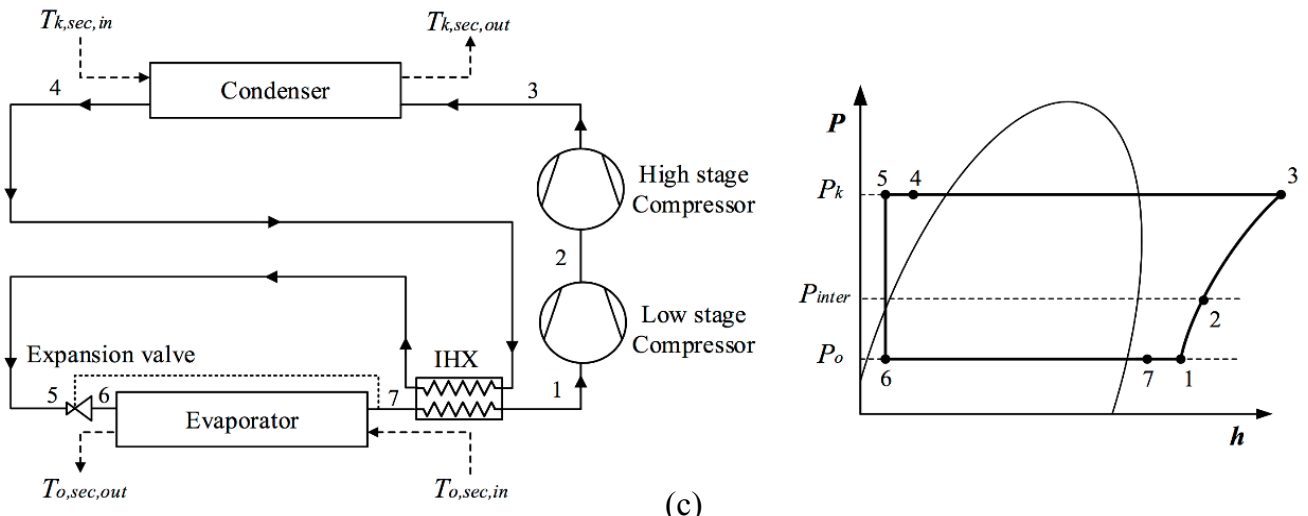

(c)

Fig. 3.2. Schematic and P-h diagram of two-stages configurations: a) two-stage cycle, b) two-stage cycle with IHX and c) two-stage cycle with intermediate-IHX. 


\subsection{Operating conditions and model description}

The heat absorbed by the evaporator $\left(\dot{Q}_{o}\right)$ is an input of the model and it is considered constant for all the operating conditions. Considering the high-temperature applications of this performance analysis and the low-grade waste heat sources, two operating parameters are combined to simulate the typical working conditions: outlet condenser temperature of the secondary fluid $\left(T_{k, \text { sec,out }}\right)$ and inlet evaporator temperature of the secondary fluid $\left(T_{o, s e c, i n}\right)$.

Firstly, outlet condenser secondary fluid temperatures of $110^{\circ} \mathrm{C}$ and $130^{\circ} \mathrm{C}$ are proposed to select an alternative working fluid and proper configuration to HFC-245fa in HTHP applications. Additionally, $150{ }^{\circ} \mathrm{C}$ as the outlet condenser secondary fluid temperature has also been considered due to the industrial development interest of higher temperatures in heat pump applications. The sub-cooling degree is assumed to be $10 \mathrm{~K}$ and the temperature difference in the condenser of the secondary fluid between the inlet $\left(T_{k, \text { sec,in }}\right)$ and the outlet $\left(T_{k, \text { sec,out }}\right)$ is considered to be $15 \mathrm{~K}$.

Secondly, inlet evaporator secondary fluid temperatures of $50{ }^{\circ} \mathrm{C}, 70{ }^{\circ} \mathrm{C}$ and $90{ }^{\circ} \mathrm{C}$ are considered in the simulations due to the interest of low-grade waste heat recovery. The superheat degree is considered to be $15 \mathrm{~K}$ and the temperature difference in the evaporator of the secondary fluid between the inlet $\left(T_{o, \text { sec,in }}\right)$ and the outlet $\left(T_{o, \text { sec,out }}\right)$ is assumed to be $10 \mathrm{~K}$. For both condenser and evaporator, the pitch point is assumed to be $5 \mathrm{~K}$.

The refrigerant thermodynamic properties have been evaluated using software Engineering Equation Solver (EES) [23]. Moreover, isenthalpic process is considered at the expansion valve and heat transfer to the surroundings and pressure drops are neglected.

Isentropic and volumetric efficiency of the compressors are calculated using the Pierre's correlations for "good" reciprocating compressors [25]. In this way, volumetric efficiency, $\eta_{v o l}$, is obtained from Eq. (3.1):

$$
\eta_{v o l}=k_{1} \cdot\left(1+k_{s} \cdot \frac{t_{2 k}-18}{100}\right) \cdot \exp \left(k_{2} \cdot \frac{p_{1}}{p_{2}}\right)
$$

where $t_{2 k}$ is the inlet temperature to the compressor and $p_{1} / p_{2}$ is the pressure ratio. The remaining symbols $k_{1}, k_{s}$ and $k_{2}$ are constants and the values of these are 1.04, 0.15 , and -0.07 , respectively.

Following the Pierre's correlations, isentropic efficiency, $\eta_{i s}$, is calculated with the Eq. (3.2) and the volumetric efficiency calculated with the Eq. (3.1).

$$
\left(\frac{\eta_{v o l}}{\eta_{i s}}\right)=\left(1+k_{e} \cdot \frac{t_{2 k}-18}{100}\right) \cdot \exp \left(a \cdot \frac{T_{1}}{T_{2}}+b\right)
$$

where $T_{1} / T_{2}$ is the ratio of the absolute temperatures (in Kelvin) of the condensation and evaporation corresponding to the discharge and the suction compressor pressures. The constants values considered are those given by Pierre for CFC-12, and therefore, $k_{e}$, $a$ and $b$ are $-0.1,-2.40$ and 2.88 , respectively. This constant values are taken from the literature [25]. The electromechanical efficiency, $\eta_{e m}$, is assumed to be 0.95 .

In two-stage system configurations, it is necessary to select the appropriate intermediate pressure to achieve competitive system efficiencies. Thus, the equations proposed by Baumann and Blass (1961), 
Eq. (3.3), De Lepeleire (1973), Eq. (3.4), and Domanski (1995), Eq. (3.5), has been analysed for HTHP applications [26].

$$
\begin{gathered}
P_{I}=\sqrt{P_{k} P_{o}} \\
P_{I}=\sqrt{P_{k} P_{o}}+0.35[\text { Bar }] \\
\theta=\frac{T_{I}-T_{o}}{T_{k}-T_{o}} \approx 0.5
\end{gathered}
$$

Fig. 3.3a shows that the resulting intermediate pressures are different depending on the configuration analysed and the equation used. On the other hand, the system performance remains almost constant in TS and TS IHX configurations whereas for the TS I-IHX configuration the Baumann and Blass (1961) equation achieves higher efficiencies than the others, as shown in Fig. 3.3b. Consequently, Eq. (3.4) is selected as an equation to calculate the intermediate pressure in all two-stage system configurations.

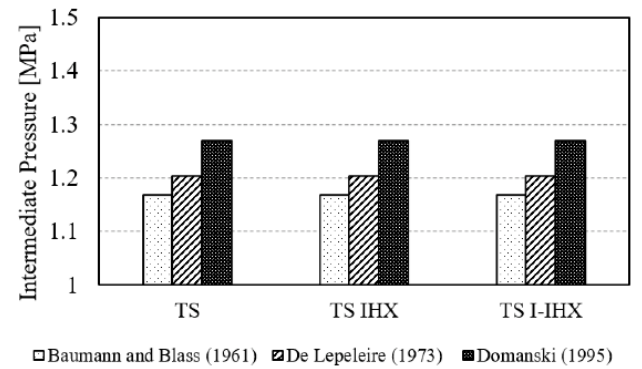

(a)

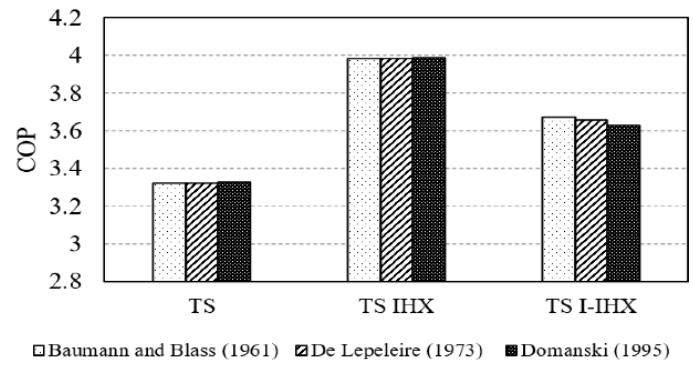

(b)

Fig. 3.3. Intermediate pressure and COP comparison analysis for different two-stage system configurations.

The refrigerant mass flow rate for all system configurations is calculated using Eq. (3.6).

$$
\dot{m}=\frac{\dot{Q}_{o}}{\left(h_{o, \text { out }}-h_{o, \text { in }}\right)}
$$

The required volumetric flow rate at the compressor suction, $\dot{V}_{s u c}$, is obtained from the mass flow rate, the suction density and the volumetric efficiency, Eq. (3.7).

$$
\dot{V}_{s u c}=\frac{\dot{m}}{\eta_{v o l} \rho_{s u c}}
$$

The maximum discharge temperature, $T_{\text {disc }}$, is limited to $180^{\circ} \mathrm{C}$ because of the degradation of HFO fluids and POE lubricants above $200{ }^{\circ} \mathrm{C}[27,28]$. Therefore, the IHX effectiveness $\left(\varepsilon_{\mathrm{IHX}}\right)$ is limited to not exceed the maximum discharge temperature, which is dependent on the enthalpy after the compressor, $h_{c, \text { out }}$, and the condenser pressure, $P_{K}$. The vapour suction temperature is calculated using the Eq. (3.8). 
Chapter 3

$$
\varepsilon_{\mathrm{IHX}}=\frac{T_{\text {suc }}-T_{o, \text { out }}}{T_{k, \text { out }}-T_{o, \text { out }}}
$$

The electric power consumption for the single-stage compressor, $\dot{W}_{C}$, is expressed in Eq. (3.9) as the product of the mass flow rate and the isentropic enthalpy increase at the compressor divided by the isentropic and electromechanical efficiencies.

$$
\dot{\mathrm{W}}_{\mathrm{C}}=\frac{\dot{m} \Delta h_{i s, c}}{\eta_{i s} \eta_{e m}}
$$

For the two-stage compressors, the electric power consumption is calculated using the Eq. (3.10).

$$
\dot{\mathrm{W}}_{\mathrm{C}}=\frac{\dot{m}}{\eta_{e m}}\left(\frac{\dot{\Delta h_{l s, c, H S}}}{\eta_{l s, H S}}+\frac{\Delta h_{i s, c, L S}}{\eta_{i s, L S}}\right)
$$

The heating capacity, $\dot{\mathrm{Q}}_{\mathrm{k}}$, is calculated using the product of the mass flow rate and the enthalpy difference between the inlet and outlet in the condenser, Eq. (3.11).

$$
\dot{\mathrm{Q}}_{\mathrm{k}}=\dot{m}\left(h_{k, \text { in }}-h_{k, \text { out }}\right)
$$

To compared properly the influence of the volumetric flow rate at the compressor suction and the heating capacity, volumetric heating capacity $\left(q_{v}\right)$ is calculate using Eq. (3.12).

$$
q_{v}=\frac{\dot{V}_{s u c}}{\dot{\mathrm{Q}}_{\mathrm{k}}}
$$

Finally, the Coefficient of Performance, COP, is calculated from the heating capacity and the compressor electric power consumption, using Eq. (3.13).

$$
C O P=\frac{\dot{\mathrm{Q}}_{\mathrm{k}}}{\dot{\mathrm{W}}_{\mathrm{C}}}
$$

\subsection{Results and discussion}

The main results of the simulations are obtained considering five configurations and five working fluids, at different outlet condenser temperature of the secondary fluid $\left(T_{k, s e c, o u t}\right)$ and inlet evaporator temperature of the secondary fluid $\left(T_{o, s e c, i n}\right)$. As exposed in Section 2, refrigerants HFO-1336mzz(Z), HCFO-1233zd(E), Butane and n-Pentane have been selected as low GWP alternatives for HFC-245fa in high-temperature applications with $T_{k, \text { sec,out }}$ below $130{ }^{\circ} \mathrm{C}$. Then, for applications with $T_{k, \text { sec,out }}$ of $150{ }^{\circ} \mathrm{C}$, HFC-245fa and Butane have been discarded by the limitation of their critical temperature, and HFO-1336mzz(Z), HCFO-1233zd(E) and n-Pentane have been analysed.

The parameters chosen in this study to evaluate the appropriate configuration and working fluid is the $\mathrm{COP}$ and the volumetric heating capacity. $\mathrm{COP}$ is commonly used to evaluate the energy performance of the system and the volumetric heating capacity is used to compare the relationship between the heating capacity and compressor and installation size. 


\subsubsection{Comparison of low GWP alternatives to HFC-245fa in moderate-high temperature applications}

For moderate and high-temperature applications, $T_{k, \text { sec,out }}$ of 110 and $130{ }^{\circ} \mathrm{C}$ respectively, the results for alternative low GWP working fluids and configurations are shown as a relative difference $(\% \mathrm{COP}$ and $\% q_{v}$ ) between each pair refrigerant-configuration taken and HFC-245fa single-stage configuration, as indicated Eq. (3.14) and Eq. (3.15).

$$
\begin{gathered}
\% C O P=\left(\frac{C O P_{\text {conf,alt.fluid }}-C O P_{S S, H F C-245 f a}}{C O P_{S S, H F C-245 f a}}\right) \\
\% q_{v}=\left(\frac{q_{v_{\text {conf,alt.fluid }}}-q_{v_{S S, H F C-245 f a}}}{q_{v_{S S, H F C-245 f a}}}\right)
\end{gathered}
$$

Fig. 3.4 presents the results for \%COP at three inlet secondary fluid temperatures on the heat source, two outlet secondary fluid temperatures on the heat sink $\left(110\right.$ and $\left.130{ }^{\circ} \mathrm{C}\right)$, five different configurations and five refrigerants. The difference between the evaporation and condensing temperature is known as temperature lift (Eq. 3.16), which is commonly used to compare the heat pump system performance. Hence, all simulation results are grouped into four different temperature lifts in order to select and analyse the proper configuration depending on each parameter.

$$
\text { Temperature lift }=T_{\text {condensation }}-T_{\text {evaporation }}
$$

On the one hand, for lift temperatures of 40 and $60 \mathrm{~K}$, single-stage cycle IHX has higher performance (COP) than the other configurations. At lower temperature lifts, two-stage cycles have smaller pressure ratios than single-stage cycles, causing a decrease of the combined isentropic compressor efficiency. It increases the electric power consumption, and therefore, decrements the COP until the pressure ratio reaches higher values.

On the other hand, for lift temperatures of 80 and $100 \mathrm{~K}$, two-stage cycle IHX has higher performance than the other configurations, as shown in Fig. 3.4. Two-stage cycle IHX achieves higher discharge temperature, heating capacity and isentropic compressor efficiency than other configurations. Therefore, higher the temperature lift, higher the performance improvement difference between twostage cycle IHX and the other configurations.

Besides, two-stage cycle IHX and two-stage cycle intermediate IHX have similar isentropic HS compressor efficiency, but the position of the IHX produces that two-stage cycle IHX has higher isentropic LS compressor efficiency than the other configuration. Thus, two-stage cycle IHX has lower overall electric power consumption and higher heating capacity, achieving the maximum COP. 


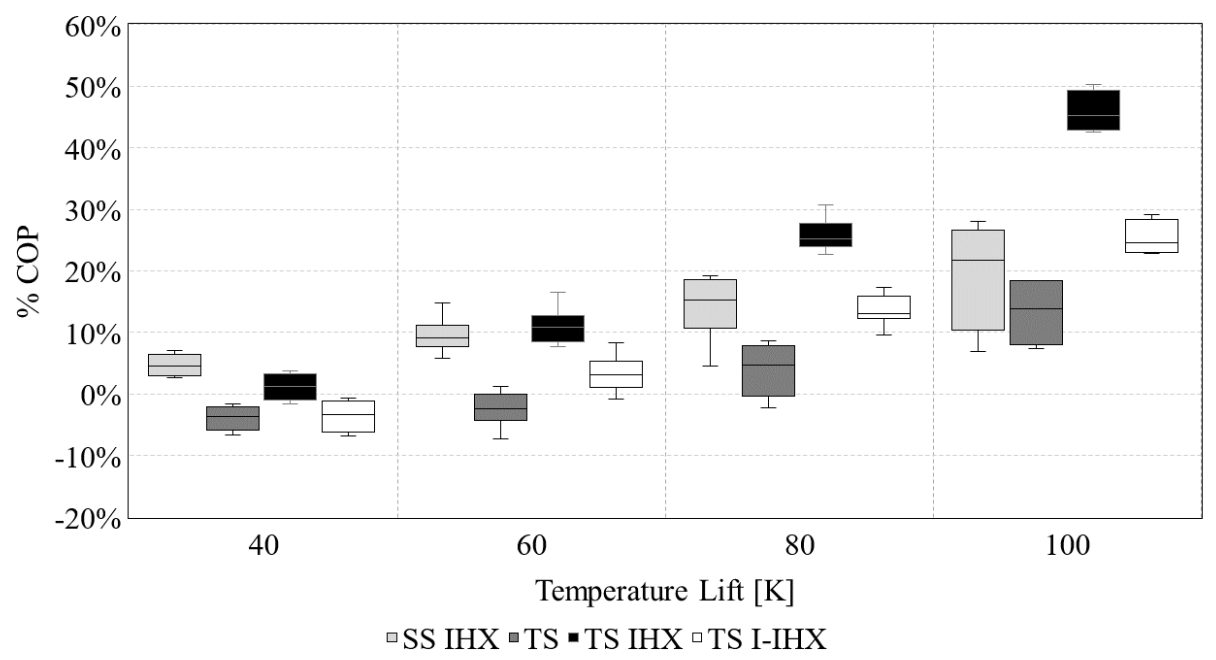

Fig. 3.4. Simulations results of $\%$ COP compared with single-stage cycle using HFC-245fa for different temperature lifts.

Attending to the COP results, single-stage with IHX is selected for analysis of the alternative working fluid in applications with temperature lifts of 40 and $60 \mathrm{~K}$, whereas two-stage cycle IHX is selected for applications with temperature lifts of 80 and $100 \mathrm{~K}$.

Fig. 3.5a presents the performance comparison of the different working fluids for a single-stage cycle with IHX configuration with temperature lifts of 40 and $60 \mathrm{~K}$. All the alternative refrigerants perform better than HFC-245fa, given the positive differences. For the temperature lift of $40 \mathrm{~K}$, higher \%COP values are obtained by n-Pentane, with a performance increment of $7 \%$ compared to HFC-245fa single-stage cycle. Then, HFO-1336mzz(Z) and HCFO-1233zd(E) show an improvement of $5 \%$ and $4 \%$, respectively. As the temperature lift increases, the \%COP increases in the same way and for the temperature lift of $60 \mathrm{~K}$, n-Pentane obtain a COP increase of 13\%-15\% whereas HCFO-1233zd(E) achieves an improvement of $9 \%-11 \%$, being the HFO-1336mzz(Z) lower than those. The lower critical temperature of Butane causes that at higher evaporation temperatures it has worse improvements than the other refrigerants.

Attending to the $q_{v}$, Fig. $3.5 \mathrm{~b}$ shows a reduction of $45 \%$ and $35 \%$ when n-Pentane and HFO$1336 \mathrm{mzz}(\mathrm{Z})$ are used instead of $\mathrm{HFC}-245 \mathrm{fa}$, whereas the reduction of the volumetric heating capacity using HCFO-1233zd(E) is between $5 \%$ and $15 \%$. Nevertheless, Butane is the unique refrigerant analysed that increases the volumetric heating capacity between $15-30 \%$, therefore, lower compressor displacement and installations size is required than using HFC-245fa. 


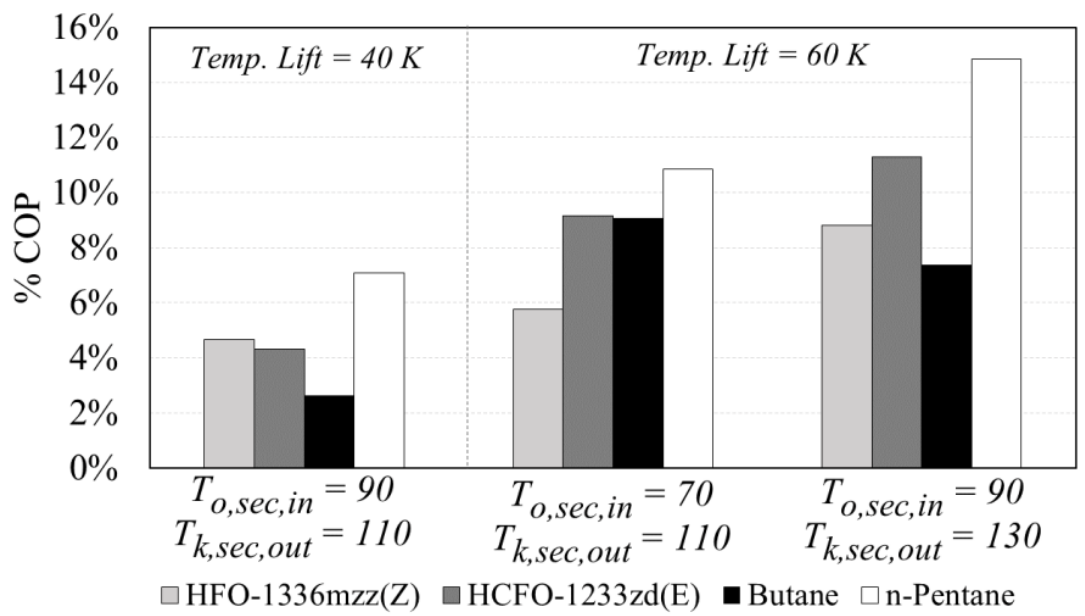

(a)

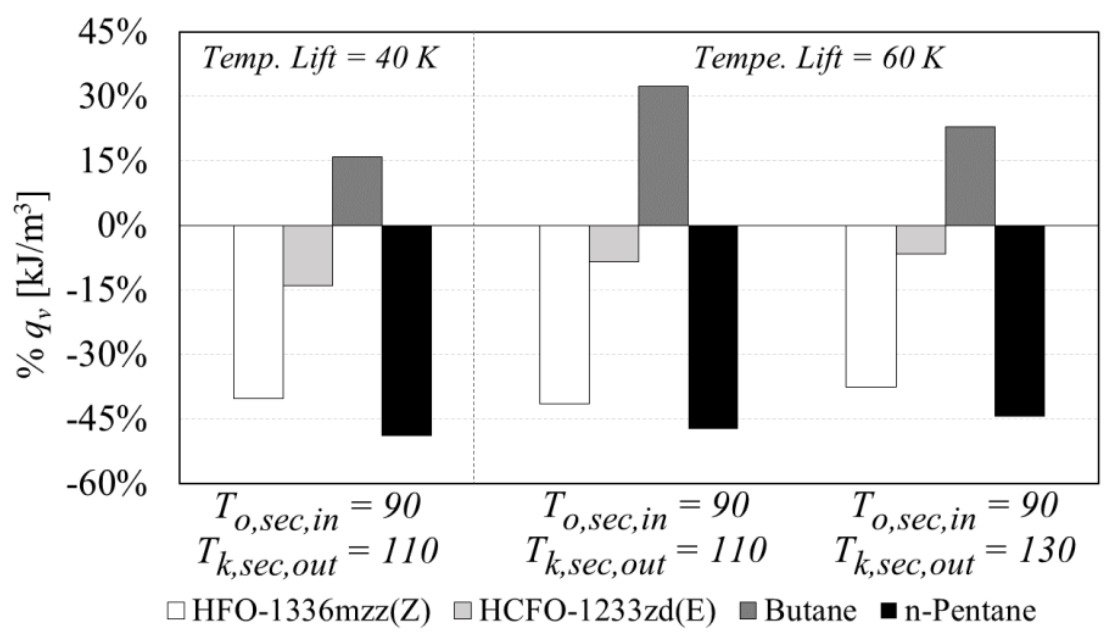

(b)

Fig. 3.5. Simulation relative results of COP and volumetric heating capacity for temperature lifts of 40 and $60 \mathrm{~K}$.

Fig. 3.6a illustrates the COP variation for temperature lift of 80 and $100 \mathrm{~K}$ in two-stage cycle with IHX. A higher temperature lift will increase the COP difference compared with the reference system. The \%COP for all the analysed refrigerants is at a similar level but again, the highest COP is obtained by n-Pentane, being $23-35 \%$ than that of HFC-245fa single-stage cycle.

However, Fig. 3.6b shows a great variation of the volumetric heating capacity between the different working fluids simulated. While n-Pentane and HFO- $1336 \mathrm{mzz}(\mathrm{Z})$ has a reduction of the volumetric heating capacity, Butane and HCFO-1233zd(E) presents an increment. Concretely, 50-70\% for Butane and $2-15 \%$ for HCFO-1233zd(E). As a result, with similar variations of COP and providing the same heating capacity, HCFO-1233zd(E) requires a slightly similar compressor and installation size whereas Butane requires a lower compressor and installation size comparing with HFC-245fa. 
Chapter 3

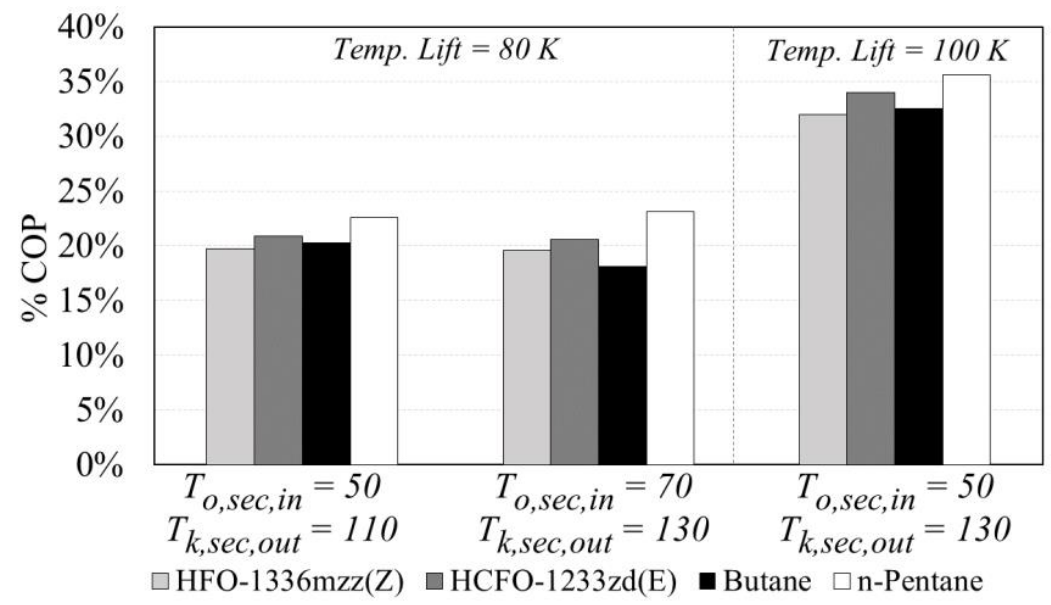

(a)

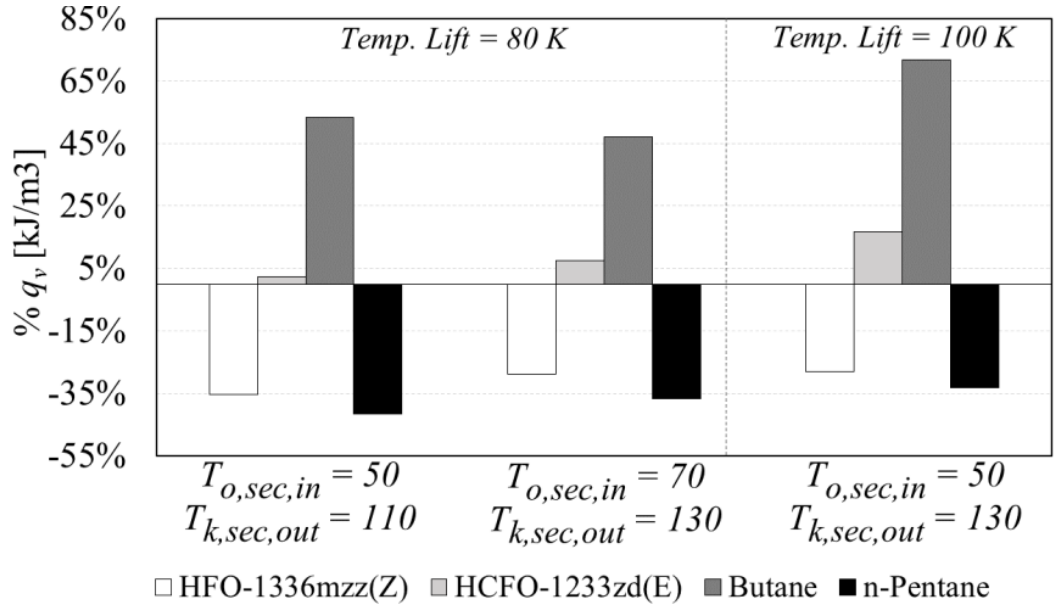

(b)

Fig. 3.6. Simulation relative results of $\mathrm{COP}$ and volumetric heating capacity for temperature lifts of 80 and $100 \mathrm{~K}$.

It can be concluded that HCFO-1233zd(E) presents promising results in all the simulations carried out, achieving remarkable increments of COP with a slight variation of the volumetric heating capacity compared to the reference HFC-245fa (positive for higher temperature lifts and negative for lower). Although the highest increment of COP is achieved by n-Pentane, this working fluid obtained the most significant reduction of the volumetric heating capacity in all the cases and would require a significantly higher investment cost than HFC-245fa (in addition to the already needed because of the security measures).

Butane has the largest increment of volumetric heating capacity, reducing the installation cost and proving higher heating capacity than HFC-245fa. Moreover, Butane has an increment of COP in all the simulations realised, nonetheless, when the heat source temperature is bringing closer to its critical temperature, this increment of COP is reduced, as it can be seen in Fig. 3.5a. Hence, Butane resulted in a proper solution if the heat source temperature does not come close to its critical temperature. Finally, HFO-1336mzz(Z) has a general increment of COP, most of the cases lower than the other 
fluids, and in addition, it has a highly decrement of the volumetric heating capacity. Thus, HFO$1336 \mathrm{mzz}(\mathrm{Z})$ is not a proper solution when the production temperature is below $130^{\circ} \mathrm{C}$.

\subsubsection{Analysis for high-temperature application solutions}

This section presents the results for the heating production temperature of $150{ }^{\circ} \mathrm{C}$ and heat source temperatures of 50,70 and $90^{\circ} \mathrm{C}$. HFC-245fa and Butane have a critical temperature below that value, therefore, these refrigerants are not considered for these conditions. Therefore, the results cannot be compared with HFC-245fa and are shown as HFO-1336mzz(Z), HCFO-1233zd(E) and n-Pentane absolute values of COP and $q_{v}$, Fig. 3.7 and Fig. 3.8.

With a heat source temperature of $90^{\circ} \mathrm{C}$, Fig. 3.7 shows that n-Pentane and HFO-1336mzz(Z) obtain a COP of 3.85 and 3.59, respectively. Nevertheless, Fig. 3.8 illustrates the volumetric heating capacity of these simulations, where HFO- $1336 \mathrm{mzz}(\mathrm{Z})$ has slightly higher volumetric heating capacity than nPentane. Note that $n$-Pentane requires security requirements because of its flammability and slight higher investment cost compared with the other two candidates due to its low volumetric heating capacity.

For heat source temperature of $70{ }^{\circ} \mathrm{C}$, Fig. 3.7 shows that, like the previous application, n-Pentane and HFO-1336mzz(Z) are the potential candidates with a COP of 2.98 and 2.74, respectively. Nevertheless, HCFO-1233zd(E) achieves a COP of 2.50 with higher volumetric heating capacity than the other two candidates, as shown in Fig. 3.8. For heat source temperature of $50^{\circ} \mathrm{C}$, similar behaviour than that for heat source temperature of $70^{\circ} \mathrm{C}$ is observed.

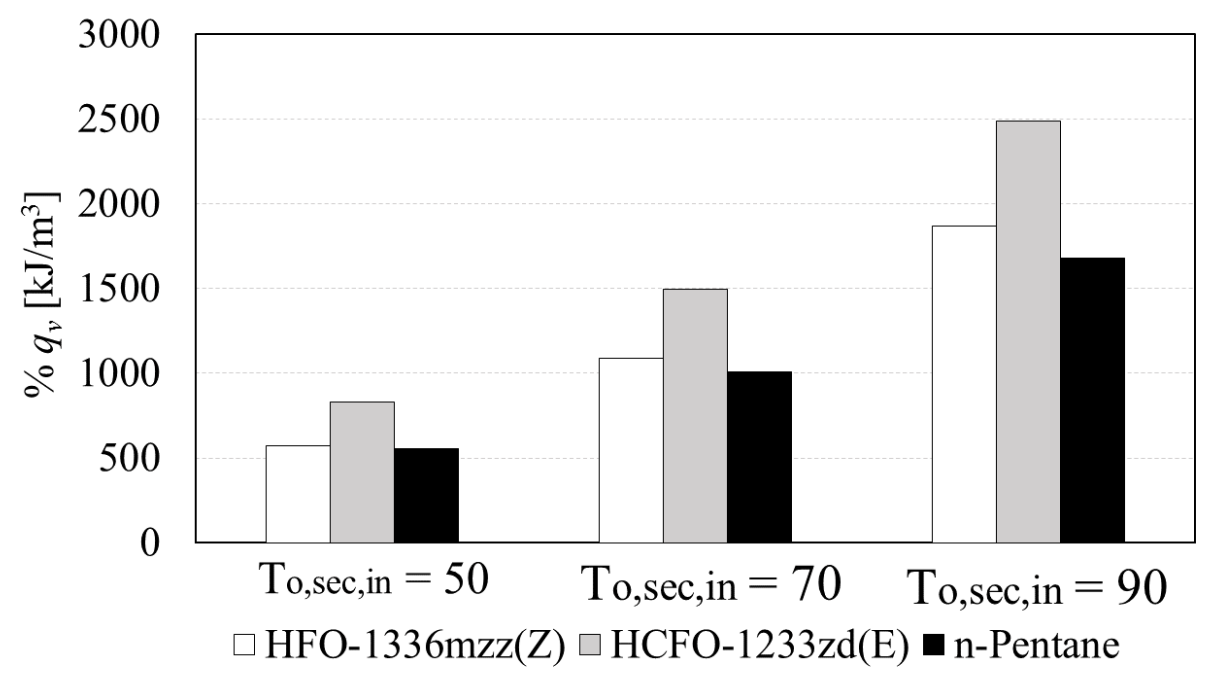

Fig. 3.7. Two-stage cycle with IHX simulations results of COP for heating production temperature of $150{ }^{\circ} \mathrm{C}$. 


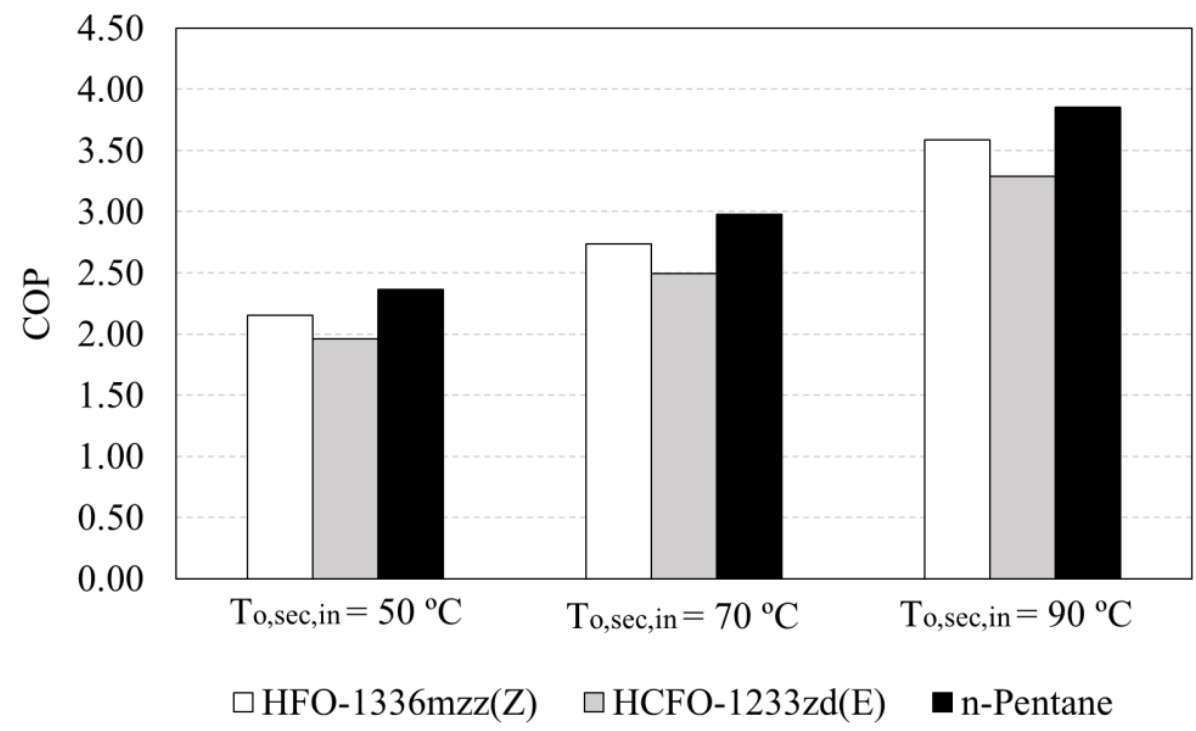

Fig. 3.8. Two-stage cycle with IHX simulations results of volumetric heating capacity for heating production.

In general, higher COPs are achieved by n-Pentane in all the options simulated, followed by HFO$1336 \mathrm{mzz}(Z)$. Nevertheless, both refrigerants obtain lower volumetric heating capacity than HCFO$1233 z d(E)$. This means that higher displacement compressor and installation size are needed for $\mathrm{n}-$ Pentane and HFO-1336mzz(Z) than for HCFO-1233zd(E).

\subsection{Conclusions}

Due to the concern for the effects of greenhouse gasses emissions on the global environment there is large interest in Europe and elsewhere for the use of high-temperature heat pumps for waste heat recovery with low GWP refrigerants. This paper has investigated the energy performance of five different system configurations for high-temperature heat pumps using low GWP alternatives to HFC-245fa.

n-Pentane, Butane, HFO-1336mzz(Z) and HCFO-1233zd(E) are the proposed replacements because of the high critical temperatures and promising thermodynamic and transport properties. The proposed configurations are single-stage and two-stage cycles with and without internal heat exchanger in different positions. The optimal intermediate pressure has been calculated for each situation.

Heating production and waste heat source temperatures are highly sensitive to the configuration and working fluid selection. Therefore, temperature lift is a key parameter to analyse the proper configuration. For temperature lift of $40 \mathrm{~K}$, single-stage with IHX presents higher performance than the other configuration, but as temperature lift increases, two-stage with IHX becomes the proper system configuration. 
For moderate-high temperature applications with low-temperature lift, single-stage cycle with IHX using n-Pentane achieves a COP improvement up to $15 \%$ compared with a single-stage cycle with HFC-245fa. However, n-Pentane has a reduction of $45 \%$ of the volumetric heating capacity whereas HCFO-1233zd(E) keeps this reduction up to $5 \%$ with a COP improvement up to $11 \%$. For higher temperature lifts, the configuration with highest energy performance is a two-stage cycle with IHX. The COP variation is slightly different for each refrigerant; therefore, volumetric heating capacity becomes the significative parameter. Butane and HCFO-1233zd(E) obtain an increment of the volumetric heating capacity of $70 \%$ and $15 \%$, respectively, whereas n-Pentane and HFO-1336mzz(Z) decrease this parameter in $40 \%$ and $35 \%$.

For high-temperature applications with production heating temperature up to $150{ }^{\circ} \mathrm{C}$, two-stage cycle with IHX using n-Pentane achieves the highest COP, followed by HFO-1336mzz(Z) (up to 3.85 and 3.59 , respectively). Otherwise, n-Pentane and HFO- $1336 \mathrm{mzz}(\mathrm{Z})$ obtain up to $50 \%$ lower volumetric heating capacity than HCFO-1233zd(E), which has a COP of 3.42. Hence, depends on the energy or the installation cost, most proper working fluid would be selected.

In conclusion, it seems likely that single-stage and two-stage cycles with IHX will be used as system configurations in high-temperature heat pumps. While the system configuration candidates are clear, working fluid selection is highly dependent on the energy and installation costs aside from the regulation and safety measures of flammable fluid in the installations.

\section{References}

[1] Brückner S, Liu S, Miró L, Radspieler M, Cabeza LF, Lävemann E. Industrial waste heat recovery technologies: An economic analysis of heat transformation technologies. Appl Energy 2015;151:157-67. doi:10.1016/j.apenergy.2015.01.147.

[2] Miró L, Brückner S, Cabeza LF. Mapping and discussing Industrial Waste Heat (IWH) potentials for different countries. Renew Sustain Energy Rev 2015;51:847-55. doi:10.1016/j.rser.2015.06.035.

[3] Forman C, Muritala IK, Pardemann R, Meyer B. Estimating the global waste heat potential. Renew Sustain Energy Rev 2016;57:1568-79. doi:10.1016/j.rser.2015.12.192.

[4] Chua KJ, Chou SK, Yang WM. Advances in heat pump systems: A review. Appl Energy 2010;87:3611-24. doi:10.1016/j.apenergy.2010.06.014.

[5] Seck GS, Guerassimoff G, Maïzi N. Heat recovery using heat pumps in non-energy intensive industry: Are Energy Saving Certificates a solution for the food and drink industry in France? Appl Energy 2015;156:374-89. doi:10.1016/j.apenergy.2015.07.048.

[6] Langan M, O’Toole K. A new technology for cost effective low grade waste heat recovery. Energy Procedia 2017;123:188-95. doi:10.1016/j.egypro.2017.07.261.

[7] Mounier V, Mendoza LC, Schiffmann J. Thermo-economic optimization of an ORC driven heat pump based on small scale turbomachinery and comparison with absorption heat pumps. Int J Refrig 2017. doi:10.1016/j.ijrefrig.2017.05.021.

[8] European Comission. Proposal for a Council Decision on the conclusion of the agreement to amend the Montreal Protocol on substances that deplete the ozone layer adopted in Kigali. Brussels, Belgium 2017. 
Chapter 3

[9] Fukuda S, Kondou C, Takata N, Koyama S. Low GWP refrigerants R1234ze(E) and R1234ze(Z) for high temperature heat pumps. Int $J$ Refrig 2014;40:161-73. doi:10.1016/j.ijrefrig.2013.10.014.

[10] Kondou C, Koyama S. Thermodynamic assessment of high-temperature heat pumps using low-GWP HFO refrigerants for heat recovery. Int J Refrig 2015;53:126-41. doi:10.1016/j.ijrefrig.2014.09.018.

[11] Mota-Babiloni A, Navarro-Esbrí J, Barragán Á, Molés F, Peris B. Theoretical comparison of low GWP alternatives for different refrigeration configurations taking R404A as baseline. Int J Refrig 2014;44:81-90. doi:10.1016/j.ijrefrig.2014.04.015.

[12] Molés F, Navarro-Esbrí J, Peris B, Mota-Babiloni A, Barragá n-Cervera ngel. Theoretical energy performance evaluation of different single stage vapour compression refrigeration configurations using R1234yf and R1234ze(E) as working fluids. Int J Refrig 2014;44:14150. doi:10.1016/j.ijrefrig.2014.04.025.

[13] Cao X-Q, Yang W-W, Zhou F, He Y-L. Performance analysis of different high-temperature heat pump systems for low-grade waste heat recovery. Appl Therm Eng 2014;71:291-300. doi:10.1016/j.applthermaleng.2014.06.049.

[14] Antonijević DL, Manić DJ, Komatina MS, Rudonja NR. Groundwater heat pump selection for high temperature heating retrofit. Energy Build 2012;49:294-9. doi:10.1016/j.enbuild.2012.02.028.

[15] Molés F, Navarro-Esbrí J, Peris B, Mota-Babiloni A. Experimental evaluation of HCFO1233zd-E as HFC-245fa replacement in an Organic Rankine Cycle system for low temperature heat sources. Appl Therm Eng 2016;98:954-61. doi:10.1016/j.applthermaleng.2016.01.011.

[16] Navarro-Esbrí J, Molés F, Peris B, Mota-Babiloni A, Kontomaris K. Experimental study of an Organic Rankine Cycle with HFO-1336mzz-Z as a low global warming potential working fluid for micro-scale low temperature applications. Energy 2017;133:79-89. doi:10.1016/j.energy.2017.05.092.

[17] Alam MJ, Islam MA, Kariya K, Miyara A. Measurement of thermal conductivity of cis1,1,1,4,4,4-hexafluoro-2-butene $(\mathrm{R}-1336 \mathrm{mzz}(\mathrm{Z}))$ by the transient hot-wire method. Int $\mathrm{J}$ Refrig 2017;84:220-7. doi:10.1016/j.jirefrig.2017.08.014.

[18] Juhasz JR. Novel Working Fluid , HFO-1336mzz ( E ), for Use in Waste Heat Recovery Application. 12th IEA Heat Pump Conf 2017, Rotterdam 2017.

[19] Moisi H, Rieberer R. Refrigerant Selection and Cycle Development for a High Temperature Vapor Compression Heat Pump. 12th IEA Heat Pump Conf 2017, Rotterdam 2017:1-10.

[20] Pan L, Wang H, Chen Q, Chen C. Theoretical and experimental study on several refrigerants of moderately high temperature heat pump. Appl Therm Eng 2011;31:1886-93. doi:10.1016/j.applthermaleng.2011.02.035.

[21] Yamazaki T, Kubo Y. Development of a High-Temperature Heat Pump. IEA Heat Pump Cent Newsl 1985;3:18-21.

[22] Jakobs R, Cibis D, Laue H. Status And Outlook: Industrial Heat Pumps. Int Refrig Air Cond Conf 2010.

[23] Klein S. Engineering Equation Solver (EES) V10.6. Fchart Software, Madison, USA WwwFchartCom 2006. 
[24] Nemati A, Nami H, Yari M. Comparaison des frigorigènes dans un cycle frigorifique transcritique à éjecteur-détente bi-étagé, basé sur une analyse environnementale et exergoéconomique. Int J Refrig 2017;84:139-50. doi:10.1016/j.jirefrig.2017.09.002.

[25] Granryd E, Ekroth I, Lundqvist P, Melinder A, Palm B, Rohlin P. Refrigeration Engineering. K Tek Högskolan 1999.

[26] Purohit N, Gupta DK, Dasgupta MS. Effect of Inter-stage Pressure on the Performance of a Two Stage Refrigeration Cycle Using Inter Cooler. Energy Procedia 2016;90:171-8. doi:10.1016/j.egypro.2016.11.182.

[27] Kontomaris K. A zero-ODP, low GWP working fluid for high temperature heating and power generation from low temperature heat: DR-2. Proc JRAIA Int Symp 2012 2012:212-6.

[28] Navarro-Esbrí J, Molés F, Peris B, Mota-Babiloni A. Small scale orc design for a cogeneration solar biomass suported application. 3rd Int Semin ORC Power Syst Oct 12-14, 2015, Brussels, Belgium 2015. 
Chapter 3 


\section{Chapter 4}

\section{Thermodynamic Analysis of Low GWP Alternatives to HFC-245fa in High-Temperature Heat Pumps: HCFO-1224yd(Z), HCFO-1233zd(E) and HFO-1336mzz(Z)}

This paper analyses the feasibility of HCFO-1224yd(Z), HCFO-1233zd(E) and HFO-1336mzz(Z), three low global warming potential (GWP) refrigerants, as alternatives to HFC-245fa in hightemperature heat pump (HTHP) systems for low-grade waste heat recovery. HTHPs are a sustainable technology that can help to mitigate the climate change through the thermal valorisation of the industrial low-grade waste heat. Before presenting and analysing the results, mapping of the minimum superheat degree requirement in the operating range, and the influence of the Internal Heat Exchanger (IHX) on each alternative are studied. The simulations were carried out at condensing temperatures from 115 to $145{ }^{\circ} \mathrm{C}$ and evaporating temperatures from 45 to $75{ }^{\circ} \mathrm{C}$, using single-stage cycle with and without IHX. Finally, Total Equivalent Warming Impact (TEWI) evaluation is performed to illustrate the environmental effect of each alternative. Attending to the results, HCFO$1233 z d(E)$ improves the COP about 27\% compared to HFC-245fa, whereas HFO-1336mzz(Z) and HCFO-1224yd(Z) show an improvement of approx. 21 and 17\%, respectively. Although HCFO$1233 z d(E)$ and $H C F O-1224 y d(Z)$ present similar suction volumetric flow rate to $H F C-245 f a$, HFO$1336 \mathrm{mzz}(Z)$ shows a relative increment up to $80 \%$, and therefore, higher compressor and installation size are expected for this refrigerant. Finally, the TEWI analysis presents a significant reduction of the equivalent CO2 emissions for each low GWP alternative, between 59 and $61 \%$. HCFO-1233zd(E) shows the highest reduction in all the simulation cases, followed by HCFO-1224yd(Z) and HFO$1336 m z z(Z)$.

\subsection{Introduction}

The concern for global warming has raised awareness about the importance of climate change mitigation during the last decades. This was evidenced in the Paris Agreement through which around 200 nations established the long-term objective of maintaining the increase in global average temperature below $2{ }^{\circ} \mathrm{C}$ above pre-industrial levels by 2100 . Moreover, the Parties noted the relevance of promoting the mitigation of greenhouse gas (GHG) emissions while fostering sustainable development [1]. According to the Fifth Assessment Report (AR5) of the Intergovernmental Panel on Climate Change (IPCC), the industry is a critical factor for climate change control since their GHG emissions have been doubled between 1970 and 2010 [2].

Therefore, from the analysis of the industrial energy demand, it can be observed that most of the consumption comes from thermal processes at temperatures above $100{ }^{\circ} \mathrm{C}$. It is mostly provided 
through fossil fuels combustion with uncertain acquisition prices and severe environmental impacts such as climate change. Moreover, a significant fraction (around 2.8\%) of the industrial energy consumption is wasted as low-grade heat below $100^{\circ} \mathrm{C}$, Fig. 4.1 [3]. Recovering the low-grade waste heat (below $100^{\circ} \mathrm{C}$ ) and transforming it into useful heat at the required temperature (above $100{ }^{\circ} \mathrm{C}$ ) employing energy-efficient technologies would increase the energy efficiency and decarbonise the industrial sector. Vapour compression high-temperature heat pump (HTHP) can be integrated into different industrial and district heating processes due to the flexibility that offers in possible operating temperatures and heat capacities.

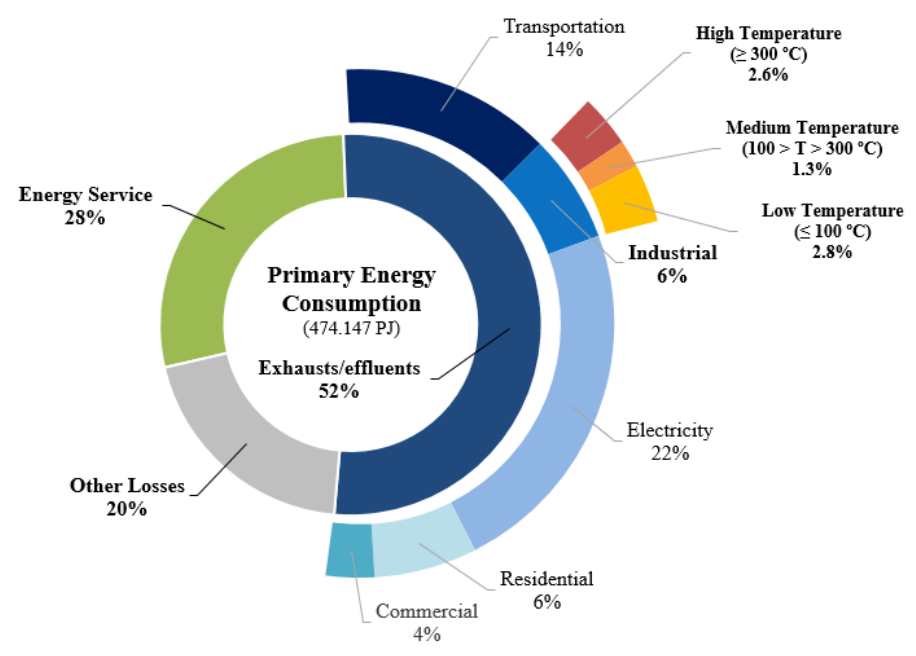

Fig. 4.1. Energy consumption breakdown and potential industrial low-grade waste heat [3].

The firstly developed HTHPs used CFC-114 [4] (chlorofluorocarbon), CFC-113 [5], and HCFC-123 [6] as refrigerants (working fluids). Nevertheless, according to the Montreal Protocol, the substances that deplete the ozone layer must be phased out [7], and other chlorine-free refrigerants appeared to be used in these applications. Therefore, Brown [8] evaluated 56 potential CFC-114 replacement refrigerants for HTHP applications and identified HFC-245fa for high-pressure operation. HFC-245fa has a relatively high critical temperature $\left(154^{\circ} \mathrm{C}\right)$, zero ozone depletion potential (ODP), and is the most commonly used third generation working fluid for HTHPs today [9].

However, in 2014, EU Regulation No. 517/2014 [10] gradually limited the hydrofluorocarbons (HFCs) allowed in most of the vapour compression systems and established market quotas to their consumption. Hence, low global warming potential (GWP) alternatives (named as fourth generation refrigerants by Calm [11]) are necessary to replace HFC-245fa, which has a GWP value of 858 . Natural refrigerants [12], hydrofluoroolefin (HFO) and hydrochlorofluorocarbon (HCFO) are becoming relevant for the today HTHPs. Due to the thermodynamic similarity with HFC-245fa, low GWP organic refrigerants (HFOs and HCFOs) receive more attention for high-temperature applications.

Tetrafluoropropene and its isomers were the first low GWP alternatives considered for HTHPs. Brown et al. [13] studied HFO-1234ze(Z) as a potential alternative for CFC-114 because of its similar 
thermodynamic and transport properties. Fukuda et al. [14] and Kondou et al. [15] performed a theoretical thermodynamic comparison using HFO-1234ze(E) and HFO-1234ze(Z). The results highlight HFO-1234ze(Z) as the most suitable low GWP refrigerant for HTHPs. Despite the satisfactory thermodynamic properties of HFO-1234ze(Z), it is still not commercially available. In addition, the isomer HFO-1234ze(E), which is commercially available [16], presents a critical temperature of $109.4{ }^{\circ} \mathrm{C}$, and it is more suitable for condensation temperatures up to $100{ }^{\circ} \mathrm{C}$. Hence, both fluids are not considered as possible alternatives, and other refrigerant candidates are receiving special attention in the last years.

HFO-1336mzz(Z) and HCFO-1233zd(E) are the most studied refrigerants today, whereas the recently developed HCFO-1224yd(Z) is becoming a potential alternative, but none studies have been found for this refrigerant. Table 4.1 shows the evolution of the characteristics for the main refrigerants used in HTHPs as well as the potential candidates for replacing HFC-245fa.

Table 4.1. Evolution of the main refrigerants used in high-temperature heat pumps.

\begin{tabular}{cccc}
\hline Refrigerant no & ODP & GWP & $\begin{array}{c}\text { ASHRAE } \\
\text { Std. 34 safety } \\
\text { class [29] }\end{array}$ \\
\hline CFC-114 & 0.5 & 8590 & A1 \\
CFC-113 & 0.81 & 5820 & A1 \\
HCFC-123 & 0.01 & 79 & B1 \\
HFC-245fa & 0 & 858 & B1 \\
HFO-1336mzz(Z) & 0 & 2 & A1 \\
HCFO-1233zd(E) & 0.00034 & 1 & A1 \\
HCFO-1224yd(Z) & 0.00012 & $<1$ & A1 \\
\hline
\end{tabular}

Kontomaris proposed $\mathrm{HFO}-1336 \mathrm{mzz}(\mathrm{Z})$ as a refrigerant candidate for high-temperature applications with condensing temperatures above $100{ }^{\circ} \mathrm{C}$. It shows $2.3 \%$ theoretical higher coefficient of performance (COP) than HFC-245fa [17] and presents high chemical stability, very low GWP, noODP, no flammability and compatibility with many plastics and elastomers [18] and with commercially available polyolester (POE) lubricants [19].

On the other hand, Gorgy [20] proved that HCFO-1233zd(E) shows 19\% higher heat transfer performance than HCFC-123 and Byun et al. [21] performed a similar study about the HCFO1233zd(E) heat transfer performance. Although it has not been yet tested in HTHPs, it shows excellent performance and heat transfer results in other high-temperature applications [22]. Nevertheless, Lee et al. [23] performed an experimental study of the pressure drop and heat transfer of HCFO-1223zd(E) compared with HFC-245fa. This study shows that similar pressure drops and a reduction of $9 \%$ of the heat transfer are expected. When compared with HFC-245fa in different HTHP configurations, HCFO-1233zd(E) highlighted in volumetric heating capacity (VHC) whereas HFO-1336mzz(Z) 
provides intermediate values in VHC and COP [24]. Thus, both become potential substitutes of HFC$245 \mathrm{fa}$.

HCFO-1224yd(Z) ((Z)-1-chloro-2,3,3,3-tetrafluoropropene, $\mathrm{CF} 3 \mathrm{CF}=\mathrm{CHCl})$ is an unsaturated organic compound approved in 2017 by the American Society of Heating, Refrigerating, and Air Conditioning Engineers (ASHRAE) [25] and proposed for HFC-245fa replacement in applications like centrifugal chillers, binary cycle generators and HTHPs. The main reasons for this statement are that its GWP value is below the unity [26] and it is considered a low-pressure refrigerant, as HFC$245 \mathrm{fa}$. HCFO-1224yd(Z) is the last pure fluid HTHP candidate approved by the ASHRAE, and due to the recent certification of this refrigerant, there are not available results about the HTHP performance using it. For the moment, only Masato et al. [27] published the experimental thermodynamic properties (vapour pressure and the PVT properties, vapour-liquid and coexistence curve saturated liquid densities, and critical temperature, density and pressure) of HCFO-1224yd(Z). From that information, this refrigerant shows closer thermodynamic properties to HFC-245fa, and therefore can be an excellent candidate to replace it in existing, redesigned or even new HTHP systems. Before to the experimentation with the refrigerant, the more appropriate operating temperature range and configuration need to be theoretically verified.

Given the number of environmentally friendly alternatives to HFC-245fa in HTHP systems developed in the last years and the lack of information, this paper analyses and compares the operating and energetic performance of HFO-1336mzz(Z), HCFO-1233zd(E) and HCFO-1224yd(Z) as a potential low GWP alternatives to replace the commonly used HFC-245fa refrigerant in high-temperature heat pumps (HTHPs). In addition, this paper provides a complete overview of the consequences of the HFC-245fa replacement, comparing the main thermodynamic and transport properties of the alternatives proposed and the influence the internal heat exchanger (IHX). This paper aims to provide comparative information of these recently developed working fluids and can be used as a guide to decide the refrigerant to use in any specific HTHP application, depending on the safety requirements, operating range of temperatures and pressures, and energy performance priorities.

\subsection{Properties Evaluation of the Proposed low GWP Refrigerants}

The low GWP refrigerants evaluated in this paper to replace HFC-245fa are HFO-1336mzz(Z), HCFO-1233zd(E) and HCFO-1224yd(Z). Table 4.2 shows the main properties of these fluids from REFPROP Version 10 [28]. This information is then used to compare some of their characteristics and predict the possible behaviour in the cycle analysis. 
Table 4.2. Properties of low GWP refrigerants and HFC-245fa.

\begin{tabular}{|c|c|c|c|c|}
\hline Parameters & HFC-245fa & HFO-1336mzz(Z) & HCFO-1233zd(E) & HCFO-1224yd(Z) \\
\hline Molecular weight $\left(\mathrm{g} \cdot \mathrm{mol}^{-1}\right)$ & 134.05 & 164.06 & 130.50 & 148.49 \\
\hline Critical temperature $\left({ }^{\circ} \mathrm{C}\right)$ & 153.86 & 171.35 & 166.45 & 155.54 \\
\hline Critical pressure (MPa) & 3.65 & 2.90 & 3.62 & 3.34 \\
\hline Normal boiling point $(\mathrm{NBP})\left({ }^{\circ} \mathrm{C}\right)$ & 15.05 & 33.45 & 18.26 & 14.62 \\
\hline Tested thermal stability $\left({ }^{\circ} \mathrm{C}\right)$ & 250 & 250 & 175 & 175 \\
\hline Condensing pressure $^{\mathrm{a}}$ (MPa) & 2.35 & 1.35 & 1.91 & 2.11 \\
\hline Pressure Ratio ${ }^{a, b}$ & 5.08 & 5.52 & 4.88 & 4.80 \\
\hline Vapour pressure $^{\mathrm{c}}(\mathrm{MPa})$ & 0.15 & 0.07 & 0.13 & 0.15 \\
\hline $\begin{array}{l}\text { Latent heat of vaporization } \\
\left(\mathbf{k J} \cdot \mathrm{kg}^{-1}\right)\end{array}$ & 169.12 & 151.33 & 171.24 & 145.21 \\
\hline $\begin{array}{l}\text { Latent heat of condensation } \\
\left(\mathrm{kJ} \cdot \mathrm{kg}^{-1}\right)\end{array}$ & 97.25 & 102.34 & 111.53 & 86.10 \\
\hline Suction density $\left(\mathrm{kg} \cdot \mathrm{m}^{-3}\right)$ & 25.45 & 16.02 & 20.73 & 27.11 \\
\hline Liquid/Vapour density ${ }^{\mathrm{a}}\left(\mathrm{kg} \cdot \mathrm{m}^{-3}\right)$ & $\begin{array}{l}938.36 / \\
156.10\end{array}$ & $1014.10 / 96.36$ & $926.88 / 113.52$ & $958.53 / 154.63$ \\
\hline $\begin{array}{l}\text { Liquid/Vapour specific heat } \\
\left(\mathbf{k J} \cdot \mathbf{k g}^{-1} \cdot \mathbf{K}^{-1}\right)\end{array}$ & $1.98 / 1.87$ & $1.57 / 1.37$ & $1.64 / 1.42$ & $1.64 / 1.56$ \\
\hline Specific heat ratio $^{b}$ & 1.44 & 1.10 & 1.45 & 1.14 \\
\hline ODP (CFC-11=1) [29] & 0 & 0 & 0.00034 & 0.00012 \\
\hline GWP100-years [29] & 858 & 2 & 1 & $<1$ \\
\hline Atmospheric lifetime [29] & 7.7 years & 26 days & 26 days & 21 days \\
\hline $\begin{array}{l}\text { ASHRAE Std. } 34 \text { safety class } \\
\text { [29] }\end{array}$ & B1 & A1 & $\mathrm{A} 1$ & $\mathrm{~A} 1$ \\
\hline AEL (ppm) $[17,26]$ & 300 & 500 & 800 & 1000 \\
\hline
\end{tabular}

${ }^{\text {a }}$ At condensing temperature of $130^{\circ} \mathrm{C}$

${ }^{\mathrm{b}}$ At evaporation temperature of $60^{\circ} \mathrm{C}$

${ }^{\mathrm{c}}$ At ambient temperature of $25^{\circ} \mathrm{C}$

All the fluids analysed in the study are dry fluids (dT/ds $>0$ ), presenting a positive slope of the saturation curves in the T-s diagram, Fig. 4.2a. Due to this fact, a particular superheating control should be required to ensure the dry compression at high-temperature lifts in order to prevent the presence of liquid drops and possible damage to the compressor [30]. HCFO-1224yd(Z) and HCFO1233zd(E) have similar T-s saturation curve slopes to HFC-245fa and, being low the dT/ds value, a minimum superheating degree is required for dry compression. In contrast, HFO-1336mzz(Z) needs a higher superheating degree to ensure a dry compression, requiring a modified vapour compression cycle [30]. For instance, this modification can be performed merely by adding an IHX, which can simultaneously increase the superheat of the suction vapour and the sub-cooling of the liquid refrigerant before the expansion valve [31]. This is the reason why an IHX analysis has been included in this paper, having a more complete and realistic analysis of the potential low GWP alternatives to HFC-245fa.

The operating pressure of all the potential alternatives is below the HFC-245fa, as shown in Fig. 4.2b. Therefore, the same security components and adjustments of HFC-245fa can be used with these alternative working fluids and lower refrigerant losses can be expected in case of leakage. 
Chapter 4

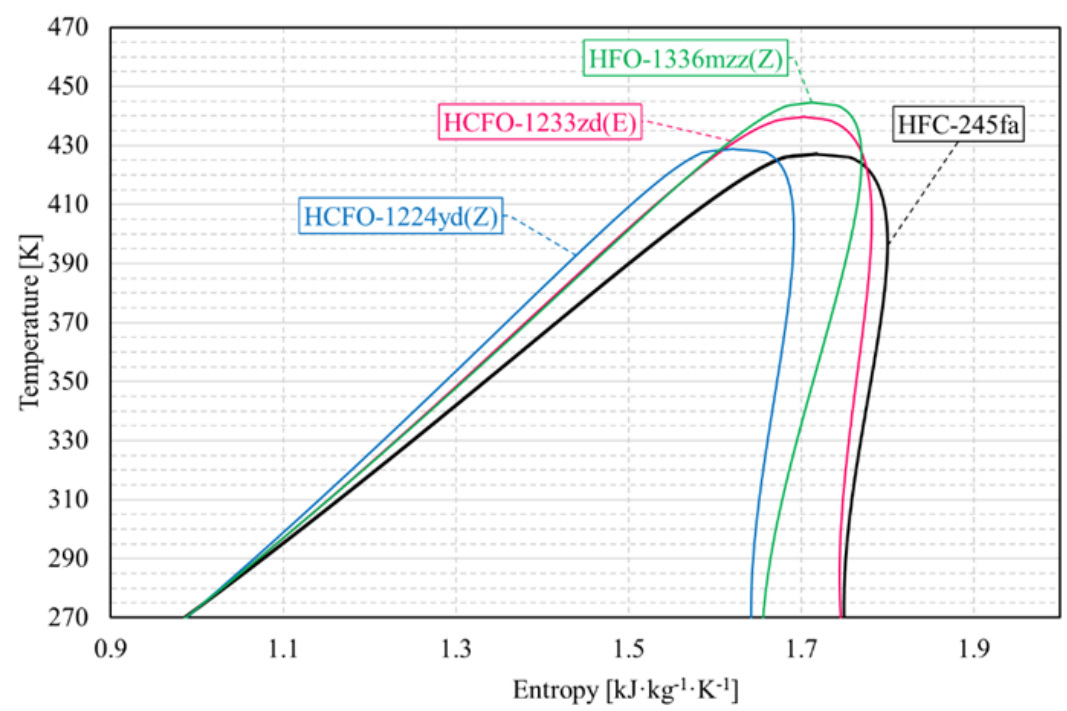

(a)

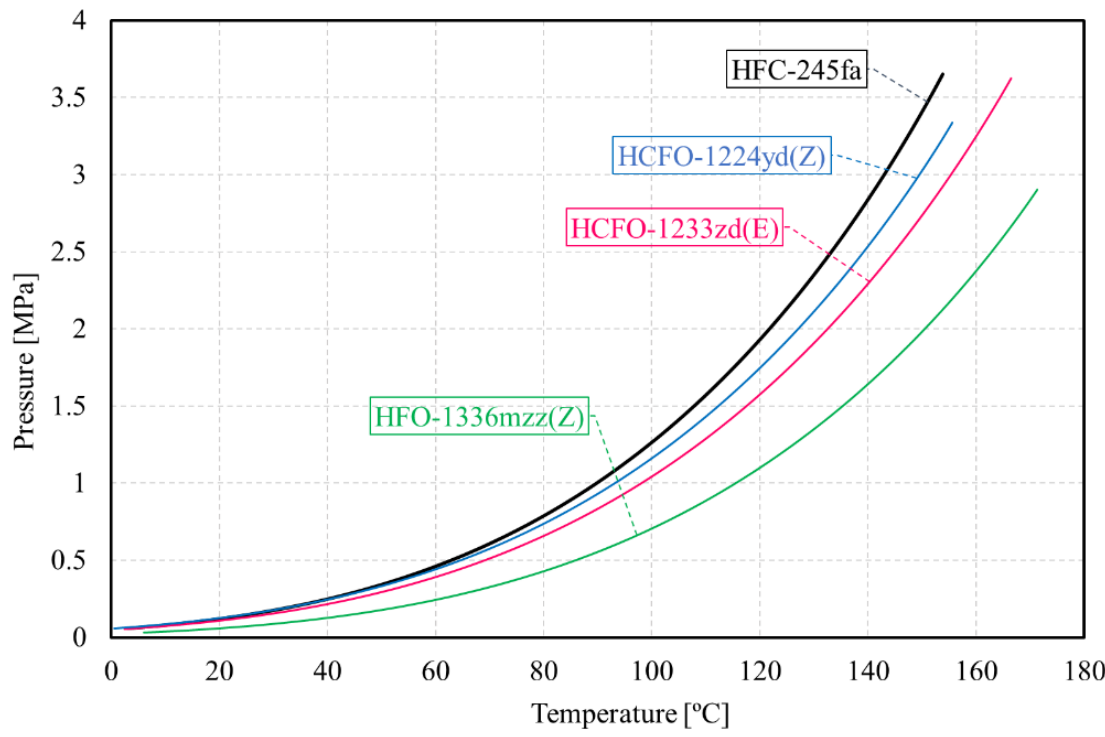

(b)

Fig. 4.2. a) T-s curves of the potential working fluids alternatives to HFC-245fa and b) Saturated vapour pressure over the operating range temperatures.

All the proposed alternatives have a higher critical temperature than HFC-245fa. Whereas HCFO$1224 \mathrm{yd}(\mathrm{Z})$ has a slight increment of $1.7^{\circ} \mathrm{C}$ compared to the reference fluid, HCFO-1233zd(E) and HFO-1336mzz(Z) show an increase of 12.6 and $17.5^{\circ} \mathrm{C}$, respectively. Therefore, all the alternatives proposed could achieve higher heating production temperatures in future developments, expanding the current operating map of the HTHPs.

Another important aspect is the normal boiling point (NBP) in order to avoid air infiltrations during system operation and downtime [32]. While the vapour NBP of HCFO-1233zd(E) and HCFO- 
$1224 \mathrm{yd}(\mathrm{Z})$ are near that of HFC-245fa and below $25^{\circ} \mathrm{C}$, HFO-1336mzz(Z) has a higher NBP $(33.45$ ${ }^{\circ} \mathrm{C}$ ) with the consequent risk of air infiltrations.

HFO-1336mzz $(Z)$ decreases the liquid density around $8 \%$, reducing the required refrigerant charge compared to HFC-245fa. In contrast, the other refrigerants result in a minor difference of this parameter, and therefore, the amount of refrigerant charge is going to be similar to HFC-245fa. The highest difference is observed in the vapour density, which can affect the resulting refrigerant mass flow rate using the same compressor. In case of the same compressor swept volume, HFO$1336 \mathrm{mzz}(\mathrm{Z})$ and HCFO-1233zd(E) are going to decrease the mass flow rate compared to HFC-245fa due to the $38 \%$ and $27 \%$ (respectively) reduction in vapour density. HCFO-1224yd(Z) shows a slight increase in the vapour density.

All the alternatives are non-flammable and low-toxic, obtaining an A1 classification. Although HFO$1336 \mathrm{mzz}(\mathrm{Z})$ has zero ODP, HCFO-1233zd(E) and HCFO-1224yd(Z) contain chlorine molecule in their composition, showing an ODP of 0.00034 and 0.00012 , respectively. Nevertheless, the effect of the leakage of these refrigerants on the atmospheric ozone atmosphere is unlikely can be considered negligible [32].

Additionally, the very low GWP values of the alternative refrigerants can substantially reduce the direct contribution to the greenhouse effect in the case of accidental leakage. Considering only the GWP value, the environmental benefit could be clear straightforward. However, the greenhouse gas liberation of fossil fuels burning for electricity generation must be accounted for to calculate the total contribution to the greenhouse effect [33]. Therefore, the energy performance of HTHP systems using these new refrigerants must be studied in deep.

Finally, an essential parameter for these new refrigerants is the thermal stability and compatibility with the installation materials and the lubricants. Laboratory tests have shown that HFO-1336mzz(Z) has a similar material and lubricant compatibility relative to copper and steel to that presented by HFC-245fa, which is widely used in high-temperature applications. Moreover, the thermal stability of HFO-1336mzz(Z) has been successfully tested up to $250{ }^{\circ} \mathrm{C}$ [30]. Although HCFO-1233zd(E) and HCFO-1224yd(Z) present good compatibility with most commonly used metals, plastics, elastomers and POEs lubricant, the copper and steel thermal studies showed turbidity and discolouration after 7 days at $250{ }^{\circ} \mathrm{C}$. Nevertheless, these refrigerants prove thermal stability until $175^{\circ} \mathrm{C}[26,34]$.

\subsection{System description and modelling}

The single-stage cycle is the system architecture selected in this paper (Fig. 4.3a) because of its simplicity and robustness; it can be used as a baseline for future installation design and experimental tests. Then, a heat exchanger can be added to the single-stage cycle configuration between the suction and the liquid line (Fig. 4.3b) to enhance the energy performance of the system. It is known as the internal heat exchanger (IHX) and at the same time heats the suction vapour (superheat) and reduces the liquid temperature before the expansion valve (sub-cooling). In contrast to refrigeration systems [34], IHX for HTHPs becomes more interesting for increasing the discharge temperature, and the superheat degree than the sub-cooling degree. Higher discharge temperature increases the thermal level of heat production and expands the operating map of the HTHP (always considering the temperature restriction of the components). 

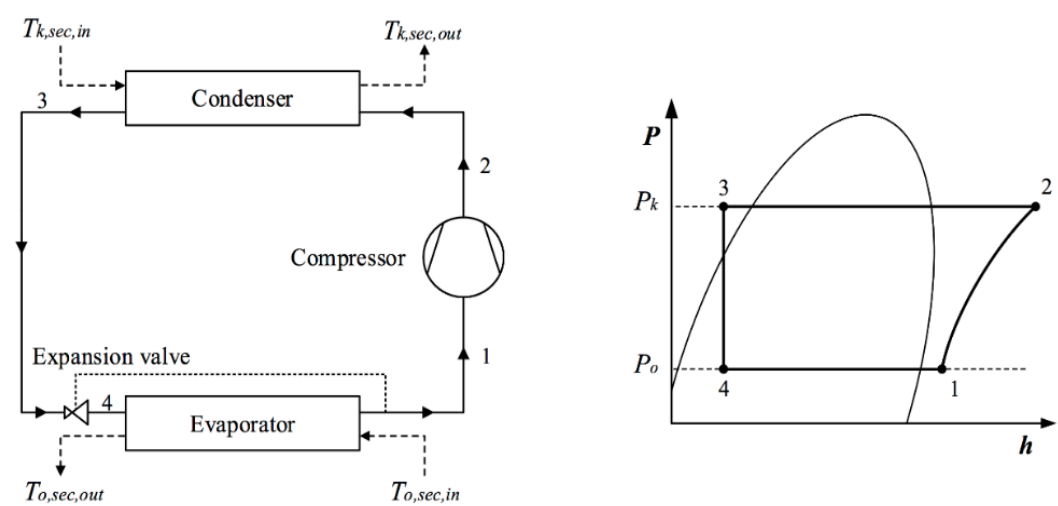

(a)
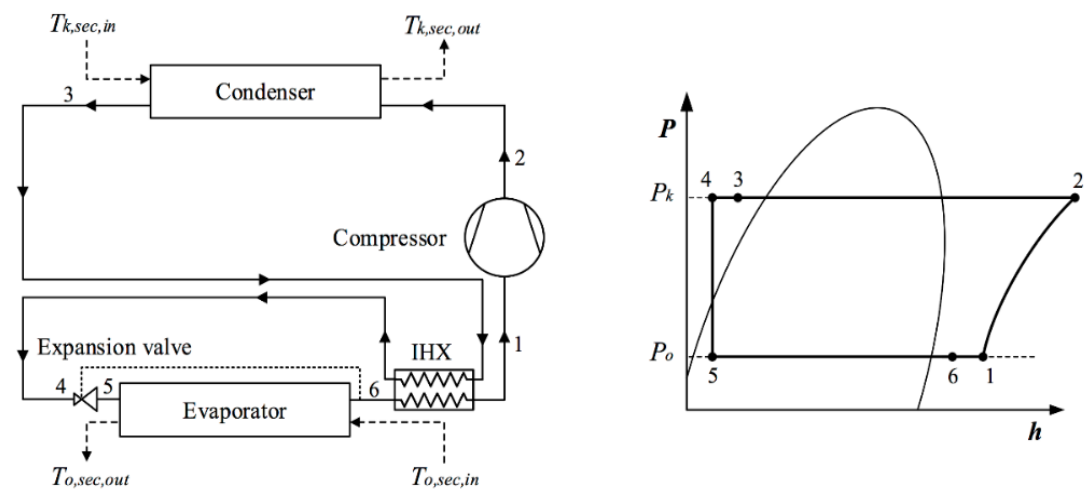

(b)

Fig. 4.3. Schematic and P-h diagram of single-stages configurations: a) single-stage cycle and b) single-stage cycle with IHX.

The heat absorbed by the evaporator $\left(\dot{Q}_{o}\right)$ is considered as input of the model, and a constant value of $100 \mathrm{~kW}$ has been considered. In order to analyse different high-temperature applications and due to the variety of low-grade waste heat sources, different condensing and evaporating (related to the lowgrade waste heat temperature) temperatures are combined to simulate the typical working conditions and analyse the system performance

Firstly, the evaporating temperature is varied from 45 to $75^{\circ} \mathrm{C}$, and the condensing temperature is set at $145^{\circ} \mathrm{C}$ to consider the limitation of the critical temperature of HFC-245fa $\left(153.86^{\circ} \mathrm{C}\right)$. Secondly, the evaporating temperature is set at the intermediate value of $60{ }^{\circ} \mathrm{C}$, whereas the condensing temperature is varied from 115 to $145^{\circ} \mathrm{C}$. Moreover, the sub-cooling degree is assumed to be $10 \mathrm{~K}$, and the superheat degree is considered to be $15 \mathrm{~K}$.

The refrigerant thermodynamic properties have been evaluated using the software REFPROP Version 10 [28] and the model has been developed using the software Engineering Equation Solver (EES) [35]. Moreover, an isenthalpic process is considered at the expansion valve and heat transfer to the surroundings and pressure drops are neglected. 
The isentropic and volumetric efficiencies of the compressors are calculated using Pierre's correlations for "good" reciprocating compressors [36]. Compressor volumetric efficiency, $\eta_{v o l}$, is obtained from Eq. (4.1).

$$
\eta_{v o l}=k_{1} \cdot\left(1+k_{s} \cdot \frac{t_{2 k}-18}{100}\right) \cdot \exp \left(k_{2} \cdot \frac{p_{1}}{p_{2}}\right)
$$

$t_{2 k}$ is the inlet temperature to the compressor and $p_{1} / p_{2}$ is the pressure ratio. The remaining symbols $k_{1}, k_{s}$ and $k_{2}$ are constants and, the values of these are $1.04,0.15$, and -0.07 , respectively.

Then, isentropic efficiency, $\eta_{i s}$, is calculated using Eq. (4.2).

$$
\left(\frac{\eta_{v o l}}{\eta_{i s}}\right)=\left(1+k_{e} \cdot \frac{t_{2 k}-18}{100}\right) \cdot \exp \left(a \cdot \frac{T_{1}}{T_{2}}+b\right)
$$

$T_{1} / T_{2}$ is the ratio of the condensation and evaporation absolute temperatures (in Kelvin) corresponding to the discharge and the suction compressor pressure. The constants $k_{e}$, $a$ and $b$ are $0.1,-2.40$ and 2.88, respectively, and are taken from the literature [36]. The electromechanical efficiency, $\eta_{\text {em }}$, is assumed to be 0.95 .

The refrigerant mass flow rate for all system configurations is calculated using Eq. (4.3).

$$
\dot{m}=\frac{\dot{Q}_{o}}{\left(h_{o, \text { out }}-h_{o, \text { in }}\right)}
$$

The required volumetric flow rate at the compressor suction, $\dot{V}_{s u c}$, is obtained from the mass flow rate, the suction density and the volumetric efficiency, Eq. (4.4).

$$
\dot{V}_{\text {suc }}=\frac{\dot{m}}{\eta_{v o l} \rho_{\text {suc }}}
$$

The maximum discharge temperature, $T_{\text {disc }}$, is limited to $175^{\circ} \mathrm{C}$ to preserve the thermal stability between the refrigerants and POE lubricants [26,30,34]. For the same reason, the IHX effectiveness $\left(\varepsilon_{\mathrm{IHX}}\right)$ is limited. Fig. 4.6a shows that HCFO-1233zd(E) achieves the highest discharge temperatures of the refrigerants analysed, and the maximum IHX effectiveness for all the simulations is fixed at 0.3 to maintain the discharge temperature below the limit in each operation conditions and refrigerants analysed. The vapour suction temperature is calculated using Eq. (4.5).

$$
\varepsilon_{\mathrm{IHX}}=\frac{h_{\text {suc }}-h_{o, \text { out }}}{h_{k, \text { out }}-h_{o, \text { out }}}
$$

The electric power consumption of the compressor, $\dot{W}_{C}$, is expressed in Eq. (4.6) as the product of the mass flow rate and the isentropic enthalpy difference at the compressor divided by the isentropic and electromechanical efficiencies.

$$
\dot{\mathrm{W}}_{\mathrm{C}}=\frac{\dot{m} \Delta h_{i s, c}}{\eta_{i s} \eta_{e m}}
$$


The heating capacity, $\dot{Q}_{k}$, is calculated using the product of the mass flow rate and the enthalpy difference at the condenser, Eq. (4.7).

$$
\dot{\mathrm{Q}}_{\mathrm{k}}=\dot{m}\left(h_{k, \text { in }}-h_{k, \text { out }}\right)
$$

To compare correctly the influence of the volumetric flow rate at the compressor suction and the heating capacity, the volumetric heating capacity (VHC) is calculated using Eq. (4.8).

$$
V H C=\frac{\dot{\mathrm{Q}}_{\mathrm{k}}}{\dot{V}_{\text {suc }}}
$$

Finally, the Coefficient of Performance, COP, is calculated from the heating capacity and the compressor electric power consumption, using Eq. (4.9).

$$
C O P=\frac{\dot{\mathrm{Q}}_{\mathrm{k}}}{\dot{\mathrm{W}}_{\mathrm{C}}}
$$

\subsection{Superheat mapping and Internal Heat Exchanger (IHX) analysis}

The positive slope of the saturated vapour curves $(\mathrm{dT} / \mathrm{ds}>0)$ in the analysed refrigerants makes necessary a particular superheating control to ensure a dry compression and prevent compressor damage. For this reason, the minimum superheat degree has been calculated for each possible combination of refrigerant and operating condition. Then, a sensitivity analysis of the IHX effectiveness has been performed to study its influence in the main operating parameters.

\subsubsection{Minimum superheat required}

Apart from the simulation analysis explained previously, a minimum superheat requirement analysis has been carried out at different discharge and suction pressures to facilitate the utilisation of these refrigerants in real installations (Fig. 4.4). This mapping has been done due to the lack of information available about the minimum superheat degree required to these refrigerants.

The highest superheat required for HFC-245fa is $5.4 \mathrm{~K}$, operating at relatively low discharge and suction pressures (0.40 and 1.9 MPa, respectively), as shown in Fig. 4.4a. Nevertheless, as the discharge and suction pressures increase, the required superheat decreases down to zero. The suction pressure variation is less significant. HCFO-1233zd(E) exhibits a mapping comparable to HFC-245fa but requires slightly higher minimum superheat, as shows Fig. 4.4b. Hence, the highest value of superheat required for $\mathrm{HCFO}-1233 \mathrm{zd}(\mathrm{E})$ is $7.1 \mathrm{~K}$ but operating at lower suction pressure and higher discharge pressure than HFC-245fa.

The mapping presented in Fig. 4.4c for HCFO-1224yd(Z) is different from the previous refrigerants analysed. In this case, the highest superheat required, $4.4 \mathrm{~K}$, occurs at intermediate suction and discharge pressures of 0.42 and $1.9 \mathrm{MPa}$, being this value lower than that obtained for HFC-245fa. In contrast, $\mathrm{HCFO}-1224 \mathrm{yd}(\mathrm{Z})$ requires the minimum superheat operating at low suction pressures, whereas HFC-245fa and HCFO-1233zd(E) show this minimum at high suction pressures. However, operating at high suction pressure reduces the minimum superheat required. 
Finally, HFO-1336mzz $(Z)$ presents a significantly different mapping to the rest of working fluids, highlighting the significant increase of the minimum superheat requirement, as shows Fig. 4.4d. The highest superheat required is $19.2 \mathrm{~K}$, operating at the intermediate suction pressure of $0.25 \mathrm{MPa}$ but at the highest discharge pressure, $1.8 \mathrm{MPa}$, and hence at different conditions. Similarly, the superheat required decreases as the suction pressure increases contrary to the other refrigerants, which requires the minimum values at high suction pressures. The isentropic curve slope for $\mathrm{HFO}-1336 \mathrm{mzz}(\mathrm{Z})$ is higher than for the other refrigerants, requiring a higher minimum superheat degree than the other alternatives.

Therefore, HCFO-1233zd(E) and HCFO-1224yd(Z) operate similar to HFC-245fa and have the minimum superheat requirement at higher heat productions temperatures, whereas HFO-1336mzz(Z) at lower ones. Besides, moderate waste heat temperatures, producing evaporation temperatures between 50 and $60^{\circ} \mathrm{C}$, require the highest superheat degree.

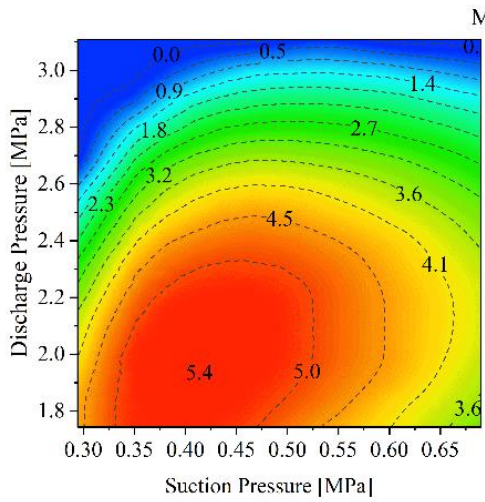

(a)

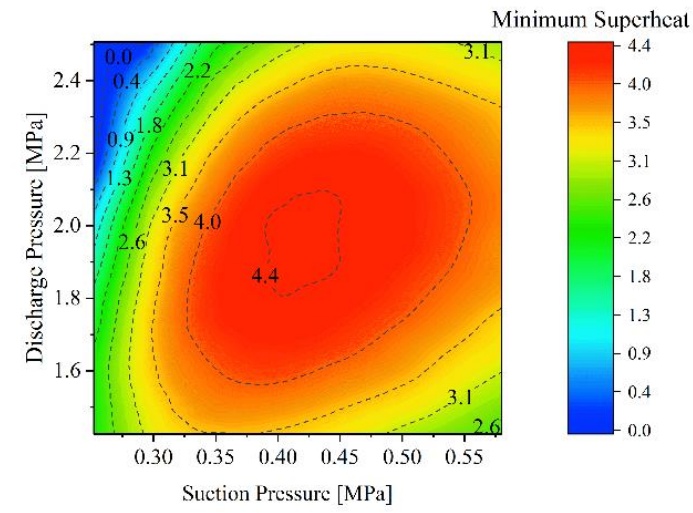

(c)

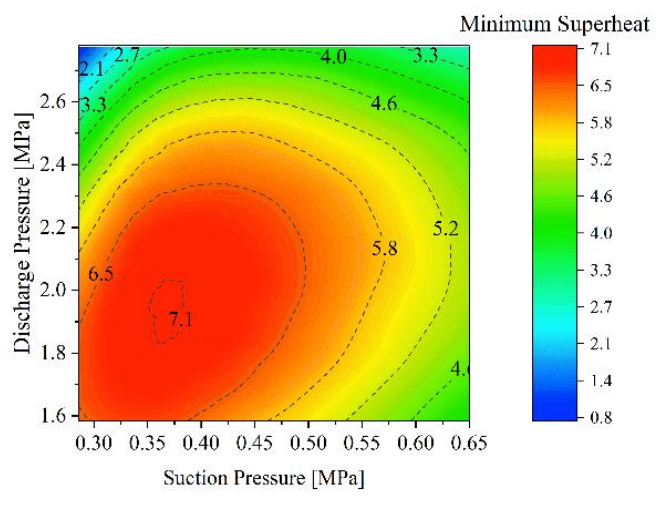

(b)

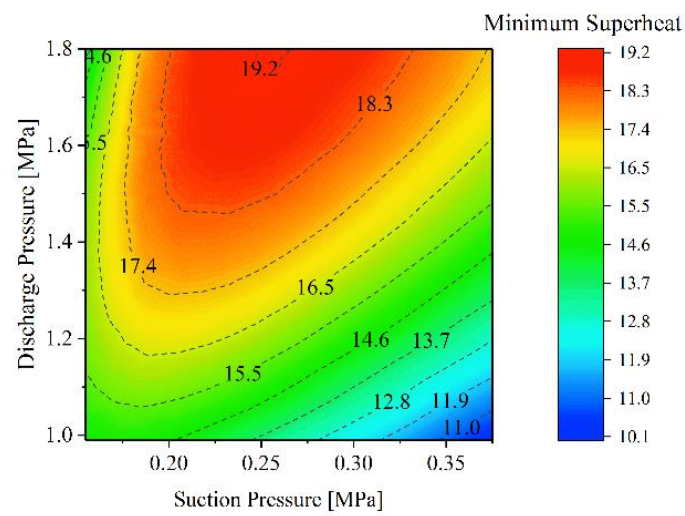

(d)

Fig. 4.4. Mapping of the minimum superheating required for: a) HFC-245fa, b) HCFO-1233zd(E), c) HCFO$1224 \mathrm{yd}(\mathrm{Z})$ and d) HFO-1336mzz(Z). 


\subsubsection{Influence of Internal Heat Exchanger (IHX)}

The addition of an IHX to a single-stage vapour compression cycle could improve the system performance, volumetric heating capacity and ensure a dry compression. Nevertheless, the system response to its introduction depends on the refrigerant and the IHX effectiveness $\left(\varepsilon_{I H X}\right)$, and there is the possibility that the system performance can deteriorate. Consequently, a sensitivity analysis of the IHX effectiveness becomes interesting. Fig. 4.5 shows the relative difference between the configuration with and without IHX adoption at varying IHX effectiveness, for all the refrigerants and selected operating parameters.

As shown in Fig. 4.5a, the discharge temperature significantly increases with the IHX effectiveness. All the low GWP alternatives show higher discharge temperature increments than HFC-245fa, becoming higher as the IHX effectiveness increases. While HCFO-1224yd(Z) and HFO-1336mzz(Z) present slightly lower discharge temperature values than HFC-245fa, HCFO-1223zd(E) shows significantly higher discharge temperature values. Looking at the specific heat ratio, HCFO$1224 \mathrm{yd}(\mathrm{Z})$ and HFO-1336mzz(Z) have lower values for this parameter than the reference fluid, whereas HCFO-1233zd(E) has higher values. Thus, this specific heat ratio difference is the main reason for the variation in discharge temperature. These increases of discharge temperature become a critical operating parameter to be considered, especially in high-temperature applications, for the components and installation limitations.

As Fig. $4.5 \mathrm{~b}$ shows, the COP increases up to $43 \%$ at high IHX effectiveness. Compared to HFC245fa, HFO-1336mzz(Z) achieves lower COP increment than HFC-245fa, followed by HCFO$1224 \mathrm{yd}(\mathrm{Z})$. On the other hand, HCFO-1233zd(E) has a significant increment of the system performance as the IHX effectiveness increases up to $8 \%$ compared to HFC-245fa with the highest IHX effectiveness.

Regarding Fig. 4.5c and 4.5d, although the heating capacity decreases as the IHX effectiveness increases, the volumetric heating capacity increases due to the more significant volumetric flow rate reduction in the compressor suction than that in the heating capacity. In this case, HFO-1336mzz(Z) shows slightly lower values than HFC-245fa. However, HCFO-1224yd(Z) and HCFO-1233zd(E) tend to be situated above HFC-245fa. Therefore, the HCFO refrigerants would provide better heating capacity with IHX than the other alternative refrigerant.

Finally, Fig. 4.5e and $4.5 \mathrm{f}$ show the variation of superheat and sub-cooling with an increment of IHX effectiveness, respectively. As it was expected, superheat and sub-cooling increase at higher IHX effectiveness. The sub-cooling improvement of HCFO-1233zd(E) compared to HFC-245fa can be considered higher, whereas the other refrigerants have similar behaviour to the reference fluid. The mass flow rate difference between HCFO-1233zd(E) and the other refrigerant would be the main responsible for this variation. The analysis shows that lower IHX effectiveness values can achieve significant increments of superheating and sub-cooling, and hence ensure the dry compression (particularly for HFO-1336mzz(Z)).

All the refrigerants present a similar response to the use of IHX. Nevertheless, HCFO-1233zd(E) shows higher performance improvements and lower heating capacity reduction than the rest alternatives. HCFO-1224yd(Z) and HFO-1336mzz(Z) have close similar values than HFC-245fa. 
Nevertheless, the discharge temperature of HCFO-1233zd(E) is considerably higher than the other alternatives, which show a lower discharge temperature than HFC-245fa with the use of IHX.

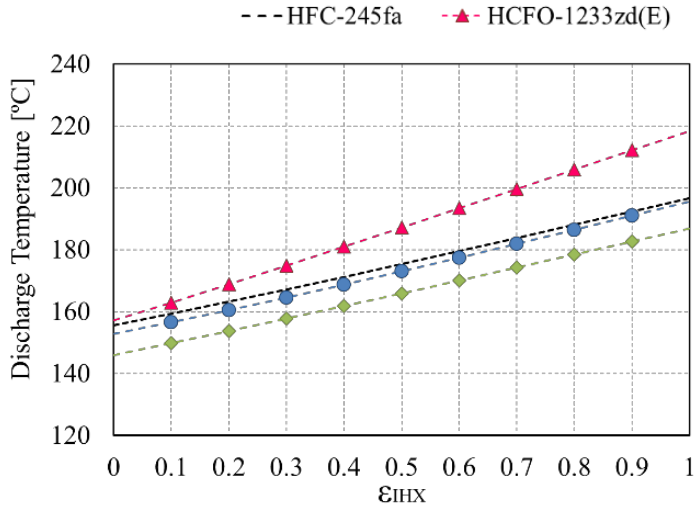

(a)

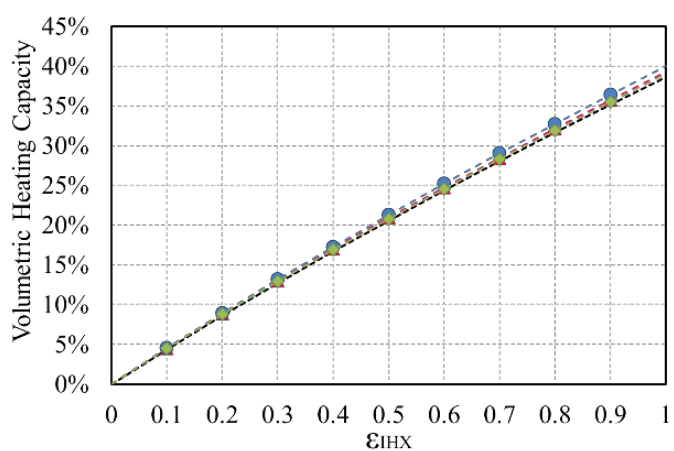

(c)

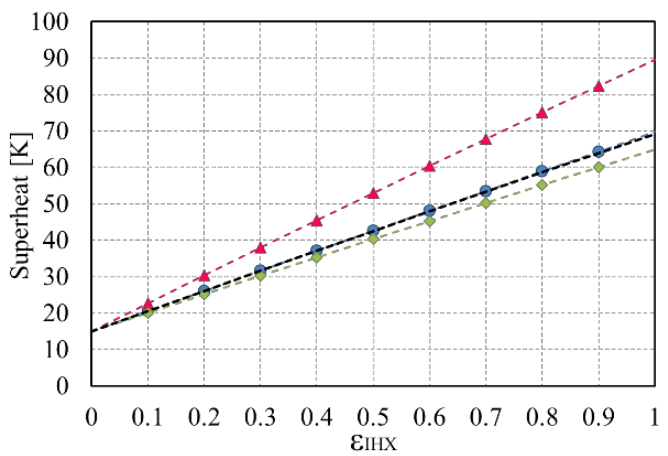

(e)

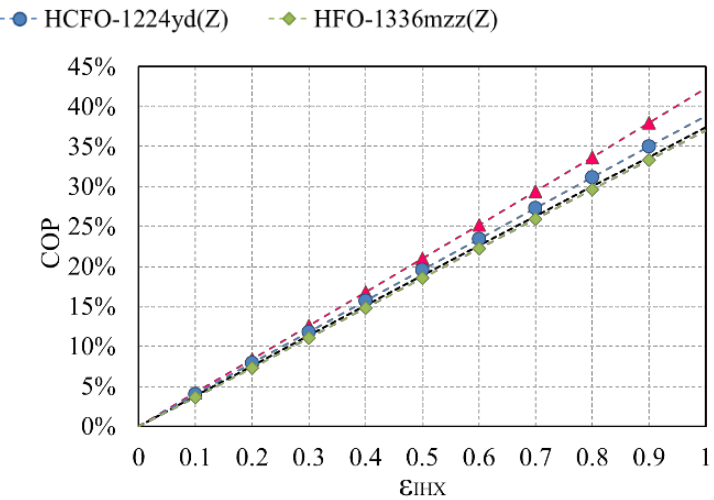

(b)

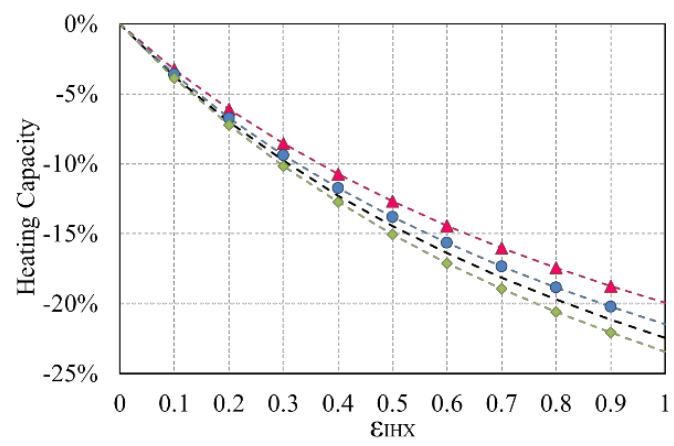

(d)

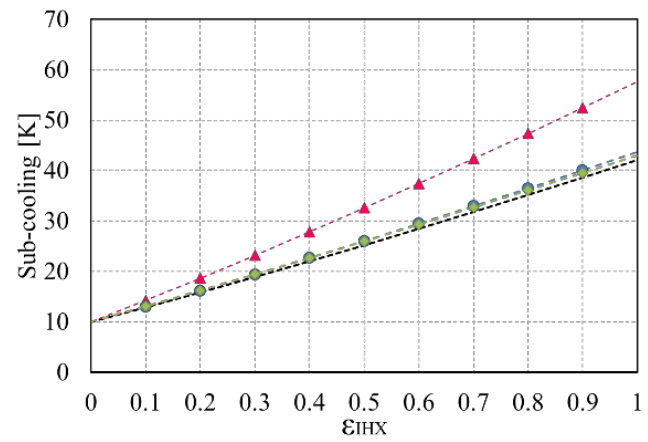

(f)

Fig. 4.5. Influence the effectiveness of the IHX in: a) Discharge Temperature, b) COP, c) Volumetric Heating Capacity, d) Heating Capacity, e) Superheat and f) Sub-cooling.

\subsection{Simulations analysis results}

This section analyses the results obtained in the simulations using HFO-1336mzz(Z), HCFO$1233 \mathrm{zd}(\mathrm{E})$ and HCFO-1224yd(Z) as low GWP alternatives to HFC-245fa, showing the variation of the main energy performance parameters: heating capacity, compressor power consumption and $\mathrm{COP}$; along with other parameters of interest as compressor volumetric flow and discharge 
temperature. Both configurations simulation results are shown as relative deviations to that of HFC$245 \mathrm{fa}$ used in the architecture without IHX, to analyse the influence of the low GWP alternatives retrofit with IHX adoption.

\subsubsection{Suction volumetric flow and mass flow rate}

When the condensing temperature is fixed to $145^{\circ} \mathrm{C}, \mathrm{HFO}-1336 \mathrm{mzz}(\mathrm{Z})$ shows the highest increment of relative suction volumetric flow difference up to 95\%, as shown in Fig. 4.6a. In contrast, HCFO$1224 \mathrm{yd}(\mathrm{Z})$ and HCFO-1233zd(E) present an $8 \%$ variation of the suction volumetric flow compared to HFC-245fa. The addition of the IHX reduces the suction volumetric flow around $20 \%$ in all the refrigerants, showing a similar response with the evaporating temperature as shown in Fig. 4.6b.

When the evaporating temperature is set constant to $60{ }^{\circ} \mathrm{C}$, the variable response of this parameter becomes lower than the previous situation. In this case, $\mathrm{HFO}-1336 \mathrm{mzz}(\mathrm{Z})$ has a constant relative increment of $80 \%$, whereas the other refrigerants remain with no significant variations, as shown in Fig. 4.6c. Integrating the IHX, HFO- $1336 \mathrm{mzz}(\mathrm{Z})$ reduces the relative difference significantly, from $80 \%$ to $45 \%$, whereas $\mathrm{HCFO}-1233 \mathrm{zd}(\mathrm{E})$ and $\mathrm{HCFO}-1224 \mathrm{yd}(\mathrm{Z})$ show a relative reduction difference up to $20 \%$ in high condensation temperatures as shown Fig. 4.6d.

Therefore, HCFO-1233zd(E) and HCFO-1224yd(Z) could be working with the existing compressor as possible drop-in replacements for HFC-245fa, whereas $\mathrm{HFO}-1336 \mathrm{mzz}(\mathrm{Z})$ requires higher compressor and installation size than HFC-245fa.

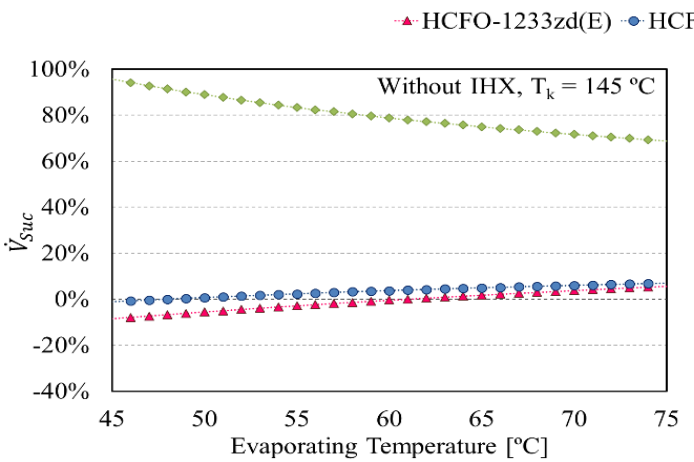

(a)

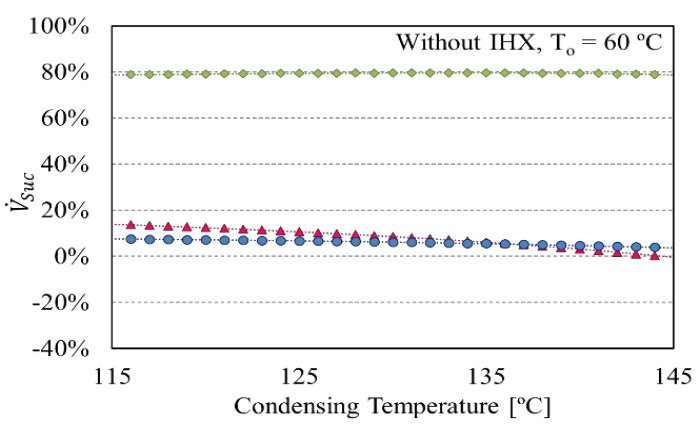

(c)

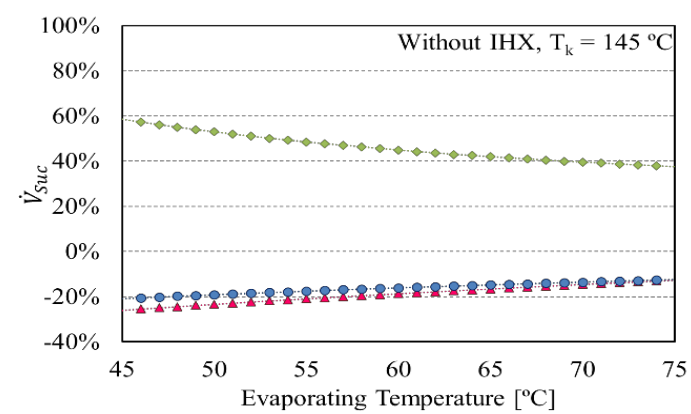

(b)

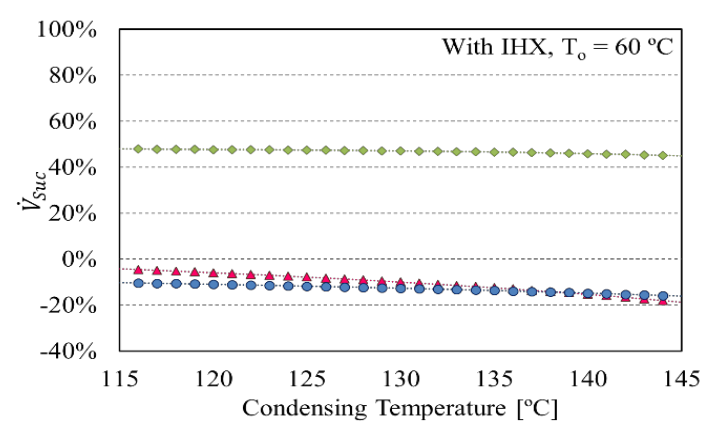

(d)

Fig. 4.6. Relative differences of the suction volumetric flow varying the condensing temperature (a) without IHX, (b) with IHX; and the evaporating temperature (c) without IHX and (d) with IHX. 
Looking at the mass flow rate difference, HCFO-1233zd(E) presents lower values of this parameter in all the operating conditions analysed. The reduction of this parameter ranges between $5 \%$ and $20 \%$ without the IHX and between $12 \%$ and $38 \%$ with it. The other candidates show a slight increase in mass flow rate without IHX, whereas this parameter is comparable or lower than HFC-245fa with the use of IHX, as shown in Fig. 4.7. With a constant cooling capacity, higher values of latent heat of vaporisation would give lower mass flow rates. Thus, the higher latent heat of vaporisation of HCFO$1223 \mathrm{zd}(\mathrm{E})$ compared with the other refrigerants is the primary responsible for this difference with the other refrigerants. This variation of mass flow rate becomes essential for the understanding of the following parameter analysis.

$\star$ HCFO-1233zd(E) * HCFO-1224yd(Z) * HFO-1336mzz(Z)

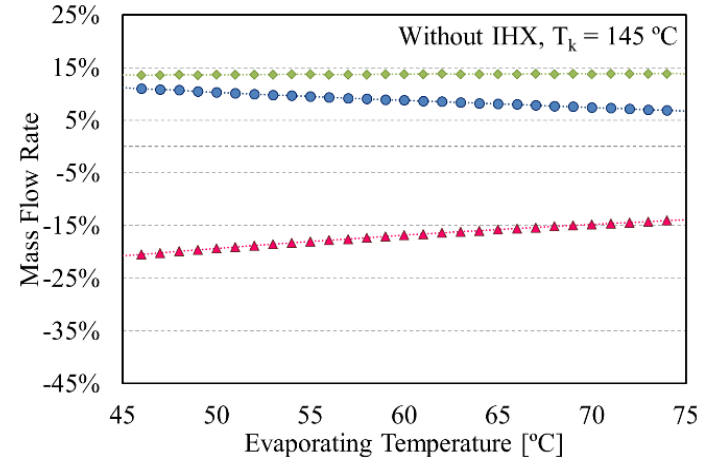

(a)

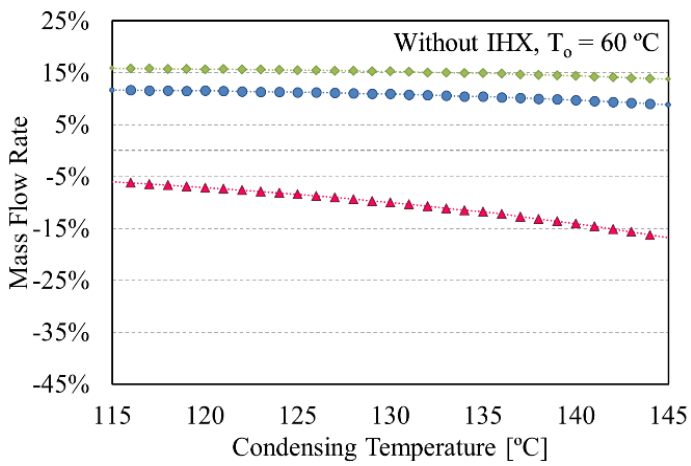

(c)

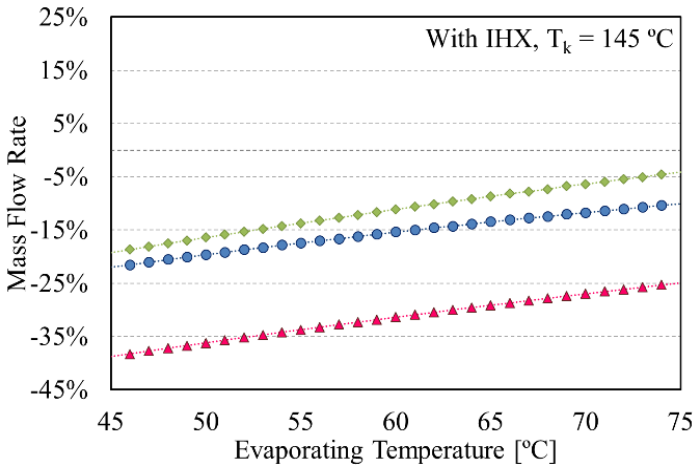

(b)

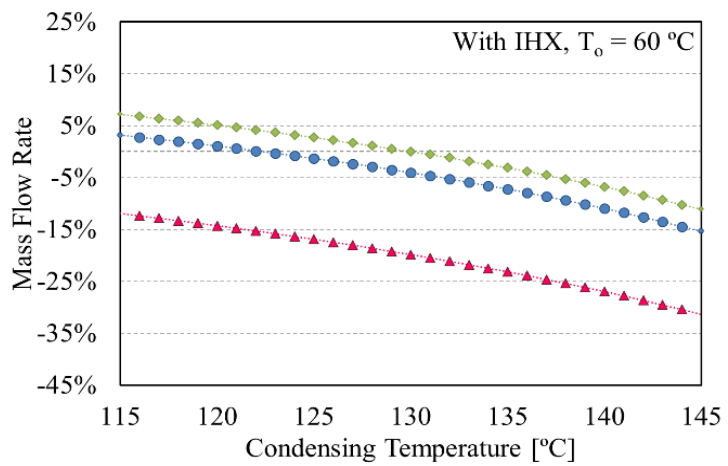

(d)

Fig. 4.7. Relative differences of the mass flow rate varying the condensing temperature (a) without IHX, (b) with IHX; and the evaporating temperature (c) without IHX and (d) with IHX.

\subsubsection{Discharge temperature}

No significant relative variation in the discharge temperature is observed using HCFO-1233zd(E) and HCFO-1224yd( $(Z)$ when the system operates without IHX, as shown Fig. 4.8a and Fig. 4.8b. Nevertheless, HFO-1336mzz(Z) presents a 5\% relative reduction. According to the IHX analyses previously performed, the addition of IHX increases the relative difference of the discharge temperature for $\mathrm{HCFO}-1233 \mathrm{zd}(\mathrm{E})$ and $\mathrm{HCFO}-1224 \mathrm{yd}(\mathrm{Z})$ up to $15 \%$ and $10 \%$, respectively, operating at low evaporation temperatures, as shown in Fig. 4.8b. As for the condensing temperature increase 
with IHX, the relative difference of all refrigerants decreases as shown Fig. 4.7c and 4.7d. This is caused by the lower critical temperature of HFC-245fa compared with the other working fluids.

As mentioned before, these discharge temperature differences are caused by a variation of the specific heat ratio in each refrigerant. HCFO-1233zd(E), with higher values of specific heat ratio, shows the highest discharge temperature relative increase. This fact should be considered in possible drop-in replacements for HFC-245fa.

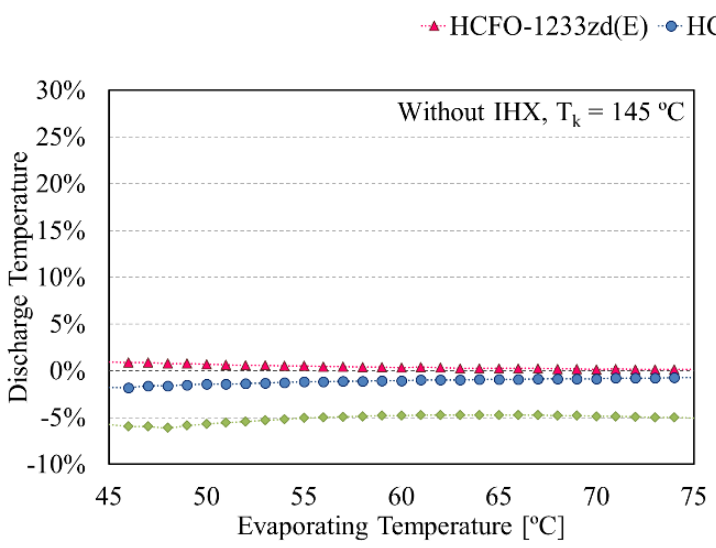

(a)

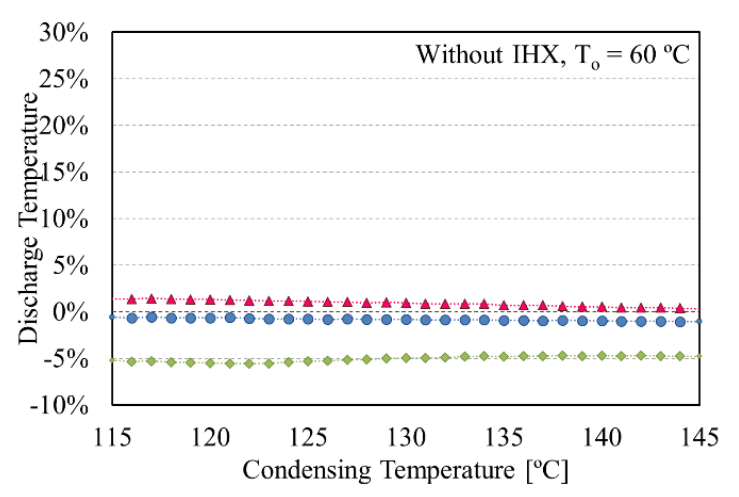

(c)

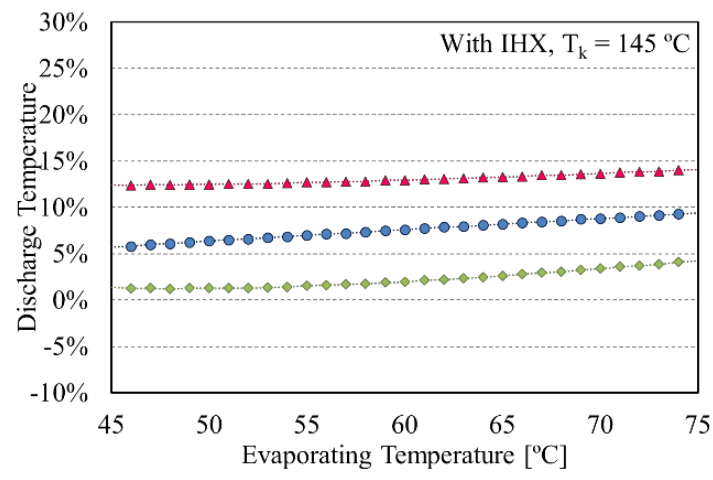

(b)

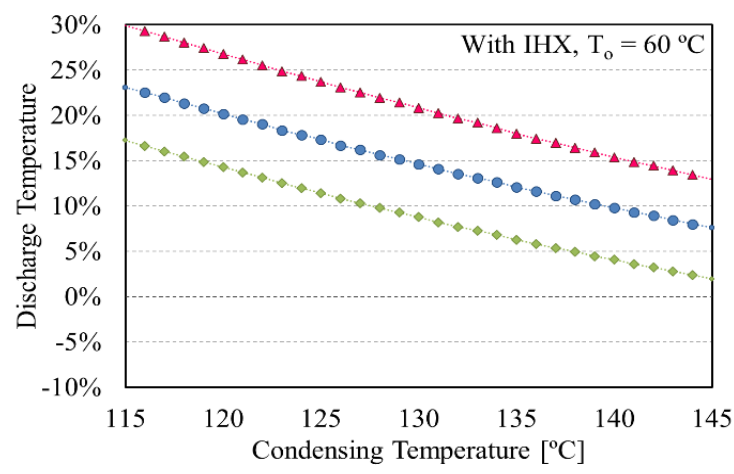

(d)

Fig. 4.8. Relative differences of the discharge temperature varying the condensing temperature (a) without IHX, (b) with IHX; and the evaporating temperature (c) without IHX and (d) with IHX.

\subsubsection{Heating capacity}

The relative variation of the heating capacity with the evaporating and condensing temperatures, with and without IHX is shown in Fig. 4.9. This parameter is a consequence of the latent heat of condensation and the mass flow rate, presented before. HFO-1336mzz(Z) and HCFO-1224yd(Z) present a $4 \%$ relative decrease with a constant condensing temperature of $145{ }^{\circ} \mathrm{C}$, as shown in Fig. 4.9a. Besides, HCFO-1233zd(E) shows an 11\% heating capacity reduction compared to HFC-245fa, which becomes lower as the evaporating temperature increases. The IHX adoption reduces the relative heating capacity difference of the considered low GWP alternatives significantly. When lower evaporating temperatures are considered, the relative difference of the heating capacity 
increases with the evaporating temperatures, as shown in Fig. 4.9b. The reduction of heating capacity for HFO-1336mzz(Z) and HCFO-1224yd(Z) is more sensitive to the adoption of IHX than HCFO$1233 z d(E)$, as mentioned above in section 4.2.

Setting the evaporating temperature at $60{ }^{\circ} \mathrm{C}$ and varying the condensing temperature, minimum relative heating capacity differences are appreciated for $\mathrm{HFO}-1336 \mathrm{mzz}(\mathrm{Z})$ and $\mathrm{HCFO}-1224 \mathrm{yd}(\mathrm{Z})$, as shown in Fig. 4.9c. Nevertheless, HCFO-1233zd(E) presents a $6 \%$ relative difference at high condensation temperatures. Adding the IHX, all the alternatives reduce the heating capacity, compared to the reference, as the condensing temperature increases, from $2 \%$ to $10 \%$ approximately, as shown in Fig. 4.9d.

$\triangle \mathrm{HCFO}-1233 \mathrm{zd}(\mathrm{E}) \cdot \mathrm{HCFO}-1224 \mathrm{yd}(\mathrm{Z}) \cdot \mathrm{HFO}-1336 \mathrm{mzz}(\mathrm{Z})$

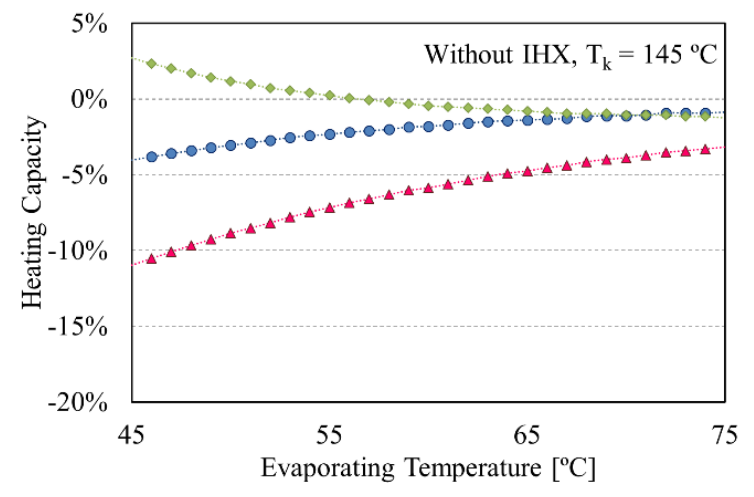

(a)

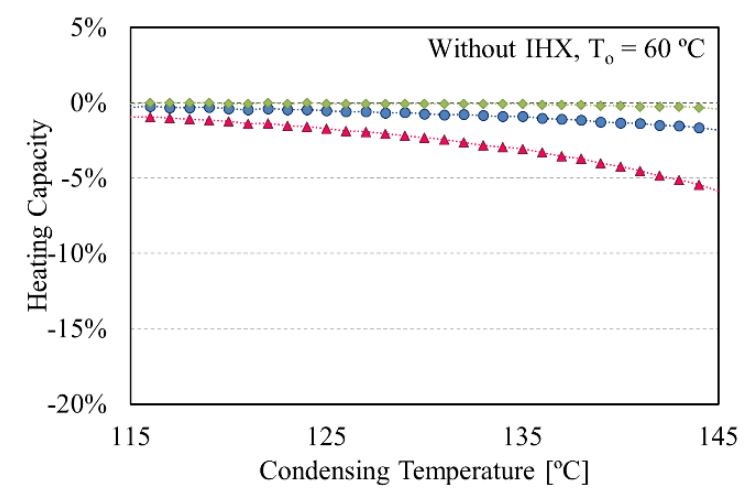

(c)

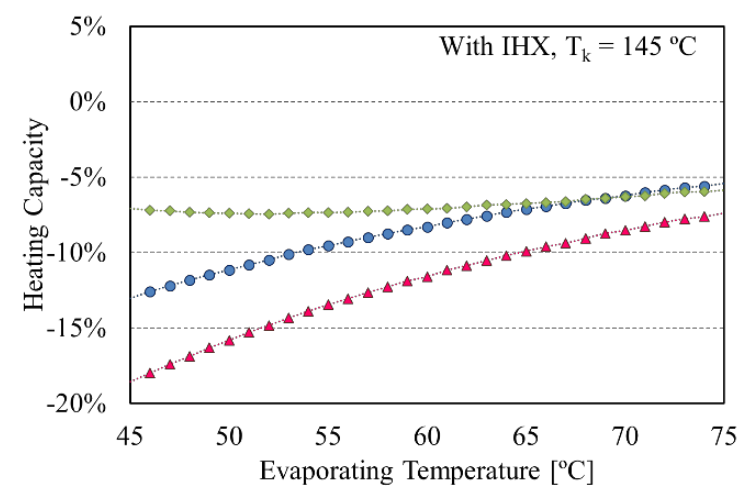

(b)

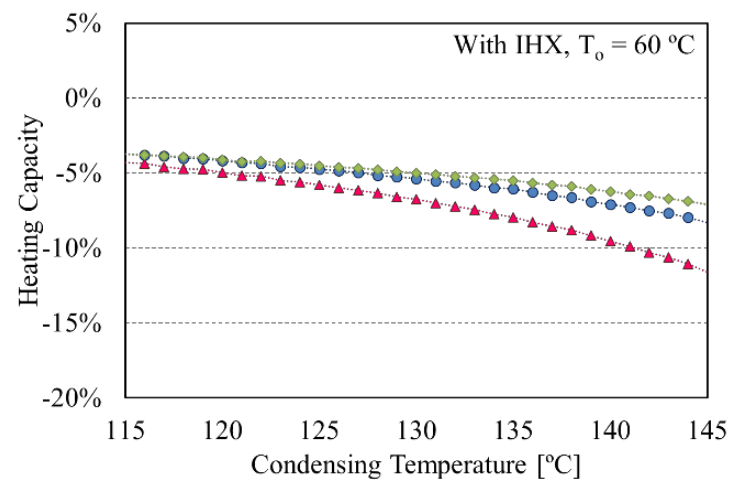

(d)

Fig. 4.9. Relative differences of the heating capacity varying the condensing temperature (a) without IHX, (b) with IHX; and the evaporating temperature (c) without IHX and (d) with IHX.

Due to the mass flow rate difference of the alternatives compared to HFC-245fa in most of the operating points, the heating capacity becomes lower. In some refrigerants, this heating reduction could be compensated with a higher latent heat of condensation, providing better heating capacity than the other refrigerants. 


\subsubsection{Compressor power consumption}

The compressor power consumption is proportional to the mass flow rate and the slope of the isentropic line of each refrigerant. As each refrigerant has a similar slope, the mass flow rate variation would be the main factor influencing the compressor power consumption.

Fig. 4.10 shows the relative compressor power consumption difference in comparison to the reference fluid.

$\star \mathrm{HCFO}-1233 \mathrm{zd}(\mathrm{E}) \cdot \mathrm{HCFO}-1224 \mathrm{yd}(\mathrm{Z}) * \mathrm{HFO}-1336 \mathrm{mzz}(\mathrm{Z})$

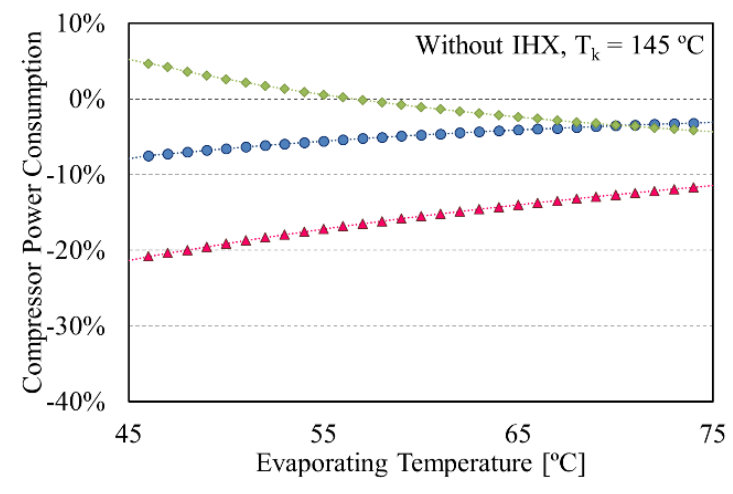

(a)

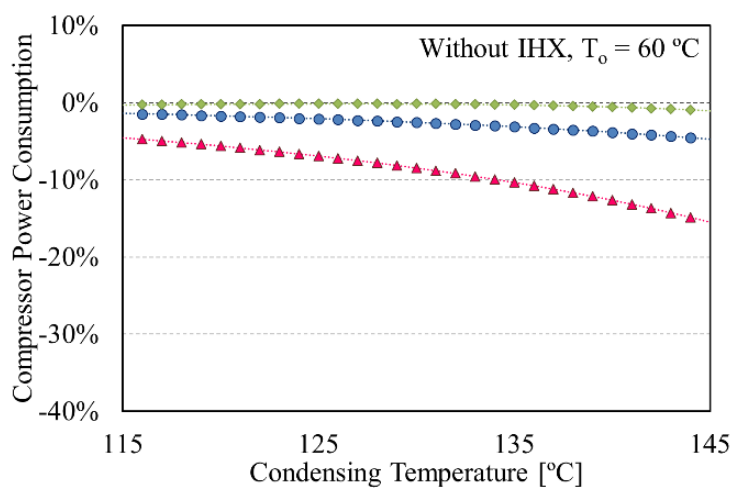

(c)

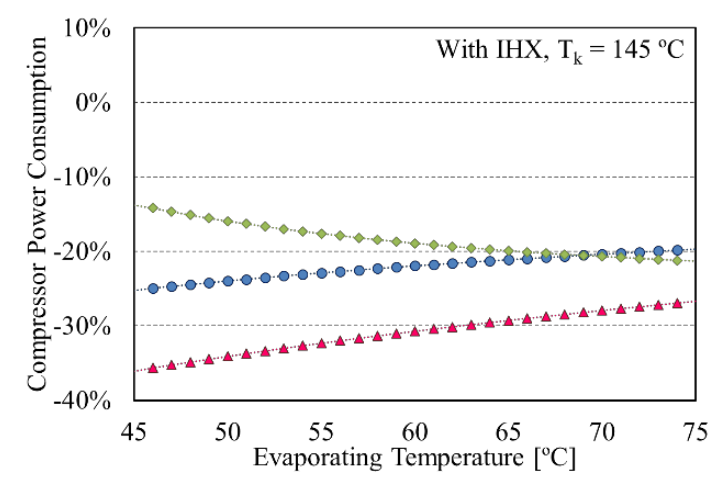

(b)

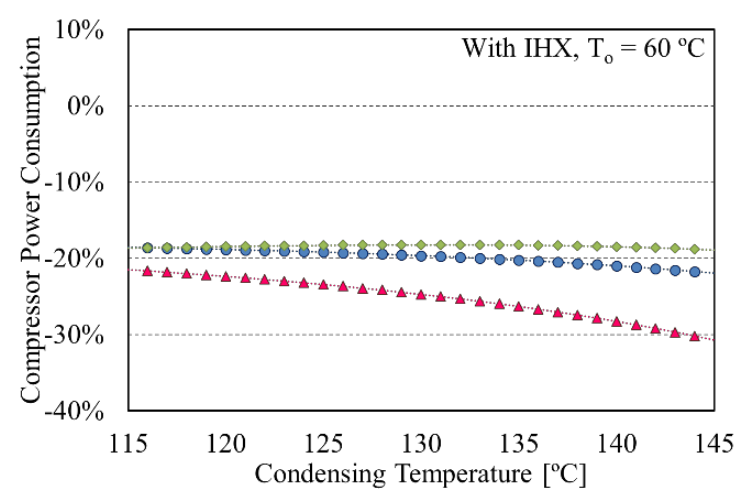

(d)

Fig. 4.10. Relative differences of the compressor power consumption varying the condensing temperature (a) without IHX, (b) with IHX; and the evaporating temperature (c) without IHX and (d) with IHX.

In this case, with a constant condensing temperature of $145^{\circ} \mathrm{C}, \mathrm{HCFO}-1233 \mathrm{zd}(\mathrm{E})$ presents the highest reduction, going from $12 \%$ to $20 \%$ as the evaporating temperature increases. This is caused due to the mass flow rate reduction of HCFO-1233zd(E) compared to the reference HFC-245fa. Considering low evaporating temperatures, $\mathrm{HFO}-1336 \mathrm{mzz}(\mathrm{Z})$ shows an increase of the relative difference, whereas HCFO-1224yd(Z) reduces it. Nevertheless, the HCFO-1224yd(Z) trend increases for higher evaporating temperature while the $\mathrm{HFO}-1336 \mathrm{mzz}(Z)$ trend decreases, becoming slightly above that of $\mathrm{HCFO}-1224 \mathrm{yd}(\mathrm{Z})$ at high evaporating temperatures, as shown Fig. 4.10a. All the refrigerants reduce the relative compressor power consumption difference when the IHX integration is 
considered. Fig. 4.10b shows that this reduction becomes more significant for HCFO-1233zd(E) and HCFO-1224yd(Z) at low evaporating temperatures, $35 \%$ and $25 \%$, respectively. However, as the evaporating temperature increases, $\mathrm{HCFO}-1233 \mathrm{zd}(\mathrm{E})$ and $\mathrm{HCFO}-1224 \mathrm{yd}(\mathrm{Z})$ reduce the relative difference around $8 \%$, whereas for $\mathrm{HFO}-1336 \mathrm{mzz}(\mathrm{Z})$ is between $12-22 \%$, as the evaporating temperature increase.

At a constant evaporating temperature of $60^{\circ} \mathrm{C}$, Fig. $4.10 \mathrm{c}$ shows that HFO-1336mzz(Z) and HCFO$1224 \mathrm{yd}(\mathrm{Z})$ present no significant variation of the relative difference whereas HCFO-1233zd(E) decrease this relative compressor power consumption difference from $5 \%$ to $17 \%$ as the condensing temperature increase. Finally, Fig. 4.10d illustrates a significant reduction of the relative difference around $20 \%$ for each refrigerant with the use of IHX. A similar evolution of power consumption than without IHX is observed as the condensing temperature increase.

\subsubsection{Coefficient of Performance (COP)}

The relative differences in the COP presented in Fig. 4.11 show that each alternative refrigerant has the same or even more performance than the reference HFC-245fa. HCFO-1233zd(E) presents the highest values of improvement, followed by the HCFO-1224yd(Z). Varying the evaporation temperature without IHX, the variation of HCFO-1233zd(E) goes from $10 \%$ to $14 \%$ as the evaporating temperature increase. In contrast, HCFO-1224yd(Z) and HFO-1336mzz(Z) have a variation below 5\%, as shown in Fig. 4.11a. The addition of IHX increases the relative difference from $14 \%$ to $27 \%$ in low evaporating temperatures for HCFO-1233zd(E), achieving similar values at the highest condition. Similar behaviour is observed for HCFO-1233zd(E), with $10 \%$ lower COP difference than HCFO-1233zd(E). Finally, HFO-1336mzz(Z) shows $7 \%$ increment of the relative difference of COP. However, instead of remaining constant for an increment of the evaporating temperature, this relative difference increases. At the highest evaporating temperatures, HFO$1336 \mathrm{mzz}(\mathrm{Z})$ presents the higher relative difference of COP than HCFO-1224yd(Z).

With a constant evaporating temperature of $60^{\circ} \mathrm{C}$, the variation of condensing temperature shows lower improvement in the relative COP difference than the previous case. Whereas HFO-1336mzz(Z) and $\mathrm{HCFO}-1224 \mathrm{yd}(\mathrm{Z})$ present no significant variations, HCFO-1233zd(E) improves this relative difference from $4 \%$ to $11 \%$ as the condensing temperature increases, as shown Fig. 4.11c. Looking 
to the use of IHX in these conditions, each refrigerant shows similar evolution than without IHX, but a $17 \%$ relative increase of COP is observed, as shown Fig. 4.11d.

$\star$ HCFO-1233zd(E) $\bullet \cdot$ HCFO-1224yd(Z) $*$ HFO-1336mzz(Z)

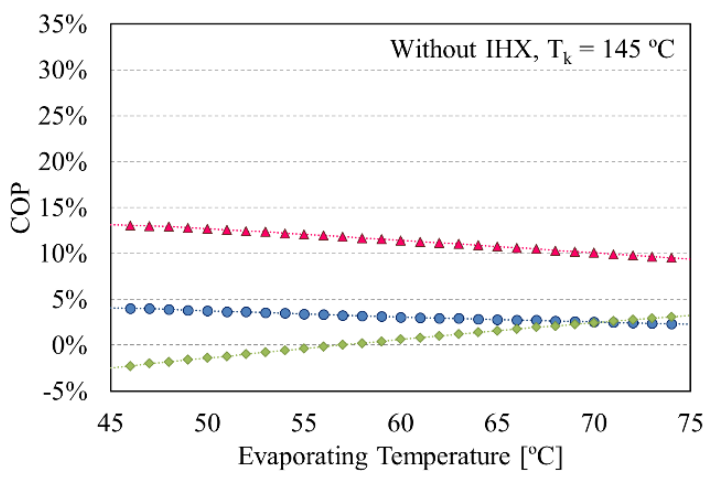

(a)

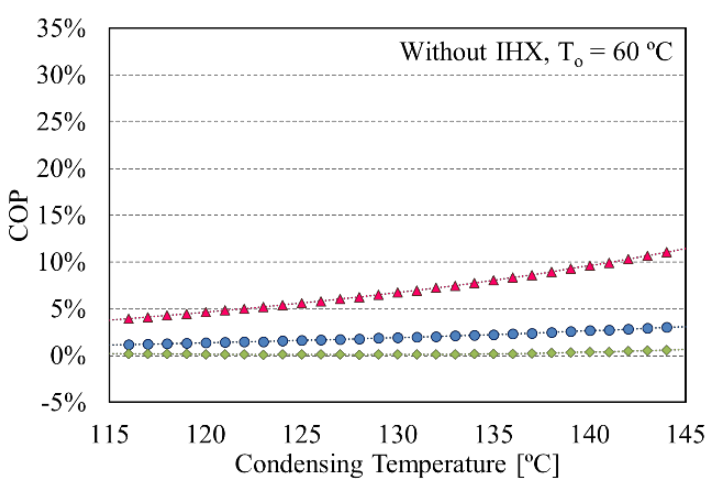

(c)

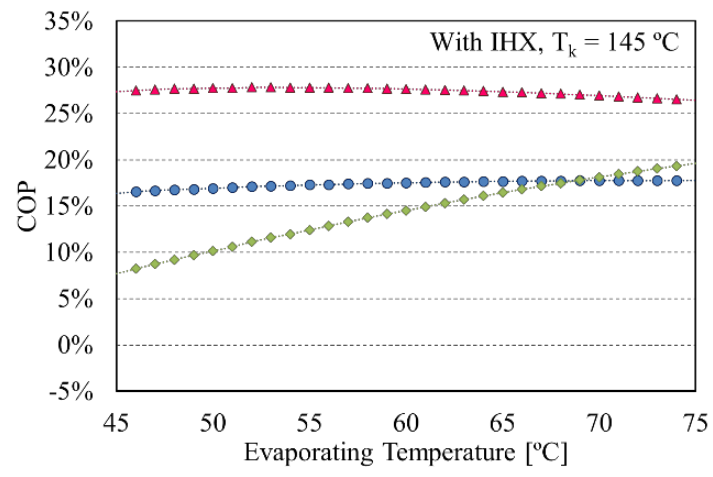

(b)

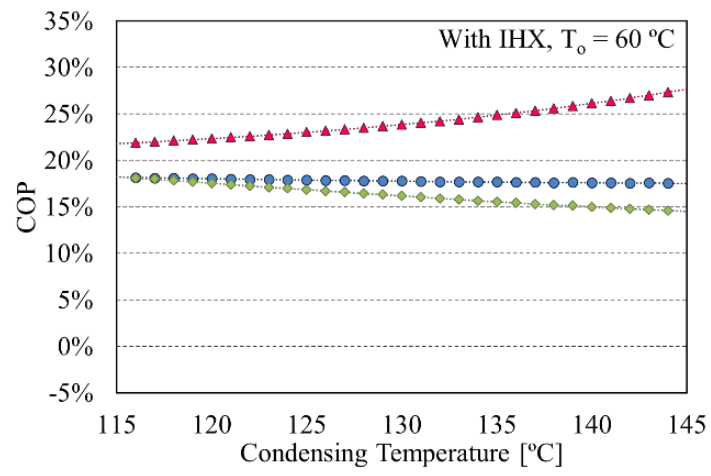

(d)

Fig. 4.11. Relative differences of the COP varying the condensing temperature (a) without IHX, (b) with IHX; and the evaporating temperature (c) without IHX and (d) with IHX.

Therefore, HFCO-1233zd(E) presents a significant energy performance improvement compared to HFC-245fa with and without IHX, being higher with IHX is integrated. Otherwise, HCFO-1224yd(Z) and HFO-1336mzz(Z) have comparable COP to HFC-245fa operating without IHX, whereas a significant COP increment could be appreciated with IHX. Finally, HFO-1336mzz(Z) shows performance improvements when the evaporating temperature increases, and therefore, this refrigerant would be appropriate for high source temperatures.

\subsubsection{Heat transfer analysis}

The thermodynamic and transport properties of each refrigerant influence the pressure drop and heat transfer in the heat exchangers of the system. An adequate comparison of both parameters under the same conditions provides useful information about its required size. This analysis can be carried out separating the independent terms in heat transfer and pressure drop correlations, (corresponding to the installation characteristics), and form what is called the figure of merit (FOM). This method for 
visualising the heat transfer and pressure drop difference was used by Palm to compare several hydrocarbons refrigerants [37]. The development of the FOM equations can be consulted in this work.

The FOM for pressure drop in a single-phase turbulent flow can be expressed, as shown in Eq. (4.10). Hence, lower $F O M_{\triangle p}$ value explains that a lower pressure drop should be expected.

$$
F O M_{\Delta p}=\frac{\mu^{1 / 4}}{\rho h_{f g}^{7 / 4}}
$$

This FOM shows that the pressure drop is influenced not only by the viscosity and that the latent heat of vaporisation is even more critical because it determines the required mass flow rate for certain cooling capacity and density. In Table 4.3, FOM $\triangle p$ is given for liquid and vapor phase at $130{ }^{\circ} \mathrm{C}$. For the liquid phase, HCFO-1233zd(E) and HFO-1336mzz(Z) show $20 \%$ and $12 \%$ lower values of $F O M_{\Delta p}$ compared to HFC-245fa, respectively, due to their higher latent heat of vaporization and liquid density. In contrast, the lower heat of vaporisation of the HCFO-1224yd(Z) seems the main responsible for the considerably higher values of $F O M_{\Delta p}$, showing that, for the same heat exchanger and heat flow, the pressure drop would be notably higher for HCFO-1224yd(Z) and lower for the other alternatives. Looking at the vapour phase, all the alternatives show higher $F O M_{\triangle p}$ than HFC$245 \mathrm{fa}$, therefore, significantly higher pressure drop would be expected for the refrigerants proposed. The main responsible for this behaviour seems to be the lower vapour density of the alternatives compared with the reference fluid.

Similarly, the convective heat transfer is evaluated using the FOMs derivate from the Dittus-Boelter equation for single turbulent phase as shown in Eq. (4.11).

$$
F O M_{S P H T}=\frac{k P r^{0.4}}{\left(h_{f g} \mu\right)^{0.8}}
$$

In contrast to the previous FOM, higher values of this parameter indicate better heat transfer. This parameter has been calculated for liquid and vapour phases, and the values are included in Table 4.3. Looking at both phases at the same time, the alternative refrigerant have lower $F O M_{S P H T}$ and, therefore, the heat transfer in single phase of the candidates would be lower than the reference fluid HFC-245fa. It seems that the lower thermal conductivity of the alternative refrigerants in liquid and vapour phase should be the main responsible for this lower heat transfer.

In vapour compression systems, heat transfer in boiling and condensation is more critical than singlephase. Thus, using Cooper's pool boiling correlation and assuming a surface roughness of $1 \mu \mathrm{m}$, the FOM presented in Eq. (4.12) is derived.

$$
\text { FOM } M_{p b}=p_{r}^{0.12}\left(-\log _{10} p_{r}\right)^{-0.55} M^{-0.5}
$$

Similarly, high values of this parameter indicate a high pool boiling heat transfer coefficient. Looking at Table 4.3, HFC-245fa shows higher pool boiling heat transfer than the alternatives. The higher molecular weight and lower reduced pressure of the other refrigerants compared to HFC-245fa would lower the pool boiling heat transfer, as Eq. (4.12) illustrates. 
In conclusion, the comparison of expected pressure drop and heat transfer performance using FOMs indicates that the alternatives proposed have a lower heat transfer compared to HFC-245fa. Among the three low GWP refrigerants discussed, HFO-1336mzz(Z) and HCFO-1233zd(E) have a lower pressure drop in a liquid phase, whereas HCFO-1224yd(Z) shows higher values of this parameter. Finally, all the candidates have a higher pressure drop in the vapour phase than HFC-245fa. The values are calculated for the temperature of $130^{\circ} \mathrm{C}$, but the relation between the values is the same at $60{ }^{\circ} \mathrm{C}$.

Table 4.3. Transport properties and figures of merit at $130^{\circ} \mathrm{C}$

\begin{tabular}{l|llll}
\hline Refrigerant & HFC-245fa & $\begin{array}{l}\text { HFO- } \\
1336 \mathrm{mzz}(\mathrm{Z})\end{array}$ & $\begin{array}{l}\text { HCFO- } \\
1233 \mathrm{zd}(\mathrm{E})\end{array}$ & $\begin{array}{l}\text { HCFO- } \\
1224 \mathrm{yd}(\mathrm{Z})\end{array}$ \\
\hline $\begin{array}{l}\text { Liquid/Vapour thermal } \\
\text { conductivity }\left(\mathbf{W} \cdot \mathbf{m}^{-\mathbf{1 . 0}} \mathbf{C}^{-1}\right)\end{array}$ & $55.50 / 23.38$ & $51.39 / 21.23$ & $54.59 / 21.91$ & $46.82 / 20.54$ \\
$\begin{array}{l}\text { Liquid/ Vapour viscosity } \\
(\boldsymbol{\mu P a} \cdot \mathbf{s})\end{array}$ & $94.82 / 15.33$ & $\begin{array}{l}108.00 / \\
14.14\end{array}$ & $94.35 / 14.01$ & $82.13 / 15.64$ \\
FOM $_{\Delta \mathbf{p}, \mathbf{l}}$ & 11.04 & 9.65 & 8.78 & 12.91 \\
FOM $_{\Delta \mathbf{p}, \mathbf{v}}$ & 42.1 & 61.1 & 44.5 & 52.8 \\
FOM $_{\text {SPHT,I }}$ & 2.42 & 1.92 & 2.00 & 2.37 \\
FOM $_{\text {SPHT,v }}$ & 3.14 & 2.41 & 2.34 & 2.75 \\
FOM $_{\mathbf{p b}}$ & 0.203 & 0.131 & 0.164 & 0.189 \\
\hline
\end{tabular}

\subsection{Guideline for the optimal refrigerant selection}

When selecting a working fluid, several parameters must be considered at the same time. Therefore, a mapping of the relative deviation of the alternative refrigerants to the baseline refrigerant for the main energetic parameters, $\mathrm{COP} / \mathrm{COP}_{\text {ref }}$ and $\mathrm{VHC} / \mathrm{VHC}_{\text {ref, }}$, have been performed to suggest the optimal refrigerant for each application.

Looking at the energetic performance, HCFO-1233zd(E) and HCFO-1224yd(Z) are comparable, providing the highest $\mathrm{COP}$ at low evaporating and high condensing temperatures. Nevertheless, it is expected to be reduced as the evaporating temperature increases or the condensing temperature decreases. In contrast, HFO-1336mzz(Z) has a different response than the other alternatives. This refrigerant has the lowest $\mathrm{COP}$ with low evaporating and high condensing temperatures, but as the evaporating temperature increases, the COP of HFO-1336mzz(Z) also increases. Moreover, a variation of the condensing temperature has no practical influence on the COP of this refrigerant, as shown in Fig. 4.12a.

On the other hand, the VHC of HCFO-1233zd(E) has similar behaviour to its COP, Fig. 4.12b. The high-performance zone also has closer VHC to that of HFC-245fa. Therefore, its optimal zone would be low evaporating and high condensing temperatures. Similarly, HCFO-1244yd(Z) has the same behaviour to the previous refrigerant mentioned, but its VHC is comparable to HFC-245fa. Therefore, 
a similar compressor and installation size could be used. Finally, HFO-1336mzz(Z) results in the lowest VHC, which indicates that a larger compressor size is required to provide the same amount of heat.

In conclusion, HCFO-1233zd(E) and HCFO-1224yd(Z) would be the optimal refrigerants for low heat source temperature and high-temperature heating production applications. Moreover, these refrigerants are highly sensitive to a heat source or heat sink temperature variation. Therefore, stable temperatures operation temperatures are recommended. On the other hand, HFO-1336mzz(Z) would be the optimal refrigerant when there is a high heat source temperature. Moreover, it could provide different heat production temperatures with similar COP and VHC. Thus, it would be recommended for applications where a range of heat production temperature is necessary at constant heat source temperature.
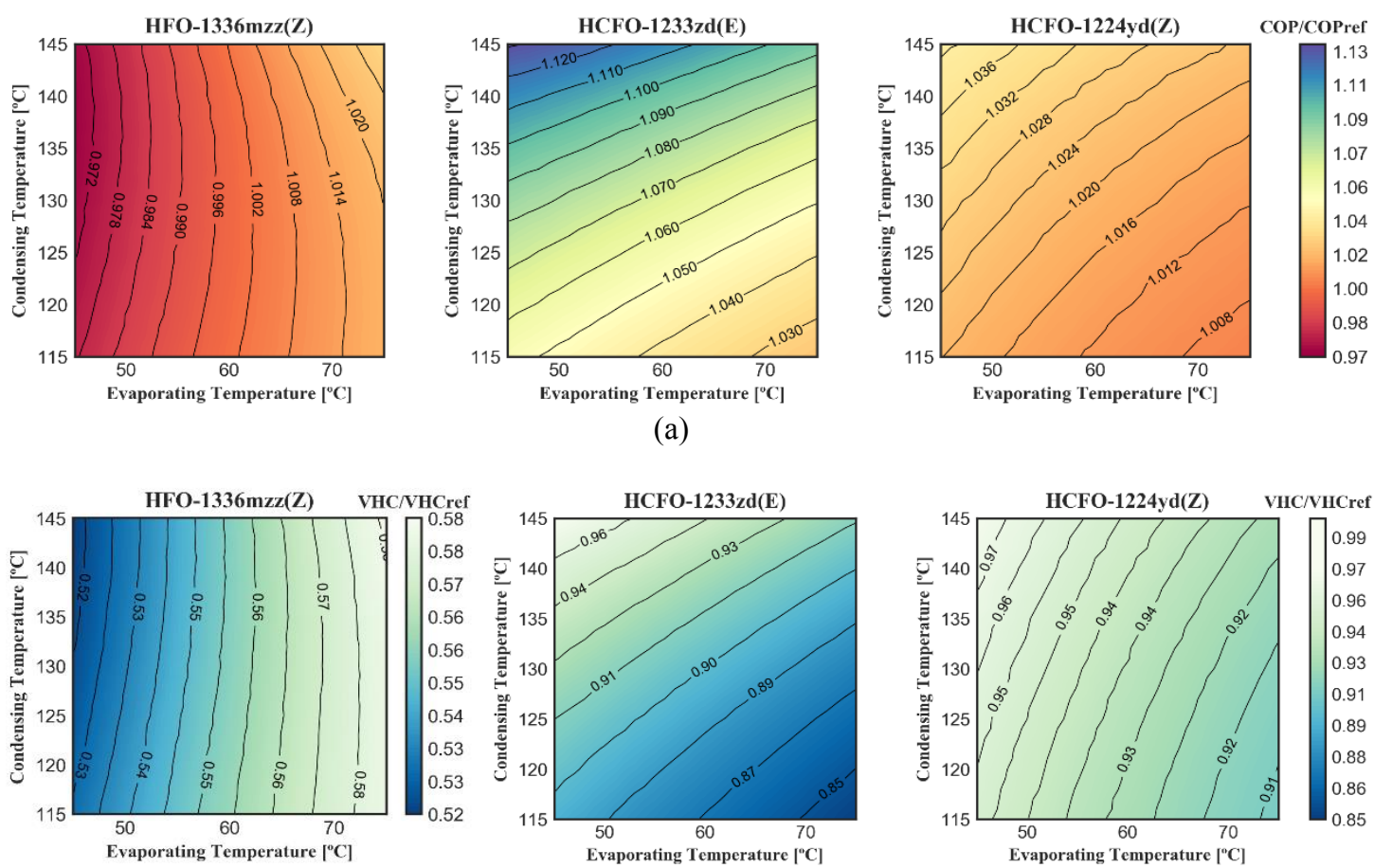

(b)

Fig. 4.12. Mapping of the guideline operating conditions of the alternative refrigerant: a) $\mathrm{COP} / \mathrm{COP}$ ref and b)

$$
\mathrm{VHC} / \mathrm{VHC}_{\text {ref. }}
$$

\subsection{Total Equivalent Warming Impact (TEWI) evaluation}

To analyse in profound the benefits of the proposed low GWP alternatives, an environmental impact evaluation that includes the effect of refrigerant leakage and energy consumption becomes necessary. Thus, the Total Equivalent Warming Impact (TEWI) of each refrigerant has been calculated to quantify the equivalent $\mathrm{CO}_{2}$ emission due to the accidental losses of refrigerant (direct emissions) and to the energy consumption of the HTHP system (indirect emissions). This method gives an appropriate approximation to the real environmental impact of vapour compression systems, and it is easy to apply. TEWI method is based on Eq. $(4.13)[33,38]$. 
Chapter 4

$$
T E W I=G W P \cdot L \cdot n+G W P \cdot m_{r} \cdot(1-\alpha)+n \cdot E_{a} \cdot \beta
$$

Previous research that includes TEWI analysis has been found in refrigeration and heat pump systems, but not in HTHPs. Therefore, this paper proposes some necessary assumptions that can be considered in this application. The constant condensing temperature of $145^{\circ} \mathrm{C}$ and three different evaporating temperatures, 45,60 and $75^{\circ} \mathrm{C}$, have been analysed. The HTHP evaporator exchanges $100 \mathrm{~kW}$ waste heat during 7884 hours per year ( $90 \%$ of the time). The lifespan of the system $(n)$ is considered 15 years.

The IPCC recommended annual leakage rate for indirect refrigeration systems contained in machinery rooms is $5 \%$ of the total refrigerant charge [39], and due to its similarity, this value is also considered for HTHPs systems in this application. The recycling factor of the refrigerant $(\alpha)$ is omitted for this comparison. Finally, the indirect emission factor $(\beta)$ value is taken from the one proposed for the European Union by the European Environment Agency, $275.9 \mathrm{~g} \mathrm{CO}_{2} \mathrm{kWh}^{-1}$ [40].

Fig. 4.13 shows the total equivalent $\mathrm{CO}_{2}$ emissions using each refrigerant for a constant condensing temperature, with and without IHX and for three different evaporating temperatures. Moreover, the resulting reduction in emissions using the alternatives compared to the reference fluid, HFC-245fa, is presented in the figure. HFCO-1233zd(E) achieves the highest reduction, between 45 and $61 \%$, followed by HFC-1224yd(Z). Although HCFO-1233zd(E) and HCFO-1224yd(Z) present similar suction volumetric flow rate to HFC-245fa, HFO-1336mzz(Z). The highest reductions are seen operating at high evaporation temperatures due to the greater improvement of COP. Moreover, the IHX addition is more significant at low evaporation temperatures, achieving emission reductions between 1 and $7 \%$, depending on the refrigerant.

Thus, the TEWI evaluation shows that HCFO-1224yd(Z), HCFO-1233zd(E) and HFO-1336mzz(Z) obtain a significant total equivalent $\mathrm{CO}_{2}$ emissions reduction compared to the reference fluid HFC$245 \mathrm{fa}$ because their direct emissions are negligible, and the indirect ones are mostly lower. Therefore, the utilisation of these low GWP alternatives can positively contribute to climate change mitigation. 


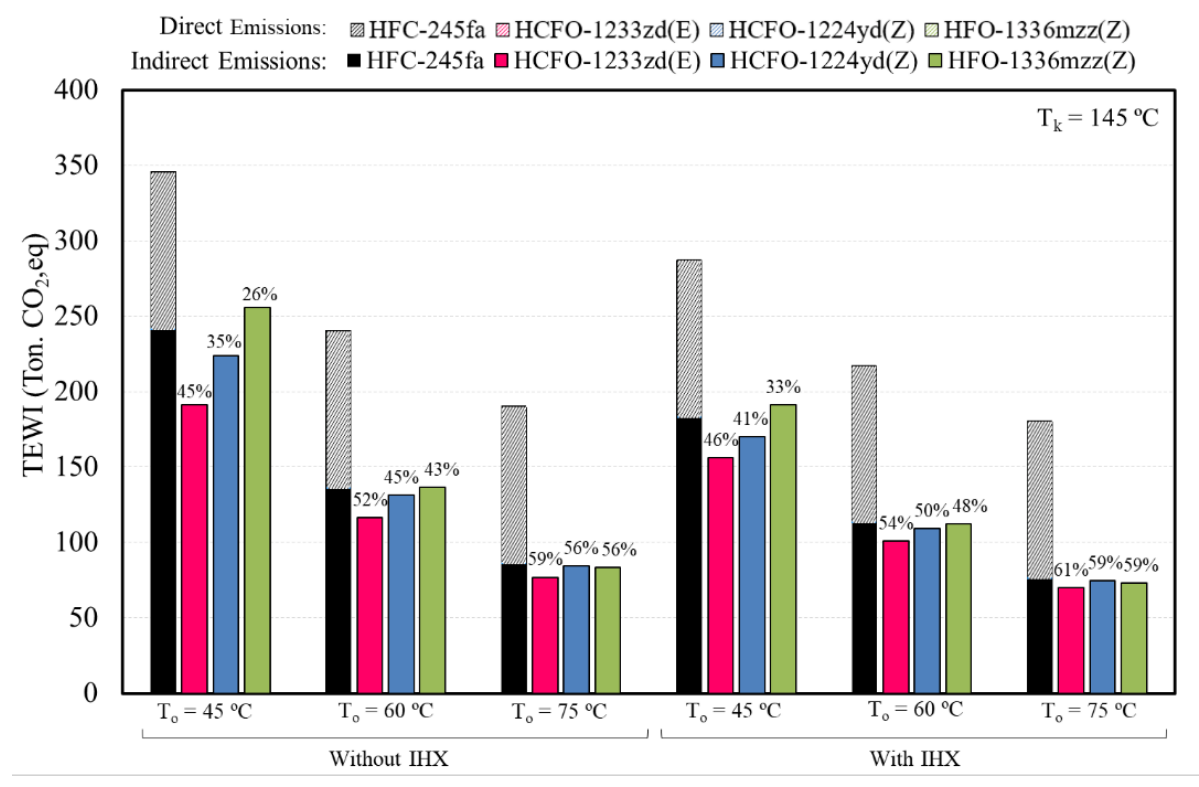

Fig. 4.13. TEWI at a constant condensing temperature of $145^{\circ} \mathrm{C}$ and percentage reduction of the total equivalent $\mathrm{CO} 2$ emissions for the low GWP alternatives compared to the reference fluid HFC-245fa.

\subsection{Conclusions}

This paper presented a preliminary thermodynamic study of the new low GWP alternatives HCFO1233zd(E), HCFO-1224yd(Z) and HFO-1336mzz(Z) for the replacement of HFC-245fa in HTHPs for low-grade waste heat recovery. Considering the lack of research for these refrigerants in this application, this paper includes a study of the properties and a discussion of the theoretical results using a single-stage cycle and IHX configuration. Moreover, the minimum superheat required for each refrigerant, and the IHX sensibility has been analysed, then included in a refrigerant guideline and the environmental impact analysis.

Alternative refrigerants present comparable thermodynamic and transport properties to HFC-245fa. Their higher critical temperature allows the increase of the heating production temperature in possible future developments. The mapping of the minimum superheat requirement to ensure a dry compression show comparable values for HCFO-1233zd(E) and HCFO-1224yd(Z) with 7.1 and 4.4 $\mathrm{K}$, respectively. Nevertheless, HFO-1336mzz(Z) requires a minimum superheat of $19.2 \mathrm{~K}$. The IHX presents comparable response for HFC-245fa, HCFO-1224yd(Z) and HFO-1336mzz(Z), whereas higher benefit in COP is observed for HCFO-1233zd(E).

The simulation analysis has been carried out using a single-stage cycle with and without IHX, varying the evaporating temperature from 45 to $75^{\circ} \mathrm{C}$ and the condensing temperature from 115 to $145^{\circ} \mathrm{C}$. The conclusions reached from the simulation results favour the utilisation of refrigerants considered. HCFO-1233zd(E) improves the COP about 27\%, whereas HFO-1336mzz(Z) and HCFO-1224yd(Z) show an improvement of about 21 and 17\%, respectively. HFO-1336mzz(Z) shows a relative increment up to $80 \%$, and therefore, higher compressor and installation size are expected for this refrigerant than the reference fluid. 
Finally, the optimal operation for HCFO-1233zd(E) and HCFO-1224yd(Z) would be located at constant heat source temperatures and higher heating production temperature. HFO-1336mzz(Z) could provide different heat production temperatures with similar COP. The TEWI analysis presents an approximate reduction of $60 \%$ of the equivalent $\mathrm{CO}_{2}$ emissions for the low GWP alternatives, being HCFO-1233zd(E) the refrigerant with the highest reduction.

\section{References}

[1] United Nations. The Paris Agreement (English version). Available at: $\mathrm{Http} / / /$ UnfcccInt/Files/Essential_background/Convention/Application/Pdf/English_paris_agr eement 2015.

[2] IPCC. Climate Change 2014: Synthesis Report. Contribution of Working Groups I, II and III to the Fifth Assessment Report of the Intergovernmental Panel on Climate Change [Core Writing Team, R.K. Pachauri and L.A. Meyer (eds.)]. Geneva, Switzerland, 2014.

[3] Forman C, Muritala IK, Pardemann R, Meyer B. Estimating the global waste heat potential. Renew Sustain Energy Rev 2016;57:1568-79. doi:10.1016/j.rser.2015.12.192.

[4] Eisa MAR, Best R, Holland FA. Working fluids for high temperature heat pumps. J Heat Recover Syst 1986;6:305-11. doi:10.1016/0198-7593(86)90116-5.

[5] Linton JW. Description and Test Results of a High Temperature Heat Pump Test Facility. Heat Pumps, 1990, p. 455-65. doi:10.1016/B978-0-08-040193-5.50055-9.

[6] Linton JW, Snelson WK. An Overview of Current High Temperature Heat Pump Technology. Heat Pumps Energy Effic. Environ. Prog., 1993, p. 217-27. doi:10.1016/B978-0-444-815347.50031-0.

[7] United Nations. Montreal Protocol on Substances that Deplete the Ozone Layer. United Nations, New York, NY, USA 1987.

[8] Brown J. Potential R-114 replacement refrigerants. ASHRAE Trans 2008.

[9] Arpagaus C, Bless F, Uhlmann M, Schiffmann J, Bertsch SS. High temperature heat pumps: Market overview, state of the art, research status, refrigerants, and application potentials. Energy 2018;152:985-1010. doi:10.1016/J.ENERGY.2018.03.166.

[10] The European Parliament and the Council of the European, Union. Regulation (EU) No $517 / 2014$ of the European Parliament and the Council of 16 April 2014 on fluorinated greenhouse gases and repealing Regulation (EC). No 842/2006 Off J Eur Union 150, 195-230 2014.

[11] Calm JM. The next generation of refrigerants - Historical review, considerations, and outlook. Int J Refrig 2008;31:1123-33. doi:10.1016/j.ijrefrig.2008.01.013.

[12] Bamigbetan O, Eikevik TM, Nekså P, Bantle M. Review of vapour compression heat pumps for high temperature heating using natural working fluids. Int J Refrig 2017;80:197-211. doi:10.1016/j.ijrefrig.2017.04.021.

[13] Brown JS, Zilio C, Cavallini A. The fluorinated olefin R-1234ze(Z) as a high-temperature heat pumping refrigerant. Int J Refrig 2009;32:1412-22. doi:10.1016/j.jirefrig.2009.03.002. 
[14] Fukuda S, Kondou C, Takata N, Koyama S. Low GWP refrigerants R1234ze(E) and R1234ze(Z) for high temperature heat pumps. Int $J$ Refrig 2014;40:161-73. doi:10.1016/j.jirefrig.2013.10.014.

[15] Kondou C, Koyama S. Thermodynamic assessment of high-temperature heat pumps using low-GWP HFO refrigerants for heat recovery. Int J Refrig 2015;53:126-41. doi:10.1016/j.jirefrig.2014.09.018.

[16] Mota-babiloni A, Navarro-esbrí J, Molés F. A review of refrigerant R1234ze ( E ) recent investigations. Appl Therm Eng 2016;95:211-22. doi:10.1016/j.applthermaleng.2015.09.055.

[17] Kontomaris K. A zero-ODP, low GWP working fluid for high temperature heating and power generation from low temperature heat: DR-2. Proc JRAIA Int Symp 2012 2012:212-6.

[18] Kontomaris K. Zero-ODP, Low-GWP, Nonflammable Working Fluids for High Temperature Heat Pumps. ASHRAE Annu Conf Seattle, Washington, July 1, 2014 2014:1-40.

[19] Kontomaris K, Simoni LD, Nilsson M, Hamacher T, Nes H. Combined Heat and Power From Low Temperature Heat : HFO-1336mzz ( Z ) as a Working Fluid for Organic Rankine Cycles. Int Compress Eng Refrig Air Cond High Perform Build Conf 2016:1-10.

[20] Gorgy E. Nucleate boiling of low GWP refrigerants on highly enhanced tube surface. Int J Heat Mass Transf 2016;96:660-6. doi:10.1016/j.ijheatmasstransfer.2016.01.057.

[21] Byun HW, Kim DH, Yoon SH, Song CH, Lee KH, Kim OJ. Pool boiling performance of enhanced tubes on low GWP refrigerants. Appl Therm Eng 2017;123:791-8. doi:10.1016/j.applthermaleng.2017.05.009.

[22] Molés F, Navarro-Esbrí J, Peris B, Mota-Babiloni A. Experimental evaluation of HCFO1233zd-E as HFC-245fa replacement in an Organic Rankine Cycle system for low temperature heat sources. Appl Therm Eng 2016;98. doi:10.1016/j.applthermaleng.2016.01.011.

[23] Lee D, Kim D, Park S, Lim J, Kim Y. Evaporation heat transfer coefficient and pressure drop of R-1233zd(E) in a brazed plate heat exchanger. Appl Therm Eng 2018;130:1147-55. doi:10.1016/J.APPLTHERMALENG.2017.11.088.

[24] Mateu-Royo C, Navarro-Esbrí J, Mota-Babiloni A, Amat-Albuixech M, Molés F. Theoretical evaluation of different high-temperature heat pump configurations for low-grade waste heat recovery. Int J Refrig 2018. doi:10.1016/j.ijrefrig.2018.04.017.

[25] ANSI/ASHRAE. Designation and Safety Classification of Refrigerants. Stand 342016.

[26] AGC Chemicals. AMOLEA ${ }^{\circledR}$ 1224yd, Technical information. ASAHI Glas Co 2017:1-18.

[27] Fukushima, Masato Hayamizu H, Hashimoto M. Thermodynamic Properties of Low-GWP Refrigerant for Centrifugal Chiller. Int Refrig Air Cond Conf 2016.

[28] Lemmon EW, Bell IH, Huber ML, McLinden MO. NIST Standard Reference Database: Reference Fluid Thermodynamic and Transport Properties-REFPROP, Version 10. Natl Inst Stand Technol Stand Ref Data Program, Boulder, CO 2018.

[29] ASHRAE. ASHRAE Handbook Fundamentals. Am Soc Heating, Refrig Air-Conditioning Eng 2017.

[30] Kontomaris K. Low-GWP, Nonflammable Working Fluids for High Temperature Heat Pumps. ASHRAE 2014 Annu Conf Seattle, Washington, USA (June 28- July 2) 2014. 
Chapter 4

[31] Moisi H, Rieberer R. Refrigerant Selection and Cycle Development for a High Temperature Vapor Compression Heat Pump. 12th IEA Heat Pump Conf 2017, Rotterdam 2017:1-10.

[32] Patten KO, Wuebbles DJ. Atmospheric lifetimes and Ozone Depletion Potentials of trans-1chloro-3,3,3-trifluoropropylene and trans-1,2-dichloroethylene in a three-dimensional model. Atmos Chem Phys 2010;10:10867-74. doi:10.5194/acp-10-10867-2010.

[33] Makhnatch P, Khodabandeh R. The role of environmental metrics (GWP, TEWI, LCCP) in the selection of low GWP refrigerant. Energy Procedia 2014;61:2460-3. doi:10.1016/j.egypro.2014.12.023.

[34] Juhasz JR, Simoni LD. a Review of Potential Working Fluids for Low Temperature Organic Rankine Cycles in Waste Heat Recovery. 3rd Int Semin ORC Power Syst 2015:1-10.

[35] Klein S. Engineering Equation Solver (EES) V10.6. Fchart Software, Madison, USA WwwFchartCom 2006.

[36] Granryd E, Ekroth I, Lundqvist P, Melinder A, Palm B, Rohlin P. Refrigeration Engineering. K Tek Högskolan 1999.

[37] Palm B. Hydrocarbons as refrigerants in small heat pump and refrigeration systems - A review. Int J Refrig 2008;31:552-63. doi:10.1016/j.ijrefrig.2007.11.016.

[38] AIRAH. Methods of calculating Total Equivalent Warming Impact (TEWI). Best Pract Guidel Aust Inst Refrig Air Cond Heat 2012.

[39] IPCC. IPCC/TEAP special report on safeguarding the ozone layer and the global climate system: Issues related to hydrofluorocarbons and perfluorocarbons. Cambridge Publ Intergov Panel Clim Chang [by] Cambridge Univ Press 2005.

[40] EEA. Overview of electricity production and use in Europe. Eur Enviroment Agency 2018. 


\section{Chapter 5 \\ Experimental Exergy and Energy Analysis of a Novel High-Temperature Heat Pump with Scroll Compressor for Waste Heat Recovery}

The industrial sector demands novel sustainable energy systems to advance in its decarbonisation and meet the targets of the Paris Agreement for climate change mitigation. High-Temperature Heat Pumps (HTHPS) are being investigated as a feasible energy conversion technology alternative to traditional fossil fuel boilers. This paper presents the first experimental results of an HTHP prototype equipped with a modified scroll compressor and internal heat exchanger (IHX). The elements of the main and secondary circuits are presented, as well as the test methodology, and heat balances are exposed. The tests have been performed using HFC-245fa at heat source temperatures between 60 and $80^{\circ} \mathrm{C}$, and heat sink temperatures between 90 and $140{ }^{\circ} \mathrm{C}$. The heating capacity and coefficient of performance (COP) varied between 10.9 and $17.5 \mathrm{~kW}$ and between 2.23 and 3.41 , respectively. An exergetic analysis indicated that the expansion valve was the component with the worst second law efficiency, and the compressor presented the greatest potential improvement over the other cycle components. A computational analysis of low global warming potential (GWP) refrigerant alternatives was carried out, which confirmed the benefits of using an internal heat exchanger (IHX) and the good performances of the low-GWP refrigerants: HCFO-1224yd(Z), HCFO-1233zd(E), and $H F O-1336 \mathrm{mzz}(\mathrm{Z})$. Finally, we proved that the proposed system could save up to $57 \%$ of the equivalent $\mathrm{CO} 2$ emissions of a natural gas boiler. This paper provides a reference for the high-temperature heat pump recovery of the low-grade waste heat from industrial energy processes

\subsection{Introduction}

Heat pumps are an innovative technology that can substitute fossil fuels boilers and contribute to improving the energy efficiency and decarbonisation of the energy-intensive industry sector. However, their main drawbacks are the associated high initial costs and the lack of technology maturity in industrial applications [1]. Bataille et al. [2] indicated industrial heat pumps as a possible technology to aid compliance with the Paris Agreement and therefore, limit the increase in the global mean surface temperature to below $2{ }^{\circ} \mathrm{C}$ above pre-industrial levels. Meyers et al. [3] proved that a larger number of operating hours of this technology could be a promising solution for lowering carbon industrial processes heat waste.

According to the Fifth Assessment Report (AR5) of the Intergovernmental Panel on Climate Change (IPCC), the carbon energy industry is critical for the climate change mitigation because their greenhouse gas (GHG) emissions have doubled between 1970 and 2010 [4]. From an analysis of the 
industrial energy demand, it can be observed that most of the consumption comes from thermal processes at temperatures above $100{ }^{\circ} \mathrm{C}$. These are mainly performed through the combustion of fossil fuels with uncertain acquisition prices and severe environmental impacts, such as climate change. Moreover, a significant fraction (around 2.8\%) of the industrial energy consumption is rejected as low-grade waste heat below $100^{\circ} \mathrm{C}$ [5]. Therefore, recovering the industrial waste heat below $100{ }^{\circ} \mathrm{C}$ and upgrading it into useful heat for the industrial thermal processes (above $100{ }^{\circ} \mathrm{C}$ ) [6] through energy efficient technologies would increase the energy efficiency and reduce the carbon emissions of the industrial sector, which as being one of the three main energy consuming sectors [7]. An option can be the use of vapour compression systems, which can be integrated into different industrial and district heating processes due to the flexibility offered in terms of the wide range of operating temperatures and heating capacities.

The need to analyse the heat pump technology in the industrial sector led Arpagaus et al. [8] to perform a comprehensive review of the heat pumps with heat sink temperatures up to $160^{\circ} \mathrm{C}$, also named high-temperature heat pumps (HTHPs). They showed that the HTHPs with higher heat sink temperatures were mainly developed in research projects and their coefficient of performance (COP) can vary from 2.2 to 6.5 ( 70 to $30 \mathrm{~K}$ temperature lift, respectively). The working fluid selected for heat pumps determines the maximum performance obtained at certain heat sink temperatures. While at lower temperatures, traditional refrigerants such as HFC-134a, HFC-32, and HC-290 can be used in the industry [9], for high-temperature applications, other fluids must be considered [10]. Moreover, for higher heat sink temperatures and temperature lifts, the COP can be improved using advanced configurations, different from the basic cycle [11].

Therefore, current research and development of HTHPs aim at covering higher heat sink temperatures with suitable working fluids and energy efficient configurations. The development status of HTHPs configurations is still mostly limited to theoretical analysis, such as those performed by Cao et al., and Mateu-Royo et al. [11,12], which considered an external heat exchanger in one and two stages, or those performed by Mota-Babiloni et al. and Yang et al. [13,14], which considered HTHP cascades. Moreover, an intensive theoretical study was performed on the energy performance benefits provided by the use of zeotropic mixtures $[15,16]$.

Experimental studies are being performed using HTHP prototypes that use different technologies and working fluids in basic cycle configurations. Bamigbetan et al. [17] studied HTHPs, with an internal heat exchanger (IHX) and receiver, to delivery heat at $115^{\circ} \mathrm{C}$ (usable in industrial processes for drying and pasteurization, among others) using HC-600. They modified a $48.82 \mathrm{~m}^{3} \mathrm{hr}^{-1}$ piston compressor lubricated by $2.5 \mathrm{~kg}$ of synthetic oil and tested frequencies from 30 to $50 \mathrm{~Hz}$. The average total and isentropic compressor efficiencies were 74 and $83 \%$, respectively. Chamoun et al. [18] used a twin-screw water HTHP equipped with a plate condenser, an electrical expansion valve, a flash tank, and a falling film evaporator. The compression ratio and rotation speed of the compressor were 4.5 and $5000 \mathrm{rpm}$, respectively. Bobelin et al. [19] constructed an HTHP with scroll compressors, a brazed-plate heat evaporator, condenser and sub-cooler, and an electronic expansion valve to supply heat up to $125{ }^{\circ} \mathrm{C}$ with a developmental mixture fluid. For evaporating and condensing at temperatures of 50 and $100{ }^{\circ} \mathrm{C}$, respectively, the COP was 4.48. Meroni et al. [20] validated a centrifugal compressor model with air, R-134a, and carbon dioxide, and developed a coupled optimization with a heat pump system to supply steam at $150^{\circ} \mathrm{C}$. A closed-loop with cyclopentane resulted in a COP of 4.74 . 
A group of researchers have tested several refrigerants mixtures prototypes in different HTHP systems. Ma et al. [21] tested the near-azeotropic mixture BY-4 in an HTHP composed by parallel scroll compressors (23.6 kW power), water-cooling condenser, dry-expansion shell, tube evaporator, and electronic expansion valve. The maximum heat capacity was $122.11 \mathrm{~kW}$ with a high COP of 3.61 and the highest heat output temperature was $110^{\circ} \mathrm{C}$. Zhang et al. [22] tested the binary near-azeotropic mixture BY-5 in an $8 \mathrm{HP}$ scroll compressor. At the heat sink temperature of $130^{\circ} \mathrm{C}$, the corresponding $\mathrm{COP}$ was 2.57. Yu et al. [23] reached a COP of 4 with heat source and heat sink temperatures of 75 and $120^{\circ} \mathrm{C}$, respectively, using the mixture MF-1 with semi-hermetic screw compressors, full-liquid tube-shell condenser, dry-type tube-shell evaporator, and electronic expansion valve. With a $14.5 \mathrm{~kW}$ scroll compressor, Deng et al. [24] used the NBY-1 prototype refrigerant to reach a COP of 2.74 at heat sink temperature of $130^{\circ} \mathrm{C}$ and temperature lift of $50^{\circ} \mathrm{C}$. Finally, Arpagaus et al. [25] developed a prototype using $\mathrm{HCFO}-1233 \mathrm{zd}(\mathrm{E})$ as the working fluid that reached a heat generation temperature of $151{ }^{\circ} \mathrm{C}$ with a COP of 1.1 .

Based on the above-discussed literature review, it can be seen that the HTHP technology is at an early stage. Thus, the purpose of this paper is to present the first experimental results of a novel HTHP with scroll compressor for low-grade waste heat recovery. The prototype is designed to test low synthetic GWP refrigerants and reach heat sink temperatures of $140{ }^{\circ} \mathrm{C}$. Nevertheless, the first experimental results are obtained using HFC-245fa as working fluid in order to establish the reference for future alternative refrigerant drop-in replacements. The rest of this paper is organised as follows. Section 2 describes the experimental setup of the HTHP prototype and presents the measurement installation. Section 3 introduces the experimental procedures and conditions, along with the presentation of the uncertainty analysis and validation data. Section 4 presents the experimental results through detailed energy and exergy analysis. Moreover, computational analysis results of low-GWP refrigerant alternatives are provided along with the environmental evaluation of the HTHP integration as a waste heat recovery system in combined heat and power (CHP) installations. Finally, the last section contains the relevant conclusions. The results of this study may provide guidelines for the further design and development of HTHPs for low-grade waste heat recovery, especially in the industrial sector.

\subsection{Experimental setup}

A schematic representation of the proposed HTHP prototype is shown in Fig. 5.1, which contains the different circuits of the complete system, and their main components, sensors, and configurations. Fig. 5.2 shows photo of the experimental prototype, which was built at the ISTENER laboratories of the Universitat Jaume I, Spain. The test bench is composed of the main vapour compression circuit, and two closed secondary circuits, one for the heat source and one that acts as a heat sink along with a water cooler closed circuit. The heat source circuit simulates the potential low-grade waste heat available from industrial processes and, the heat sink simulates the high-temperature consumptions. 
Chapter 5

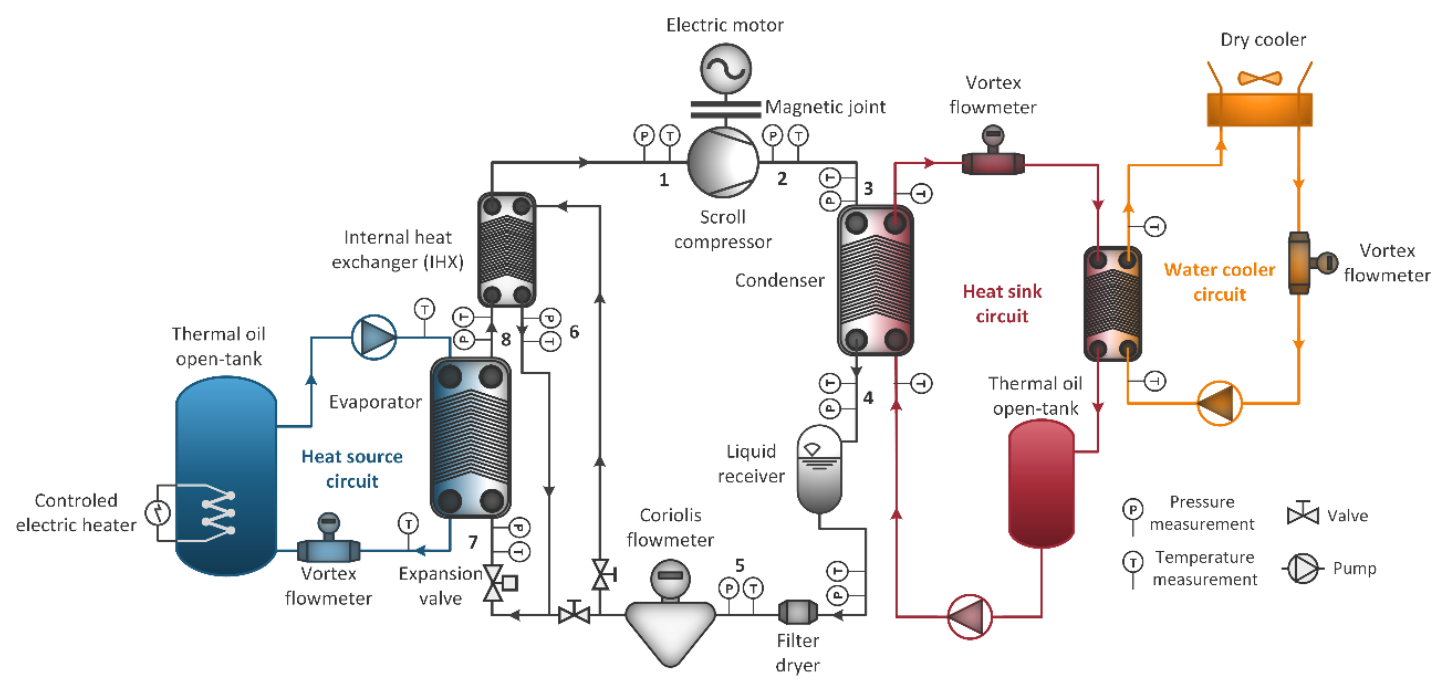

Fig. 5.1. Schematic diagram of the experimental test bench

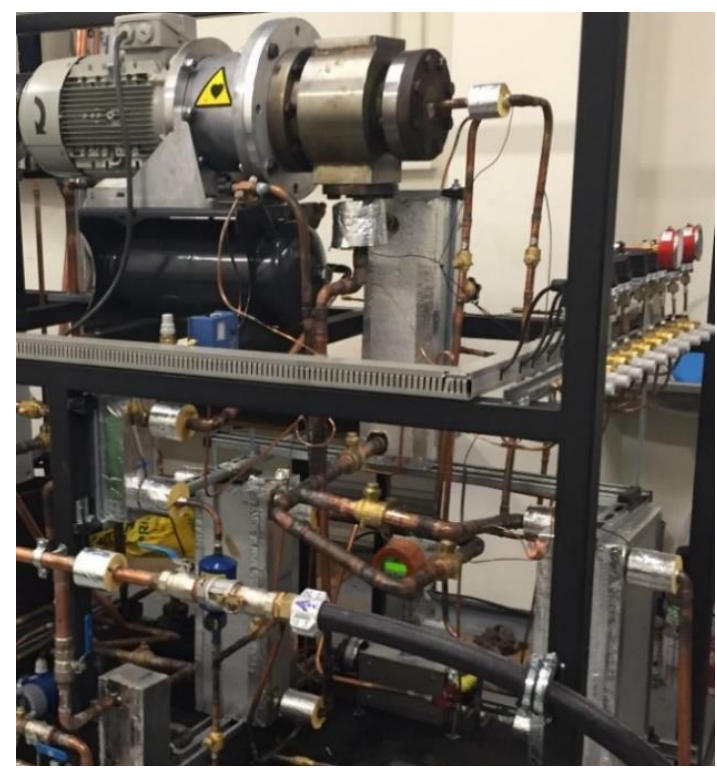

(a)

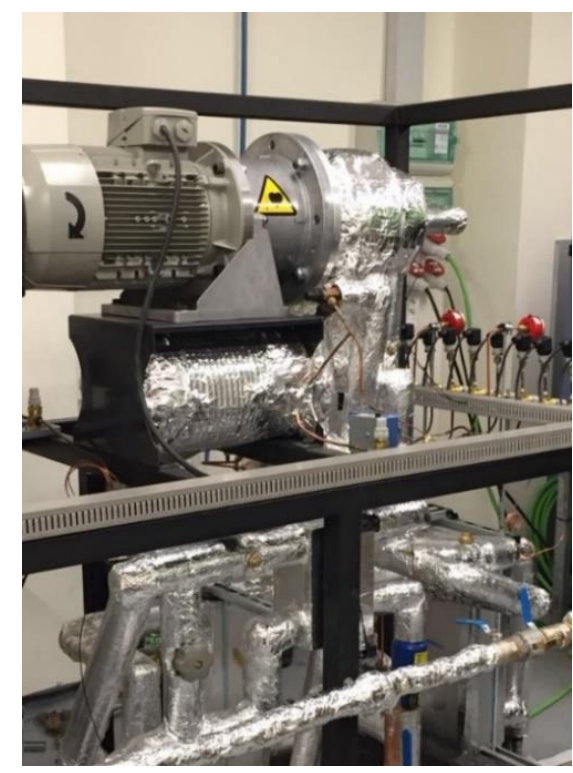

(b)

Fig. 5.2. Photo of the experimental prototype (ISTENER, Universitat Jaume I, Spain). (a) Start-up test without thermal insulation and (b) experimental campaign once thermally insulated.

The vapour compression heat pump circuit consists of a scroll open-type compressor modified by Expander Tech S.L. with a variable-speed electric motor of $7.5 \mathrm{~kW}$ nominal power and displacement of $121.1 \mathrm{~cm}^{3}$ per revolution ( $2900 \mathrm{rpm}$ at $230 \mathrm{~V}$ and $50 \mathrm{~Hz}$ ), magnetically coupled to each other. The compressor was modified with internal adjustments and magnetic coupling in order to ensure the operation at high-temperatures and proper lubrication. The polyester oil with a viscosity of $40 \mathrm{~mm}^{2}$ $\mathrm{s}^{-1}$ (at $60{ }^{\circ} \mathrm{C}$ ) is used to ensure the required compressor lubrication at high operating temperatures. All the heat exchangers (condenser, evaporator and IHX) are brazed plate type. A liquid receiver, 
installed after the condenser, is used to ensure the absence of bubbles before the expansion process. A manual expansion valve is installed to control the correct superheating degree owing to the lack of thermostatic models for high-temperature vapour compression applications.

The secondary circuits are used to set the targeted evaporation and condensation temperatures. The heat sink circuit uses thermal oil as the secondary fluid and is cooled by a closed-type cooling system, which allows the control of the thermal oil temperature. The volumetric flow rate can be adjusted through the variable-speed pump. The water-cooling system is composed of a PID controlled dry cooler that ensures the temperature stability of the heat sink circuit. The heat source circuit that simulates the waste heat demand also regulates the secondary thermal oil temperature through a set of immersed PID controlled electrical resistances.

The thermodynamic states of the refrigerant are obtained with the pressure and temperature measurements (obtained with thermocouples, calibrated in our laboratory using certified references, and pressure transducers) in the locations specified in Fig. 5.1. The refrigerant mass flow rate is measured by a Coriolis mass flow meter located at the liquid line, and the compressor electricity consumption is measured using a digital wattmeter. In the secondary circuits, the temperatures and volumetric flow rate are measured. Table 5.1 shows the characteristics of the sensors and their uncertainty. Finally, the thermodynamic properties are calculated using the REFPROP 10.0 [26].

Table 5.1. Summary of measurement sensors and uncertainties.

\begin{tabular}{ccc}
\hline Measured parameters & Sensor & Uncertainty \\
\hline Temperatures & J-type thermocouples & $\pm 0.3 \mathrm{~K}$ \\
Pressures & Piezoelectric pressure transducers & $\pm 0.04 \%$ of reading \\
Refrigerant mass flow rate & Coriolis mass flow meter & $\pm 0.17 \%$ of reading \\
Heat source volumetric flow rate & Vortex flow meter & $\pm 0.5 \%$ of reading \\
Heat sink volumetric flow rate & Vortex flow meter & $\pm 0.028 \mathrm{~m}^{3} \mathrm{~h}^{-1}$ \\
Compressor power consumption & Digital wattmeter & $\pm 1.55 \%$ \\
\hline
\end{tabular}

\subsection{Methodology}

\subsubsection{Test conditions}

The test operating conditions for the experimental start-up of the HTHP system are described in Table 5.2. The superheating degree at the evaporator provided by IHX results in $35 \mathrm{~K}$. This value is obtained by passing a whole refrigerant mass flow rate thought the IHX. Nevertheless, the superheating degree should be control in other operating points or using different refrigerants to avoid exceeding the maximum discharge temperature.

Table 5.2. Operating conditions in the start-up experimental test.

\begin{tabular}{cc}
\hline Controlled parameters & Values \\
\hline Heat sink outlet temperature & $90-140{ }^{\circ} \mathrm{C}$ \\
Heat source inlet temperature & $60-80{ }^{\circ} \mathrm{C}$ \\
Superheating degree (SH) with IHX & $35 \mathrm{~K}$ \\
Compressor drive frequency & $50 \mathrm{~Hz}$ \\
\hline
\end{tabular}


The process followed for the selection of a steady state test consists in measuring for a time period of $40 \mathrm{~min}$, with a sample period of one second, in which the condensing and evaporating pressure are within an interval of $3.5 \mathrm{kPa}$. During every steady-state test, all the temperatures are within a deviation of $\pm 0.25 \mathrm{~K}$ and the refrigerant mass flow rate is within $\pm 0.0007 \mathrm{~kg} \cdot \mathrm{s}^{-1}$. Once the steady-state operation is achieved (with 2400 direct measurements), the data is processed with an algorithm in order to find the most suitable steady-state period (highest precision and accuracy) of 10 minutes (600 direct measurements). Fig. 5.3 shows the fluctuation and mean value for the evaporating and condensing pressures, the heat sink outlet temperature, and the refrigerant mass flow rate.

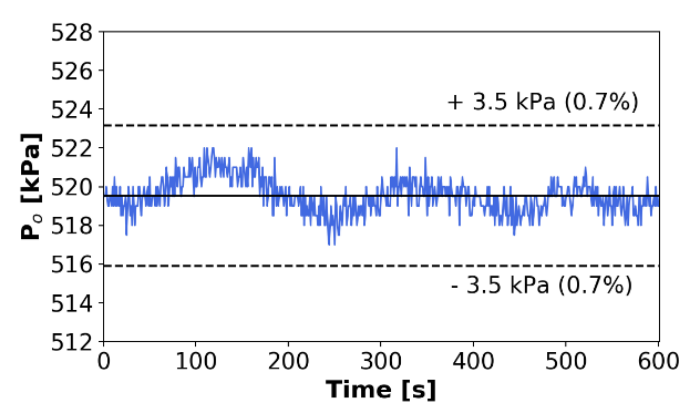

(a)

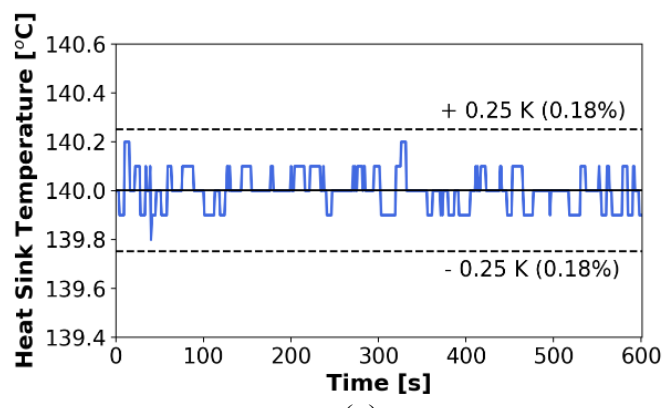

(c)

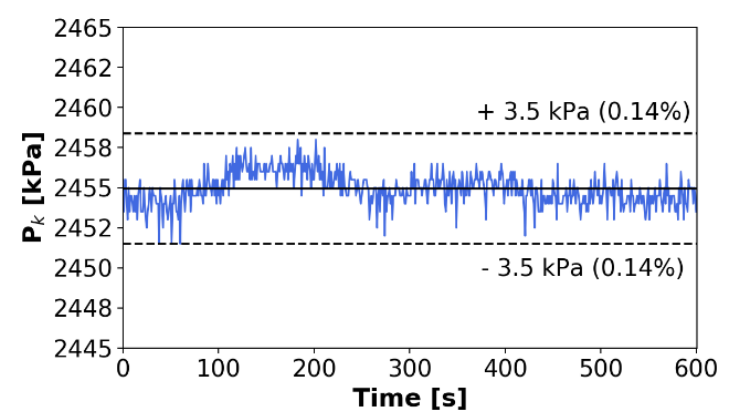

(b)

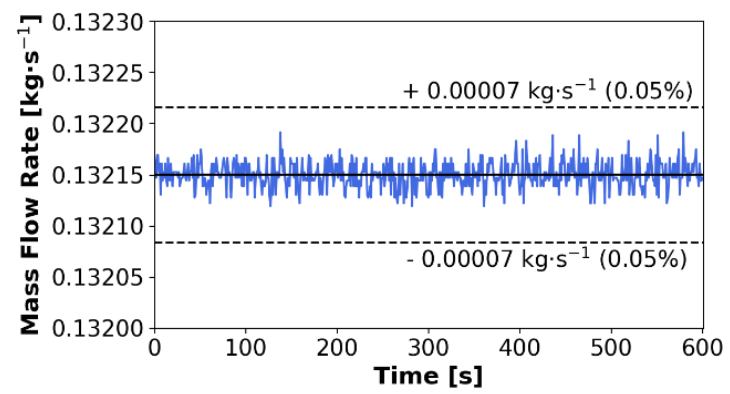

(d)

Fig. 5.3. Fluctuations of operating parameters of the highest heating production temperature steady-state test. (a) Evaporating pressure, (b) condensing pressure, (c) heat sink outlet temperature, (d) refrigerant mass flow rate. 
The T-s diagram of the highest heating production temperature steady-state test is shown in Fig. 5.4. In order to clarify the interpretation of the T-s diagram, the cycle points are listed by the schematic diagram in Fig. 5.1.

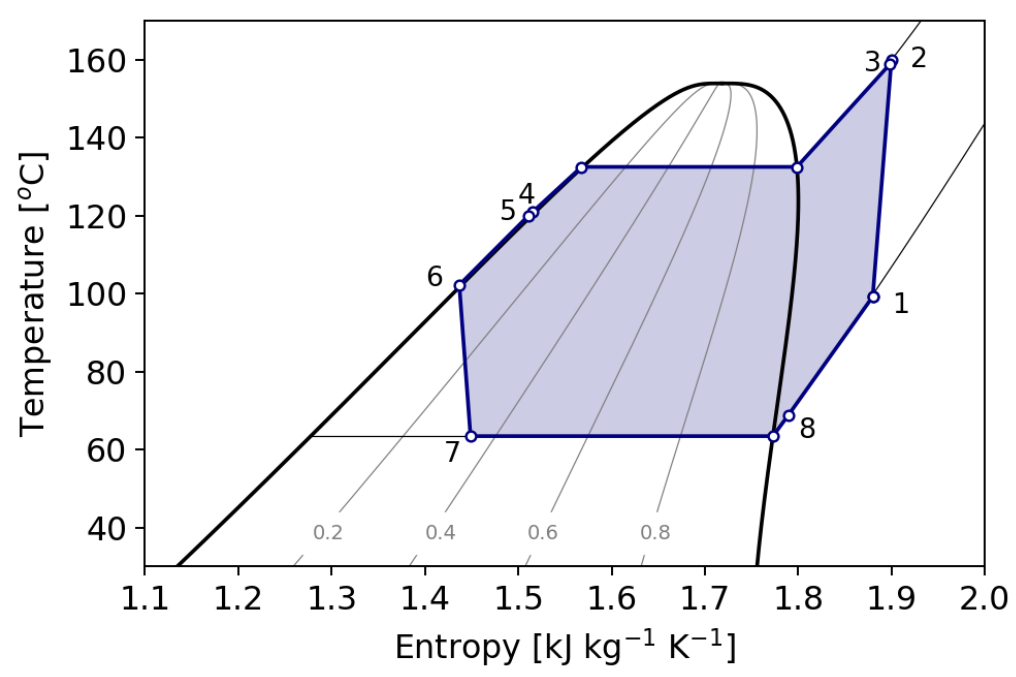

Fig. 5.4. T-s diagram of the highest heating production temperature steady-state test.

\subsubsection{Data validation}

To evaluate the accuracy of the measurements, a comparison between the heat load supplied from the refrigerant and the heat supplied to the thermal oil at the condenser is carried out, including all the experimental tests as shown in Fig. 5.5.

The heating capacity at the refrigerant side is obtained as the product of the experimental refrigerant mass flow rate $\left(\dot{m}_{r e f}\right)$ and the heating effect, calculated as the measured refrigerant thermodynamic states at the condenser inlet $\left(h_{k, \text { in }}\right)$ and outlet $\left(h_{k, \text { out }}\right)$. Hence the heating capacity is expressed as in Eq. (5.1).

$$
\dot{Q}_{k}=\dot{m}_{r e f}\left(h_{k, \text { in }}-h_{k, \text { out }}\right)
$$

Further, the heating capacity at the heat sink side is obtained using the measured thermal oil mass flow rate $\left(\dot{m}_{\operatorname{sink}}\right)$ and the temperature difference between the condenser outlet $\left(T_{\operatorname{sink}, \text { out }}\right)$ and inlet $\left(T_{\text {sink,in }}\right)$, as in Eq. (5.2).

$$
\dot{Q}_{\operatorname{sink}}=\dot{m}_{\operatorname{sink}} c_{p, \operatorname{sink}}\left(T_{\sin k, \text { out }}-T_{\operatorname{sink}, \text { in }}\right)
$$




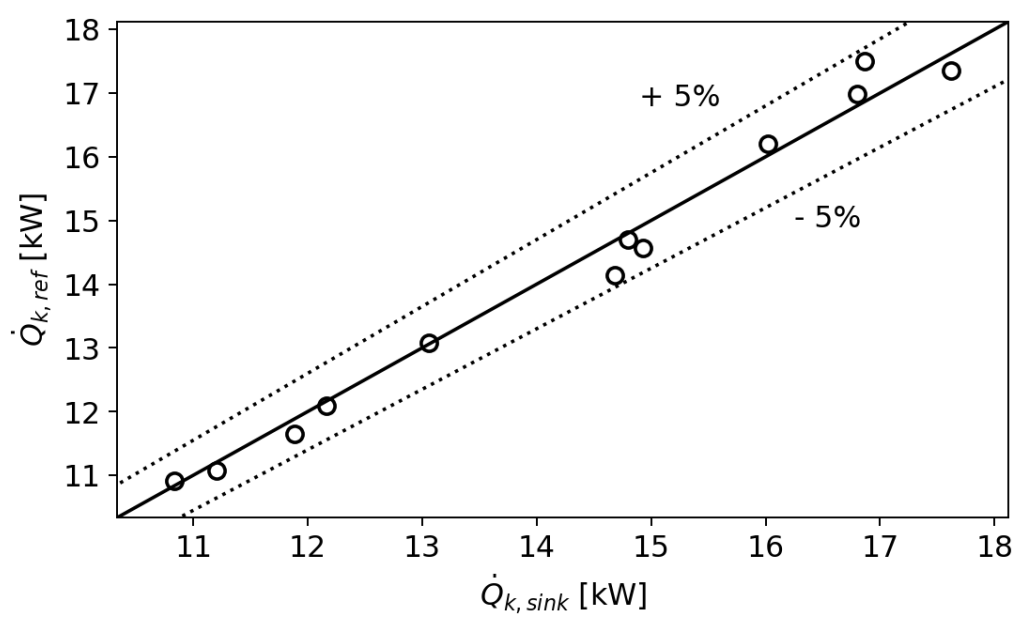

Fig. 5.5. Heating capacity at the condenser (comparing refrigerant and heat sink sides).

The condenser heat balance shows a good agreement between both sides, as all the experimental tests are within a deviation of $\pm 5 \%$. Moreover, the main steady-state at a heat source temperature of 80 ${ }^{\circ} \mathrm{C}$ and heat sink temperature of $140{ }^{\circ} \mathrm{C}$ were validated through the repeatability of this condition, showing a deviation lower than $5 \%$ between the measured and calculated parameters of each measurement.

\subsubsection{Propagation of errors in the estimated parameters}

In this section, we describe the uncertainty propagation methodology of the characteristic parameters. The uncertainty of the measurements consists of systematic and random errors. While systematic errors produce an offset to the actual value, the random errors scatter around the mean value. The influence of the systematic errors can be reduced or even corrected by calibrating the measuring system, owing to the reproducibility of the offset. Thus, the thermocouples and pressure transducers were calibrated in our laboratory in order to reduce the systematic error of the measurements. The measurement accuracies of the applied sensors are listed in Table 5.1.

On the other hand, random errors are not reproducible and therefore, cannot be corrected. However, measurements often exhibit the characteristics of a normally distributed events, and therefore, random errors can be characterised by statistical methods. In general, the series of measurements, extracted from the statistical population, can be described as follows:

$$
\bar{x} \pm \sigma_{x}
$$

where $\bar{x}$ is the arithmetic average, $\sigma_{x}$ is the empirical standard deviation, Eq. (5.4), $i$ indicates the measurement, and $n$ is the number of measurements.

$$
\sigma_{x}=\sqrt{\frac{1}{n-1}} \sum_{i=1}^{n}\left(x_{i}-\bar{x}\right)^{2}
$$


The confidence interval of the arithmetic average and the empirical standard deviation is $68.3 \%$. To obtain a $95.5 \%$ of confidence level, the empirical standard deviation is multiplied by 2 [27]. Finally, the uncertainty of the measurement $\bar{\sigma}_{x}$, which involves systematic and random errors, is obtained by the root-sum-of-squares (RSS) method.

However, there are interesting parameters that cannot be measured directly but are derived from other parameters such as the temperature and pressure, which can be measured. Thus, the Gaussian law of error propagation can be applied to quantify the uncertainty of the derived parameters. When the quantity desired $Y$ is calculated as a function of one or more variables from direct measurement, $Y=$ $f\left(x_{1}, x_{2} x_{3}, \ldots, x_{k}\right)$, the standard deviation of the derived quantity is described by:

$$
\sigma_{y}=\sqrt{\sum_{j=1}^{k}\left(\frac{\partial Y}{\partial x_{j}}\right)^{2} \bar{\sigma}_{x}^{2}}
$$

where the index $j$ describes the influencing variables of the derived quantity $Y$. The software EES [28] has been used to implement the partial derivative of a function to calculate the uncertainty of the desired quantity with the uncertainty of the measured quantities. Moreover, REFPROP 10.0 could be implemented in EES to provide the refrigerant properties. In summary, the uncertainty propagation was calculated with the methodology explained above, introducing the uncertainty of the measurement $\bar{\sigma}_{x}$ calculated with the systematic and random error, in the EES software and using REFPROP 10.0 as refrigerant database.

\subsubsection{Exergy analysis}

As well as the energetic (first law) analysis of the HTHP prototype, an exergetic (second law) analysis can help to identify the maximum potential work of a given measurement point concerning the reference state. This analysis provides useful information to determine the efficient use of the available energy and therefore, understand the direction of potential improvements. Vapour compression cycles have several irreversibility sources (exergy destruction) that separate the real performance from the ideal one. Accordingly, the main objective of this section is to evaluate the exergy destruction (irreversibility) and efficiency of each cycle component.

The total and the specific exergy of a fluid is:

$$
\begin{gathered}
\dot{E} x=\dot{m} \cdot e x \\
e x=\left(h-h_{o}\right)-T_{o}\left(s-s_{o}\right)
\end{gathered}
$$

where $h$ is the specific enthalpy, $s$ is the specific entropy and $h_{o}, s_{o}$ and $T_{o}$ correspond to the entropy, enthalpy and temperature at the dead state. Because of the variation of the heat source pressure and temperature in each measurement point, the temperature of the dead state $T_{o}$ has been selected as $T_{\text {source,out }}-\Delta T$, being $\Delta T 20 \mathrm{~K}$, but other references can be selected. The difference between $T_{\text {source,out }}$ and evaporation temperature is between $2-10{ }^{\circ} \mathrm{C}$, which increases as the temperature lift decreases. Finally, the refrigerant reference pressure $\left(P_{o}\right)$ is taken as the saturation pressure at $T_{o}[29]$. 
The exergy destruction, $\dot{E} x_{d, t o t}$, represents the real energy losses that cannot be identified in an energy balance, it can be expressed as shown in Eq. (5.8) as a general expression for any control volume.

$$
\dot{E} x_{d, t o t}=\sum\left(1-\frac{T_{0}}{\bar{T}}\right) \dot{Q}-\dot{W}_{\text {in }}+\sum_{\text {in }} \dot{m} \cdot e x-\sum_{\text {out }} \dot{m} \cdot e x
$$

The entropy-averaged temperatures $\bar{T}$ correspond to the average temperature in the T-s diagram of the secondary fluids, thermal oil in the condenser, and, in this case, thermal oil in the evaporator. For constant pressure and heating capacity, the entropy-averaged temperatures can be calculated using Eq. (5.9) [30].

$$
\bar{T}=\frac{h_{\text {out }}-h_{\text {in }}}{S_{\text {out }}-s_{\text {in }}}=\frac{T_{\text {out }}-T_{\text {in }}}{\ln \left(\frac{T_{\text {out }}}{T_{\text {in }}}\right)}
$$

In this study, the overall exergy destruction for the vapour compression system is obtained as the accumulation of the exergy destruction in each cycle component, as in Eq. (5.10).

$$
\dot{E} x_{d}=\dot{E} x_{d, c}+\dot{E} x_{d, c o n d}+\dot{E} x_{d, e v}+\dot{E} x_{d, e x}+\dot{E} x_{d, I H X}
$$

Based on the previous expressions, the exergy destruction for each component is defined according to the following equations:

$$
\begin{aligned}
& \dot{E} x_{d, c}=\dot{W}_{c}+\dot{m}_{r e f} \cdot\left(e x_{\text {out }}-e x_{i n}\right)=\dot{W}_{c}+\dot{m}_{r e f}\left[\left(h_{\text {out }}-h_{\text {in }}\right)-T_{0}\left(s_{\text {out }}-s_{\text {in }}\right)\right] \\
& \dot{E} x_{d, \text { cond }}=\dot{m}_{r e f} \cdot\left[\left(h_{k, \text { in }}-h_{k, \text { out }}\right)-T_{0} \cdot\left(s_{k, \text { in }}-s_{k, \text { out }}\right)\right]-\dot{Q}_{k} \cdot\left(1-\frac{T_{0}}{\bar{T}_{k}}\right) \\
& \dot{E} x_{d, \text { evap }}=\dot{Q}_{o} \cdot\left(1-\frac{T_{0}}{\bar{T}_{o}}\right)-\dot{m}_{r e f} \cdot\left[\left(h_{o, \text { in }}-h_{o, \text { out }}\right)-T_{0} \cdot\left(s_{o, \text { in }}-s_{o, \text { out }}\right)\right] \\
& \left.\dot{E} x_{d, e v}=\dot{m}_{r e f} \cdot T_{0} \cdot\left(s_{e x, o u t}-s_{e x, \text { in }}\right)\right] \\
& \dot{E} x_{d, I H X}=\dot{m}_{\text {ref }}\left(\left[\left(h_{I H X, l i q, \text { in }}-h_{I H X, l i q, o u t}\right)-\left(h_{I H X, v a p, o u t}-h_{I H X, v a p, \text { in }}\right)\right]\right. \\
& \left.-T_{0}\left[\left(s_{I H X, \text { liq,in }}-s_{I H X, l i q, o u t}\right)-\left(s_{I H X, v a p, o u t}-s_{I H X, v a p, \text { in }}\right)\right]\right)
\end{aligned}
$$


The exergy efficiency can be defined in the vapour compression cycles as the ratio of the minimum power required by a reversible system to the actual exergy input. The exergy analysis is carried out using the following equations:

$$
\begin{aligned}
& \psi_{c}=\frac{\dot{m}_{r e f} \cdot\left[\left(h_{\text {out }}-h_{\text {in }}\right)-T_{0} \cdot\left(s_{\text {out }}-s_{\text {in }}\right)\right]}{\dot{W}_{c}} \\
& \psi_{\text {cond }}=\frac{\dot{m}_{r e f} \cdot\left[\left(h_{k, \text { out }}-h_{k, \text { in }}\right)-T_{0} \cdot\left(s_{k, \text { out }}-s_{k, \text { in }}\right)\right]}{\dot{Q}_{k} \cdot\left(1-\frac{T_{0}}{\bar{T}_{k}}\right)} \\
& \psi_{\text {evap }}=\frac{\dot{m}_{r e f} \cdot\left[\left(h_{o, \text { in }}-h_{o, \text { out }}\right)-T_{0} \cdot\left(s_{o, \text { in }}-s_{o, \text { out }}\right)\right]}{\dot{Q}_{o} \cdot\left(1-\frac{T_{0}}{\bar{T}_{o}}\right)} \\
& \psi_{e v}=\frac{\left(h_{e v, \text { out }}-h_{0}\right)-T_{0} \cdot\left(s_{e v, \text { out }}-s_{o}\right)}{\left(h_{e v, \text { in }}-h_{0}\right)-T_{0} \cdot\left(s_{e v, \text { in }}-s_{o}\right)} \\
& \psi_{I H X}=\frac{\left(h_{I H X, v a p, \text { out }}-h_{I H X, \text { vap }, \text { in }}\right)-T_{0} \cdot\left(s_{I H X, \text { vap }, \text { out }}-s_{I H X, \text { vap }, \text { in }}\right)}{\left(h_{I H X, \text { liq }, \text { in }}-h_{I H X, \text { liq }, \text { out }}\right)-T_{0} \cdot\left(s_{I H X, \text { liq, in }}-s_{I H X, \text { liq }, \text { out }}\right)}
\end{aligned}
$$

The total exergy efficiency of the high-temperature heat pump is obtained using Eq. (5.21).

$$
\psi_{H T H P}=\frac{\dot{W}_{c}-\dot{E} x_{d, t o t}}{\dot{W}_{c}+\dot{Q}_{o} \cdot\left(1-\frac{T_{0}}{\bar{T}_{o}}\right)}
$$

Finally, the relative irreversibility (IR) provides useful information of the irreversibility contribution of each component over the whole system and is calculated using Eq. (5.22). This parameter shows the most remarkable potential improvement for each component from an exergetic point of view. The higher is the RI; the greater are the potential improvements.

$$
R I_{i}=\frac{\dot{E} x_{d, i}}{\dot{E} x_{d, t o t}}
$$

\subsubsection{Prototype design, development and analysis process}

The experimental results of HTHP prototype presented in this paper required several essential previous steps as illustrated in Fig. 5.6. This design, development, and analysis methodology establishes the baseline for future prototypes development and alternative low-GWP refrigerants evaluation. 


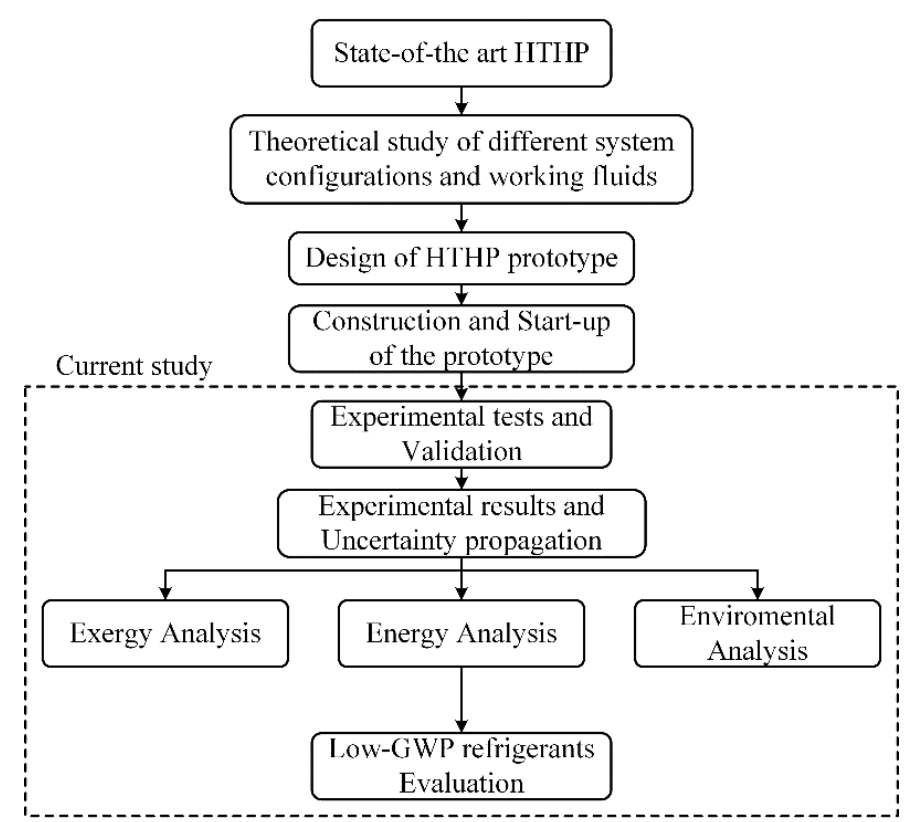

Fig. 5.6. Diagram methodology flow of the novel HTHP prototype design, development, and analysis.

\subsection{Results and discussions}

In this section, the results of the experimental investigation are given and discussed. Firstly, the energy performance results are presented and complemented with the exergy analysis of the experimental prototype. Secondly, alternative low-GWP alternative refrigerants are evaluated as potential candidates in HTHPs. Finally, HTHP integration as a waste heat recovery system in CHP installation is proposed along with the environmental emissions analysis.

\subsubsection{Energy performance results}

In this subsection, the compressor performance, heating capacity, and COP results are presented and discussed for heat sink temperatures between 90 and $140{ }^{\circ} \mathrm{C}$ and heat source temperatures between 60 and $80{ }^{\circ} \mathrm{C}$. The results are presented for different heat sink temperatures and temperature lifts, which, in this study, is considered as the temperature difference between the condenser outlet $\left(T_{\text {sink,out }}\right)$ and the evaporator inlet $\left(T_{\text {source, in }}\right)$.

\section{- Compressor performance}

The directly measured compressor power consumption is presented in Fig. 5.7. This parameter is highly influenced by the heat sink temperature due to the increment results in a higher mass flow rate, corresponding to the specific compression work. The values are not significantly affected by the temperature lift but by two other effects. Whereas the mass flow rate decreases at low evaporation temperatures, the specific work increases as illustrates Eq. (5.23). As a result, the compressor power consumption value remains at a similar level.

$$
\dot{W}_{C}=\dot{m}_{r e f} \Delta h_{c}
$$




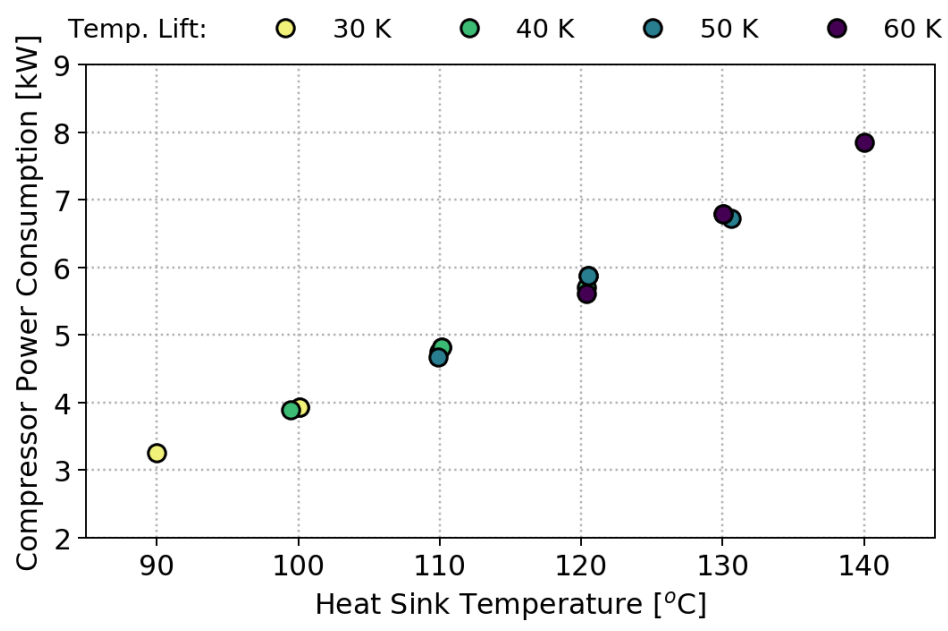

Fig. 5.7. Experimental compressor power consumption variation as a function of the heat sink temperature.

Fig. 5.8 show the results of the mass flow rate measured directly. At constant compressor rotational speed, the mass flow rate is proportional to the suction density of the refrigerant, which is calculated using the suction pressure and temperature measurements. A lower heat source temperature has a detrimental effect on the mass flow rate because it reduces volumetric efficiency and suction density. The mass flow rate is highly influenced by the suction temperature, which is directly related to the heat source temperature. Thus, higher heat source or heat sink temperatures produce an increase in the mass flow rate, which can considerably influence the performance parameters. Hence, an increment of the heat source temperature produces a decrease of the suction density and therefore, an increase of the mass flow rate. Moreover, higher heat sink temperatures with constant heat source temperatures produce an increment in the internal heat exchanger (IHX) effectiveness, which induces a reduction in the suction density and accordingly, an increment in the mass flow rate.

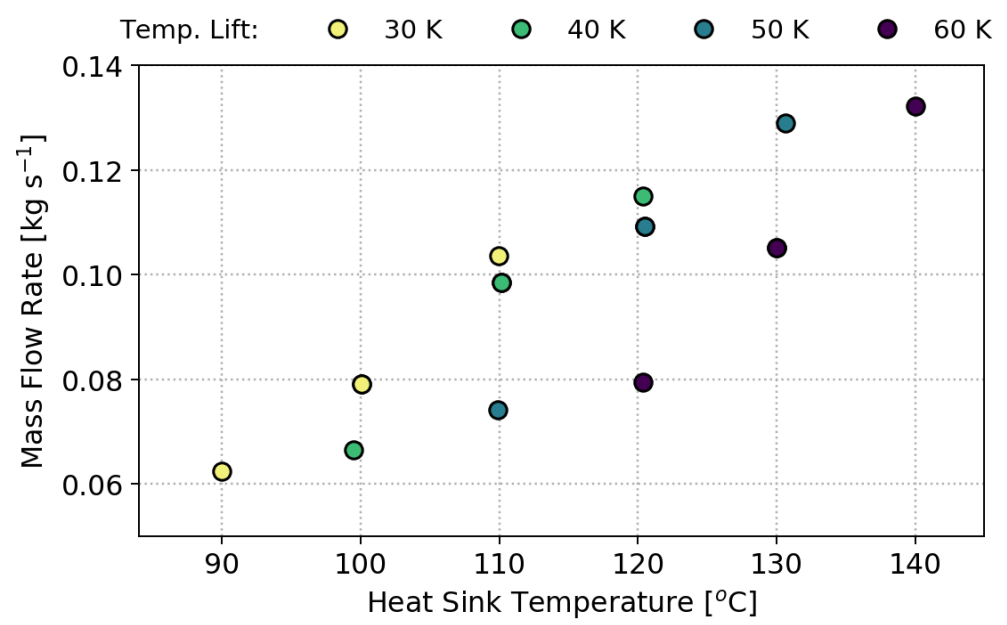

Fig. 5.8. Experimental mass flow rate variation regarding the heat sink temperature. 
Finally, the discharge temperature of the compressor affects the heat transferred to the refrigerant during the evaporation, superheating (in the evaporator, internal heat exchanger, suction line, and compressor suction), and compression processes. This is considered the most critical temperature point of the refrigerant in the vapour compression system, especially for high-temperature applications.

The discharge temperature affects the maximum temperature achievable by the heat sink fluid and therefore, determines the maximum temperature range of the application. As expected, the discharge temperature is highly affected by the heat sink temperature. As the heat sink temperature increases, the discharge temperature increases almost proportionally, as shown in Fig. 5.9. The highest discharge temperature achieved with a heat sink temperature of $140{ }^{\circ} \mathrm{C}$ is $160{ }^{\circ} \mathrm{C}$. Although this discharge temperature value remains under that for the thermal stability of the refrigerant and installation materials, further developments with high production temperatures will require special attention to this parameter due to the materials and fluid stability issues at such high-temperatures.

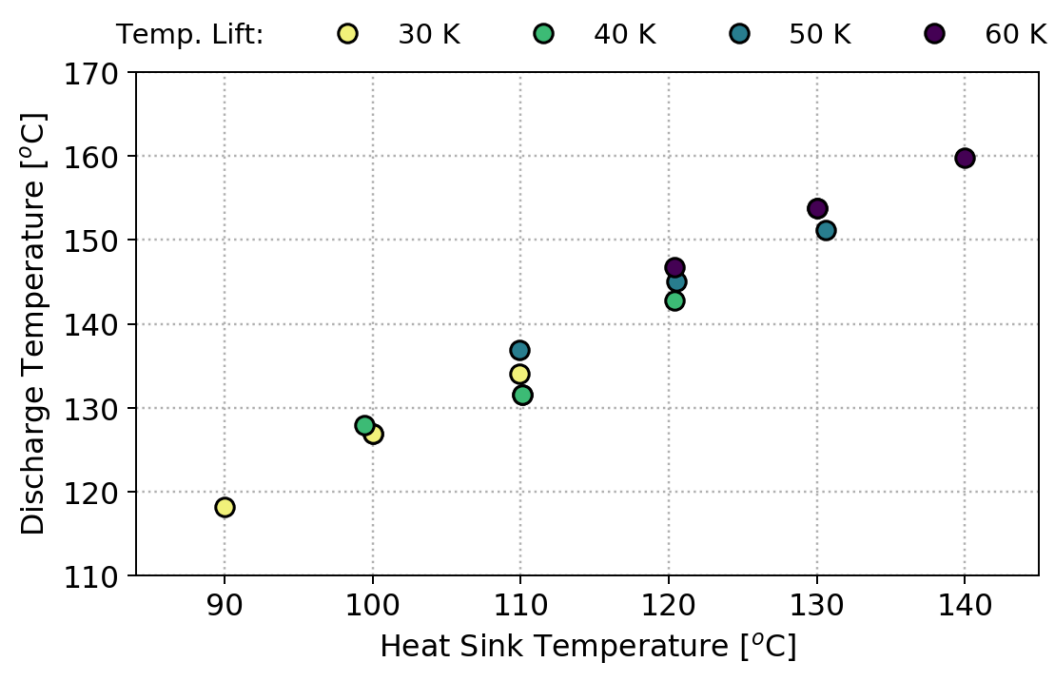

Fig. 5.9. Experimental discharge temperature as function of the heat sink temperature.

\section{- Heating capacity}

The heating capacity at the condenser (refrigerant side), which has been validated in a heat balance in Section 3.3, is shown in Fig. 5.10, and the estimated uncertainty propagation is described in Table 5.3.

The heat absorbed in the evaporator was revalorised, becoming a useful heat upon transfer to the secondary fluid. The relevance of the heat source and sink operating temperatures is reflected in this parameter, which is affected by the refrigerant mass flow rate and the enthalpy difference at the condenser. This HTHP prototype can produce between 16.20 and $17.51 \mathrm{~kW}$ of heat at the highest heat source temperature, and between 10.92 and $12.09 \mathrm{~kW}$ at the lowest temperature $\left(60{ }^{\circ} \mathrm{C}\right)$. The heat sink temperature has a small effect on this parameter, and a variation of the source does not deteriorate the heat production. Thus, attention must be paid to the heat source temperature during the HTHP design stage. 


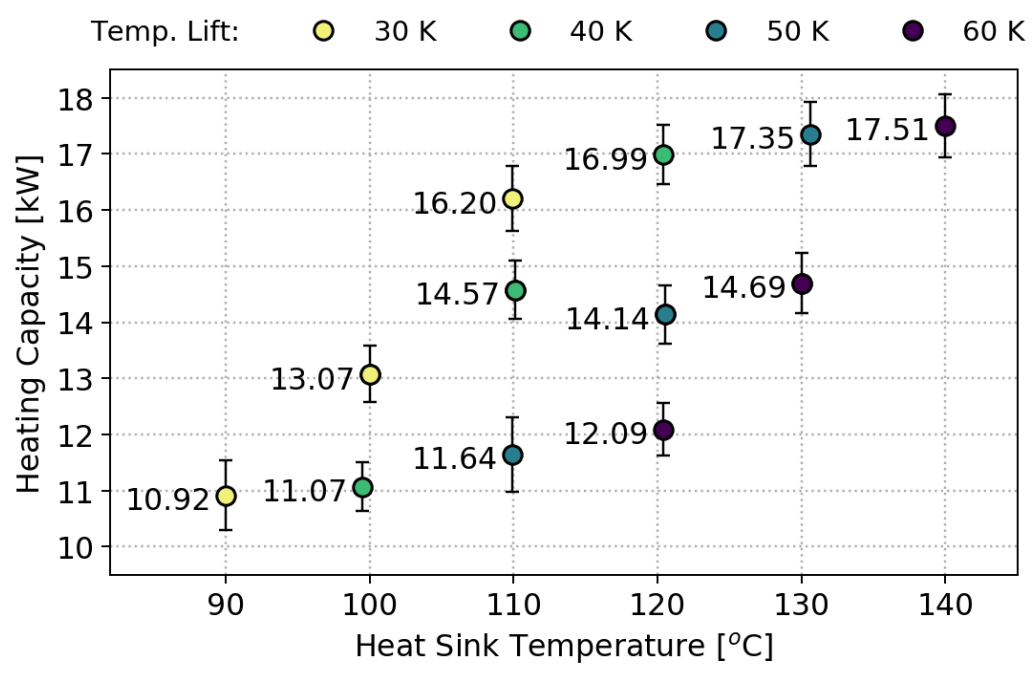

Fig. 5.10. Experimental heating capacity at the tested conditions with the estimated uncertainty propagation.

\section{- Coefficient of Performance (COP)}

The COP of the HTHP is obtained using Eq. (5.24) and the previously presented values of the compressor power consumption and heating capacity.

$$
C O P=\frac{\dot{Q}_{k}}{\dot{W}_{C}}
$$

Fig. 5.11 shows an overview of the experimental COP results over the different operating points analysed.

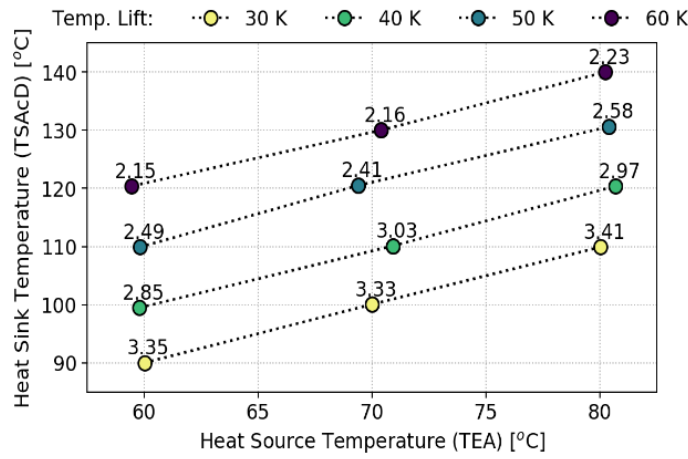

(a)

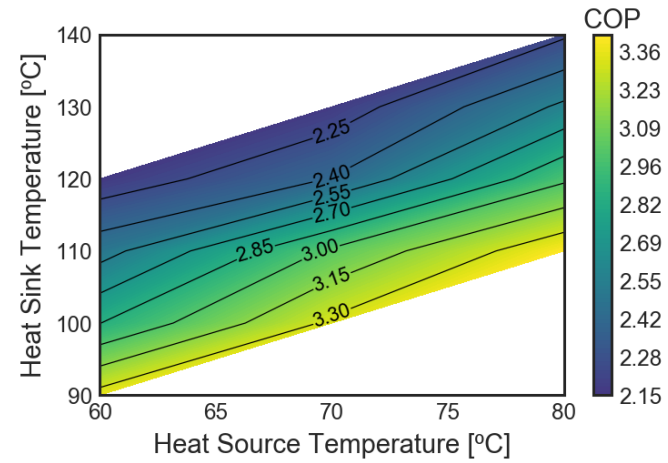

(b)

Fig. 5.11. Experimental COP results at different operating points: (a) Experimental steady-state of the preliminary COP results and (b) COP mapping of the experimental results.

Although the compressor power consumption and heating capacity increase as the heat sink temperature increases, the specific enthalpy difference at the compressor presents an increase of the specific enthalpy differences at the condenser. Thus, the refrigerant mass flow rate has no direct effect on the COP; instead, the major effect is caused by the compression ratio and therefore, the temperature 
lift, as shown in Fig. 5.12. Consequently, four levels of COP can be observed, corresponding to the four temperature lifts considered, along with the uncertainties and errors presented in Table 5.4.

Table 5.3. Summary of the heating capacity values along with the absolute and relative uncertainties.

\begin{tabular}{cccccc}
\hline $\begin{array}{c}\boldsymbol{T}_{\text {sink,out }} \\
\left({ }^{\circ} \mathbf{C}\right)\end{array}$ & $\begin{array}{c}\boldsymbol{T}_{\text {source,in }} \\
\left.\mathbf{(}^{\mathbf{}} \mathbf{C}\right)\end{array}$ & $\begin{array}{c}\text { Temperature } \\
\text { Lift }(\mathbf{K})\end{array}$ & $\begin{array}{c}\text { Heating } \\
\text { Capacity } \\
(\mathbf{k W})\end{array}$ & $\begin{array}{c}\text { Absolute } \\
\text { Uncertainty }\end{array}$ & $\begin{array}{c}\text { Relative } \\
\text { Uncertainty }\end{array}$ \\
\hline 90.0 & 60.0 & 30 & 10.92 & \pm 0.62 & $\pm 5.65 \%$ \\
100.1 & 70.0 & 30 & 13.07 & \pm 0.50 & $\pm 3.84 \%$ \\
109.9 & 80.0 & 30 & 16.20 & \pm 0.58 & $\pm 3.56 \%$ \\
99.5 & 59.8 & 40 & 11.07 & \pm 0.43 & $\pm 3.91 \%$ \\
110.1 & 70.9 & 40 & 14.57 & \pm 0.52 & $\pm 3.55 \%$ \\
120.4 & 80.7 & 40 & 16.99 & \pm 0.54 & $\pm 3.15 \%$ \\
109.9 & 59.8 & 50 & 11.64 & \pm 0.67 & $\pm 5.73 \%$ \\
120.5 & 69.4 & 50 & 14.14 & \pm 0.52 & $\pm 3.67 \%$ \\
130.6 & 80.4 & 50 & 17.35 & \pm 0.57 & $\pm 3.29 \%$ \\
120.4 & 59.4 & 60 & 12.09 & \pm 0.47 & $\pm 3.87 \%$ \\
130.0 & 70.4 & 60 & 14.69 & \pm 0.54 & $\pm 3.64 \%$ \\
140.0 & 80.2 & 60 & 17.51 & \pm 0.56 & $\pm 3.21 \%$ \\
\hline
\end{tabular}

Table 5.4. Summary of the COP values along with the absolute and relative uncertainties.

\begin{tabular}{cccccc}
\hline $\begin{array}{c}\boldsymbol{T}_{\text {sink,out }} \\
\left({ }^{\mathbf{O}} \mathbf{C}\right)\end{array}$ & $\begin{array}{c}\boldsymbol{T}_{\text {source,in }} \\
\left({ }^{\mathbf{O}} \mathbf{C}\right)\end{array}$ & $\begin{array}{c}\text { Temperature } \\
\text { Lift (K) }\end{array}$ & COP & $\begin{array}{c}\text { Absolute } \\
\text { Uncertainty }\end{array}$ & $\begin{array}{c}\text { Relative } \\
\text { Uncertainty }\end{array}$ \\
\hline 90.0 & 60.0 & 30 & 3.35 & \pm 0.21 & $\pm 6.15 \%$ \\
100.1 & 70.0 & 30 & 3.33 & \pm 0.15 & $\pm 4.38 \%$ \\
109.9 & 80.0 & 30 & 3.41 & \pm 0.14 & $\pm 4.07 \%$ \\
99.5 & 59.8 & 40 & 2.85 & \pm 0.13 & $\pm 4.44 \%$ \\
110.1 & 70.9 & 40 & 3.03 & \pm 0.12 & $\pm 4.06 \%$ \\
120.4 & 80.7 & 40 & 2.97 & \pm 0.11 & $\pm 3.66 \%$ \\
109.9 & 59.8 & 50 & 2.49 & \pm 0.15 & $\pm 6.06 \%$ \\
120.5 & 69.4 & 50 & 2.41 & \pm 0.10 & $\pm 4.13 \%$ \\
130.6 & 80.4 & 50 & 2.58 & \pm 0.10 & $\pm 3.76 \%$ \\
120.4 & 59.4 & 60 & 2.15 & \pm 0.09 & $\pm 4.27 \%$ \\
130.0 & 70.4 & 60 & 2.16 & \pm 0.09 & $\pm 4.07 \%$ \\
140.0 & 80.2 & 60 & 2.23 & \pm 0.08 & $\pm 3.66 \%$ \\
\hline
\end{tabular}

It is observed that the available waste heat and the heat demand conditions have a great influence on the energy efficiency of the HTHP system. Hence, the highest COP, with a value of 3.41, is achieved at a $110{ }^{\circ} \mathrm{C}$ heat sink temperature and $80{ }^{\circ} \mathrm{C}$ heat source temperature. Nevertheless, the most interesting performance value for this application is achieved at a heat source temperature of $80^{\circ} \mathrm{C}$ and heat sink temperature of $140{ }^{\circ} \mathrm{C}$ with a COP value of 2.23 . This performance value is considered relevant based on the comparison of other similar experimental installations with single stage configuration with IHX, using HFC-245fa as working fluid [8]. Nevertheless, further investigations 
on different configurations and working fluids could improve the energy efficiency of this technology, and make it a sustainable energy system.

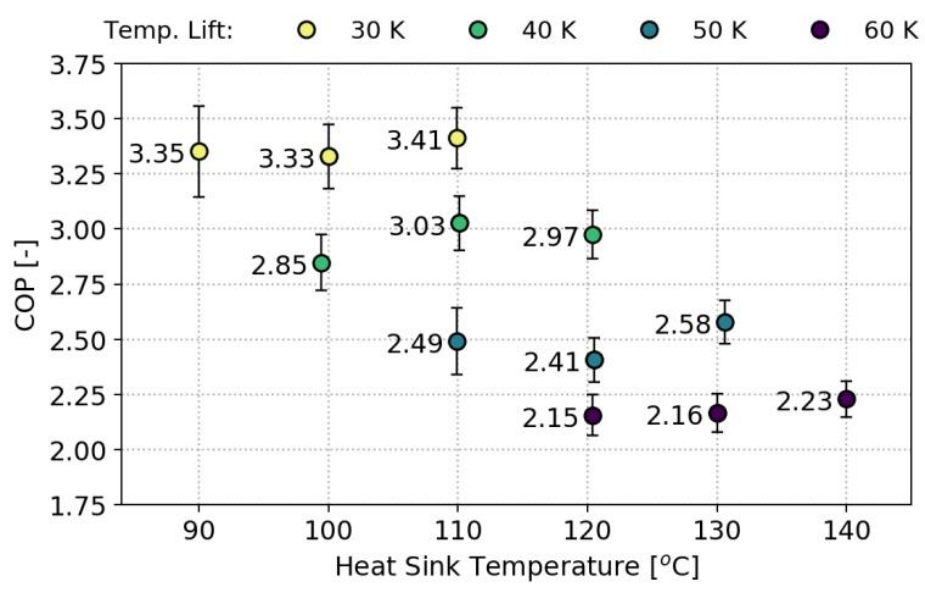

Fig. 5.12. Experimental $\mathrm{COP}$ at the tested conditions with the estimated uncertainty propagation.

\section{- Influence of the IHX}

An internal heat exchanger (IHX) becomes an interesting component that presents strong influence in the system performance, especially in high-temperature applications. Hence, estimated IHX influence in low-GWP alternatives based on experimental data can provide useful information for future designs or drop-in replacements. Firstly, experimental IHX effectiveness results, shown in Fig. 5.13 , is increasing as the heat sink temperature increases and therefore, this parameter will be critical for higher heating production temperature. Thus, the IHX influence is studied for the $140{ }^{\circ} \mathrm{C}$ heat sink temperature and $80{ }^{\circ} \mathrm{C}$ heat source temperature condition (highest temperature lift tested). The resulting experimental value of the IHX effectiveness $\left(\varepsilon_{I H X}\right)$ in HFC-245fa is 0.38 . This value is assumed constant for each refrigerant for the performance parameters calculations in a basic vapour compression cycle with IHX.

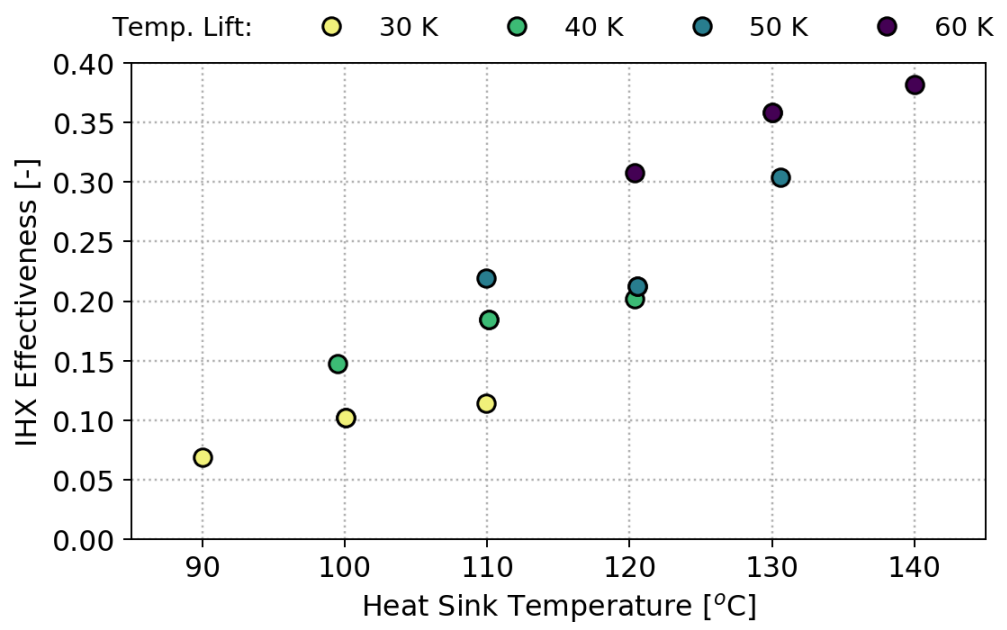

Fig. 5.13. Experimental IHX effectiveness in the different operating conditions. 


\subsubsection{Exergy results}

A general overview of the exergy efficiency, destruction, and RI of the main components and the overall vapor compression circuit is provided in Table 5.5 and 5.6. The maximum, minimum and average values of the experimental sets are included.

Table 5.5. Summary of the experimental exergy efficiency results.

\begin{tabular}{cc|cccccc}
\hline $\begin{array}{c}\text { Exergy } \\
\text { Parameters }\end{array}$ & Measure & Compressor & Condenser & Evaporator & $\begin{array}{c}\text { Expansion } \\
\text { Valve }\end{array}$ & IHX & System \\
\hline Exergy & Max & 63.27 & 96.24 & 49.54 & 27.54 & 73.92 & 30.80 \\
Efficiency & Ave & 60.30 & 90.01 & 41.74 & 27.44 & 51.08 & 25.48 \\
[\%] & Min & 58.21 & 87.91 & 32.63 & 27.28 & 27.29 & 20.94 \\
\hline
\end{tabular}

Table 5.6. Summary of the experimental exergy destruction and RI results.

\begin{tabular}{cc|cccccc}
\hline $\begin{array}{c}\text { Exergy } \\
\text { Parameters }\end{array}$ & Measure & Compressor & Condenser & Evaporator & $\begin{array}{c}\text { Expansion } \\
\text { Valve }\end{array}$ & IHX & Total \\
\hline Exergy & Max & 2.71 & 0.63 & 0.41 & 1.21 & 0.44 & 4.83 \\
Destruction & Ave & 1.78 & 0.48 & 0.22 & 0.80 & 0.21 & 3.51 \\
{$[\mathbf{k W}]$} & Min & 1.12 & 0.36 & 0.09 & 0.45 & 0.05 & 2.29 \\
\hline \multirow{3}{*}{ RI [\%] } & Max & 56.70 & 17.27 & 12.68 & 26.58 & 11.26 & - \\
& Ave & 50.62 & 14.26 & 6.91 & 22.54 & 5.65 & - \\
& Min & 45.31 & 8.76 & 2.39 & 19.76 & 1.61 & - \\
\hline
\end{tabular}

From this information, one can see that in the expansion valve, the exergy efficiency is minimal compared to that in the other components. Given the logarithmic mean temperature difference between the secondary fluids and the refrigerant, the exergy efficiency is higher in the condenser than in the evaporator.

The RI of each component is represented graphically in Fig. 5.14. The compressor and the expansion valve are the components that show the highest RI values, with averages of 50.62 and $22.54 \%$, respectively. Hence, the compressor becomes the most influent component in the vapour compression system and the main source of system performance improvements. This is the case because the compressor is the cycle component with the highest mechanical and isentropic losses and therefore, the component with the higher reversibility of the system. Improvements in the compressor and the expansion valve will increase the energy efficiency of the whole installation. 


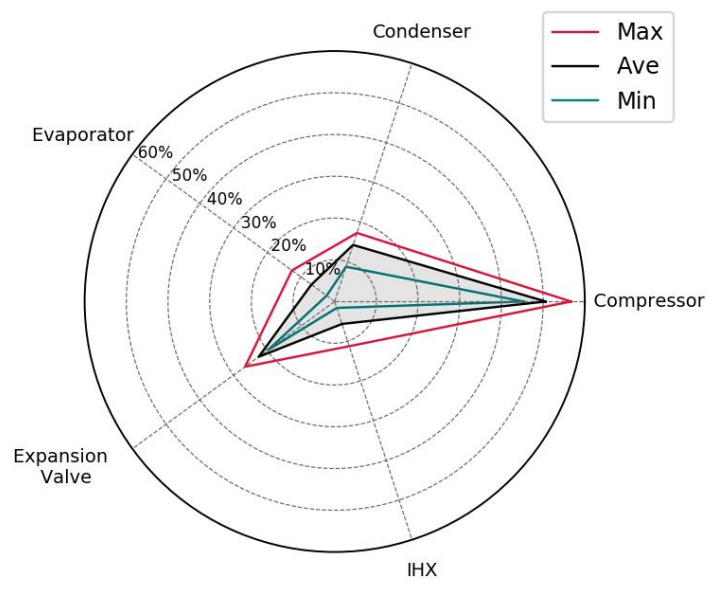

Fig. 5.14. RI diagram of each vapour compression component

Fig. 5.15 shows the exergy diagram obtained at a heat sink temperature of $140{ }^{\circ} \mathrm{C}$ and heat source temperature of $80{ }^{\circ} \mathrm{C}$. This figure helps to understand that a big part of the exergy is lost in the compressor, followed by the expansion valve. Thus, the experimental exergy analysis of this HTHP prototype installation provides useful information on the primary source of potential performance improvements. In this case, the most significant exergy destruction occurs at the compressor, which could be improved in future designs, by developing novel lubricant oils and mechanical construction designs. Furthermore, the expansion valve is the cycle component with the second highest value of exergy destruction. Accordingly, the number of studies on ejectors as alternatives to expansion valves have increased recently, and the performance of HTHPs are improving.

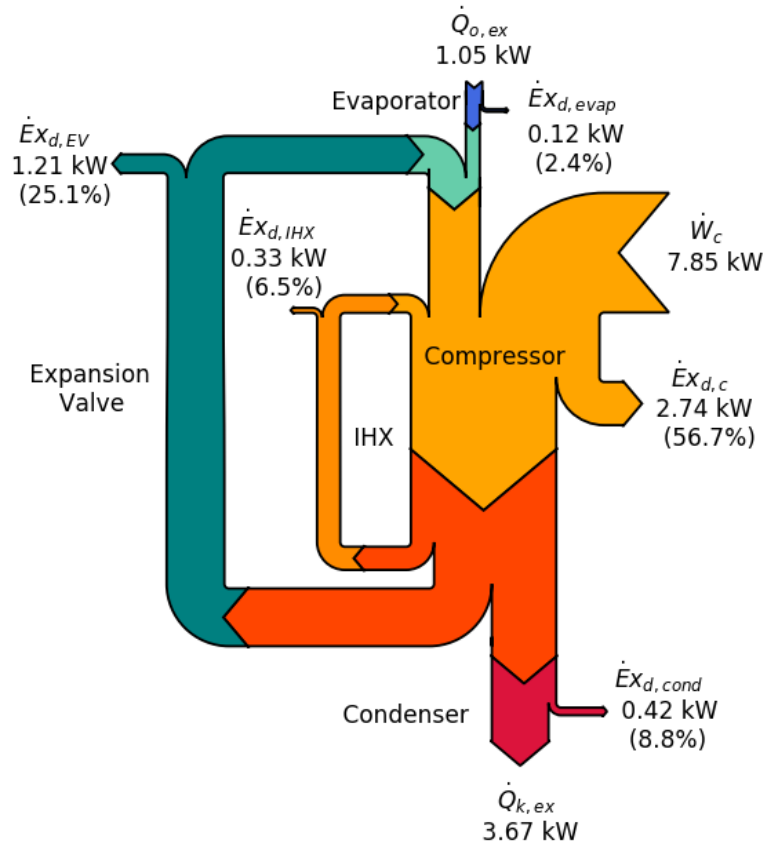

Fig. 5.15. Sankey diagram of the exergy flows in the HTHP system operating at heat sink temperature of 140 ${ }^{\circ} \mathrm{C}$ and heat source temperature of $80^{\circ} \mathrm{C}$. 


\subsubsection{Semi-empirical low-GWP refrigerants assessment}

To provide more in-depth knowledge of the potential of alternative low-GWP refrigerants, theoretical evaluations of HCFO-1224yd(Z), HCFO-1233zd(E), and HFO-1336mzz(Z), selected because of their similarities with the traditional HFC-245fa, were carried out, as shown in Fig. 5.16. The alternative refrigerant present similar or even higher critical temperatures than HFC-245fa. Although HCFO$1224 \mathrm{yd}(\mathrm{Z})$ and HCFO-1233zd(E) show similar saturated vapour curve slopes, different from that of HFO-1336mzz(Z).

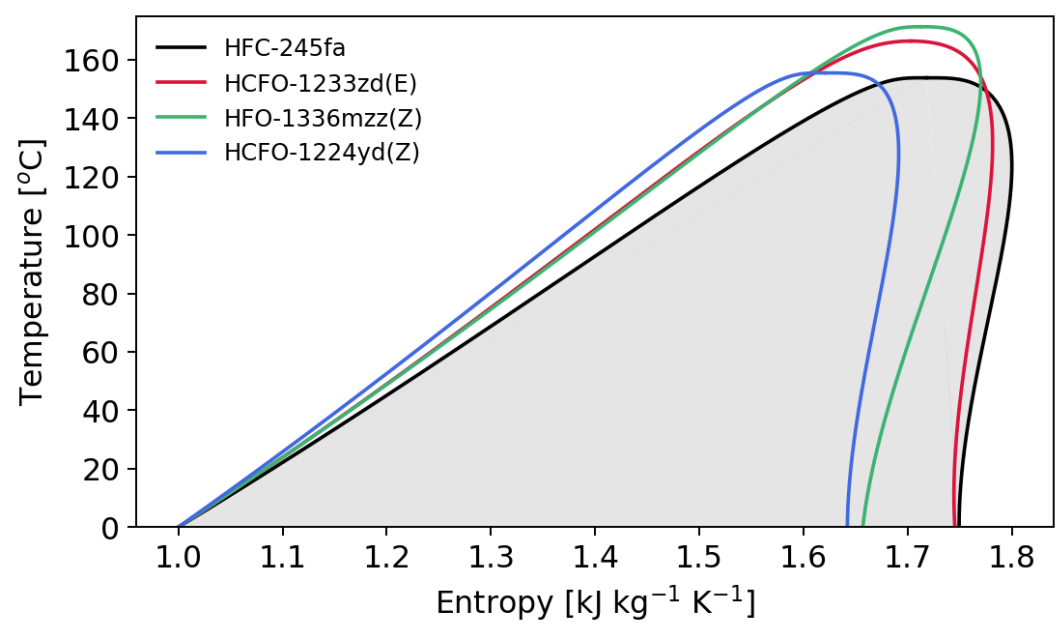

Fig. 5.16. T-s diagram of the low-GWP refrigerants alternative to HFC-245fa: HCFO-1233zd(E), HCFO$1224 \mathrm{yd}(\mathrm{Z})$ and HFO-1336mzz(Z).

Table 5.7 shows the main thermodynamic properties of HFC-245fa and the potential alternatives refrigerants. It can be seen from the table that the suction density of HCFO-1233zd(E) and HCFO$1224 \mathrm{yd}(\mathrm{Z})$ are close to the reference fluid, while that of $\mathrm{HFO}-1336 \mathrm{mzz}(\mathrm{Z})$ is lower. Thus, a higher suction volumetric flow rate is expected for HFO- $1336 \mathrm{mzz}(\mathrm{Z})$ than the other refrigerants, which causes a decrease of the volumetric heating capacity.

Hence, the thermodynamic properties and saturated vapour slope differences of HFO-1336mzz(Z) compared to the other refrigerants will be the main cause of the distinctive behaviour that this refrigerant shows in the results. 
Table 5.7. Properties of HFC-245fa and the alternative low GWP refrigerants.

\begin{tabular}{|c|c|c|c|c|}
\hline Parameters & HFC-245fa & HFO-1336mzz(Z) & HCFO-1233zd(E) & HCFO-1224yd(Z) \\
\hline $\begin{array}{l}\text { Molecular weight } \\
\left(\mathrm{g} \cdot \mathrm{mol}^{-1}\right)\end{array}$ & 134.05 & 164.06 & 130.50 & 148.49 \\
\hline $\begin{array}{l}\text { Critical } \\
\text { temperature }\left({ }^{\circ} \mathrm{C}\right)\end{array}$ & 153.86 & 171.35 & 166.45 & 155.54 \\
\hline $\begin{array}{l}\text { Critical pressure } \\
(\mathrm{MPa})\end{array}$ & 3.65 & 2.90 & 3.62 & 3.34 \\
\hline $\begin{array}{l}\text { Normal boiling } \\
\text { point }(\mathrm{NBP})\left({ }^{\circ} \mathrm{C}\right)\end{array}$ & 15.05 & 33.45 & 18.26 & 14.62 \\
\hline $\begin{array}{l}\text { Tested thermal } \\
\text { stability }\left({ }^{\circ} \mathrm{C}\right)\end{array}$ & 250 & 250 & 175 & 175 \\
\hline $\begin{array}{l}\text { Suction density } \\
\left(\mathrm{kg} \cdot \mathrm{m}^{-3}\right)\end{array}$ & 25.45 & 16.02 & 20.73 & 27.11 \\
\hline $\begin{array}{c}\text { ODP }(\mathrm{CFC}-11=1) \\
{[31]}\end{array}$ & 0 & 0 & 0.00034 & 0.00012 \\
\hline $\mathrm{GWP}_{100 \text {-years }}[31]$ & 858 & 2 & 1 & $<1$ \\
\hline $\begin{array}{l}\text { ASHRAE Std. } 34 \\
\text { safety class [31] }\end{array}$ & B1 & A1 & A1 & A1 \\
\hline
\end{tabular}

${ }^{\mathrm{a}}$ At condensing temperature of $60^{\circ} \mathrm{C}$

The theoretical evaluation of the alternative low-GWP refrigerants is based on the corrected compressor efficiencies obtained from Eqs. (5.25) and (5.26). These equations consider the difference in thermodynamic properties between the reference refrigerant HFC-245fa and the alternatives.

$$
\eta_{\text {is,low } G W P}=\frac{\left[\left(\frac{P_{2}}{P_{1}}\right)^{\left(\frac{\gamma-1}{\gamma}\right)}\right]_{l o w G W P}}{\left[\left(\frac{P_{2}}{P_{1}}\right)^{\left(\frac{\gamma-1}{\gamma}\right)}\right]_{H F C-245 f a}} \cdot \eta_{i s, H F C-245 f a}
$$




$$
\eta_{\text {vol, low } G W P}=1-\frac{\left[\left(\frac{P_{2}}{P_{1}}\right)^{\left(\frac{1}{\gamma}\right)}\right]_{\text {low } G W P}}{\left[\left(\frac{P_{2}}{P_{1}}\right)^{\left(\frac{1}{\gamma}\right)}\right]_{H F C-245 f a}}\left(1-\eta_{v o l, H F C-245 f a}\right)
$$

The corrected compressor efficiencies for each refrigerant enables the theoretical evaluation of each candidate based on the HFC-245fa experimental results. The same evaporating and condensing temperatures of HFC-245fa presented in Section 4.1.4 were considered, and the electromechanical efficiency $\left(\eta_{e m}\right)$ is assumed to be constant. The subcooling and superheating degrees are assumed equal for each refrigerant. Fig. 5.17 shows the isentropic and volumetric corrected efficiencies of the low-GWP refrigerant alternatives. The experimental results of HFC-245fa illustrate that the compressor isentropic efficiency tends to increase with increasing pressure ratio until the maximum pressure ratio between 3.4 and 4 is achieved, after which the isentropic efficiency decreases. Similarly, the compressor volumetric efficiency increases until the maximum value is achieved, which is higher than that of the isentropic efficiency, after which the compressor volumetric efficiency decreases slowly. Both isentropic and volumetric efficiencies present reasonable values for this application technology.

The alternative low-GWP refrigerants have trends similar to the reference working fluid HFC-245fa. While HCFO-1224yd(Z) and HCFO-1233zd(E) have similar behaviour to HFC-245fa in both efficiencies, HFO-1336mzz(Z) shows an entirely different trend. At lower pressure ratios, all candidates show lower isentropic efficiencies: this reduction is higher for HFO-1336mzz(Z). However, in this condition, HCFO-1224yd(Z) and HCFO-1233zd(E) have higher volumetric efficiency than HFC-245fa, whereas HFO-1336mzz(Z) presents a reduction of this value. For higher pressure ratios, HFO-1336mzz(Z) presents higher isentropic and volumetric efficiencies than HFC$245 \mathrm{fa}$, whereas the other candidates have similar or even lower values of these compressor parameters.

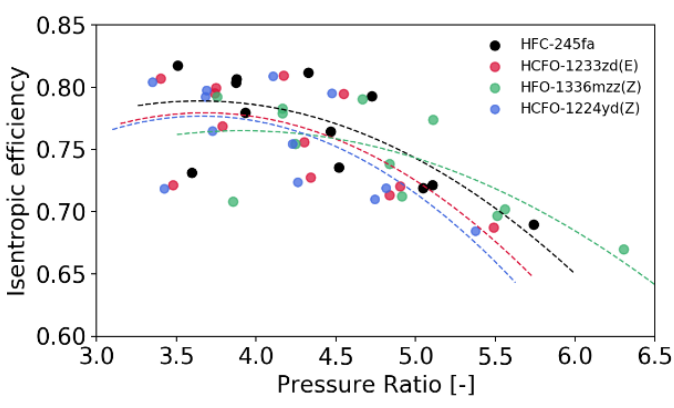

(a)

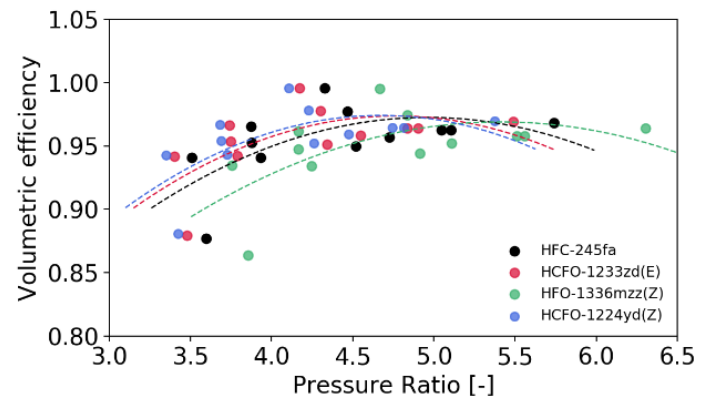

(b)

Fig. 5.17. Isentropic and volumetric corrected efficiencies of the alternative low-GWP refrigerants. 
The COP results are shown in Fig. 5.18, HFC-245fa shows lower COP values than alternative lowGWP refrigerants. While HCFO-1233zd(E) and HCFO-1224zd(Z) have similar trends, HFO$1336 \mathrm{mzz}(\mathrm{Z})$ has the highest COP. This fluid also presents a similar trend to HFC-245fa.

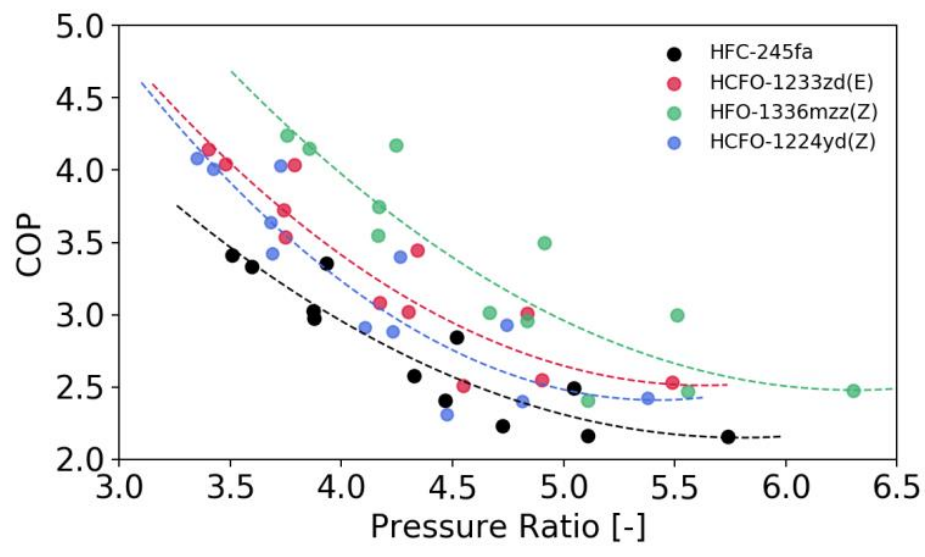

Fig. 5.18. Estimated COP versus pressure ratio for alternative low-GWP refrigerants.

Although HFO-1336mzz(Z) presents the highest COP, it presents the lowest heating capacity for the same compressor volume swept, as shown in Fig. 5.19. Hence, it requires a larger compressor than the other alternatives, which exhibit heating capacities similar to that of HFC-245fa. These results are in concordance with the conclusions achieved by Mateu-Royo et al. [32] for the thermodynamic analysis of HCFO and HFO compared to HFC-245fa. Therefore, in the case of a retrofit, the selected HCFOs would offer a good alternative and hence they will be considered in future experimental tests with the prototype.

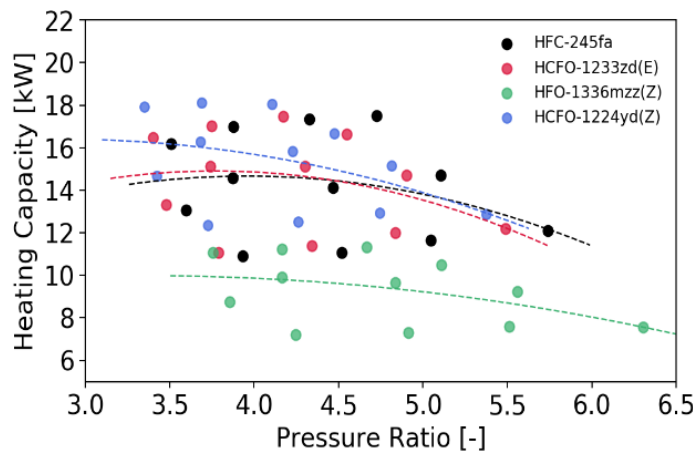

(a)

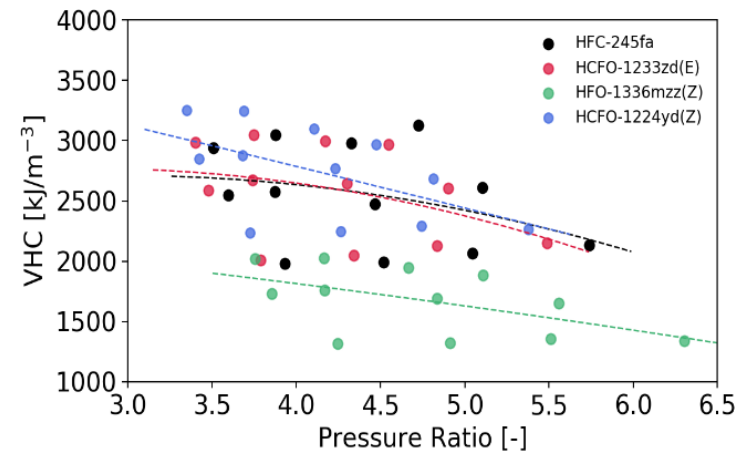

(b)

Fig. 5.19. Estimated performance parameters for alternative low-GWP refrigerants: a) Heating capacity and b) volumetric heating capacity (VHC).

Additionally, the basic cycle (without IHX) is also simulated to consider the theoretical influence of IHX in each refrigerant and provide valuable knowledge in future experimental tests. The experimental results of HFC-245fa with IHX is used as a reference to present the results calculated as the relative difference. The refrigerant that mostly benefited by the IHX is the HFO-1336mzz(Z), followed by HCFO-1224yd(Z) and HFC-245fa, as shown in Fig. 5.20. The first observation can be justified attending to that mentioned by Mateu-Royo et al. [11], who mentions that the refrigerant 
with the highest IHX benefit is the one that performs worse in the basic cycle. Then, the similarity between the traditional refrigerant HFC-245fa and the alternative low-GWP refrigerants can be explained attending to the similar thermophysical properties of both fluids, highlighted in MateuRoyo et al. [32].

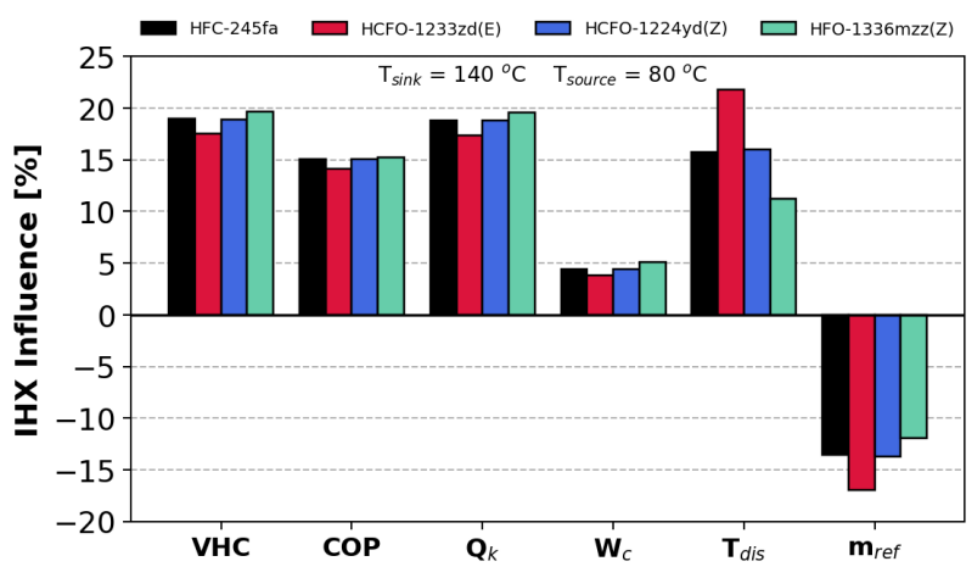

Fig. 5.20. Estimated IHX influence in each refrigerant for different operating and performance parameters.

\subsubsection{Environmental evaluation of HTHP integration as a waste heat recovery system}

In addition to the primary energy consumption, the equivalent $\mathrm{CO}_{2}$ emissions represent another useful indicator for policymakers when comparing different heating technologies. As the HTHP prototype is designed to substitute fossil fuel burners in industrial processes, this section compares it with a conventional natural gas-powered burner in terms of $\mathrm{CO}_{2}$ equivalent emissions.

CHP systems tend to improve the overall system efficiency as they produce electricity along with the heat recovered from the exhausts gases [33]. Hence, CHP systems improve the usage of primary energy, and therefore, the European Directive 2012/27/EU [34] encourage European countries to use these systems in order to reduce greenhouses gasses emissions. Nevertheless, CHP requires cooling systems to control the temperature inside the combustion chamber. Although both heats gained by combustion air cooling and heat extracted from jacket cooling water could be used directly for building heating (offices or industrial building) along with the production of domestic hot water, the outlet temperatures of this cooling engine system are between $70-100{ }^{\circ} \mathrm{C}$ [35] and therefore cannot be used for electricity or steam production useful for the industry. Hence, the low-grade heat extracted from jacket cooling water of the engine, which represents up to $30 \%$ of the total energy input in the system [35], is rejected to the ambient as waste heat, as shown in Fig. 5.21.

This low-grade waste heat can be recovered and upgraded using an HTHP system [36]. HTHP can absorb the low-grade waste heat from the cooling engine system and upgrade it up to $140{ }^{\circ} \mathrm{C}$ in order to produce steam or pressurized water useful again for the industrial processes. Consequently, the primary energy of the system along with the total equivalent $\mathrm{CO}_{2}$ emissions is reduced, improving the performance efficiency of the overall system and decarbonizing the industrial sector. A schematic representation of the integration of HTHP as waste heat system is presented in Fig. 5.21. 


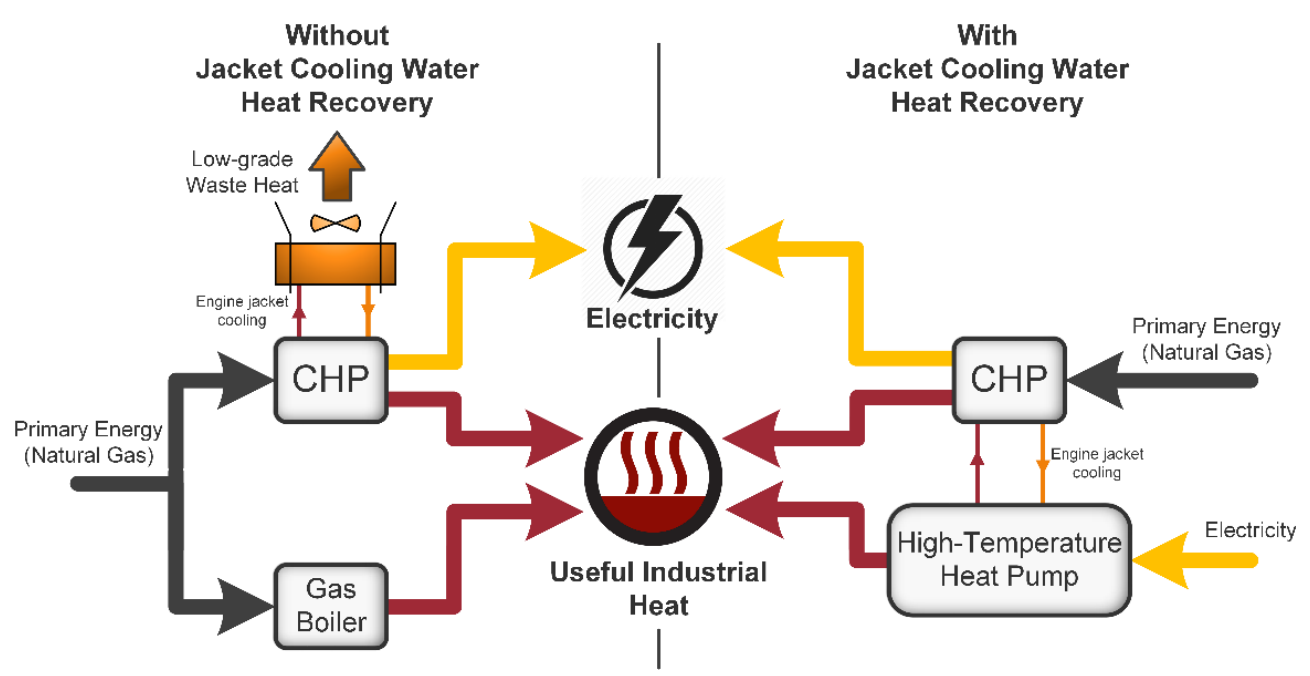

Fig. 5.21. Integration of HTHP as low-grade waste heat recovery system in CHP installations.

The Total Equivalent Warming Impact (TEWI) indicator has been calculated to quantify the equivalent $\mathrm{CO}_{2}$ emission due to the accidental losses of refrigerant (direct emissions) and to the energy consumption of the HTHP system (indirect emissions). It gives an appropriate approximation to the real environmental impact of vapour compression systems. TEWI method is based on Eq. (5.27) $[37,38]$.

$$
T E W I=G W P \cdot L \cdot n+G W P \cdot m_{r} \cdot(1-\alpha)+n \cdot E_{a} \cdot \beta
$$

The constant evaporation temperature of $80^{\circ} \mathrm{C}$ and four different condensing temperatures, 110,120 , 130 and $140{ }^{\circ} \mathrm{C}$, have been analysed. Also, this method requires some necessary assumptions depending on the application. The HTHP evaporator exchanges waste heat, based on the experimental data, during 7884 hours per year ( $90 \%$ of the time). The lifespan of the system $(n)$ is 15 years. The IPCC recommended an annual leakage rate for indirect refrigeration systems contained in machinery rooms of $5 \%$ of the total refrigerant charge $(20 \mathrm{~kg}$ ) [39]. Nevertheless, in other to have an overview of the sensitivity of the refrigerant leak, 5,10 and $15 \%$ of the total refrigerant charge are considered as annual leakage rate for HTHP systems. The recycling factor of the refrigerant $(\alpha)$ is omitted for this comparison.

The calculations have been performed at the UE level, and the indirect emission factor $(\beta)$ value is taken from the one proposed for the European Union by the European Environment Agency, $275.9 \mathrm{~g}$ $\mathrm{CO}_{2} \mathrm{kWh}^{-1}$ [40]. For what concerns the natural gas boiler, the efficiency varies between 0.87 and 0.83 for heat sink temperatures between 110 and $140{ }^{\circ} \mathrm{C}$ (respectively) [41] and an emissions factor of 205 $\mathrm{g} \mathrm{CO}_{2} \mathrm{kWh}^{-1}$ has been used [42].

The resulting $\mathrm{CO}_{2}$ equivalent emissions reduction of both systems are shown in Fig. 5.22. The environmental results show that HTHP system could reduce the equivalent $\mathrm{CO}_{2}$ emission up to $57.3 \%$ compared to conventional heating technology, in this case, a natural gas boiler. Moreover, the refrigerant leak in HTHP system using HFC-245fa could have a slight influence on the total emissions. However, it could also be concluded that the use of the previously mentioned low-GWP 
refrigerants, with lower values of GWP and higher energy performance than HFC-245fa, could lead to higher reductions of the equivalent $\mathrm{CO}_{2}$ emissions.

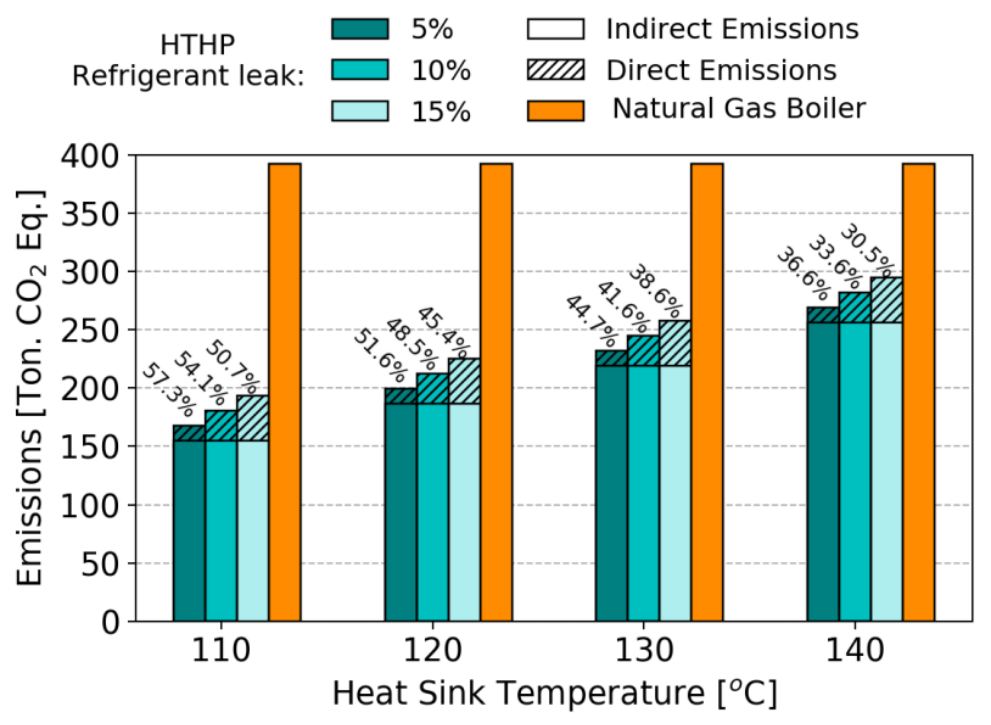

Fig. 5.22. Equivalent $\mathrm{CO} 2$ emission reduction and values of HTHP as recovery system compared to conventional heating technology, natural gas boiler.

\subsection{Conclusions}

In this paper, we presented the first results of a novel HTHP based on a scroll compressor with an IHX for low-grade waste heat recovery. The focus was on the analysis of the different system parameters to provide guidelines for further design improvement and development. To this end, a twofold approach was followed:

1. System parameters, such as COP and the heating capacity, were determined for a wide range of heat sink and heat source temperatures in order to provide a comprehensive energy evaluation of the HTHP prototype. Moreover, an experimental exergy analysis was realised to determine the components of the system with the highest improvement potential through the exergy evaluation of each vapour compression component.

2. The estimated performance behaviour of the low-GWP refrigerants considered, namely HCFO-1224yd(Z), HCFO-1233zd(E), and HFO-1336mzz(Z), were estimated based on a semi-empirical computational study to provide guidelines for further design advancements and development of HTHPs for low-grade waste heat recovery. Finally, an environmental evaluation of HTHP integration as a waste heat recovery system in CHP installations was presented to illustrate its potential in the decarbonisation of the energy-intensive industry sector.

The following conclusions can be drawn from the results of this study:

- The novel HTHP system with a scroll compressor provides significant performance improvements for low-grade waste heat recovery. At heat source temperature of $80{ }^{\circ} \mathrm{C}$ and 
heat sink temperature of $140{ }^{\circ} \mathrm{C}$, the COP was 2.23 . The highest COP was 3.41 , achieved at heat source and sink temperatures of 80 and $110^{\circ} \mathrm{C}$, respectively.

- The energy analysis showed that the heating capacity is highly influenced by the heat source temperature, while the COP is significantly affected by the heat sink temperature. Thus, other designs with a variable heat source and sink temperatures will require a detailed analysis of both performance parameters.

- The exergy analysis illustrated the areas of potential performance improvements. The compressor is the cycle component with the highest irreversibility and therefore, has the highest margin of improvement. Mechanical design and lubrication improvements in this component could increase the overall system efficiency. The expansion valve is the component with the second highest irreversibility of the system. Its replacement with ejector could improve the performance of the installation.

- The semi-empirical computational evaluation showed that either HCFO-1233zd(E) or HCFO-1224yd(Z) could be used possible drop-in replacements for HFC-245fa in hightemperature heat pumps. Although HFO-1336mzz(Z) presents a higher COP than the other refrigerants, it requires a greater compressor size to provide similar heating capacities owing to its lower suction density.

- The potential of HTHP as waste heat recovery systems was demonstrated with the integration of this technology in a CHP installation. The environmental results showed that the HTHP system could reduce the equivalent $\mathrm{CO}_{2}$ emission up to $57.3 \%$ compared to conventional heating technologies, in this case, a natural gas boiler.

\section{References}

[1] Wesseling JH, Lechtenböhmer S, Åhman M, Nilsson LJ, Worrell E, Coenen L. The transition of energy intensive processing industries towards deep decarbonization: Characteristics and implications for future research. Renew Sustain Energy Rev 2017;79:1303-13. doi:10.1016/J.RSER.2017.05.156.

[2] Bataille C, Åhman M, Neuhoff K, Nilsson LJ, Fischedick M, Lechtenböhmer S, et al. A review of technology and policy deep decarbonization pathway options for making energy-intensive industry production consistent with the Paris Agreement. J Clean Prod 2018;187:960-73. doi:10.1016/J.JCLEPRO.2018.03.107.

[3] Meyers S, Schmitt B, Vajen K. The future of low carbon industrial process heat: A comparison between solar thermal and heat pumps. Sol Energy 2018;173:893-904. doi:10.1016/J.SOLENER.2018.08.011.

[4] IPCC. Climate Change 2014: Synthesis Report. Contribution of Working Groups I, II and III to the Fifth Assessment Report of the Intergovernmental Panel on Climate Change [Core Writing Team, R.K. Pachauri and L.A. Meyer (eds.)]. Geneva, Switzerland, 2014.

[5] Forman C, Muritala IK, Pardemann R, Meyer B. Estimating the global waste heat potential. Renew Sustain Energy Rev 2016;57:1568-79. doi:10.1016/j.rser.2015.12.192.

[6] Seck GS, Guerassimoff G, Maïzi N. Heat recovery using heat pumps in non-energy intensive 
industry: Are Energy Saving Certificates a solution for the food and drink industry in France? Appl Energy 2015;156:374-89. doi:10.1016/j.apenergy.2015.07.048.

[7] Brückner S, Liu S, Miró L, Radspieler M, Cabeza LF, Lävemann E. Industrial waste heat recovery technologies: An economic analysis of heat transformation technologies. Appl Energy 2015;151:157-67. doi:10.1016/j.apenergy.2015.01.147.

[8] Arpagaus C, Bless F, Uhlmann M, Schiffmann J, Bertsch SS. High temperature heat pumps: Market overview, state of the art, research status, refrigerants, and application potentials. Energy 2018;152:985-1010. doi:10.1016/J.ENERGY.2018.03.166.

[9] Wang JF, Brown C, Cleland DJ. Heat pump heat recovery options for food industry dryers. Int J Refrig 2018;86:48-55. doi:10.1016/J.IJREFRIG.2017.11.028.

[10] Bamigbetan O, Eikevik TM, Nekså P, Bantle M. Review of vapour compression heat pumps for high temperature heating using natural working fluids. Int J Refrig 2017;80:197-211. doi:10.1016/j.jijrefrig.2017.04.021.

[11] Mateu-Royo C, Navarro-Esbrí J, Mota-Babiloni A, Amat-Albuixech M, Molés F. Theoretical evaluation of different high-temperature heat pump configurations for low-grade waste heat recovery. Int J Refrig 2018. doi:10.1016/j.ijrefrig.2018.04.017.

[12] Cao X-Q, Yang W-W, Zhou F, He Y-L. Performance analysis of different high-temperature heat pump systems for low-grade waste heat recovery. Appl Therm Eng 2014;71:291-300. doi:10.1016/j.applthermaleng.2014.06.049.

[13] Mota-Babiloni A, Mateu-Royo C, Navarro-Esbrí J, Molés F, Amat-Albuixech M, BarragánCervera Á. Optimisation of high-temperature heat pump cascades with internal heat exchangers using refrigerants with low global warming potential. Energy 2018;165:1248-58. doi:10.1016/j.energy.2018.09.188.

[14] Yang W wei, Cao X qi, He Y ling, Yan F yu. Theoretical study of a high-temperature heat pump system composed of a $\mathrm{CO} 2$ transcritical heat pump cycle and a R152a subcritical heat pump cycle. Appl Therm Eng 2017;120:228-38. doi:10.1016/j.applthermaleng.2017.03.098.

[15] Liu Z, Zhao L, Zhao X, Li H. The occurrence of pinch point and its effects on the performance of high temperature heat pump. Appl Energy 2012;97:869-75. doi:10.1016/j.apenergy.2011.12.061.

[16] Zühlsdorf B, Jensen JK, Cignitti S, Madsen C, Elmegaard B. Analysis of temperature glide matching of heat pumps with zeotropic working fluid mixtures for different temperature glides. Energy 2018;153:650-60. doi:10.1016/J.ENERGY.2018.04.048.

[17] Bamigbetan O, Eikevik TM, Nekså P, Bantle M, Schlemminger C. Experimental investigation of a prototype R-600 compressor for high temperature heat pump. Energy 2019;169:730-8. doi:10.1016/J.ENERGY.2018.12.020.

[18] Chamoun M, Rulliere R, Haberschill P, Peureux J-L. Experimental and numerical investigations of a new high temperature heat pump for industrial heat recovery using water as refrigerant. Int J Refrig 2014;44:177-88. doi:10.1016/j.ijrefrig.2014.04.019.

[19] Bobelin D, Bourig A, Peureux J. Experimental results of a newly developed very high temperature industrial heat pump $\left(140^{\circ} \mathrm{C}\right)$ equipped with scroll compressors and working with a new blend refrigerant. Int Refrig Air Cond Conf 2012.

[20] Meroni A, Zühlsdorf B, Elmegaard B, Haglind F. Design of centrifugal compressors for heat 
pump systems. Appl Energy 2018;232:139-56. doi:10.1016/J.APENERGY.2018.09.210.

[21] Ma X, Zhang Y, Fang L, Yu X, Li X, Sheng Y, et al. Performance analysis of a cascade high temperature heat pump using R245fa and BY-3 as working fluid. Appl Therm Eng 2018;140:466-75. doi:10.1016/J.APPLTHERMALENG.2018.05.052.

[22] Zhang Y, Zhang Y, Yu X, Guo J, Deng N, Dong S, et al. Analysis of a high temperature heat pump using BY-5 as refrigerant. Appl Therm Eng 2017;127:1461-8. doi:10.1016/J.APPLTHERMALENG.2017.08.072.

[23] Yu X, Zhang Y, Kong L, Zhang Y. Thermodynamic analysis and parameter estimation of a high-temperature industrial heat pump using a new binary mixture. Appl Therm Eng 2018;131:715-23. doi:10.1016/j.applthermaleng.2017.12.039.

[24] Deng N, Jing X, Cai R, Gao J, Shen C, Zhang Y, et al. Molecular simulation and experimental investigation for thermodynamic properties of new refrigerant NBY-1 for high temperature heat pump. Energy Convers Manag 2019;179:339-48. doi:10.1016/J.ENCONMAN.2018.10.076.

[25] Arpagaus C, Bless F, Uhlmann M, Büchel E, Frei S, Schiffmann J, et al. High temperature heat pump using HFO and HCFO refrigerants - System design , simulation, and first experimental results. 17th Int Refrig Air Cond Conf Purdue, July 9-12, 2018 2018:1-10.

[26] Lemmon EW, Bell IH, Huber ML, McLinden MO. NIST Standard Reference Database: Reference Fluid Thermodynamic and Transport Properties-REFPROP, Version 10. Natl Inst Stand Technol Stand Ref Data Program, Boulder, CO 2018.

[27] Taylor BN, Kuyatt CE. Guidelines for Evaluating and Expressing the Uncertainty of NIST Measurement Results. Natl Inst Stand Technol 1994.

[28] Klein S. Engineering Equation Solver (EES) V10.6. Fchart Software, Madison, USA WwwFchartCom 2006.

[29] Dincer I, Rosen MA. Exergy: Energy, Environment and Sustainable Development (2nd Edition). Elsevier 2013.

[30] Hasan AA, Goswami DY, Vijayaraghavan S. First and second law analysis of a new power and refrigeration thermodynamic cycle using a solar heat source. Sol Energy 2002;73:38593. doi:10.1016/S0038-092X(02)00113-5.

[31] ASHRAE. ASHRAE Handbook Fundamentals. Am Soc Heating, Refrig Air-Conditioning Eng 2017.

[32] Mateu-Royo C, Navarro-Esbrí J, Mota-Babiloni A, Amat-Albuixech M, Molés F. Thermodynamic analysis of low GWP alternatives to HFC-245fa in high-temperature heat pumps: HCFO-1224yd(Z), HCFO-1233zd(E) and HFO-1336mzz(Z). Appl Therm Eng 2019. doi:10.1016/j.applthermaleng.2019.02.047.

[33] Martinez S, Michaux G, Salagnac P, Bouvier J-L. Micro-combined heat and power systems (micro-CHP) based on renewable energy sources. Energy Convers Manag 2017;154:262-85. doi:10.1016/J.ENCONMAN.2017.10.035.

[34] Directive 2012/27/EU of the European Parliament and of the Council of 25 October 2012 on energy efficiency, amending Directives 2009/125/EC and 2010/30/EU and repealing Directives 2004/8/EC and 2006/32/EC 2012. 
[35] Hoang AT. Waste heat recovery from diesel engines based on Organic Rankine Cycle. Appl Energy 2018;231:138-66. doi:10.1016/J.APENERGY.2018.09.022.

[36] Urbanucci L, Bruno JC, Testi D. Thermodynamic and economic analysis of the integration of high-temperature heat pumps in trigeneration systems. Appl Energy 2019;238:516-33. doi:10.1016/J.APENERGY.2019.01.115.

[37] Makhnatch P, Khodabandeh R. The role of environmental metrics (GWP, TEWI, LCCP) in the selection of low GWP refrigerant. Energy Procedia 2014;61:2460-3. doi:10.1016/j.egypro.2014.12.023.

[38] AIRAH. Methods of calculating Total Equivalent Warming Impact (TEWI). Best Pract Guidel Aust Inst Refrig Air Cond Heat 2012.

[39] IPCC. IPCC/TEAP special report on safeguarding the ozone layer and the global climate system: Issues related to hydrofluorocarbons and perfluorocarbons. Cambridge Publ Intergov Panel Clim Chang [by] Cambridge Univ Press 2005.

[40] EEA. Overview of electricity production and use in Europe. Eur Enviroment Agency 2018.

[41] Baldi S, Quang T Le, Holub O, Endel P. Real-time monitoring energy efficiency and performance degradation of condensing boilers. Energy Convers Manag 2017;136:329-39. doi:10.1016/J.ENCONMAN.2017.01.016.

[42] Scoccia R, Toppi T, Aprile M, Motta M. Absorption and compression heat pump systems for space heating and DHW in European buildings: Energy, environmental and economic analysis. J Build Eng 2018;16:94-105. doi:10.1016/J.JOBE.2017.12.006. 


\section{Chapter 6}

\section{Semi-Empirical and Environmental Assessment of the Low GWP Refrigerant HCFO-1224yd(Z) to Replace HFC-245fa in High Temperature Heat Pumps}

This paper investigates a promising low-GWP refrigerant, HCFO-1224yd(Z), as an environmentally friendly replacement for HFC-245fa in high temperature heat pumps (HTHPs). First, thermophysical properties of both fluids were analysed, and a single-stage cycle with Internal Heat Exchanger (IHX) was modelled. Then, a semi-empirical drop-in test replacement was assessed. The heat source temperature was fixed in $80^{\circ} \mathrm{C}$, whereas the heat sink temperature was varied from 110 to $140{ }^{\circ} \mathrm{C}$ to cover a wide range of industrial applications. The theoretical and semi-empirical results illustrate that HCFO-1224yd(Z) heating capacity becomes around 8.9\% lower than HFC-245fa. However, the higher suction density of $\mathrm{HCFO}-1224 y d(\mathrm{Z})$ compared to the reference fluid can compensate for this effect, reducing the compressor power consumption. Hence, HCFO-1224yd(Z) presents a COP increase up to $4.5 \%$ compared to the reference fluid. At heat sink temperature of $140{ }^{\circ} \mathrm{C}, \mathrm{HCFO}$ $1224 y d(Z)$ shows a COP of 2.33, whereas HFC-245fa only reaches 2.23. The carbon footprint assessment illustrates a significant equivalent CO2,eq emissions reduction down to $90 \%$, depending on the country (carbon emission factor). Therefore, HCFO-1224yd(Z) can be used as an alternative to HFC-245fa in HTHP systems due to its beneficial operating, energetic and environmental characteristics.

\subsection{Introduction}

Heat pumps are systems based on the thermodynamic principles that can revalorise heat using a relatively small electric energy. Recent heat pump prototypes have efficiently extended the operating ranges of this technology becoming possible to produce heating at temperatures from 90 to $140{ }^{\circ} \mathrm{C}$ $[1,2]$. This technological improvement modified the classification of the heat pumps, becoming known as high temperature heat pumps (HTHPs) [3]. HTHPs represent a strategical tool to decarbonise different EU industries with heat consumption between 100 and $150{ }^{\circ} \mathrm{C}$, covering around 21.5 TWh per year [4]. Apart from the HTHPs potential because of the gap in these temperatures, they also present higher energy performance, flexibility in design, and they can be combined with other technologies in trigeneration systems [5], or district heating networks [6], among other representative examples. 
Previous experimental studies illustrate that HTHP prototypes are based on different technologies and working fluids in basic cycle configurations. Bamigbetan et al. [7] used HC-600 in a basic cycle with an internal heat exchanger (IHX) and receiver to deliver heat at $115^{\circ} \mathrm{C}$. They use a modified piston compressor due to the operation at a high temperature, lubricated with synthetic oil and tested at frequencies from 30 to $50 \mathrm{~Hz}$. The total and isentropic efficiencies of the compressor were $74 \%$ and $83 \%$, respectively. Chamoun et al. [8] proposed twin-screw as the compressor technology and water as the refrigerant. The system is also composed by a plate condenser, flash tank, electrical expansion valve, and falling film evaporator. The rotational speed of the compressor was $5000 \mathrm{rpm}$, whereas the compression ratio achieved was 4.5. Bobelin et al. [9] obtained a supply heat up to $125^{\circ} \mathrm{C}$ with a developmental mixture as the refrigerant, using an HTHP composed by a scroll compressor, brazedplate evaporator, condenser, sub-cooler, and electronic expansion valve. The COP obtained was 4.48, for evaporating and condensing temperatures of 50 and $100{ }^{\circ} \mathrm{C}$, respectively. Meroni et al. [10] validated a centrifugal compressor model using air, HFC-134a, and carbon dioxide, developing a coupled system with a heat pump to supply steam at $150^{\circ} \mathrm{C}$.

HTHPs, mainly based on vapour compression technology, typically use hydrofluorocarbons (HFCs) as working fluids (refrigerants), which have high values of global warming potential (GWP) [3]. However, in 2014, the EU Regulation No. 517/2014 [11] gradually limited acquisition of HFCs, establishing market quotas to their consumption (put into the market). Given this situation, the commonly called fourth generation of refrigerants appeared to replace HFCs [12]. HFC-245fa is considered the reference fluid for high temperature applications up to $140{ }^{\circ} \mathrm{C}$. Therefore, different low GWP alternatives are available to replace HFC-245fa to promote the sustainable development of HTHPs systems [13].

A prominent candidate is $\mathrm{HCFO}-1224 \mathrm{yd}(\mathrm{Z})$, an unsaturated organic compound approved in 2017 by the American Society of Heating, Refrigerating, and Air Conditioning Engineers (ASHRAE) [14] and proposed for HFC-245fa replacement in applications like centrifugal chiller, HTHPs, or ORCs, among others. The main advantages are its GWP value below the unity [15], and it is considered a low-pressure refrigerant, as happens for HFC-245fa, and is classified as A1 refrigerant (low toxicity and non-flammable). Furthermore, the magnitude for some properties is comparable, resulting in similar thermodynamic performance [16,17]. Consequently, HCFO-1224yd(Z) could help spread HTHPs [18].

The interest of the heat pump industry in $\mathrm{HCFO}-1224 \mathrm{yd}(\mathrm{Z})$ is demonstrated through the rising yearly number of publications, once that its properties are being accurately determined [19]. HCFO$1224 \mathrm{yd}(\mathrm{Z})$ has been considered in HTHPs based on different configurations, such as cycles including ejectors [20,21] or two-stage cascades [22]. However, up to this day, only Arpagaus and Bertsch [2] experimentally investigated $\mathrm{HCFO}-1224 \mathrm{yd}(\mathrm{Z})$, illustrating the high potential of this refrigerant for future HTHP applications and retrofit systems.

Semi-empirical models enable accurate prediction of system operation and performance at varying conditions [23]. It is a powerful tool for prototype design at an early stage of the development of any technology. At this time, there is a lack of HCFO-1224yd(Z) results in HTHPs and the environmental, energetic and safety benefits that could provide the introduction of this refrigerant in these systems. This paper presents a semi-empirical evaluation of the alternative low-GWP refrigerant HCFO$1224 \mathrm{yd}(\mathrm{Z})$ as a replacement for HFC-245fa in high temperature heat pumps through a thermodynamic 
assessment and semi-empirical comparison. Single-stage cycle with IHX is used as the test bench configuration, operating with a fixed heat source inlet temperature of $80^{\circ} \mathrm{C}$. In contrast, the heat sink outlet temperature varies from 110 to $140{ }^{\circ} \mathrm{C}$. The main parameters studied are heating capacity, compressor power consumption, volumetric heating capacity, and coefficient of performance (COP). Finally, expected theoretical results and the semi-empirical results are compared and discussed to comprehensively evaluate HCFO-1224yd(Z) potential as an alternative to HFC-245fa.

\subsection{Overview of studied refrigerants}

HCFO-1224yd(Z) is a non-flammable substance considered to replace HFC-245fa with minor system modifications. Both refrigerants are pure fluids with slightly different thermophysical properties. Thus, Table 6.1 shows the main thermodynamic and transport properties of both working fluids.

Table 6.1. Main thermodynamic and transport properties of HFC-245fa and HCFO-1224yd(Z).

\begin{tabular}{lll}
\hline Parameters & HFC-245fa & HCFO-1224yd(Z) \\
\hline Molecular weight $\left(\mathrm{g} \cdot \mathrm{mol}^{-1}\right)$ & 134.05 & 148.49 \\
Critical temperature $\left({ }^{\circ} \mathrm{C}\right)$ & 153.86 & 155.54 \\
Critical pressure $(\mathrm{MPa})$ & 3.65 & 3.34 \\
Normal boiling point $(\mathrm{NBP})\left({ }^{\circ} \mathrm{C}\right)$ & 15.05 & 14.62 \\
Latent heat of condensation $\left(\mathrm{kJ} \cdot \mathrm{kg}^{-1}\right)$ & 97.25 & 86.10 \\
Suction density $\left(\mathrm{kg} \cdot \mathrm{m}^{-3}\right)$ & 25.45 & 27.11 \\
ODP $(\mathrm{CFC}-11=1)[20]$ & 0 & 0.00012 \\
GWP & 858 & $<1$ \\
ASHRAE-years $[20]$ & $\mathrm{B} 1$ & $\mathrm{~A} 1$ \\
\hline
\end{tabular}

${ }^{a}$ At a condensing temperature of $130^{\circ} \mathrm{C}$

${ }^{\mathrm{b}}$ At an evaporation temperature of $60^{\circ} \mathrm{C}$

This alternative low-GWP refrigerant is classified as A1 safety class: lower toxicity refrigerant with no flame propagation. Its GWP is more than thousand times lower than HFC-245fa, reducing the direct greenhouse emissions when this alternative refrigerant is leaked. Whereas HFC-245fa has zero ODP, HCFO-1224yd(Z) contains chlorine in its molecule, showing an ODP of 0.00012. Nevertheless, the consequence of leakages on the atmospheric ozone atmosphere could be considered barely negligible [25]. The critical temperature of HCFO-1224yd(Z) is $1.7{ }^{\circ} \mathrm{C}$ higher than HFC-245fa. Therefore, the alternative refrigerant can reach even slightly higher heating production temperatures than the reference working fluid.

HCFO-1224yd(Z) presents a decrease of the latent heat of condensation (about 11.5\%) compared to HFC-245fa, as shown in Table 6.2. This reduction illustrates that a heating capacity decrease is expected in a system that operates with a constant compression volume. Nevertheless, a considerable mass flow rate increase can compensate for this phenomenon. However, the mass flow rate is highly influenced by suction density. In this case, HCFO- $1224 \mathrm{yd}(\mathrm{Z})$ shows a slight increase of $6.5 \%$ of the suction density compared to HFC-245fa. Thus, a heating capacity decrease between $6-8 \%$ is expected with HTHP operating with HCFO-1224yd(Z) instead of HFC-245fa. 
The heating capacity decrease can be compensated with a considerable reduction of the compressor power consumption, operating with HCFO-1224yd(Z). The suction density increase of the alternative refrigerant will produce a slight increment of the mass flow rate that can be compensated with lower compressor specific work. Additionally, based on the investigation of Mateu-Royo et al. [13], HCFO$1224 \mathrm{yd}(\mathrm{Z})$ and HFC-245fa are pure fluids with slightly similar heat transfer parameters based on the analysis of figures of merit.

Comparing both refrigerants in P-h and T-s diagrams illustrates that the slope of the isentropic line of HFC-245fa is higher than HCFO-1224yd(Z), as shown in Fig. 6.1. Hence, lower compressor specific work is required using HCFO-1224yd(Z). Therefore, the mass flow rate increase of HCFO-1224yd(Z) can be compensated, resulting in lower compressor power consumption. However, a comprehensive theoretical and semi-empirical analysis must provide a detailed performance comparison between both refrigerants.

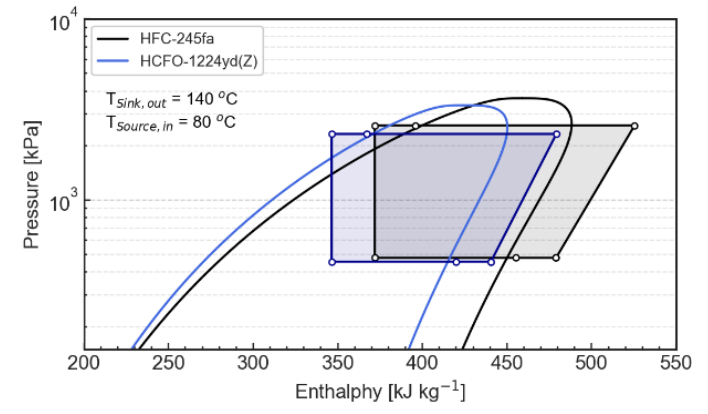

(a)

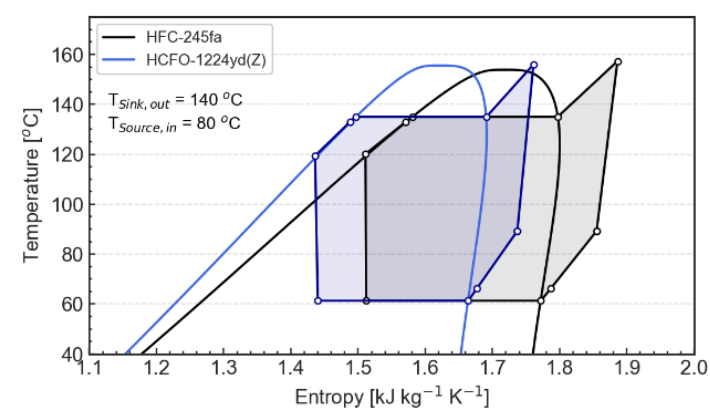

(b)

Fig. 6.1. Thermodynamic diagrams of a single-stage cycle with IHX, using HFC-245fa and HCFO-1224yd(Z) as working fluids: a) Pressure-enthalpy and b) Temperature-entropy.

\subsection{Methodology}

This section presents the methodology followed in this study where a preliminary theoretical study is carried out to illustrate the potential performance difference between the novel refrigerant HCFO$1224 \mathrm{yd}(\mathrm{Z})$ and the reference fluid HFC-245fa. Then, the experimental setup and acquisition procedure to obtain the experimental data of HFC-245fa is presented. Thus, experimental data is used to calculate the expected HCFO-1224yd(Z) performance results through an approach based on the thermophysical differences between both refrigerants, obtaining a semi-empirical evaluation. Finally, environmental analysis is realised using the TEWI metric.

A preliminary theoretical study is carried out to estimate the main parameters for both refrigerants analysed. The heat sink temperatures between 110 and $145^{\circ} \mathrm{C}$ simulate an industrial process's thermal level, whereas the heat source temperature is fixed at $80^{\circ} \mathrm{C}$. In this theoretical study, the following assumptions are stablished:

- Constant electro-mechanic efficiency of 0.75 is considered.

- Variable isentropic and volumetric efficiency are considered based on experimental data [1]

- Sub-cooling degree of $2 \mathrm{~K}$ is considered at the condenser outlet. 
- Superheating degree of $5 \mathrm{~K}$ is considered at the evaporator outlet.

- Pitch point is considered $3 \mathrm{~K}$ at the condenser and between 2.5 to $11 \mathrm{~K}$ in the evaporator.

- $\Delta \mathrm{T}$ between inlet and outlet of the secondary circuits is considered $15 \mathrm{~K}$ in both, condenser and evaporator.

- The IHX effectiveness varies between 0.1 and 0.5 , depending on the outlet heat sink temperature.

- Isenthalpic process is considered at the expansion valve.

- Either pressure losses or heat losses in any components are neglected.

The refrigerant mass flow rate $\left(\dot{m}_{r e f}\right)$ is calculated as follows:

$$
\dot{m}_{\text {ref }}=\rho_{\text {suc }} V_{c} \eta_{v o l}\left(\frac{N}{60}\right)
$$

The heating capacity $\left(\dot{Q}_{k}\right)$ is defined as the product of the refrigerant mass flow rate and the refrigerating effect (enthalpy difference between evaporator outlet and inlet):

$$
\dot{Q}_{k}=\dot{m}_{r e f}\left(h_{k, \text { in }}-h_{k, \text { out }}\right)
$$

The suction enthalpy is calculated with Eq. (6.3), using an experimental value of IHX effectiveness for each operating condition and the condenser and evaporator's outlet states. For an IHX with a fixed area, the effectiveness values change in the different conditions. Therefore, the values used in this study are based on the experimental data obtained in the previous test for HFC-245fa. In the theoretical analysis, the IHX effectiveness is assumed the same for both refrigerants. However, the semi-empirical analysis uses a thermodynamic approach of this value based on the thermophysical properties.

On the other hand, it is used an enthalpy difference instead of a temperature ratio because the specific heat value significantly increases where the point becomes close to the two-phase region. Thus, the temperature difference ratio becomes not a proper method to calculate the IHX effectiveness, whereas the enthalpy difference ratio provides more accurate results. It is observed this phenomenon in several experimental tests, realising the energy balance and improving the theoretical calculations using enthalpy difference for the refrigerant side where some point can be close to the two-phase region. Then, the suction temperature is calculated with the evaporating pressure and the calculated suction enthalpy.

$$
\varepsilon_{\mathrm{IHX}}=\frac{h_{\text {suc }}-h_{o, \text { out }}}{h_{k, \text { out }}-h_{o, \text { out }}}
$$

The electric power consumption of the compressor $\left(\dot{W}_{C}\right)$, is expressed in Eq. (6.4) as the product of the mass flow rate and the isentropic enthalpy difference at the compressor divided by the isentropic and electromechanical efficiencies.

$$
\dot{W}_{C}=\frac{\dot{m} \Delta h_{i s, c}}{\eta_{i s} \eta_{e m}}
$$


The volumetric heating capacity (VHC) is calculated using Eq. (6.5) to compare the influence of the volumetric flow rate correctly at the compressor suction and the heating capacity.

$$
V H C=\frac{\dot{\mathrm{Q}}_{\mathrm{k}}}{\dot{m}_{\text {ref }}} \eta_{v o l} \rho_{\text {suc }}
$$

The theoretical COP only depends on thermodynamic states at the inlet and outlet of the condenser and the compressor, defined as:

$$
C O P=\frac{\dot{Q}_{k}}{\dot{W}_{C}}
$$

The experimental setup is a high temperature heat pump prototype with a heating capacity of 17.5 $\mathrm{kW}$, as presented in Fig. 6.2. The vapour compression circuit consists of a magnetic coupling scroll compressor with a variable-speed electric motor of $7.5 \mathrm{~kW}$ nominal power. All the heat exchangers (condenser, evaporator and IHX) are brazed plate type. Liquid receiver between condenser and subcooler is used to ensure the absence of bubbles before the expansion process. Due to the lack of electronic expansion valves for high-temperature applications, a hand expansion valve is installed to control the correct superheating degree at the evaporator's outlet. Polyester oil with a viscosity of $40 \mathrm{~mm}^{2} \mathrm{~s}^{-1}$ (at $60^{\circ} \mathrm{C}$ ) is used to ensure the required compressor lubrication at high operating temperatures for both refrigerants. However, the oil behaviour between both refrigerants is not analysed in this study.

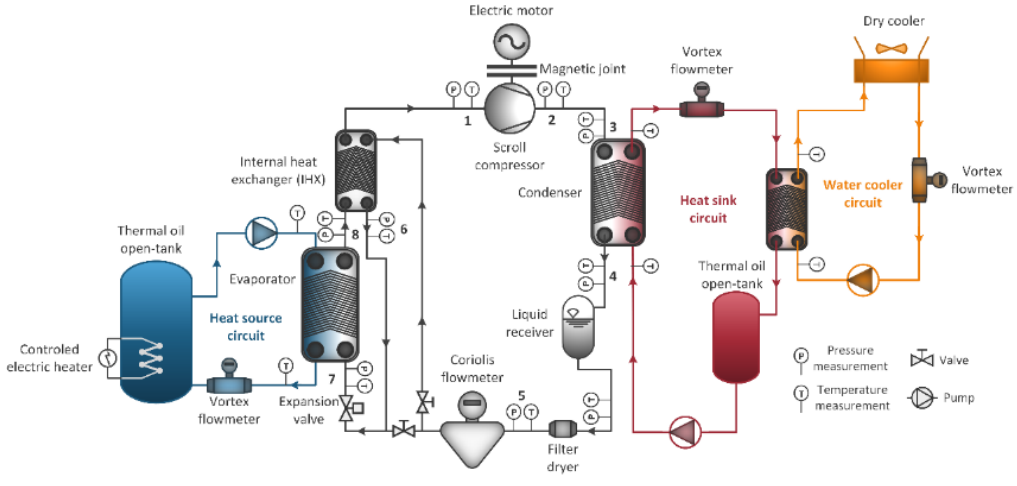

(a)

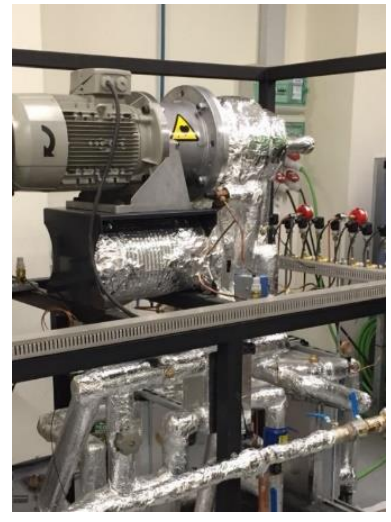

(b)

Fig. 6.2. Experimental setup: a) Schematic diagram of the experimental test bench and b) Photo of the HTHP prototype.

The secondary circuits are used to set the targeted evaporation and condensation temperatures. The heat sink circuit uses thermal oil as the secondary fluid and is cooled by a closed-type cooling system that controls the thermal oil temperature. Moreover, the volumetric flow rate can be adjusted using a variable-speed pump. This cooling water system is composed of a Proportional Integrative Derivative (PID) controlled dry cooler to ensure the heat sink circuit's temperature stability. 
The waste heat simulation system (heat source circuit) also regulates the secondary thermal oil temperature through a set of immersed PID controlled electrical resistances. The test operating conditions for the experimental tests of the HTHP system are described in Table 6.2.

Table 6.2. Operating conditions in the start-up experimental test.

\begin{tabular}{ll}
\hline Controlled parameters & Values \\
\hline Heat sink outlet temperature & $110-140{ }^{\circ} \mathrm{C}$ \\
Heat source inlet temperature & $80{ }^{\circ} \mathrm{C}$ \\
Superheating degree $(\mathrm{SH})$ with $\mathrm{IHX}$ & $35 \mathrm{~K}$ \\
Compressor drive frequency & $50 \mathrm{~Hz}$ \\
\hline
\end{tabular}

The refrigerant's thermodynamic states are calculated using pressure and temperature measurements in the required locations of the system. These values are measured with calibrated thermocouples and pressure transducers. The refrigerant mass flow rate is measured by a Coriolis mass flow meter located at the liquid line while the power compressor consumption is measured using a digital wattmeter. The secondary circuits include temperature and volumetric flow rate sensors. Table 6.3 shows the characteristics of all sensors and their uncertainty. Finally, the thermodynamic properties are calculated using the REFPROP software [26].

Table 6.3. Summary of measurement sensors and uncertainties.

\begin{tabular}{lll}
\hline Measured parameters & Sensor & Uncertainty \\
\hline Temperatures & J-type thermocouples & $\pm 0.3 \mathrm{~K}$ \\
Pressures & Piezoelectric pressure transducers & $\pm 0.04 \%$ of reading \\
Refrigerant mass flow rate & Coriolis mass flow meter & $\pm 0.17 \%$ of reading \\
Heat source volumetric flow rate & Vortex flow meter & $\pm 0.5 \%$ of reading \\
Heat sink volumetric flow rate & Vortex flow meter & $\pm 0.028 \mathrm{~m}^{3} \mathrm{~h}^{-1}$ \\
Compressor power consumption & Digital wattmeter & $\pm 1.55 \%$ \\
\hline
\end{tabular}

The process for selecting a steady-state test consists of measuring for a time period of $40 \mathrm{~min}$, with a sample period of $1 \mathrm{~s}$. The condensing and evaporating pressure are within an interval of $\pm 3.5 \mathrm{kPa}$. During the test, all the temperatures are within a deviation of $\pm 0.25 \mathrm{~K}$ and the refrigerant mass flow rate is within $\pm 0.0007 \mathrm{~kg} \mathrm{~s}^{-1}$. Then, once the steady-state operation is achieved (it involves 2400 direct measurement), the data is processed with an algorithm to find the steady-state period of $10 \mathrm{~min}$ (600 direct measurements) with the highest precision and accuracy.

Finally, the carbon footprint using HFC-245fa and HCFO-1224yd(Z) is compared using the TEWI metric, which has proved to be accurate enough to have an idea of the effects of refrigerant replacement in different applications [27]. The TEWI metric is calculated as indicated in Eq. (6.7), being the two main components of the equation, the direct and the indirect $\mathrm{CO}_{2 \text {,eq }}$ emissions.

$$
T E W I=G W P L n+G W P m_{r}(1-\alpha)+n E_{a} \beta
$$

Some necessary assumptions can be considered to carry out every TEWI analysis. The lifespan of the system $(n)$ is considered 15 years and the recycling factor of the refrigerant $(\alpha)$ is assumed 0.7 . It is 
considered a refrigerant charge $\left(m_{r}\right)$ of $20 \mathrm{~kg}$, based on the experimental field analysis. Finally, different values of the annual leakage rate and the indirect emission factor $(\beta)$ are considered in order to provide a practical environmental evaluation of these parameters. Heat sink and source temperatures considered are $140{ }^{\circ} \mathrm{C}$ and $80^{\circ} \mathrm{C}$, respectively.

\subsection{Results and Discussion}

\subsubsection{Theoretical Analysis}

Fig. 6.3 presents the theoretical comparison of the main performance parameters (volumetric heating capacity, compressor power consumption, heating capacity and COP) for the reference fluid HFC$245 \mathrm{fa}$ and its alternative low-GWP refrigerant HCFO-1224yd(Z). The volumetric heating capacity of HCF-1224yd(Z) becomes lower than the reference working fluid HFC-245fa, specifically, up to $8.52 \%$ less volumetric heating capacity, as shown in Fig. 6.3a. This phenomenon is a consequence of the heating capacity reduction that presents HCFO-1224yd(Z) compared with HFC-245fa. The lower latent heat of condensation that exhibits HCFO-1224yd(Z), in comparison with HFC-245fa, is not compensated by a mass flow rate increase, resulting in lower heating capacity, as shown in Fig. 6.3c.

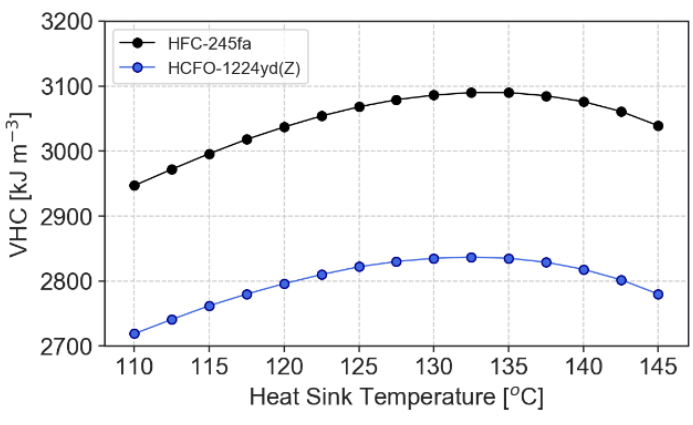

(a)

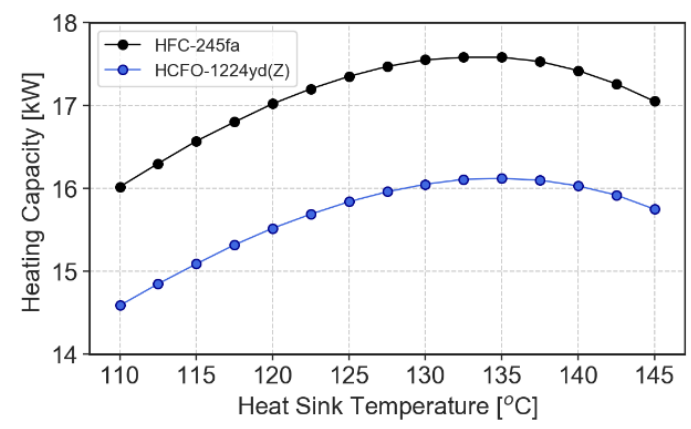

(c)

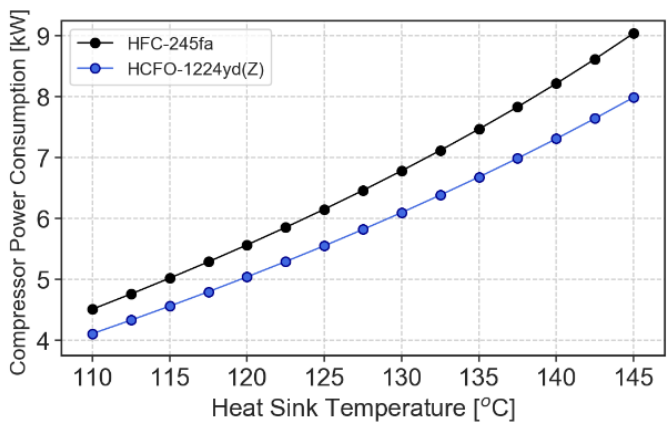

(b)

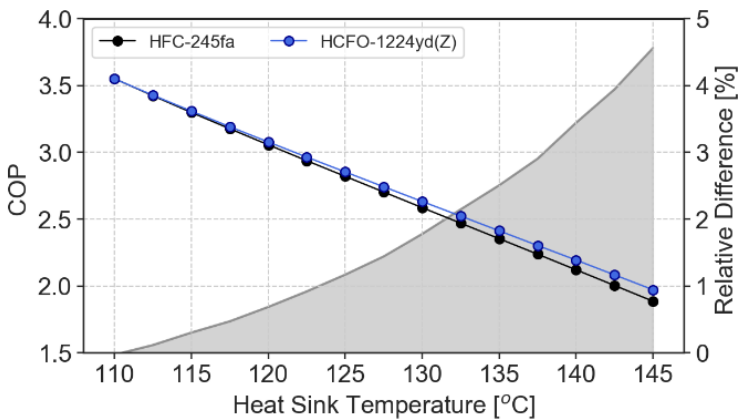

(d)

Fig. 6.3. Theoretical evaluation of single-stage cycle with IHX using HFC-245fa and HCFO-1224yd(Z) with a constant inlet heat sink temperature of $80^{\circ} \mathrm{C}$ : a) Volumetric heating capacity, b) compressor power consumption, c) heating capacity and d) COP. 
Nevertheless, HCFO-1224yd(Z) presents a decrease of the compressor power consumption, up to $11.52 \%$ in comparison with HFC-245fa, illustrated in Fig. 6.3b. As the heat sink temperature increase, the difference in compressor power consumption increases. According to the previous refrigerants analysis, this reduction can be resulting in a lower specific work that shows HCFO$1224 \mathrm{yd}(\mathrm{Z})$ compared to HFC-245fa. Hence, the compressor power consumption drop can compensate for the heating capacity reduction, providing similar or even higher COP when the HTHP operates with HCFO-1224yd(Z) instead of HFC-245fa.

\subsubsection{Semi-empirical comparison}

This section describes the semi-empirical results obtained with HCFO-1224yd(Z) based on experimental data from HFC-245fa, showing the main energy performance parameters, previously analysed in the theoretical evaluation: volumetric heating capacity, compressor power consumption, heating capacity and COP (Fig. 6.4).

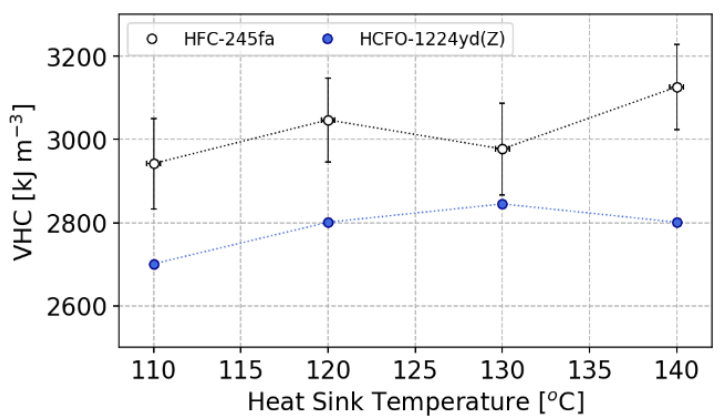

(a)

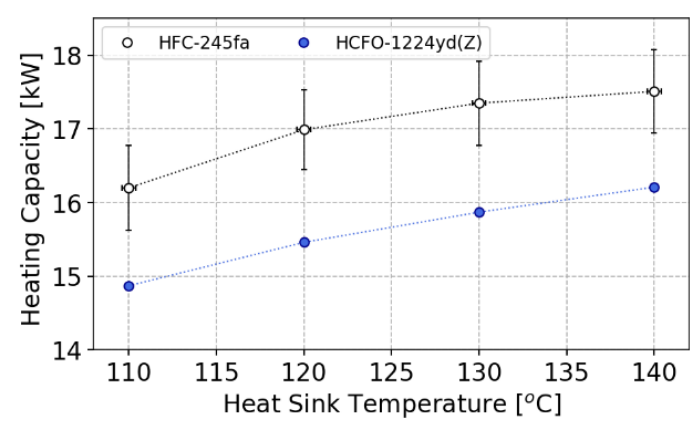

(c)

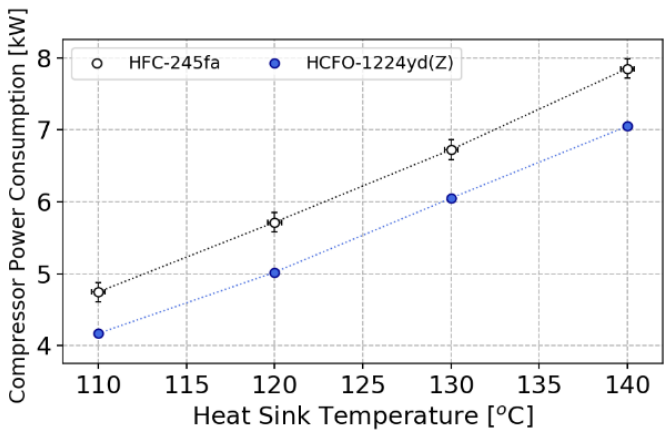

(b)

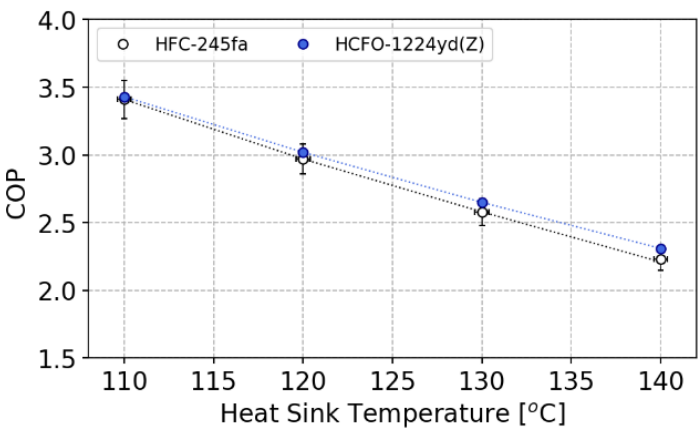

(d)

Fig. 6.4. Semi-empirical results of HFC-245fa and HCFO-1224yd(Z) with a constant inlet heat source temperature of $80^{\circ} \mathrm{C}$ : a) Heating capacity, b) compressor power consumption, c) volumetric heating capacity and d) COP.

The semi-empirical calculations of the volumetric heating capacity present a similar trend than the expected theoretical evaluation, showing lower values for HCFO-1224yd(Z) than the reference HFC$245 \mathrm{fa}$. About the compressor power consumption, Fig. 6.4b illustrates a considerable reduction, between 7 and $11 \%$ of HCFO-1224yd(Z) in comparison of HFC-245fa, showing similar trends than the expected theoretical evaluation. Although the mass flow rate value of HCFO-1224yd(Z) becomes 
higher than HFC-245fa, the isentropic lines slope difference produces a variation in the specific compressor work of each refrigerant that becomes higher as the heat sink temperature increase.

The heating capacity of HCFO-1224yd(Z) suffers a reduction compared to HFC-245fa, specifically, between 7.2 and $8.9 \%$, depending on the heat sink temperature. Operating with a heat sink temperature of $140{ }^{\circ} \mathrm{C}, \mathrm{HCFO}-1224 \mathrm{yd}(\mathrm{Z})$ provides a heating capacity of $16.36 \mathrm{~kW}$, whereas HFC$245 \mathrm{fa}$ presents a value of $17.51 \mathrm{~kW}$. Finally, the semi-empirical COP shows slightly similar behaviour than the expected theoretically, obtaining an increment up to $4.5 \%$ operating with HCFO-1224yd(Z) instead of HFC-245fa. At the maximum heat sink temperature of $140{ }^{\circ} \mathrm{C}, \mathrm{HFC}-245 \mathrm{fa}$ ends with a COP of 2.23, whereas HCFO-1224yd(Z) presents a value of 2.33.

\subsubsection{Carbon footprint comparison}

As an application that has attracted attention recently, HTHP systems do not have previous guidelines published for carbon footprint analysis, and therefore, it is challenging to select concrete input values. Therefore, following that recommended by Mota-Babiloni et al. [26], different carbon emission factors and leakage rates are simulated. Moreover, Fig. 6.5 contains relative results (TEWI reduction) between HCFO-1224yd(Z) and HFC-1245fa to minimise the effect of other input parameters. Emission factors of selected countries and the European Union have been placed as indicators of the magnitude of these values.

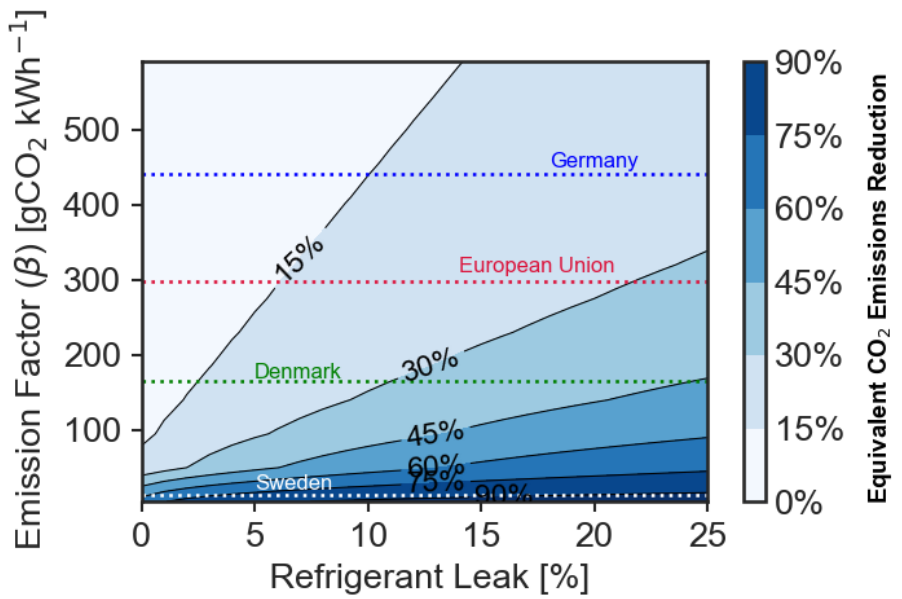

Fig. 6.5. TEWI reduction using HCFO-1224yd(Z) instead of HFC-245fa.

The use of the low-GWP refrigerant HCFO-1224yd(Z) instead of HFC-245fa provides a significant equivalent $\mathrm{CO}_{2, \mathrm{eq}}$ emissions reduction that becomes positive for climate change mitigation, as shown in Fig. 6.5. Considering an annual refrigerant leakage of 5\% for HTHP contained in the machinery room, an equivalent $\mathrm{CO}_{2 \text {,eq }}$ emission reduction up to $15 \%$ is achieved, using the European Union emission factor. This reduction becomes higher for countries with lower emissions factor; for instance, in Denmark, it can reach a reduction of $45 \%$ if the highest refrigerant leak is considered. Thus, the use of renewable energies for the electricity generation will reduce the emission factor in each country and therefore, the use of low GWP refrigerants as HCFO-1224yd(Z) will improve the decarbonisation of these countries. Hence, HCFO-1224yd(Z) becomes a potential sustainable 
refrigerant to replace HFC-245fa in HTHPs systems due to its low-GWP value and higher energy efficiency in high temperature applications.

\subsection{Conclusions}

This paper presents a theoretical and semi-empirical analysis of HCFO-1224yd(Z) as a drop-in replacement for HFC-245fa in a high temperature heat pump (HTHP) based on a single-stage cycle with IHX. The HFC-245fa tests have been performed varying the heat sink temperature from 110 to $140{ }^{\circ} \mathrm{C}$ with a constant heat source temperature of $80^{\circ} \mathrm{C}$. Volumetric heating capacity, compressor power consumption, heating capacity and $\mathrm{COP}$ are used as performance indicators in the refrigerant evaluation. The main conclusions of this paper can be summarised as follows:

- HCFO-1224yd(Z) volumetric heating capacity is approximately $8.5 \%$ lower than HFC-245fa used as a drop-in in replacement in an HFC-245fa experimental setup. This difference is strongly related to heating capacity reduction, operating with the same volumetric flow rate.

- The heating capacity using HCFO-1224yd(Z) becomes about $8.9 \%$ lower than that obtained with HFC-245fa, which can be compensated with the $11.3 \%$ compressor power consumption decrease that presents HCFO-1224yd(Z) compared to HFC-245fa.

- The COP values obtained with HCFO-1224yd(Z) are comparable or even $4.5 \%$ higher than those obtained with HFC-245fa. At the maximum heat sink temperature of $140{ }^{\circ} \mathrm{C}$, HCFO$1224 \mathrm{yd}(\mathrm{Z})$ provides a COP of 2.33 , whereas HFC-245fa shows a value of 2.23.

- The environmental analysis using the TEWI metrics illustrates that HCFO-1224yd(Z) instead of HFC-245fa provide a significant equivalent $\mathrm{CO}_{2}$ emissions reduction. Considering an annual refrigerant leakage of 5\%, equivalent $\mathrm{CO}_{2, \text { eq }}$ emissions reduction between $10-90 \%$ can be achieved, depending on the energy mix of each country.

Finally, from the semi-empirical results, it can be concluded that the energy performance parameters of HCFO-1224yd(Z) in a drop-in replacement are close to those obtained with HFC-245fa in high temperature heat pumps. Hence, HCFO-1224yd(Z) becomes a potential low-GWP alternative to replace the reference working fluid HFC-245fa.

The comparison between the theoretical and semi-empirical results confirms the latter analysis as a useful tool to evaluate the potential of recently developed refrigerants in existing systems. Semiempirical assessment is recommended to complement the theoretical analysis and confirm a refrigerant potential in vapour compression systems, before starting experimental campaigns at extreme conditions as those existing in HTHPs. Then, semi-empirical data can be used to validate experimental results by comparing both in a more accurate way than taking theoretical values as the reference. 


\section{References}

[1] Mateu-Royo C, Navarro-Esbrí J, Mota-Babiloni A, Molés F, Amat-Albuixech M. Experimental exergy and energy analysis of a novel high-temperature heat pump with scroll compressor for waste heat recovery. Appl Energy 2019;253:113504. doi:10.1016/j.apenergy.2019.113504.

[2] Arpagaus C, Bertsch SS. Experimental results of HFO/HCFO refrigerants in a laboratory scale HTHP with up to $150{ }^{\circ} \mathrm{C}$ supply temperature. 2nd Conf High Temp Heat Pumps, Copenhagen, Denmark 2019.

[3] Arpagaus C, Bless F, Uhlmann M, Schiffmann J, Bertsch SS. High temperature heat pumps: Market overview, state of the art, research status, refrigerants, and application potentials. Energy 2018;152:985-1010. doi:10.1016/j.energy.2018.03.166.

[4] Kosmadakis G. Estimating the potential of industrial (high-temperature) heat pumps for exploiting waste heat in EU industries. Appl Therm Eng 2019;156:287-98. doi:10.1016/J.APPLTHERMALENG.2019.04.082.

[5] Urbanucci L, Bruno JC, Testi D. Thermodynamic and economic analysis of the integration of high-temperature heat pumps in trigeneration systems. Appl Energy 2019;238:516-33. doi:10.1016/J.APENERGY.2019.01.115.

[6] Mateu-Royo C, Sawalha S, Mota-Babiloni A, Navarro-Esbrí J. High temperature heat pump integration into district heating network. Energy Convers Manag 2020;210:112719. doi:10.1016/J.ENCONMAN.2020.112719.

[7] Bamigbetan O, Eikevik TM, Nekså P, Bantle M, Schlemminger C. Experimental investigation of a prototype R-600 compressor for high temperature heat pump. Energy 2019;169:730-8. doi:10.1016/J.ENERGY.2018.12.020.

[8] Chamoun M, Rulliere R, Haberschill P, Peureux J-L. Experimental and numerical investigations of a new high temperature heat pump for industrial heat recovery using water as refrigerant. Int J Refrig 2014;44:177-88. doi:10.1016/j.ijrefrig.2014.04.019.

[9] Bobelin D, Bourig A, Peureux J. Experimental results of a newly developed very high temperature industrial heat pump $\left(140^{\circ} \mathrm{C}\right)$ equipped with scroll compressors and working with a new blend refrigerant. Int. Refrig. Air Cond. Conf., 2012, p. 1-10.

[10] Meroni A, Zühlsdorf B, Elmegaard B, Haglind F. Design of centrifugal compressors for heat pump systems. Appl Energy 2018;232:139-56. doi:10.1016/J.APENERGY.2018.09.210.

[11] European Commission, The European Parliament and the Council of the European Union. Regulation (EU) No 517/2014 of the European Parliament and of the Council of 16 April 2014 on fluorinated greenhouse gases and repealing Regulation (EC) No 842/2006. Off J Eur Union 2014;150:195-230. doi:https://doi.org/10.4271/1999-01-0874.

[12] Calm JM. The next generation of refrigerants - Historical review, considerations, and outlook. Int J Refrig 2008;31:1123-33. doi:10.1016/j.ijrefrig.2008.01.013.

[13] Mateu-Royo C, Navarro-Esbrí J, Mota-Babiloni A, Amat-Albuixech M, Molés F. Thermodynamic analysis of low GWP alternatives to HFC-245fa in high-temperature heat pumps: HCFO-1224yd(Z), HCFO-1233zd(E) and HFO-1336mzz(Z). Appl Therm Eng 2019. doi:10.1016/j.applthermaleng.2019.02.047.

[14] ANSI/ASHRAE. Designation and Safety Classification of Refrigerants. Stand 342016.

[15] AGC Chemicals. AMOLEA ${ }^{\circledR}$ 1224yd, Technical information. ASAHI Glas Co 2017:1-18. 
[16] Navarro-Esbrí J, Amat-Albuixech M, Molés F, Mateu-Royo C, Mota-Babiloni A, Collado R. HCFO-1224yd(Z) as HFC-245fa drop-in alternative in low temperature ORC systems: Experimental analysis in a waste heat recovery real facility. Energy 2020;193:116701. doi:https://doi.org/10.1016/j.energy.2019.116701.

[17] Eyerer S, Dawo F, Kaindl J, Wieland C, Spliethoff H. Experimental investigation of modern ORC working fluids R1224yd(Z) and R1233zd(E) as replacements for R245fa. Appl Energy 2019;240:946-63. doi:10.1016/J.APENERGY.2019.02.086.

[18] Frate GF, Ferrari L, Desideri U. Analysis of suitability ranges of high temperature heat pump working fluids. Appl Therm Eng 2019;150:628-40. doi:10.1016/J.APPLTHERMALENG.2019.01.034.

[19] Fedele L, Bobbo S, Scattolini M, Zilio C, Akasaka R. HCFO refrigerant cis-1-chloro-2,3,3,3 tetrafluoropropene $[\mathrm{R} 1224 \mathrm{yd}(\mathrm{Z})]$ : Experimental assessment and correlation of the liquid density. Int J Refrig 2020;118:139-45. doi:https://doi.org/10.1016/j.ijrefrig.2020.06.001.

[20] Mateu-Royo C, Navarro-Esbrí J, Mota-Babiloni A, Barragán-Cervera Á. Theoretical performance evaluation of ejector and economizer with parallel compression configurations in high temperature heat pumps. Int J Refrig 2020. doi:https://doi.org/10.1016/j.ijrefrig.2020.07.016.

[21] Bai T, Yan G, Yu J. Thermodynamic assessment of a condenser outlet split ejector-based high temperature heat pump cycle using various low GWP refrigerants. Energy 2019;179:850-62. doi:10.1016/J.ENERGY.2019.04.191.

[22] Mota-Babiloni A, Mateu-Royo C, Navarro-Esbrí J, Molés F, Amat-Albuixech M, BarragánCervera Á. Optimisation of high-temperature heat pump cascades with internal heat exchangers using refrigerants with low global warming potential. Energy 2018;165:1248-58. doi:10.1016/j.energy.2018.09.188.

[23] Dechesne BJ, Tello-Oquendo FM, Gendebien S, Lemort V. Residential air-source heat pump with refrigerant injection and variable speed compressor: Experimental investigation and compressor modeling. Int J Refrig 2019;108:79-90. doi:https://doi.org/10.1016/j.ijrefrig.2019.08.034.

[24] ASHRAE. ASHRAE Handbook Fundamentals. Am Soc Heating, Refrig Air-Conditioning Eng 2017.

[25] Patten KO, Wuebbles DJ. Atmospheric lifetimes and Ozone Depletion Potentials of trans-1chloro-3,3,3-trifluoropropylene and trans-1,2-dichloroethylene in a three-dimensional model. Atmos Chem Phys 2010;10:10867-74. doi:10.5194/acp-10-10867-2010.

[26] Lemmon EW, Bell IH, Huber ML, McLinden MO. NIST Standard Reference Database: Reference Fluid Thermodynamic and Transport Properties-REFPROP, Version 10. Natl Inst Stand Technol Stand Ref Data Program, Boulder, CO 2018.

[27] Mota-Babiloni A, Barbosa JR, Makhnatch P, Lozano JA. Assessment of the utilization of equivalent warming impact metrics in refrigeration, air conditioning and heat pump systems. Renew Sustain Energy Rev 2020;129:109929. doi:https://doi.org/10.1016/j.rser.2020.109929.

[28] Mateu-Royo C, Navarro-Esbrí J, Mota-Babiloni A, Molés F, Amat-Albuixech M. SemiEmpirical Evaluation of HCFO-1224yd(Z) as a Replacement for HFC-245fa in High Temperature Heat Pumps. IIR Int. Conf. Rank. 2020 - Appl. Cool. Heat. Power Gener., Glasgow (United Kingdom): International Institute of Refrigeration (IIR); 2020, p. Paper ID: 1117. doi:10.18462/iir.rankine.2020.1117. 
Chapter 6 


\title{
Chapter 7 Multi-Objective Optimization of a Novel Reversible High- Temperature Heat Pump - Organic Rankine Cycle (HTHP- ORC) for Industrial Low-Grade Waste Heat Recovery
}

\begin{abstract}
Nowadays, a high amount of industrial thermal energy is still lost due to the lack of competitive solutions for energy revalorization. Facing this challenge, this paper presents a novel technology, based on a reversible High-Temperature Heat Pump (HTHP) and Organic Rankine Cycle (ORC). The proposed system recovers low-grade waste heat to generate electricity or useful heat in accordance with consumer demand. Compressor and expander semi-empirical models have been considered for the reversible system computational simulation, being HFC-245fa the working fluid selected. The built-in volume ratio and Internal Heat Exchanger (IHX) effectiveness have been optimized to reach the maximum energy efficiency in each operating condition. Although HFC-245fa exhibits energy performance attributes, its high Global Warming Potential (GWP) is an issue for climate change mitigation. Hence, multi-objective optimisation of the environmentally friendly working fluids Butane, Pentane, HFO-1336mzz(Z), R-514A, HCFO-1233zd(E) and HCFO$1224 y d(Z)$ has been carried out. The results show that the system proposed, working with HFC-245fa, achieves a Coefficient of Performance (COP) of 2.44 for condensing temperature of $140{ }^{\circ} \mathrm{C}$, operating in HTHP mode, whereas the ORC mode provides a net electrical efficiency of $8.7 \%$ at condensing temperature of $40{ }^{\circ} \mathrm{C}$. Besides, HCFO-1233zd(E) and HCFO-1224yd(Z) are both appropriate alternatives for the HFC-245fa replacement. These working fluids provide a COP improvement of $9.7 \%$ and $5.8 \%$ and electrical net efficiency improvement of $2.1 \%$ and $0.8 \%$, respectively, compared to HFC-245fa. This paper provides a reference study for further designs and developments of reversible HTHP-ORC systems used for industrial low-grade waste heat recovery.
\end{abstract}

\subsection{Introduction}

The Energy Efficiency Directive (EU) 2012/27/EU targeted an energy efficiency increase of $20 \%$ by 2020 using solutions at all the energy chain stages, from production to final consumption, including all energy supplied to industry, transport, households, services and agriculture [1]. The challenging Paris Agreement climate goals [2] produced a revision of the Energy Efficiency Directive (EU) $2018 / 2002$ that set an energy efficiency increment of $32.5 \%$ by 2030 [3].

The Fifth Assessment Report (AR5) of the Intergovernmental Panel on Climate Change (IPCC) states that the industrial sector becomes critical for the climate change mitigation since their associated greenhouse gasses (GHG) emissions have been doubled between 1970 and 2010 [4]. Low-grade 
waste heat, commonly associated with temperatures below $200{ }^{\circ} \mathrm{C}[5]$, represents about one-third of the total waste heat potential estimated in EU, approximately $300 \mathrm{TWh} /$ year [6].

Regarding energy efficiency measures, industrial waste heat recovery demonstrated higher profitability ratios compared to the adoption of renewable energies or the use of technologies for energy consumption reduction [7]. Waste heat can be recovered to be used in close industrial processes with minor heat requirements. On the other hand, a more versatile solution could use the energy available, such as low-temperature power generation or heat pump systems [8]. It has been proven that operating costs and equivalent $\mathrm{CO}_{2}$ emissions could be reduced by $26 \%$, where $18 \%$ of this reduction should be overcome by waste heat recovery technologies [9].

Heat pump and low-temperature power generation systems are technically and economically feasible solutions for heat recovery from low-temperature heat sources. Focusing on the power generation technologies within the low-temperature range, the Organic Rankine Cycle (ORC) is a better alternative than the Kalina cycle, which is more appropriate for waste heat recovery at medium temperatures [10].

While heat pumps can be used to convert waste heat into useful heat, ORC systems can generate clean electricity. Nonetheless, these technologies are not widely used enough in the industry due to different limitations. The ORC is an emerging opportunity that has been successfully installed in industrial applications [11], but heat pump technology requires further development to operate at higher temperatures to produce useful industrial heat. Therefore, waste heat recovery in existing processes represents a technical challenge because additional aspects influence the usability of the available waste heat [12]. The type of process should always be examined to select the appropriate method of waste heat recovery for optimising energy efficiency [10]. The selection of technology mostly depends on the heat sink temperatures [13] and the needs of the specific industrial plant and process [12].

Xia et al. [14] illustrated that combined comparisons of the optimal scenarios and conditions for different waste heat recovery technologies are going to become relevant in the future. Moreover, they highlighted the selection and modification of the working fluid pairs through various technologies. In the medium-scale petroleum refinery study case, the site energy efficiency increased up to $10 \%$ when waste heat recovery technologies were combined to exploit all the available waste heat. The diversity of heat demands can increase site energy efficiency [9]. According to Meyers et al. [15], a higher number of heat pumps operating hours makes it a promising solution for low carbon industrial process heat, and despite the relatively higher energy efficiency of heat pump technology, it is only profitable above $4000 \mathrm{~h}$ per year [16]. However, the maximum yearly operation is limited because these systems only can work if the heat sink is requiring energy. Besides unacceptable temperature levels, between supply and demand by time, location, and quantities can be a discrepancy and diminish the heat pump viability [12].

A more versatile heat pump system could increase the operating hours. Among different options, a reversible system that can operate as a heat pump and organic Rankine cycle can be built sharing most of the components. Using a bypass, a 4-way valve, a modified compressor to allow its operation as an expander, an additional pump, and a series of 3-way valves, the cycle can be reverted [17]. This system has been simulated mainly in buildings with heat storage together in combination with or compared to other technologies. In this way, Dumont [17] has concluded that this technology is 
profitable in buildings with significant heat demand. Dumont et al. [18] provide some insights to design an optimum heat pump-ORC system more competitive than a heat pump combined with photovoltaic solar panels.

On the other hand, Quoilin et al. [19] present the optimisation of some continuous parameters based on favourable performance indicators as well as for practical constraints. Carmo et al. [20] assessed four different control strategies to lessen the adverse effects of cycling in the compressor. The thermal input requirements strongly influence the thermal and electrical demand covered by renewable energy, but the control strategies allowed to increase the share of renewable energy used. Schimpf et al. [21] studied this reversible system in three different locations activated by thermal and ground source energy (evacuated tube and flat plate collectors), and they have proven that it is energetically superior compared to a conventional system by the minor additional investment required. Staub et al. [22] suggested that a more promising prospect requires the optimisation of the isentropic efficiencies of the compressor by the application of this idea in larger applications or smaller plant sizes with tailor-made compressor/expander machinery.

As it has been proven, the combination of different waste heat recovery systems in the industry can provide economic and energetic benefits; however, the simulation of innovative heat pump-ORC systems has been limited to small domestic applications, in which it is compared with other traditional renewable technologies. However, the integration of these systems into industrial processes could be beneficial. A recent interest appeared in the industrial sector referred to heat pumps that operate at higher temperatures than those of the residential sector. These systems are named as high-temperature heat pumps (HTHPs) due to their capacity to achieve heating temperatures between 100 and $160{ }^{\circ} \mathrm{C}$ [5]. These compression heat pumps provide high-temperature and larger-capacity, becoming one of the practical solutions to meet the requirement of industrial waste heat recovery [23]. Urbanucci et al. [24] conducted an HTHPs integration in trigeneration, showing that this integration provides flexibility to cover variable energy demands along with valuable economic and energy performance improvements. According to Xia et al. [14], recent studies about heat pumps used for low-grade waste heat recovery are developing multiple stages and cascade systems. Moreover, Johnson et al. [25] considered that new working fluids are essential in the development of this emerging technology.

On the other hand, advanced architectures in HTHP are required in order to efficiently cover larger temperature differences between the heat sink and heat source (temperature lift). Mateu-Royo et al. [26] proved that with temperature lift above $60 \mathrm{~K}$ two stage configuration with IHX is the one that results in higher performance. Accordingly, Cao et al. [27] considered different two stage configurations than Mateu-Royo et al. [26], and they obtained higher efficiency with two stages using flash tank (with or without intercooler) than the single-stage arrangement. Finally, Mota-Babiloni et al. and Yang et al. $[28,29]$ obtained positive results with HTHP cascades due to the optimisation of the refrigerants for each configuration.

The working fluid used in the HTHP is different from those seen in refrigeration and heat pump applications owing to the unusual higher operating temperatures. HFC-245fa becomes the most common working fluid used in HTHP and ORC, but its high Global Warming Potential (GWP) requires an alternative low-GWP working fluid for sustainable future developments [5]. Natural fluids represent a clean option, but they are highly flammable (in the case of hydrocarbons) or toxic (ammonia) [30]. Alternative options are recently developed through synthetic working fluids as 
HCFO-1233zd(E), HFO-1336mzz(Z) and HCFO-1224yd(Z), which have been thermodynamic performance analysed in HTHPs by Mateu-Royo et al. [31]. A drop-in or retrofit substitution of HFC$245 \mathrm{fa}$ by one of these alternatives can be reduced by approximately $60 \%$ of $\mathrm{CO}_{2}$ equivalent emissions. Frate et al. [32] agreed with Mateu-Royo et al. [31] concluding that HCFO-1233zd(E) provides a good trade-off between energy performance and volumetric heating capacity in comparison with other alternatives. They also concluded that in the final design of the HTHP, several factors influence on the optimal selection of the refrigerant such as the number of compression stages, operating temperatures, and compressor technology, among others. Zühlsdorf et al. [33] proved that the zeotropic behaviour of refrigerant mixtures could be used to improve the energy performance of the HTHP.

HTHPs are still in an earlier stage of development, and the first results using different types of prototypes, compressor technologies, working fluids, and configurations are being published. MateuRoyo et al. [34] have developed an HTHP prototype with scroll compressor that provides a Coefficient of Performance (COP) of 2.23, working with a heat sink and source temperatures of 140 and $80^{\circ} \mathrm{C}$, respectively. Moreover, Bamigbetan et al. [35] present the development of hydrocarbon HTHP with internal heat exchanger and receiver to produce useful heat at $115^{\circ} \mathrm{C}$ using $\mathrm{HC}-600$ as working fluid. The data generated by this prototype was used to calculate the economic and environmental benefits in comparison with boilers in industry, recovering waste heat between 30 and $60{ }^{\circ} \mathrm{C}$ [36]. Chamoun et al. [37] developed an HTHP equipped with a twin-screw compressor that uses water as a working fluid. Two innovations to highlight were the flash tank and a falling film evaporator. Bobelin et al. [38] constructed an HTHP with scroll compressors and included a subcooler to deliver heat up to $125^{\circ} \mathrm{C}$ (the composition of the working fluid was not revealed). Finally, Arpagaus et al. [39] developed a prototype using the recently developed synthetic fluid HCFO$1233 z d(E)$. Its high critical temperature allows reaching heating production temperature above 150 ${ }^{\circ} \mathrm{C}$.

ORC, as the other operational mode of the proposed reversible system for low-grade industrial waste heat recovery, has been more widely investigated than the HTHPs [40]. Similar to HTHPs, the ORC system efficiency is mainly dependent on the heat source temperature, thermophysical working fluid properties, and turbine efficiency. Mahmoudi et al. [41] highlights the critical state, sensible heat and ratio of vaporisation latent heat as the essential refrigerant properties, and includes heat source types, operating conditions and temperature levels to the factors that influence on the final ORC efficiency for waste heat recovery. About the ORC architecture, Braimakis et al. [42] illustrate that ORC recuperative cycles always provide better performance that non-recuperative cycle. Analogous to HTHPs, HFC-245fa is the most popular working fluid [43]. For small scales systems, volumetric machines were the preferred expansion machines, either off-the-shelf, modified compressors or motors because of the lower cost [44]. Then, HCFO-1233zd(E) is also a promising candidate for ORCs waste heat recovery $[45,46]$. ORCs stage of development is more advanced than HTHPs, and the largest share of publications deals with the application of ORC technology [47], making it already a reliable method to efficiently recover waste heat.

Based on the above-discussed literature review, it can be seen that the combination of HTHP and ORC technologies in a single reversible system is technically viable. Both systems have in common most of the cycle components along with the operating temperatures and working fluids. Hence, the combination of both waste heat recovery technologies will provide higher economic and operating 
flexibility benefits. Nevertheless, the proposed system has not yet been considered for industrial applications, which becomes a significant waste heat recovery source. Thus, in this paper, we presented a novel reversible HTHP-ORC system for industrial low-grade waste heat recovery. The focus was set on the optimisation analysis and multi-objective low-GWP alternative refrigerant selection to provide guidelines for further design improvement and sustainable development.

The main contributions of the present work are as follows:

- A novel reversible HTHP-ORC system was proposed for low-grade industrial waste heat recovery using HFC-245fa as working fluid, based on semi-empirical compressor-expander validated models.

- A comprehensive energy performance and volumetric machines efficiency evaluation was realised along with an optimisation of the system parameters as a built-in volume ratio and IHX.

- The semi-empirical performance and efficiencies results from the reversible model using HFC-245fa were used as a reference to realise an alternative low-GWP refrigerants evaluation.

- A multi-objective evaluation for a proper working fluid selection was applied, considering Pentane, Butane, HFO-1336mzz(Z), R-514A, HCFO-1233zd(E) and HCFO-1224yd(Z) as the alternative low-GWP refrigerants.

To achieve this purpose, the study is structured as follows. Section 2 describes the reversible HTHPORC system and the model based on semi-empirical compressor and expander validated models. This section also describes the alternative low-GWP working fluid modelling process. Section 3 introduces the methodology for the built-in volume ration and IHX optimisation processes along with the simulation operating conditions. Section 4 presents the results through detailed performance analysis of the reversible system proposed the optimised performance values and efficiencies. Moreover, this section shows the results of the multi-objective evaluation of alternative low-GWP refrigerants. Finally, the last section contains the relevant conclusions. The results of this study may provide guidelines for the further design and development of reversible HTHP-ORC systems for low-grade waste heat recovery, especially in the industrial sector.

\subsection{System description and modelling}

In this section, the reversible HTHP-ORC system and its components are described in detail. Moreover, the compressor and expander models are presented and validated. Finally, the thermodynamic properties of selected alternative low-GWP working fluids to HFC-245fa are discussed along with the assumptions considered.

\subsubsection{Description of the reversible HTHP-ORC system}

The HTHP and ORC systems are mainly composed of the same components, as shown in Fig. 7.1. Due to this fact, the development of a single system with the capacity of operating either in HTHP or in ORC mode is technically viable, applying some modifications. The development of this system that can operate in both modes represents a challenge, going one step forward in the development of HTHP and ORC technology. The combinations of both technologies maximise the waste heat recovery of the industrial processes and establish the baseline for future analysis and developments of this novel system. 
In Fig. 7.1a, the operation of the reversible system in HTHP mode is shown. This mode is based on the main components of vapour compression cycles with the particularity of including an Internal Heat Exchanger (IHX). The IHX increases the degree of superheating of the refrigerant in the compressor suction line along with the sub-cooling before the expansion process. This improves the system energy efficiency, varying at the same time the rest of the operating parameters, like the heating capacity and discharge temperature, among others [48]. Therefore, an optimisation of the IHX is crucial to reach the maximum energy performance without exceeding the boundaries of the technical limitations.

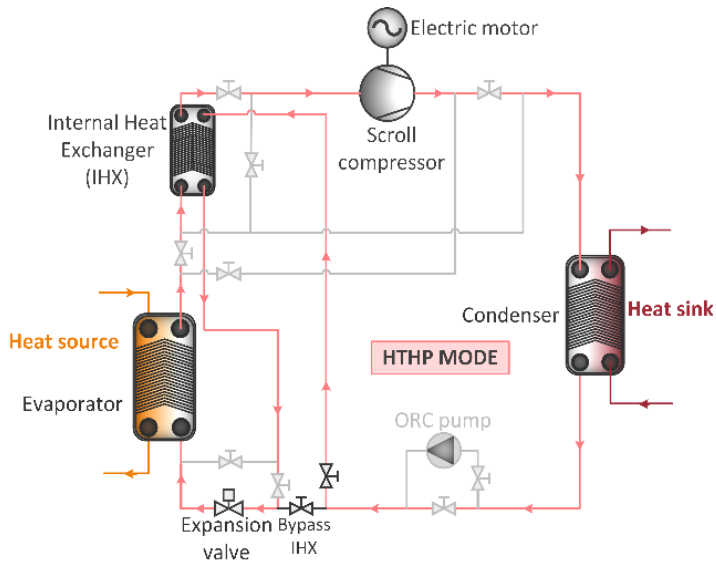

(a)

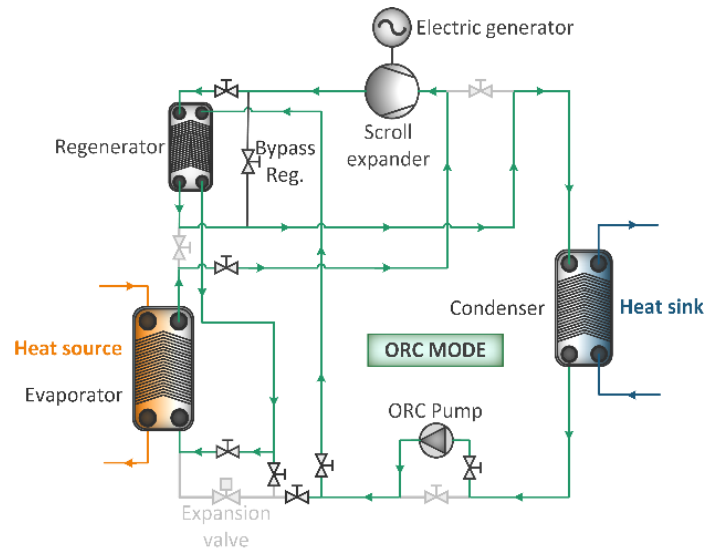

(b)

Fig. 7.1. Schematic diagram of the reversible HTHP-ORC system, operating in: a) HTHP mode and b) ORC mode.

On the other hand, the basic vapour compression cycle with IHX could be modified to operate in ORC mode and, therefore, allowing a reversible operation in a single system. Fig. 7.1b shows that evaporator and condenser are standard components of both modes without requiring any modification. Moreover, the heat exchanger used as IHX in HTHP mode can be used as regenerator in ORC mode, resulting as a basic cycle configuration with regeneration in ORC mode. Besides, the scroll compressor used in the HTHP mode requires minor modifications, switching the refrigerant inlet of this component with an additional valve circuit, to operate as an expander in the ORC mode. Finally, the expansion valve is by-passed, and a refrigerant pump is added after the condenser. Through these modifications, this novel system can be operated either in HTHP or in ORC mode, by changing the position of the valve.

T-s diagram of the reversible HTHP-ORC system is shown in Fig. 7.2, with a standard evaporating temperature of $90^{\circ} \mathrm{C}$ for both systems and HTHP and ORC condensing temperatures of 140 and 40 ${ }^{\circ} \mathrm{C}$, respectively. This diagram illustrates the differences between HTHP and ORC thermodynamic cycles along with a graphical description of the concept 'reversible' of the proposed system. 


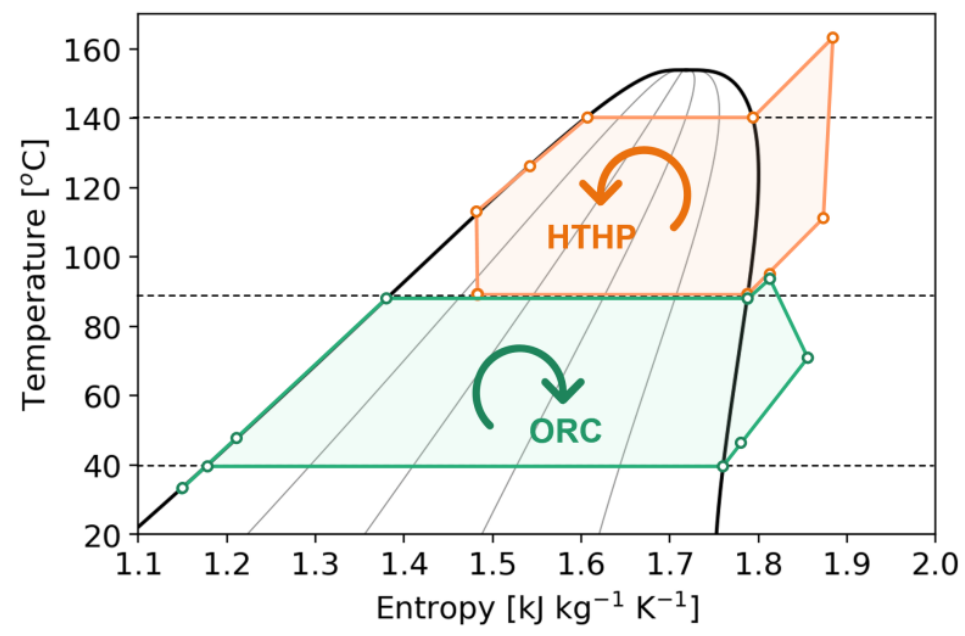

Fig. 7.2. T-s diagram of the reversible HTHP-ORC system at an evaporating temperature of $90{ }^{\circ} \mathrm{C}$ and HTHP and ORC condensing temperatures of 140 and $40{ }^{\circ} \mathrm{C}$, respectively.

\subsubsection{Compressor-Expander modelling}

The reversible system modelling is built from semi-empirical models of scroll compressor and expander, due to its high efficiency against other technologies $[49,50]$.

The scroll compressor semi-empirical model proposed by Winandy et al. [51,52] could be generalised to scroll compressors using a discharge valve, as Lemort [53] proposed. The motivation is to increase the accurate prediction of the electrical consumption along with the compressor efficiencies. Hence, the modelling of heat pump systems was improved through the modification of compressors that are typically using discharge valves [53].

A schematic representation of the proposed compressor model is shown in Fig. 7.3a, based on the literature reviewed $[50,51,53]$. In this model, the evolution of the refrigerant is decomposed into the following consecutive steps:

- Isobaric supply heating-up $\left(s u \rightarrow s u,,_{1}\right)$

- Adiabatic mixing with internal leakage $\left(s u,,_{1} \rightarrow s u,,_{2}\right)$

- Adiabatic and reversible compression to the "adapted" pressure imposed by the built-in volume ratio of the machine $(\mathrm{su}, 2 \rightarrow a d)$

- Adiabatic compression at a constant machine volume $(a d \rightarrow e x, 2)$

- Adiabatic exhaust pressure drop $\left(e x,,_{2} \rightarrow e x,,_{1}\right)$

- Isobaric exhaust cooling-down $\left(e x,,_{1} \rightarrow e x\right)$

The fictitious dissociation of the heat transfer, supply pressure drop, and internal leakage from the actual compression process results in an accurate estimation of the compressor power consumption along with the volumetric and isentropic compressor efficiencies. These parameters are then essentials in the development of the refrigerant comparison model. The complete description of these semi-empirical compressor model, along with the equations used in this paper are described by Lemort [53]. 
On the other hand, the semi-empirical expander model is adapted from the compressor model proposed by Winandy et al. [51] for hermetic scroll compressors. Similarly to the compressor model, the schematic of the expander model, Fig. 7.3b, shows consecutive steps of the refrigerant evolution through the expander:

- Adiabatic supply pressure drop $(s u \rightarrow s u, 1)$

- Isobaric supply cooling-down $\left(s u,,_{1} \rightarrow s u, 2\right)$

- Adiabatic and reversible expansion to the "adapted" pressure imposed by the built-in volume ratio of the machine $(\mathrm{su}, 2 \rightarrow \mathrm{ad})$

- Adiabatic expansion at a constant machine volume $(a d \rightarrow e x, 2)$

- Adiabatic mixing between supply and leakage flows $\left(e x, 2 \rightarrow e x,,_{1}\right)$

- Isobaric exhaust cooling-down or heating-up $\left(e x,,_{1} \rightarrow e x\right)$

Similar to the compressor-expander model, the complete description of these semi-empirical compressor model along with the equations used in this paper are described by Lemort [50] and Lemort et al. [54].

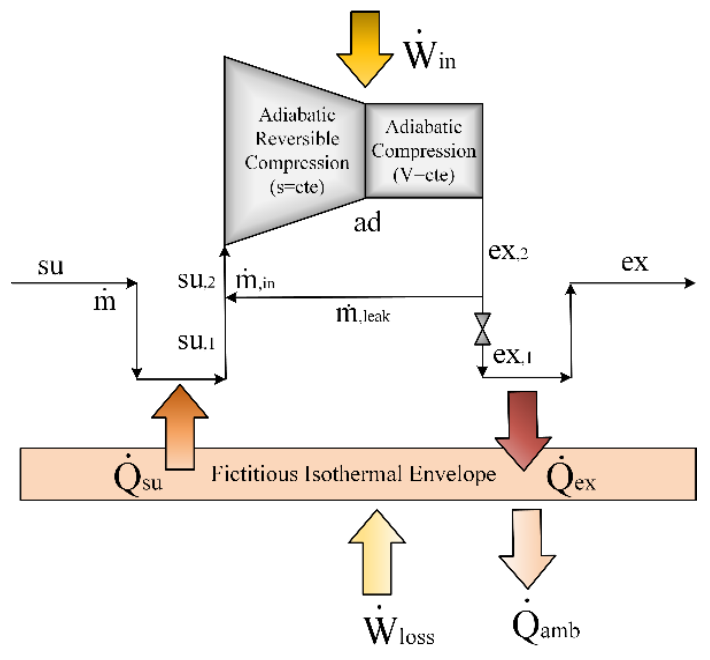

(a)

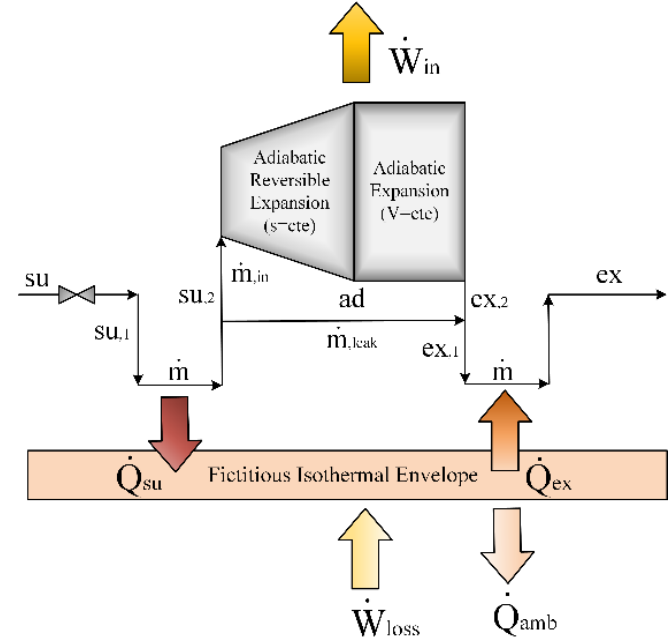

(b)

Fig. 7.3. Schematic representation of semi-empirical models: a) Scroll compressor and b) Scroll expander.

\subsubsection{Reversible HTHP-ORC modelling}

A proper selection and implementation of several geometric constraints make possible the reversible operation between HTHP and ORC cycles. Compressor and expander are volumetric machines that have a fixed geometry. The internal built-in volume ratio $\left(r_{V}\right)$ is dependent on the final and the initial volume in both compressor and expander components. For a given refrigerant at specific conditions, the energy efficiency of the volumetric machine is highly dependent on the built-in volume ratio, which is related to the internal pressure ratio.

Nevertheless, if the system pressure ratio is higher or lower than the internal pressure ratio, over- and under-compression/expansion appear. Under this condition, the system operation is considered to be not adapted to the conditions and, therefore, the compressor power consumption is higher, or the 
expander power generation is lower compared to the optimum values. Hence, a proper design of the internal built-in volume ratio will provide significant energy efficiency for given operating conditions.

The operating pressure ratio in both modes should be similar in order not to penalise energy efficiency. Nevertheless, the optimal built-in volume ratio has different values between compressors and expanders to provide the maximum energy efficiency in both situations [55]. While an expander operates at its maximum energy efficiency, considering lower built-in volume ratio values, a compressor requires higher values of this parameter, as shown in Fig. 7.4. Henceforth, an optimisation of the built-in volume ratio is required in order to provide a trade-off value between both modes that maximise the overall energy efficiency.

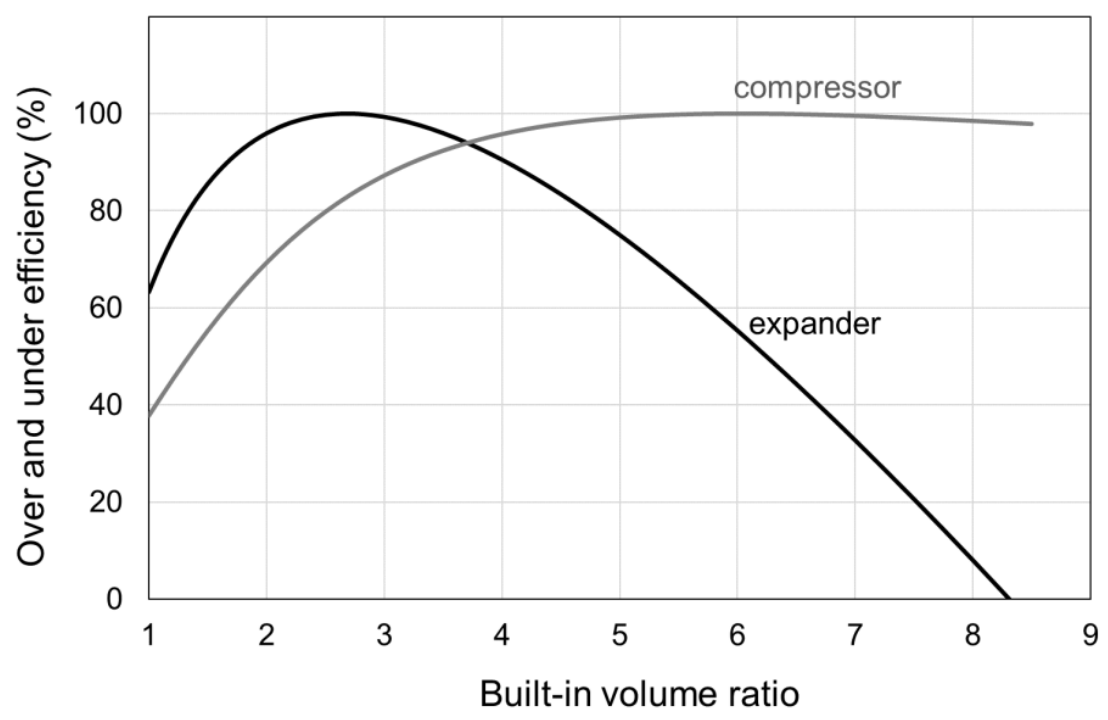

Fig. 7.4. Over- and under-efficiency at different built-in volume ratio for compressor and expander [55].

On the other hand, the internal heat exchanger in HTHP mode or the regenerator in ORC mode is based on a common component for both configurations. Therefore, the geometry of this component should be the same. While ORC systems present almost no limitations in the regenerator effectiveness value, an HTHP system is highly influenced by the IHX effectiveness value. Higher values of this parameter increase the compressor discharge temperature, and the installation materials along with the lubricant and refrigerant can start to degrade. Due to this fact, the reversible model uses an optimisation IHX effectiveness algorithm that calculates its maximum possible value. Then, the regenerator effectiveness is calculated assuming the same AU value for both IHX and regenerator through the NTU method [56], Eq. (7.1).

$$
\frac{\ln \left(1-\varepsilon_{I H X}\right)}{C_{p, H T H P} \dot{m}_{r e f, H T H P}}=\frac{\ln \left(1-\varepsilon_{R e g}\right)}{C_{p, O R C} \dot{m}_{r e f, O R C}}
$$




\subsubsection{Validation of the models}

Semi-empirical models of the compressor and expander are developed to obtain several modelling coefficients based on experimental data. Nevertheless, the interest of this paper is the estimation of the performance parameters based on semi-empirical models modification. Hence, implementing the semi-empirical coefficients obtained and validated by Lemort [50] and Lemort et al. [54], it is obtained the performance parameters of the compressor and expander. The experimental coefficients used in compressor and expander semi-empirical models are presented in Table 7.1.

Table 7.1. Semi-empirical modelling coefficients for compressor and expander models.

\begin{tabular}{|c|c|c|}
\hline Semi-empirical modelling coefficients & $\begin{array}{l}\text { Compressor } \\
{[50]}\end{array}$ & $\begin{array}{l}\text { Expander } \\
{[54]}\end{array}$ \\
\hline Heat transfer coefficient with the ambient $\left(A U_{a m b}\right)\left[\mathrm{W} \mathrm{K}^{-1}\right]$ & $30\left(\frac{\dot{m}_{r e f}}{0.091}\right)^{0.8}$ & 6.4 \\
\hline Supply heat transfer coefficient $\left(A U_{s u}\right)\left[\mathrm{W} \mathrm{K}^{-1}\right]$ & $20\left(\frac{\dot{m}_{r e f}}{0.091}\right)^{0.8}$ & 21.2 \\
\hline Exhaust heat transfer coefficient $\left(A U_{e x}\right)\left[\mathrm{W} \mathrm{K}^{-1}\right]$ & 3 & 34.2 \\
\hline Nominal mass flow rate $\left(\dot{m}_{r e f, n}\right)\left[\mathrm{kg} \mathrm{s}^{-1}\right]$ & 0.091 & 0.12 \\
\hline Leakage area $\left(A_{\text {leak }}\right)\left[\mathrm{mm}^{2}\right]$ & 0.39 & 4.6 \\
\hline Supply port cross-sectional area $\left(A_{s u}\right)\left[\mathrm{mm}^{2}\right]$ & - & 27.43 \\
\hline Mechanical loss torque $\left(T_{\text {loss }}\right)[\mathrm{N} \mathrm{m}]$ & - & 0.47 \\
\hline Mechanical losses coefficient $(\alpha)[-]$ & 0.23 & - \\
\hline Constant mechanical losses $\left(\dot{W}_{\text {loss }, 0}\right)[\mathrm{W}]$ & 100 & - \\
\hline
\end{tabular}

\subsubsection{Alternative refrigerants modelling}

The synthetic refrigerant HFC-245fa was used in the semi-empirical models for the identification of the semi-empirical modelling coefficients. Nevertheless, HFC-245fa presents a relatively high Global Warming Potential (GWP) value, which can contribute to aggravating the climate change issue. Hence, other refrigerants with low-GWP may be alternatives to HFC-245fa in this reversible system in order to develop more sustainable technology. The selected low-GWP refrigerants and their main properties are presented in Table 7.2. 
Table 7.2. Comparative refrigerant properties for HTHP/ORC application.

\begin{tabular}{|c|c|c|c|c|c|c|c|}
\hline Fluids & $\begin{array}{l}\mathbf{T}_{\text {crit }} \\
\left({ }^{\circ} \mathbf{C}\right)\end{array}$ & $\begin{array}{l}\mathbf{P}_{\text {crit }} \\
\text { (MPa) }\end{array}$ & $\begin{array}{l}\text { NBP } \\
\left({ }^{\circ} \mathrm{C}\right)\end{array}$ & $\begin{array}{l}\text { Suction } \\
\text { density }^{\mathrm{e}}(\mathrm{kg} \\
\left.\mathbf{m}^{-3}\right)\end{array}$ & ODP & $\begin{array}{l}\text { GW } \\
\mathbf{P}_{100}\end{array}$ & $\begin{array}{l}\text { ASHRAE } \\
\text { Std. } 34 \\
\text { safety } \\
\text { class [44] }\end{array}$ \\
\hline HFC-245fa & 153.8 & 3.65 & 15.1 & 40.56 & 0 & 858 & B1 \\
\hline $\begin{array}{l}\text { HC-600 } \\
\text { (Butane) }\end{array}$ & 152.0 & 3.80 & -0.5 & 23.15 & 0 & 4 & A3 \\
\hline $\begin{array}{l}\text { HC-601 } \\
\text { (Pentane) }\end{array}$ & 196.6 & 3.37 & 36.1 & 9.52 & 0 & 5 & A3 \\
\hline HFO-1336mzz(Z) ${ }^{\mathrm{a}}$ & 171.4 & 2.90 & 33.4 & 25.78 & 0 & 2 & A1 \\
\hline $\mathrm{R} 514 \mathrm{~A}^{\mathrm{b}}$ & 178.0 & 3.52 & 29.1 & 24.39 & 0 & 2 & B1 \\
\hline HCFO-1233zd(E) ${ }^{c}$ & 166.5 & 3.62 & 18.3 & 32.36 & 0.00034 & 1 & A1 \\
\hline HCFO-1224yd(Z) ${ }^{\mathrm{d}}$ & 155.5 & 3.33 & 14.6 & 42.09 & 0.00012 & $<1$ & A1 \\
\hline
\end{tabular}

${ }^{\mathrm{a} O p t e o n}{ }^{\mathrm{TM} M Z}$ from Chemours [58], ${ }^{\mathrm{b}}$ Opteon ${ }^{\mathrm{TM} X P 30}$ (R-514A) from Chemours [59], ${ }^{\mathrm{c} S o l s t i c e}{ }^{\circledR} \mathrm{zd}$ from Honeywell [60], ${ }^{\mathrm{d}}$ AMOLEA ${ }^{\circledR} 1224 \mathrm{yd}$ from AGC Chemicals [61], ${ }^{\mathrm{e}}$ At suction temperature of

$95^{\circ} \mathrm{C}$.

In order to simulate the reversible system with alternative low-GWP refrigerants, compressor and expander efficiencies should be corrected according to the thermodynamic properties of the potential candidates. Therefore, isentropic and volumetric efficiencies are adjusted using Eqs. (7.2) and (7.3), considering that the refrigerant inside the compressor or expander can be considered as an ideal gas [34].

$$
\begin{gathered}
\eta_{\text {is,low } G W P}=\frac{\left[\left(\frac{P_{2}}{P_{1}}\right)^{\left(\frac{\gamma-1}{\gamma}\right)}\right]_{\text {low } G W P}}{\left[\left(\frac{P_{2}}{P_{1}}\right)^{\left(\frac{\gamma-1}{\gamma}\right)}\right]_{H F C-245 f a}} \cdot \eta_{i s, H F C-245 f a} \\
\eta_{\text {vol,low } G W P}=1-\frac{\left[\left(\frac{P_{2}}{P_{1}}\right)^{\left(\frac{1}{\gamma}\right)}\right]_{l o w G W P}}{\left[\left(\frac{P_{2}}{P_{1}}\right)^{\left(\frac{1}{\gamma}\right)}\right]_{H F C-245 f a}}\left(1-\eta_{v o l, H F C-245 f a}\right)
\end{gathered}
$$

Then, the corrected efficiencies are implemented in a basic compressor-expander model with the same constraints explained in Section 2.2. Moreover, over- and under-expansion/compression effects are implemented in the model, Eqs. (7.4) and (7.5), as proposed by Peris et al. [55]. These equations depend on the built-in volume ratio $\left(r_{v}\right)$, which is defined as the geometric volume ratio between the ports of the displacement machine. The optimum value of the $r_{v}$ parameter is affected by several variables, such as the operating conditions or the working fluid used. Therefore, an optimization of the built-in volume ratio has been subsequently included in the model to select a proper suitable working fluid for both operation modes [55]. 
Chapter 7

$$
\begin{gathered}
\eta_{\text {over-under,exp }}=\frac{\left(h_{s u, 2}-h_{a d}\right)+\frac{P_{a d}-P_{e x, 2}}{\rho v_{a d}}}{h_{a d}-h_{e x, 2, i s}} \\
\eta_{\text {over-under,comp }}=\frac{h_{a d}-h_{e x, 2, i s}}{\left(h_{a d}-h_{s u, 2}\right)+\frac{P_{e x, 2}-P_{a d}}{\rho v_{a d}}}
\end{gathered}
$$

Over-under efficiencies for the compressor and expander are included in the equations to calculate the power consumption of the compressor, Eq. (7.6), and the power generated by the expander, Eq. (7.7). In addition, the electrical consumption of the ORC pump is presented in Eq. (7.8).

$$
\begin{gathered}
\dot{W}_{\text {comp }}=\frac{\dot{m}_{\text {ref,HTHP }}\left(h_{\text {comp }, \text { out }, \text { is }}-h_{\text {comp }, \text { in }}\right)}{\eta_{\text {is,comp }} \eta_{\text {em }} \eta_{\text {over-under,comp }}} \\
\dot{W}_{\text {exp }}=\dot{m}_{\text {ref }, \text { ORC }}\left(h_{\text {exp }, \text { in }}-h_{\text {exp }, \text { out }, \text { is }}\right) \eta_{\text {is,exp }} \eta_{\text {em }} \eta_{\text {over-under }, \text { exp }} \\
\dot{W}_{\text {pump }}=\frac{\dot{m}_{\text {ref }, \text { ORC }}\left(h_{\text {pump }, \text { out }, \text { is }}-h_{\text {pump }, \text { in }}\right)}{\eta_{\text {is,pump }} \eta_{\text {em }}}
\end{gathered}
$$

Finally, the performance of the reversible system can be expressed through two performance parameters: the net electrical efficiency of the ORC $\left(\eta_{n e t}\right)$ by Eq. (7.9), and the coefficient of performance (COP) of the HTHP by Eq. (7.10). This analysis assumes normalized values, in which a unit of thermal power input is recovered in both operating modes.

$$
\begin{gathered}
\eta_{\text {net }}=\frac{\dot{W}_{\text {exp }}-\dot{W}_{\text {pump }}}{\dot{Q}_{\text {in }}} \\
C O P=\frac{\dot{Q}_{\text {out }}}{\dot{W}_{\text {comp }}}
\end{gathered}
$$

\subsection{Methodology}

\subsubsection{System optimization}

This section describes the optimization process of the built-in volume ratio along with the IHXregenerator. The reversible installation, as a single system, requires sharing the main components of the circuit and therefore, the common circuit components should have the same geometry. Hence, the optimisation of these components is crucial to provide the highest energy efficiency working in both ORC and HTHP modes. 


\section{- Built-in volume ratio}

The optimisation of the built-in volume ratio becomes a challenge because the highest energy performance working as compressor or expander demands built-in volume ratio values explained in Section 2.3. Hence, a trade-off between both modes is crucial and therefore, optimisation of this geometrical parameter becomes necessary. The optimisation process is graphically described in Fig. 7.5 .

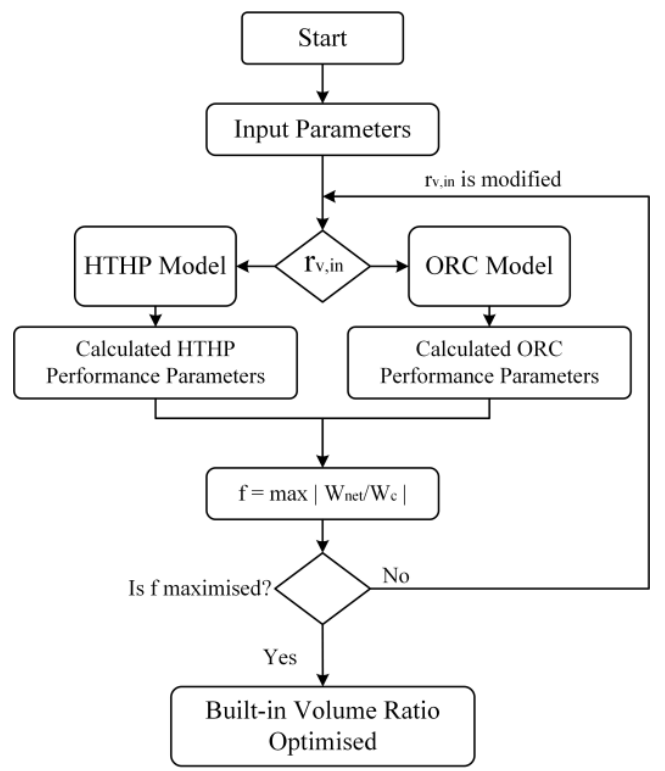

Fig. 7.5. Built-in volume ratio optimisation process for HTHP-ORC models.

The experimental coefficients for each model described in Section 2.4 are implemented as input parameters in the optimisation model along with the condensation temperatures of both systems and the evaporation temperature, which is related with the industrial waste heat source. These models are developed in the software Engineering Equation Solver (EES) [57], which is linked to the refrigerant thermophysical properties database REFPROP Version 10.0 [58]. Using the Conjugate Directions method implemented in the software EES, the function $f$, shown in Fig. 7.5, is maximized to find the built-in volume ratio value that provides the highest power production in ORC mode and the lowest power consumption in HTHP mode. Finally, the built-in volume ratio is optimised for one specific condition and therefore, this process is repeated for each simulation condition included in this study.

\section{- Internal heat exchanger (IHX)}

After optimising the built-in volume ratio, the IHX should be optimised in order to maximise the energy efficiency of the whole system. Higher IHX effectiveness increases the degree of sub cooling and superheating degree in the system and therefore, the energy efficiency in both systems increase. Nevertheless, it also results in higher compressor discharge temperature [31], which should be limited due to the installations materials, refrigerants and lubricants thermal limitations. Hence, the built-in volume ratio algorithm, described in the previous section, is followed by the IHX effectiveness optimisation algorithm, presented in Fig. 7.6. 


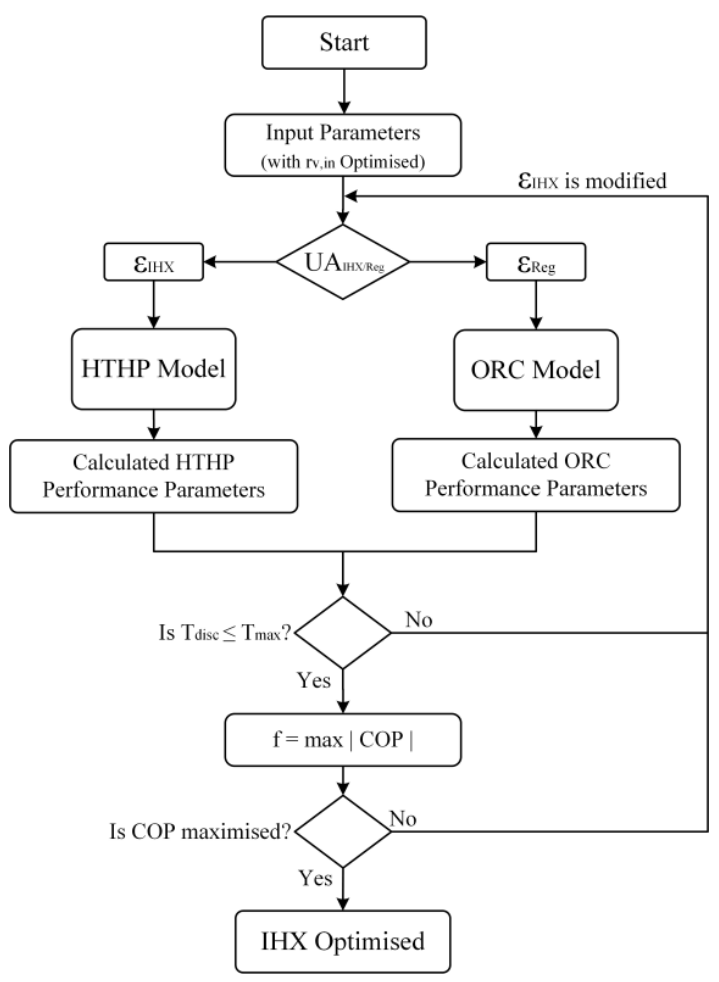

Fig. 7.6. Internal Heat Exchanger (IHX) optimisation process for HTHP-ORC models.

The IHX optimisation algorithm receives the optimised results of the built-in volume ratio algorithm as input parameters. The compressor discharge temperature is limited to $175^{\circ} \mathrm{C}$ in order to ensure the material resistance as well as to prevent the refrigerant and lubricant tested degradation [31]. Following the previous optimisation methodology, the Conjugate Directions method implemented in EES is used to maximise the COP without exceeding the maximum compressor discharge temperature. Finally, the regenerator effectiveness of ORC system is calculated using the NTU method with the optimised IHX effectiveness and assuming equal UA in the IHX-Reg., for both ORC and HTHP modes. This assumption is reasonable because each mode works with the same refrigerant, and the heat exchanger has a single geometry for both modes.

Finally, the optimisation process provides the optimum built-in volume ratio and IHX-Reg effectiveness, which provides the maximum performance efficiency with a compromise between HTHP and ORC modes. Depending on the application or requirements, both algorithms can be adapted to find the optimised parameters that prioritize HTHP or ORC mode. Nevertheless, the algorithms in this study are developed to find the equilibrium between both operating modes.

\subsubsection{Simulation of the operating conditions}

This section describes the operating conditions proposed for the reversible system modelling. The heat absorbed by the evaporator $\left(\dot{Q}_{o}\right)$, the input parameter of the model, is considered constant for all the operating conditions to end with a comparative analysis. Finally, Table 7.3 presents the operating conditions of both cycles. 
Table 7.3. Operating parameters of the reversible system modelling.

\begin{tabular}{ll}
\hline Parameters & Numeric values \\
\hline Evaporating temperature $\left({ }^{\circ} \mathrm{C}\right)$ & $70-100$ \\
HTHP condensing temperature $\left({ }^{\circ} \mathrm{C}\right)$ & 145 \\
ORC condensing temperature $\left({ }^{\circ} \mathrm{C}\right)$ & 40 \\
Superheat degree $(\mathrm{K})$ & 15 \\
Sub-cooling degree $(\mathrm{K})$ & 5 \\
Electromechanical efficiency $\left(\eta_{\text {em }}\right)$ & 0.75 \\
ORC pump efficiency $\left(\eta_{\text {pump }}\right)$ & 0.9 \\
\hline
\end{tabular}

\subsection{Results and discussions}

\subsubsection{Reversible HTHP-ORC}

This section presents the results obtained by the semi-empirical reversible model working with HFC$245 \mathrm{fa}$ as working fluid. Firstly, the system optimisation results are exposed, comparing the maximum efficiency in both modes, which depends on the built-in volume ratio along with the maximum point optimised. Then, an analysis of different condensing temperatures in both systems with a fixed evaporating temperature is performed in order to provide a complete view of the system behaviour. Finally, the energy performance of both modes is presented along with the compressor and expander efficiencies.

\section{- System optimisation}

The optimisation of the built-in volume ratio is crucial in volumetric machines and especially, for the reversible system proposed in this paper. Considering that the same component is operating as compressor and expander, the same geometry is required for both HTHP and ORC modes. Nevertheless, the maximum efficiency points in HTHP and ORC modes are different as the evaporating temperature varies. For lower evaporating temperatures, HTHP mode requires higher built-in volume ratio than working in ORC mode, as shown in Fig. 7.7. However, this situation changes when the system operates at higher evaporating temperatures. In these conditions, the ORC mode requires higher built-in volume ratio values than HTHP mode. Therefore, higher evaporating temperatures decrease the built-in volume ratio requirements in HTHP modes, whereas this requirement increases if working in ORC mode. These built-in volume ratio requirements differences in both modes represent a challenge to find the optimum value. Hence, using the optimization algorithm presented in Section 3.1.1, the optimum built-in volume ratio for the reversible system working in both modes is presented in Fig. 7.7. 


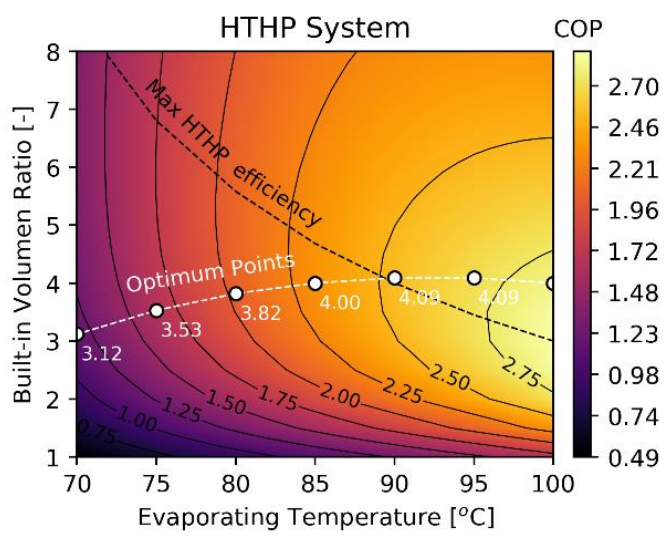

(a)

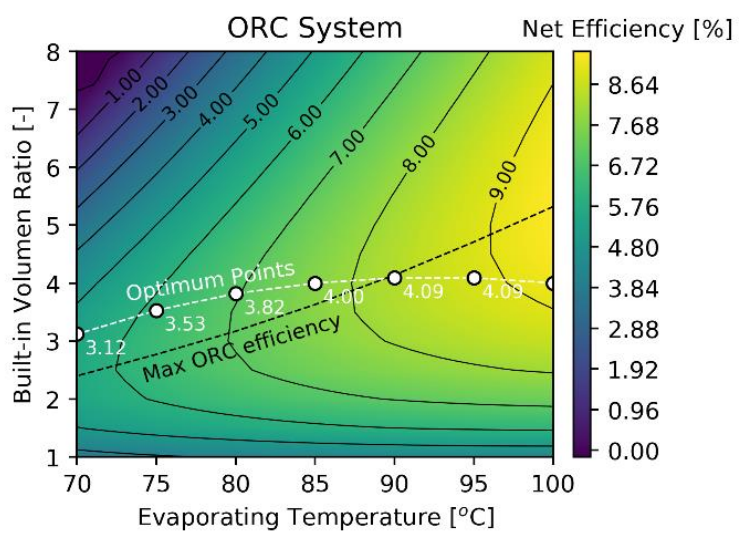

(b)

Fig. 7.7. Optimised values of built-in volume ratio for reversible system working in: a) HTHP mode and b) ORC mode.

In order to provide a complete view of the proper built-in volume ratio, this parameter has been optimised for different condensing temperatures in HTHP and ORC modes, fixing the evaporating temperature at $85{ }^{\circ} \mathrm{C}$, as shown in Fig. 7.8. As the HTHP condensing temperature increases, the reversible system requires higher built-in volume ratio in order to provide the maximum energy efficiency. Nevertheless, an ORC condensing temperature increment produces the contrary reaction, decreasing the requirements system in built-in volume ratio. Similar to the Fig. 7.8 , there is a difference in the built-in volume ratio requirements for both modes. Therefore, depending on the operating temperatures and the applications, the reversible system will require a specific optimisation of this parameter to provide the highest energy performance.

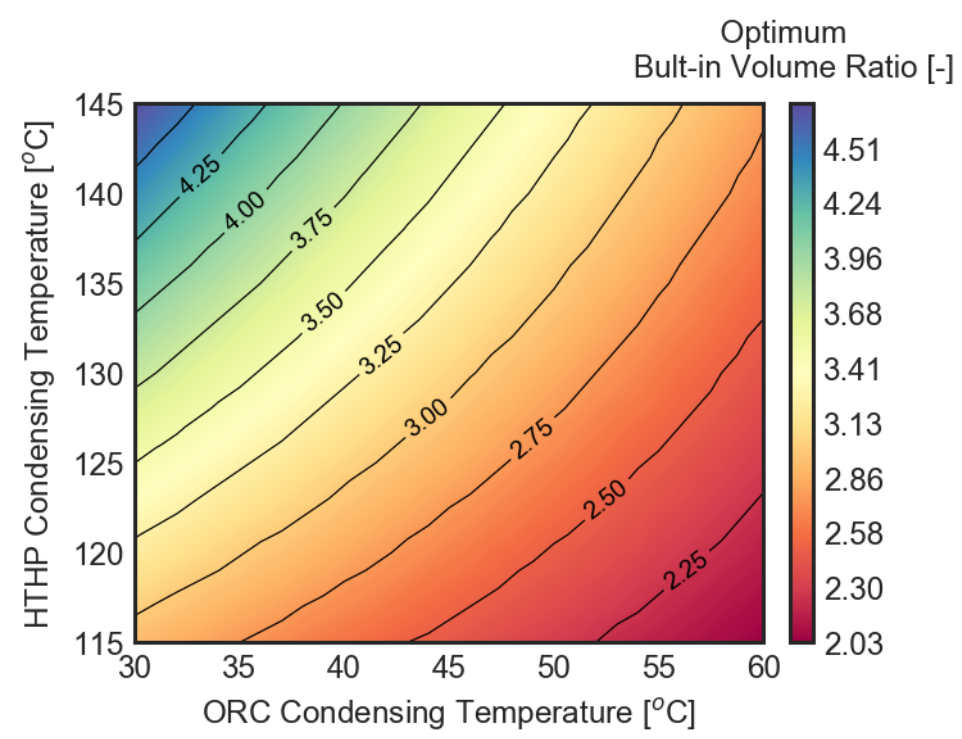

Fig. 7.8. Optimum built-in volume ratio for different HTHP-ORC condensing temperatures with a fixed evaporating temperature of $85^{\circ} \mathrm{C}$. 


\section{- Performance evaluation}

In Fig. 7.9, the COP and net efficiency of HTHP and ORC modes are presented, respectively. As the evaporating temperature rises, both the energy parameter increases. These are expected results because as the evaporating temperature increases, the distance between the heat source and heat sink for HTHP is reduced. Therefore, the compressor requires lower power consumption, providing higher COP. On the contrary, as the evaporating temperature increases, the heat source and sink in ORC mode is increasing. Nevertheless, this increase provides an advantage for ORC mode because the pressure ratio between the expander inlet and outlet increases and therefore, higher power can be generated.

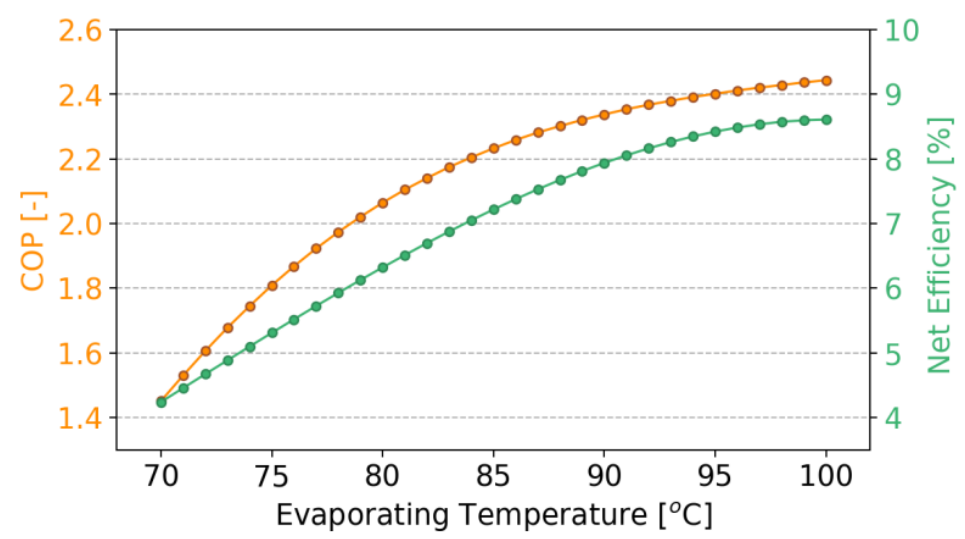

Fig. 7.9. COP and net efficiency results of the semi-empirical reversible system modelling.

Finally, semi-empirical modelling provides the compressor-expander isentropic efficiencies. These values have considerable importance because establishing the baseline for the low-GWP alternative refrigerant analysis explained in Section 2.5. Fig. 7.10 shows the main compressor and expander isentropic and volumetric efficiency results at different evaporating temperatures. This semiempirical efficiency results will be corrected for each alternative low-GWP refrigerant in order to estimate the compressor and expander efficiencies and therefore, achieve the multi-objective comparison.

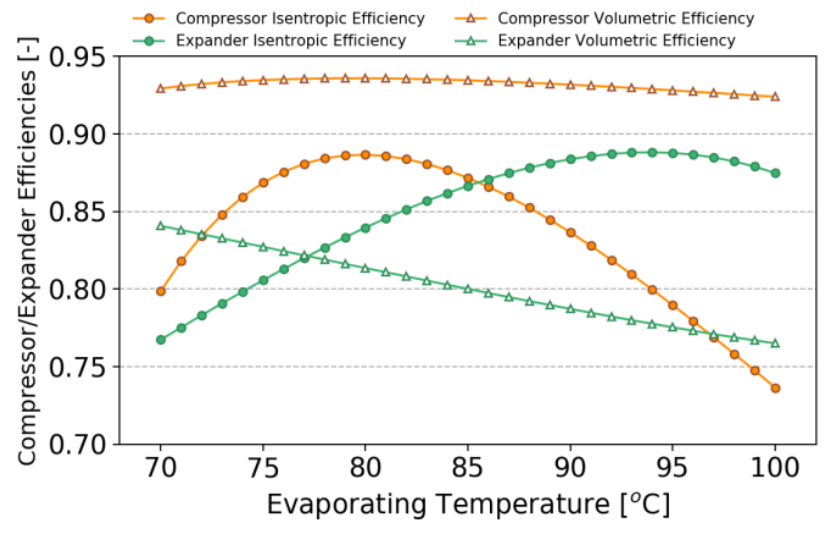

Fig. 7.10. Compressor-expander isentropic and volumetric efficiencies from semi-empirical reversible modelling. 


\subsubsection{Alternative Low-GWP refrigerants}

This section presents the results of the alternative low-GWP refrigerants for HFC-245fa in the reversible system proposed. These results are based on the semi-empirical models and the corrected efficiencies, depending on the thermophysical properties of each refrigerant. The results of this section will illustrate the benefits of different refrigerants from energy and installation size points of view.

\section{- Corrected isentropic and volumetric efficiencies}

Isentropic and volumetric efficiencies are highly related to the thermophysical properties of the refrigerant uses in the system. Therefore, the efficiencies estimated with semi-empirical models using HFC-245fa as refrigerant can be used as a baseline in order to calculate the alternative low-GWP refrigerants efficiencies through the Eqs. (3) and (4).

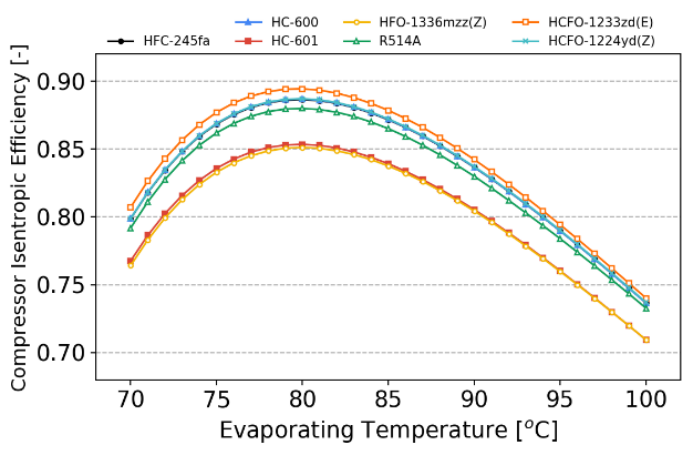

(a)

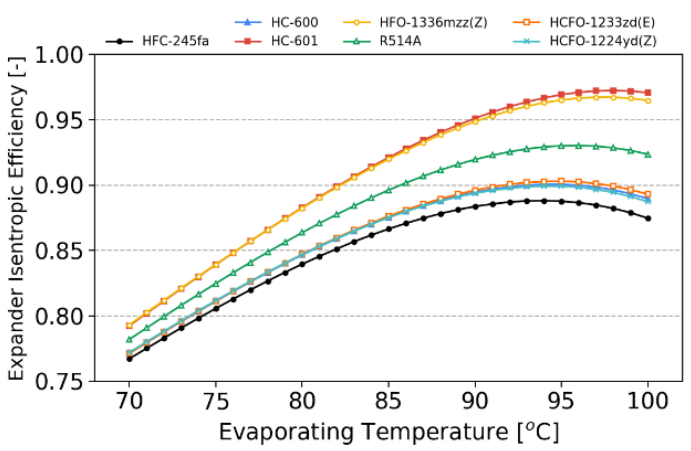

(b)

Fig. 7.11. Corrected isentropic efficiencies at different evaporating temperatures working as: a) Compressor and b) expander.

Fig. 7.11a shows the results of the corrected isentropic efficiencies for compressor and expander. On the one hand, HCFOs and Butane present higher compressor isentropic efficiency than HFC-245fa, while R-514A shows comparable values to the traditional HFC-245fa. On the other hand, Pentane and HFO-1336mzz(Z) have considerably lower isentropic compressor values due to their different thermophysical properties to HFC-245fa. In contrast, the isentropic efficiencies in the expander show utterly different behaviour than working as a compressor, as shown in Fig. 7.11b. In this case, Pentane and HFO-1336mzz(Z) present the highest isentropic efficiency working as an expander, followed by R-514A. Finally, although HFOs and Butane show the lowest expander isentropic efficiencies, their values are still higher than HFC-245fa.

The volumetric efficiencies of the compressor and expander are presented in Fig. 7.12. In this case, HFO-1336mzz(Z) shows the highest volumetric efficiency working as compressor, followed by Pentane and R-514A, as shown in Fig. 7.12a. While these three refrigerants present higher compressor volumetric efficiency than HFC-245fa, the other refrigerants show lower values of this parameter, being Butane the refrigerant with the lowest volumetric compressor efficiency. As expander, the refrigerants show again a significantly different behaviour, as shown in Fig. 7.12b. In this case, Butane and HCFOs have higher volumetric efficiencies than HFC-245fa, being Butane the refrigerant 
with the highest volumetric efficiency. Nevertheless, HFO-1336mzz(Z), R-514A and Pentane have lower expander volumetric efficiencies, showing the HFO the lowest value.

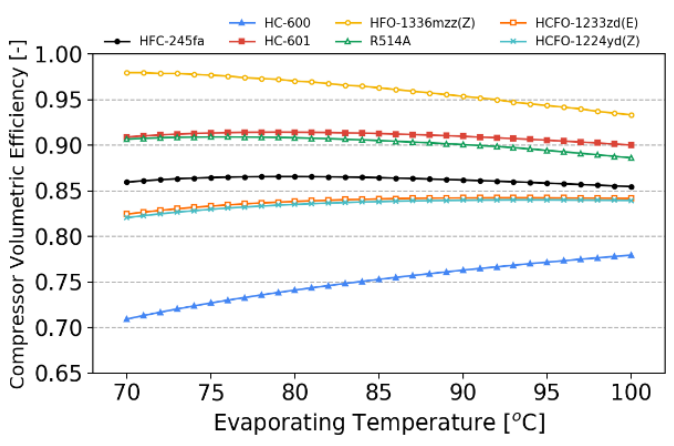

(a)

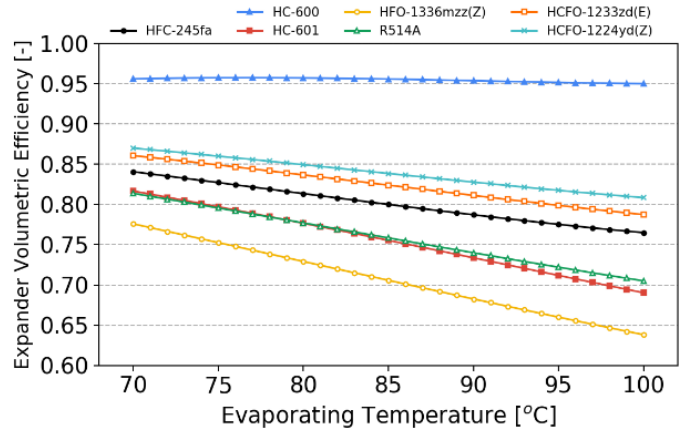

(b)

Fig. 7.12. Corrected volumetric efficiencies at different evaporating temperatures working as: a) Compressor and $b)$ expander.

\section{- Optimized evaluation}

This section presents the results of the optimised built-in volume ratio for the reversible system proposed along with the IHX-Reg. effectiveness optimisation. Before the optimisation processes mentioned in Section 3.1, the optimised results will illustrate the main difference of each refrigerant in the system.

Fig. 7.13 shows the results of the optimised built-in volume ratio for each refrigerant at different evaporating temperatures. As the evaporating temperature increases, the optimum built-in volume ratio increases for each refrigerant until an evaporating temperature of $90{ }^{\circ} \mathrm{C}$, where this parameter shows a slight decrement. This behaviour is caused due to the maximum efficiencies trend of both HTHP and ORC systems presented in Fig. 7.7. At the evaporating temperature of $90^{\circ} \mathrm{C}$, the maximum efficiency lines of HTHP and ORC system cross among each other, resulting in the optimum built-in volume ratio decrease showed in Fig. 7.13.

HFO-1336mzz(Z) presents the highest optimised built-in volume ratio value, whereas Butane shows the lowest value of this parameter. All the refrigerants, apart from HFO-1336mzz(Z) present a lower optimum built-in volume ratio for operating in both HTHP and ORC mode. Moreover, most of the refrigerants simulate have close values to HFC-245fa, and therefore, the design of the reversible system for HFC-245fa can operate with other refrigerants with a slight difference from the built-in volume ratio point of view. 
Chapter 7

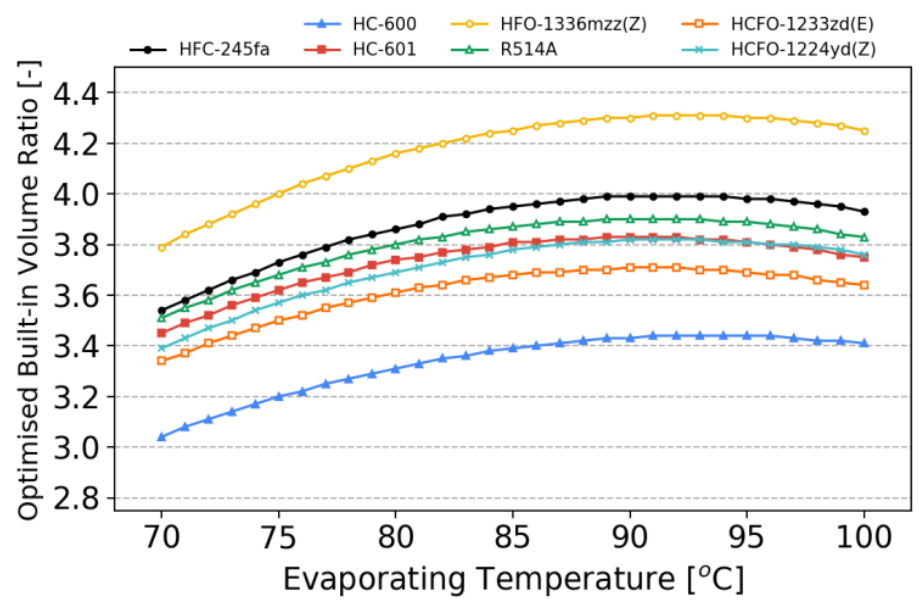

Fig. 7.13. Optimised built-in volume ratio for each alternative low-GWP refrigerant at different evaporating temperatures.

Fig. 7.14 shows the effectiveness of the IHX-Regenerator working as a compressor or expander. Both parameters are proportional because is the same heat exchanger for both modes and therefore, similar behaviour in both HTHP and ORC mode is expected. As the evaporating temperature increases, the IHX-Reg value decreases due to the maximum compressor discharge temperature allowed. HFO$1336 \mathrm{mzz}(\mathrm{Z})$ and Butane are the refrigerants that can operate with the highest IHX effectiveness values without exceeding the maximum compressor discharge temperature. Contrary, HCFO-1233zd(E) and R-514A have the lowest values of effectiveness, and therefore, the performance improvement caused by the IHX is expected to be lower.

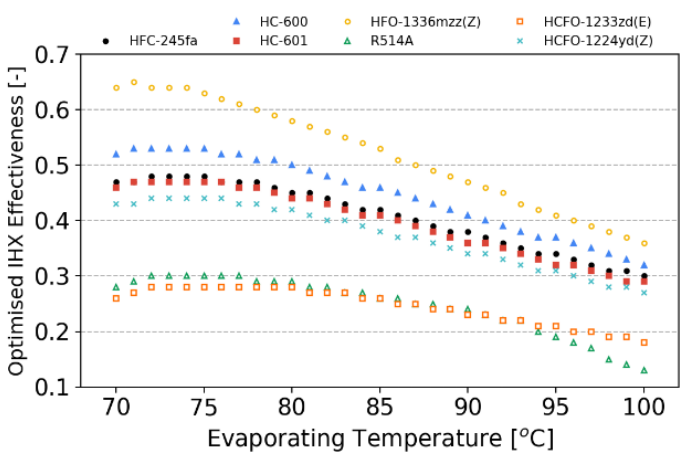

(a)

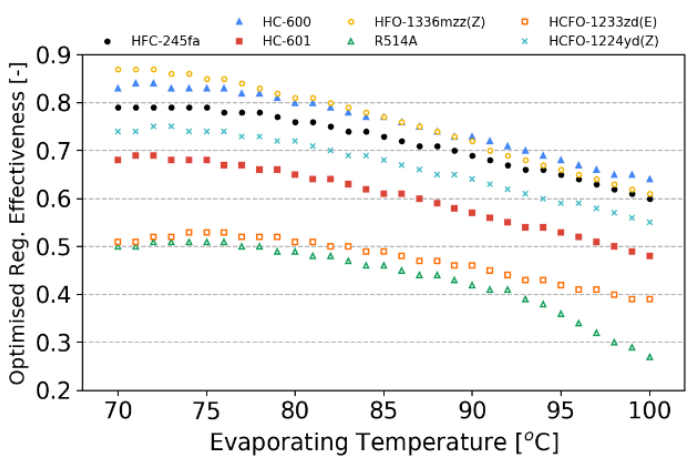

(b)

Fig. 7.14. Optimised effectiveness at different evaporating temperatures: a) IHX and b) Regenerator.

\section{- Performance comparison}

This section presents the performance results for the alternative low-GWP refrigerants along with the reference fluid HFC-245fa. Moreover, an analysis of the compressor power consumption and expander power generation is performed in order to provide a complete view of the reversible system. 
Working as HTHP, the performance energy efficiency for each refrigerant is estimated with the COP, as shown in Fig. 7.15. While Butane shows lower COP than the traditional working fluid HFC-245fa, the other candidates present higher energy performance values. Pentane, HFO-1336mzz(Z) and R-514A, which is a blend of HFO-1336mzz(Z), have the highest values of COP followed by the HCFOs (HCFO-1233zd(E) and HCFO-1224yd(Z)).

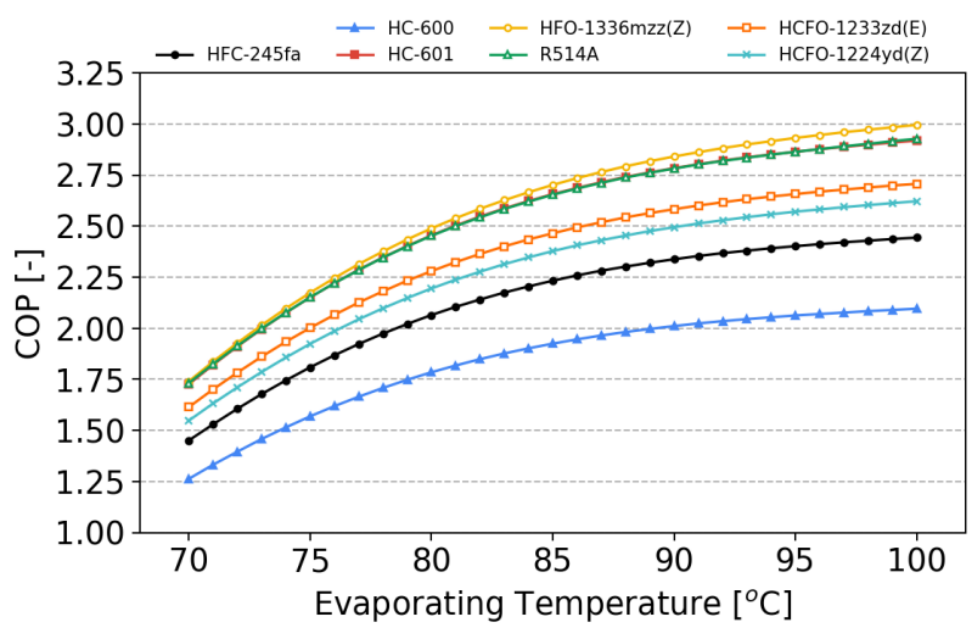

Fig. 7.15. COP results for the alternative low-GWP refrigerants and HFC-245fa at different evaporating temperatures.

Similar to HTHP mode, the highest net efficiency values working as ORC are shown in Pentane and HFO-1336mzz(Z), followed by its blend, R-514A. In this case, HCFOs are close to HFC-245fa behaviour, and Butane shows slightly higher net efficiency values, as shown in Fig. 7.16.

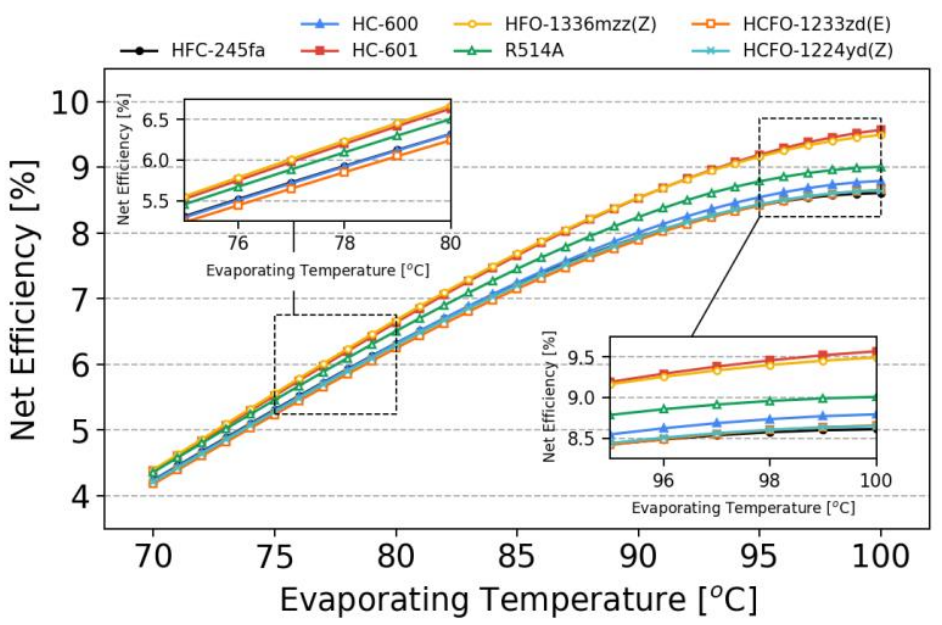

Fig. 7.16. Net efficiency results for the alternative low-GWP refrigerants and HFC-245fa at different evaporating temperatures.

Finally, the compressor power consumption is compared with the expander power generation in order to illustrate the possibility to use the same component working as motor and generator, as shown in Fig. 7.17. At lower evaporating temperatures, the electric motor working as a compressor should have 
25 times the capacity of the generator. Nevertheless, this difference is reduced as the evaporating temperature increases. At higher evaporating temperatures, the power capacity between the motor (compressor) and expander (generator) is reduced, obtaining values between 5-8 times. Although the power capacity difference is relatively small, all the refrigerants analysed will require different power capacities for the electric motor and generator. Hence, a single component can be used as a compressor or expander, but the electric motor and generator should be different. One possible solution is connecting the compressor/expander in a single shaft along with an electric motor and generator with different capacities that transmit or receive the power.

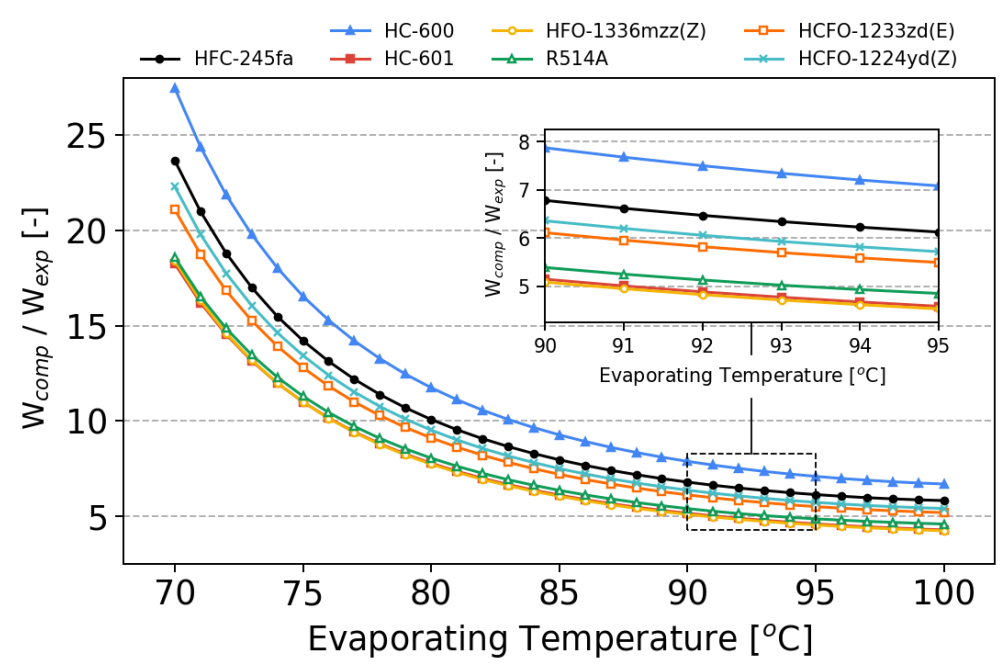

Fig. 7.17. Electric power differences between the motor and generator capacities.

\section{- Multi-objective evaluation}

The evaluation between different alternative low-GWP refrigerants requires more than one parameter to achieve the optimum selection and most cases; different scenarios provide a variety of optimal solutions. In vapour compression systems, the proper refrigerant selection depends on the application, energy efficiency and the installation size. Nevertheless, for a particular application, the refrigerant that provides the highest energy efficiency often requires larger installation size and vice versa. Due to this fact, a multi-objective evaluation is proposed in this paper, in order to compare the refrigerant behaviour working as HTHP, ORC or as a reversible system in different scenarios. Five different scenarios are proposed in this analysis comparing the energy efficiency of each refrigerant and the installation size.

In order to perform this multi-objective evaluation, two different coefficients are prosed that will weigh the relevance of the energy efficiency and installation size, depending on the scenario. Hence, the scenario 1 has the consumption coefficient $\left(C_{c}\right)$ in the maximum value whereas the installation size coefficient $\left(C_{S}\right)$ has the lowest possible value. The consumption and size coefficients weight are gradually varying in the different scenarios until scenario 5 , which is the opposite case of scenario 1 . The compressor and ORC pump power consumption corresponds to the energy efficiency evaluation, and the compressor and expander volumetric flow rate illustrates the installation size evaluation. These parameters are presented in the multi-objective analysis as the relative difference between the 
alternative low-GWP refrigerants and HFC-245fa, multiplying by consumption coefficient $\left(C_{c}\right)$ and installation size coefficient $\left(C_{S}\right)$ in each scenario.

Fig. 7.18 shows the multi-objective evaluation considering that the reversible system will be operating only as HTHP or ORC, without being reversible. As HTHP, Pentane, HFO-1336mzz(Z) and R-514A are the potential candidates to HFC-245fa in scenario 1 where the energy efficiency has the whole weight, as shown in Fig. 7.18a. Nevertheless, other refrigerants as Butane and HCFOs be positioned as potential candidates as the installation size increase the weight in the evaluation. Therefore, Pentane, HFO-1336mzz(Z) and R-514A have lower energy consumption and require larger installation size, whereas the other refrigerants have higher power consumption but require smaller installation size. Similar to HTHP mode, Pentane, HFO-1336mzz(Z) and R-514A are the proper candidates from an energy efficiency point of view (scenario 1), as shown Fig. 7.18b. Nevertheless, Butane becomes a potential candidate taking into account only the installation size (scenario 5). Finally, the most equilibrated candidates between the energy performance and the installation size are HCFO-1233zd(E) and HCFO-1224yd(Z).

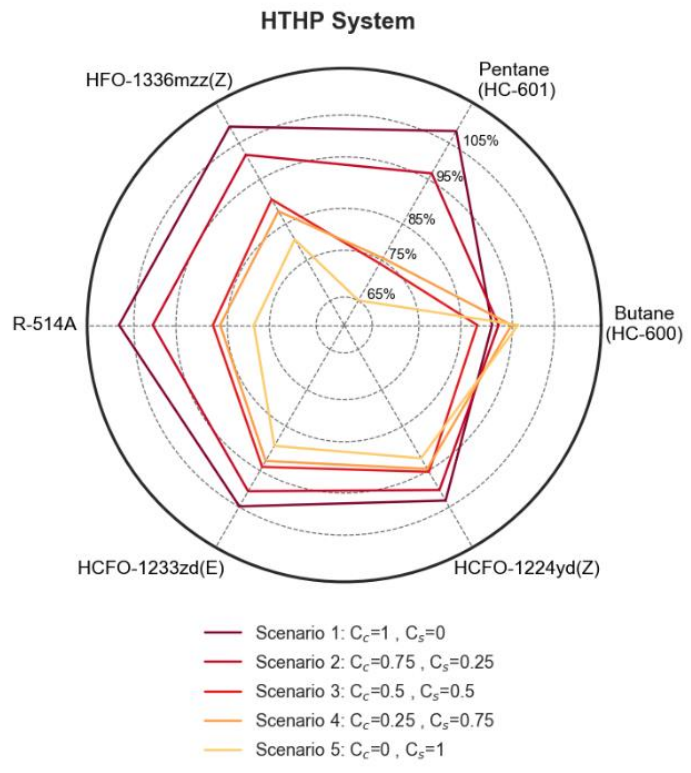

(a)

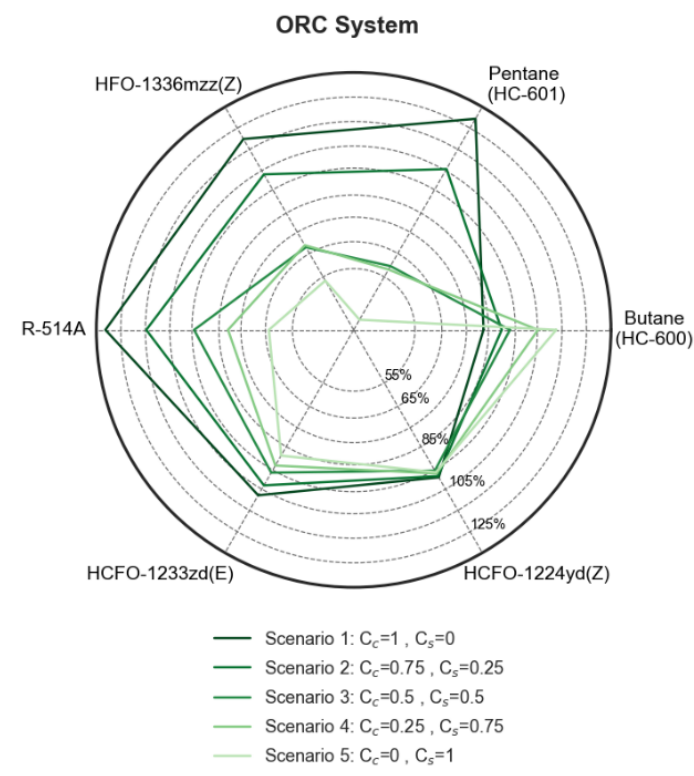

(b)

Fig. 7.18. Multi-objective evaluation of alternative low-GWP refrigerants in different scenarios, operating only in: a) HTHP mode and b) ORC mode.

Following the main objective of this paper, Fig. 7.19 shows the multi-objective optimised evaluation of different alternative low-GWP refrigerants to replace HFC-245fa in the proposed technology. Similar to the previous comparison, Pentane. HFO-1336mzz(Z) and R-514A are the proper candidates from an energy efficiency point of view, whereas Butane, HCFO-1233zd(E) and HCFO$1224 \mathrm{yd}(\mathrm{Z})$ stand out for their lower installation size requirements. Nevertheless, an optimal selection will be a trade-off between energy efficiency and the installation size requirements, which 
corresponds to scenario 3. In this case, HCFO-1233zd(E) and HCFO-1224yd(Z) are the most appropriate low-GWP alternative to replace HFC-245fa with a significant GWP reduction.

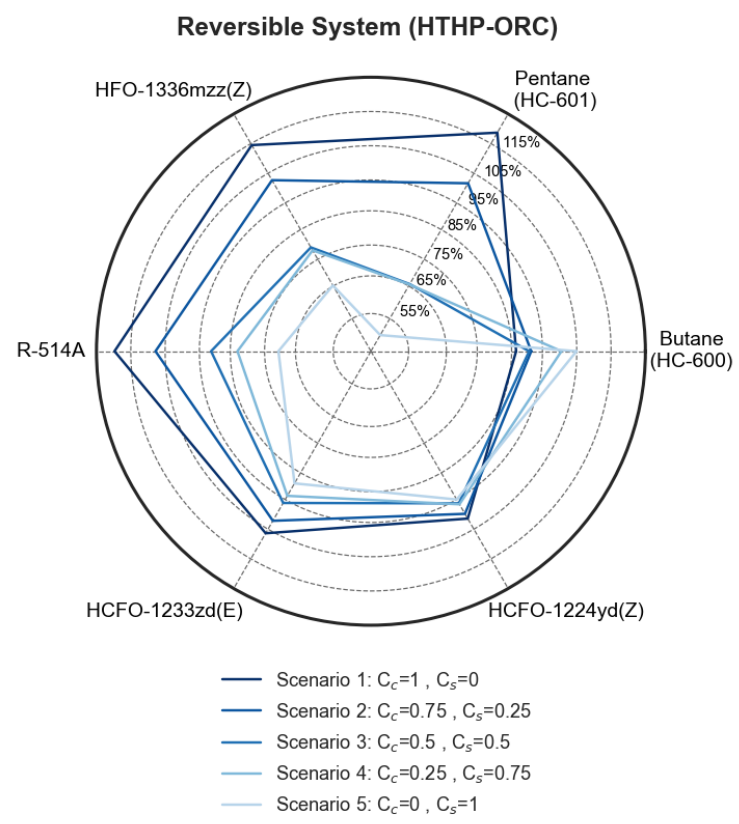

Fig. 7.19. Multi-objective evaluation of alternative low-GWP refrigerants in different scenarios, operating as a reversible system.

\subsection{Conclusions}

In this paper, we presented a novel reversible HTHP-ORC system for industrial low-grade waste heat recovery. The focus was set on the optimisation analysis and multi-objective low-GWP alternative refrigerant selection to provide guidelines for further design improvement and sustainable development. To this end, a twofold approach was followed:

1. A reversible HTHP-ORC system was modelled, based on compressor and expander semiempirical validated models to provide a comprehensive energy performance and volumetric machines efficiencies evaluation. Moreover, system parameters as built-in volume ratio and IHX were optimised in order to maximise the energy performance working in both HTHPORC modes.

2. The semi-empirical performance and efficiencies results from the reversible model using HFC-245fa were used as a reference to perform an alternative low-GWP refrigerants evaluation. Pentane, Butane, HFO-1336mzz(Z), R-514A, HCFO-1233zd(E) and HCFO$1224 \mathrm{yd}(\mathrm{Z})$ were proposed as potential candidates to replace the currently used HFC-245fa. System optimisation of each alternative working fluid was achieved along with a multiobjective evaluation for a proper working fluid selection.

The following conclusions can be drawn from the results of this study:

- The novel HTHP-ORC system proposed provides a significant performance improvement for low-grade waste heat recovery. At the middle evaporating temperature of $85^{\circ} \mathrm{C}$, a $\mathrm{COP}$ of 
2.22 is achieved condensing at $140{ }^{\circ} \mathrm{C}$, working as HTHP mode, whereas the ORC mode achieves a net electrical efficiency of $7.25 \%$ at a condensing temperature of $40{ }^{\circ} \mathrm{C}$. The highest performance results are a COP of 2.44 and a net electric efficiency of $8.75 \%$, both considering an evaporating temperature of $100^{\circ} \mathrm{C}$.

- The semi-empirical computational evaluation shows that higher heat source temperatures will increase the energy efficiency of the system. About the system architecture, different power capacities for the electric motor and generator are required. Therefore, a single component can be used as a compressor or expander, but electric motor and generator should be different.

- The multi-objective optimised selection for alternative low-GWP refrigerants shows that HCFO-1233zd(E) and HCFO-1224yd(Z) were the proper refrigerants to replace HFC-245fa in the proposed reversible system from energy efficiency and installation size points of view. These refrigerants present a COP improvement of $9.7 \%$ and $5.8 \%$ compared to HFC-245fa, respectively, and electrical net efficiency improvement of $2.1 \%$ and $0.8 \%$, respectively, at an evaporating temperature of $90^{\circ} \mathrm{C}$. These refrigerants represent a proper trade-off between the energy performance and installation size compared with HFC-245fa.

\section{References}

[1] European Parliament. Directive 2012/27/EU of the European Parliament and of the Council on energy efficiency. 2012. doi:10.3000/19770677.L_2012.315.eng.

[2] United Nations. Paris Climate Change Conference-November 2015, COP 21. Adopt. Paris Agreem., 2015. doi:FCCC/CP/2015/L.9/Rev.1.

[3] The European Paliament and the Council of the European Union. Directive (Eu) 2018/843 of the European Parliament and of the Council. Off J Eur Union 2018;2018:43-74.

[4] IPCC. Climate Change 2014: Synthesis Report. Contribution of Working Groups I, II and III to the Fifth Assessment Report of the Intergovernmental Panel on Climate Change [Core Writing Team, R.K. Pachauri and L.A. Meyer (eds.)]. Geneva, Switzerland, 2014.

[5] Arpagaus C, Bless F, Uhlmann M, Schiffmann J, Bertsch SS. High temperature heat pumps: Market overview, state of the art, research status, refrigerants, and application potentials. Energy 2018;152:985-1010. doi:10.1016/J.ENERGY.2018.03.166.

[6] Papapetrou M, Kosmadakis G, Cipollina A, La Commare U, Micale G. Industrial waste heat: Estimation of the technically available resource in the EU per industrial sector, temperature level and country. Appl Therm Eng 2018;138:207-16. doi:10.1016/J.APPLTHERMALENG.2018.04.043.

[7] Woolley E, Luo Y, Simeone A. Industrial waste heat recovery: A systematic approach. Sustain Energy Technol Assessments 2018;29:50-9. doi:10.1016/J.SETA.2018.07.001.

[8] Forman C, Muritala IK, Pardemann R, Meyer B. Estimating the global waste heat potential. Renew Sustain Energy Rev 2016;57:1568-79. doi:10.1016/j.rser.2015.12.192.

[9] Oluleye G, Jobson M, Smith R, Perry SJ. Evaluating the potential of process sites for waste heat recovery. Appl Energy 2016;161:627-46. doi:10.1016/j.apenergy.2015.07.011.

[10] Jouhara H, Khordehgah N, Almahmoud S, Delpech B, Chauhan A, Tassou SA. Waste heat recovery technologies and applications. Therm Sci Eng Prog 2018;6:268-89. 
doi:10.1016/J.TSEP.2018.04.017

[11] Peris B, Navarro-Esbrí J, Molés F, Mota-Babiloni A. Experimental study of an ORC (organic Rankine cycle) for low grade waste heat recovery in a ceramic industry. Energy 2015;85:53442. doi:10.1016/J.ENERGY.2015.03.065.

[12] Law R, Harvey A, Reay D. A knowledge-based system for low-grade waste heat recovery in the process industries. Appl Therm Eng 2016;94:590-9. doi:10.1016/J.APPLTHERMALENG.2015.10.103.

[13] Oluleye G, Smith R, Jobson M. Modelling and screening heat pump options for the exploitation of low grade waste heat in process sites. Appl Energy 2016;169:267-86. doi:10.1016/j.apenergy.2016.02.015.

[14] Xia L, Liu R, Zeng Y, Zhou P, Liu J, Cao X, et al. A review of low-temperature heat recovery technologies for industry processes. Chinese J Chem Eng 2018. doi:10.1016/J.CJCHE.2018.11.012.

[15] Meyers S, Schmitt B, Vajen K. The future of low carbon industrial process heat: A comparison between solar thermal and heat pumps. Sol Energy 2018;173:893-904. doi:10.1016/J.SOLENER.2018.08.011.

[16] Brückner S, Liu S, Miró L, Radspieler M, Cabeza LF, Lävemann E. Industrial waste heat recovery technologies: An economic analysis of heat transformation technologies. Appl Energy 2015;151:157-67. doi:10.1016/j.apenergy.2015.01.147.

[17] Dumont O. Investigation of a heat pump reversible into an organic Rankine cycle and its application in the building sector 2017:236. doi:10.13140/RG.2.2.19499.13604.

[18] Dumont o., Carmo C, Randaxhe F, Quoilin S, Lemort V. Performance Comparison of Two Types of Technologies Associated with a Positive Energy Building: a Reversible Heat Pump/orc Unit and a Heat Pump Coupled with PV Panels 2017:1-6. doi:10.18086/swc.2015.04.13.

[19] Quoilin S, Dumont O, Harley Hansen K, Lemort V. Design, Modeling, and Performance Optimization of a Reversible Heat Pump/Organic Rankine Cycle System for Domestic Application. J Eng Gas Turbines Power 2015;138:011701. doi:10.1115/1.4031004.

[20] Carmo C, Nielsen MP, Elmegaard B, Dumont O. Performance Evaluation of a HP / ORC ( Heat Pump / Organic Rankine Cycle ) System with Optimal Control of Sensible Thermal Storage. Int Compress Eng Refrig Air Cond High Perform Build Conf 2016:1-10.

[21] Schimpf S, Span R. Simulation of a solar assisted combined heat pump - Organic rankine cycle system. Energy Convers Manag 2015;102:151-60. doi:10.1016/j.enconman.2015.01.083.

[22] Staub S, Bazan P, Braimakis K, Müller D, Regensburger C, Scharrer D, et al. Reversible heat pump-organic rankine cycle systems for the storage of renewable electricity. Energies 2018;11. doi:10.3390/en11061352.

[23] Hu B, Xu S, Wang RZ, Liu H, Han L, Zhang Z, et al. Investigation on advanced heat pump systems with improved energy efficiency. Energy Convers Manag 2019;192:161-70. doi:10.1016/J.ENCONMAN.2019.04.031.

[24] Urbanucci L, Bruno JC, Testi D. Thermodynamic and economic analysis of the integration of high-temperature heat pumps in trigeneration systems. Appl Energy 2019;238:516-33. 
doi:10.1016/J.APENERGY.2019.01.115.

[25] Johnson I, Choate WT, Davidson A. Waste Heat Recovery. Technology and Opportunities in U.S. Industry. 2008. doi:10.2172/1218716.

[26] Mateu-Royo C, Navarro-Esbrí J, Mota-Babiloni A, Amat-Albuixech M, Molés F. Theoretical evaluation of different high-temperature heat pump configurations for low-grade waste heat recovery. Int J Refrig 2018. doi:10.1016/j.ijrefrig.2018.04.017.

[27] Cao X-Q, Yang W-W, Zhou F, He Y-L. Performance analysis of different high-temperature heat pump systems for low-grade waste heat recovery. Appl Therm Eng 2014;71:291-300. doi:10.1016/j.applthermaleng.2014.06.049.

[28] Mota-Babiloni A, Mateu-Royo C, Navarro-Esbrí J, Molés F, Amat-Albuixech M, BarragánCervera Á. Optimisation of high-temperature heat pump cascades with internal heat exchangers using refrigerants with low global warming potential. Energy 2018;165:1248-58. doi:10.1016/j.energy.2018.09.188.

[29] Yang W, Cao X, He Y, Yan F. Theoretical study of a high-temperature heat pump system composed of a $\mathrm{CO} 2$ transcritical heat pump cycle and a R152a subcritical heat pump cycle. Appl Therm Eng 2017;120:228-38. doi:10.1016/J.APPLTHERMALENG.2017.03.098.

[30] Bamigbetan O, Eikevik TM, Nekså P, Bantle M. Review of vapour compression heat pumps for high temperature heating using natural working fluids. Int J Refrig 2017;80:197-211. doi:10.1016/j.jijrefrig.2017.04.021.

[31] Mateu-Royo C, Navarro-Esbrí J, Mota-Babiloni A, Amat-Albuixech M, Molés F. Thermodynamic analysis of low GWP alternatives to HFC-245fa in high-temperature heat pumps: HCFO-1224yd(Z), HCFO-1233zd(E) and HFO-1336mzz(Z). Appl Therm Eng 2019. doi:10.1016/j.applthermaleng.2019.02.047.

[32] Frate GF, Ferrari L, Desideri U. Analysis of suitability ranges of high temperature heat pump working fluids. Appl Therm Eng 2019;150:628-40. doi:10.1016/J.APPLTHERMALENG.2019.01.034.

[33] Zühlsdorf B, Jensen JK, Elmegaard B. Heat pump working fluid selection-economic and thermodynamic comparison of criteria and boundary conditions. Int J Refrig 2019;98:500-13. doi:10.1016/J.IJREFRIG.2018.11.034.

[34] Mateu-Royo C, Navarro-Esbrí J, Mota-Babiloni A, Molés F, Amat-Albuixech M. Experimental exergy and energy analysis of a novel high-temperature heat pump with scroll compressor for waste heat recovery. Appl Energy 2019;253:113504. doi:10.1016/j.apenergy.2019.113504.

[35] Bamigbetan O, Eikevik TM, Nekså P, Bantle M, Schlemminger C. Experimental investigation of a prototype R-600 compressor for high temperature heat pump. Energy 2019;169:730-8. doi:10.1016/J.ENERGY.2018.12.020.

[36] Bamigbetan O, Eikevik TM, Nekså P, Bantle M, Schlemminger C. The development of a hydrocarbon high temperature heat pump for waste heat recovery. Energy 2019;173:1141-53. doi:10.1016/J.ENERGY.2019.02.159.

[37] Chamoun M, Rulliere R, Haberschill P, Peureux J-L. Experimental and numerical investigations of a new high temperature heat pump for industrial heat recovery using water as refrigerant. Int J Refrig 2014;44:177-88. doi:10.1016/j.jirefrig.2014.04.019. 
[38] Bobelin D, Bourig A, Peureux J. Experimental results of a newly developed very high temperature industrial heat pump $\left(140^{\circ} \mathrm{C}\right)$ equipped with scroll compressors and working with a new blend refrigerant. Int Refrig Air Cond Conf 2012.

[39] Arpagaus C, Bless F, Uhlmann M, Büchel E, Frei S, Schiffmann J, et al. High temperature heat pump using HFO and HCFO refrigerants - System design, simulation, and first experimental results. 17th Int Refrig Air Cond Conf Purdue, July 9-12, 2018 2018:1-10.

[40] Pethurajan V, Sivan S, Joy GC. Issues, comparisons, turbine selections and applications - An overview in organic Rankine cycle. Energy Convers Manag 2018;166:474-88. doi:10.1016/J.ENCONMAN.2018.04.058.

[41] Mahmoudi A, Fazli M, Morad MR. A recent review of waste heat recovery by Organic Rankine Cycle. Appl Therm Eng 2018;143:660-75. doi:10.1016/J.APPLTHERMALENG.2018.07.136.

[42] Braimakis K, Karellas S. Energetic optimization of regenerative Organic Rankine Cycle (ORC) configurations. Energy Convers Manag 2018;159:353-70. doi:10.1016/J.ENCONMAN.2017.12.093.

[43] Landelle A, Tauveron N, Haberschill P, Revellin R, Colasson S. Organic Rankine cycle design and performance comparison based on experimental database. Appl Energy 2017;204:117287. doi:10.1016/J.APENERGY.2017.04.012.

[44] Park B-S, Usman M, Imran M, Pesyridis A. Review of Organic Rankine Cycle experimental data trends. Energy Convers Manag 2018;173:679-91. doi:10.1016/J.ENCONMAN.2018.07.097.

[45] Xia XX, Wang ZQ, Hu YH, Zhou NJ. A novel comprehensive evaluation methodology of organic Rankine cycle for parameters design and working fluid selection. Appl Therm Eng 2018;143:283-92. doi:10.1016/J.APPLTHERMALENG.2018.07.061.

[46] Zhi L-H, Hu P, Chen L-X, Zhao G. Thermodynamic analysis of a novel transcriticalsubcritical parallel organic Rankine cycle system for engine waste heat recovery. Energy Convers Manag 2019;197:111855. doi:10.1016/J.ENCONMAN.2019.111855.

[47] Imran M, Haglind F, Asim M, Zeb Alvi J. Recent research trends in organic Rankine cycle technology: A bibliometric approach. Renew Sustain Energy Rev 2018. doi:10.1016/j.rser.2017.08.028.

[48] Mateu-Royo C, Navarro-Esbrí J, Mota-Babiloni A, Amat-Albuixech M, Molés F. Thermodynamic analysis of low GWP alternatives to HFC-245fa in high-temperature heat pumps: HCFO-1224yd(Z), HCFO-1233zd(E) and HFO-1336mzz(Z). Appl Therm Eng 2019. doi:10.1016/j.applthermaleng.2019.02.047.

[49] Dumont O, Parthoens A, Dickes R, Lemort V. Experimental investigation and optimal performance assessment of four volumetric expanders (scroll, screw, piston and roots) tested in a small-scale organic Rankine cycle system. Energy 2018;165:1119-27. doi:10.1016/J.ENERGY.2018.06.182.

[50] Lemort V. Contribution to the characterization of scroll machines in compressor and expander modes. PhD Thesis, Thermodyn Lab Aerosp Mech Eng Dep Univ Liège 2008.

[51] Winandy E, O CS, Lebrun J. Experimental analysis and simplified modelling of a hermetic scroll refrigeration compressor. Appl Therm Eng 2002;22:107-20. doi:10.1016/S13594311(01)00083-7. 
[52] Winandy E, Saavedra O C, Lebrun J. Simplified modelling of an open-type reciprocating compressor. Int J Therm Sci 2002;41:183-92. doi:10.1016/S1290-0729(01)01296-0.

[53] Cuevas C, Lebrun J, Lemort V, Winandy E. Characterization of a scroll compressor under extended operating conditions. Appl Therm Eng 2010;30:605-15. doi:10.1016/J.APPLTHERMALENG.2009.11.005.

[54] Lemort V, Quoilin S, Cuevas C, Lebrun J. Testing and modeling a scroll expander integrated into an Organic Rankine Cycle. Appl Therm Eng 2009;29:3094-102. doi:10.1016/J.APPLTHERMALENG.2009.04.013.

[55] Peris B, Navarro-Esbrí J, Molés F, Mota-Babiloni A, Amat-Albuixech M, Mateu-Royo C, et al. Low GWP working fluids for reversible systems of high temperature heat pump and organic rankine cycle (HTHP/ORC). 13th IIR Gustav Lorentzen Conf Nat Refrig Nat Refrig Solut Warm Clim Ctries (GL 2018) Val 2018.

[56] Incropera FP, De Witt DP. Fundamentals of heat and mass transfer. New York J Wiley 2002.

[57] ASHRAE. ASHRAE Handbook Fundamentals. Am Soc Heating, Refrig Air-Conditioning Eng 2017.

[58] Hughes J, Juhasz J. Low GWP Refrigerant Solutions for Heat Pumps. Chemours Co 2019.

[59] Chemours. Opteon ${ }^{\mathrm{TM}}$ XP30 (R-514A), Technical information 2019:1-16.

[60] Honeywell. Solstice ${ }^{\circledR} \mathrm{zd}$, Technical information 2015:1-5.

[61] AGC Chemicals. AMOLEA ${ }^{\circledR}$ 1224yd, Technical information. ASAHI Glas Co 2017:1-18. 
Chapter 7 


\section{Chapter 8 High Temperature Heat Pump Integration into District Heating Networks}

This study illustrates the potential of high temperature heat pumps (HTHPS) integration into district heating network (DHN) through a twofold approach, using DHN as a heat sink and source. It is used as a heat sink of HTHP that uses waste heat from the supermarket's refrigeration system as a heat source whereas it is used as a heat source to HTHP that provides heat to industrial applications. When the DHN acts as the heat sink, the integrated system provides a coefficient of performance (COP) of the waste heat recovery (WHR) system between 3.2 and 5.4, reducing the operating costs between $50 \%$ and $100 \%$ with an average price ratio of 2.25 compared with the standard CO2 refrigeration system. If the DHN is the heat source, the integrated system provides a COP from 2.8 to 5.7 for a heat sink of $110^{\circ} \mathrm{C}$. The alternative low-GWP refrigerants assessment illustrates that $H C$ 290, HFO-1234ze(E) and HFO-1234yf were considered the ideal candidates to replace the HFC134a, whereas HCFO-1233zd(E) and HCFO-1224yd(Z) were the most promising low-GWP refrigerants to replace $H F C-245 f a$. Finally, the environmental results showed that the utilisation of the DHN as the heat sink in the integrated system solution produces about $60 \%$ lower equivalent CO2 emissions than the DHN generation mix. Moreover, using DHN as the heat source, the equivalent CO2 emissions can be reduced up to 98\% in Sweden compared to conventional natural gas boilers. Hence, the combination of HTHPs and the DHN represents a step forward in the mitigation of climate change through the utilisation of sustainable energy conversion technologies.

\subsection{Introduction}

The growing concern about climate change requires a transformative change, integrated with sustainable development to limit the increase in global temperature to $1.5^{\circ} \mathrm{C}$ above pre-industrial levels. Among other measures, the Intergovernmental Panel on Climate Change proposes the adopting of low-emission innovations as heat pumps and district heating and cooling as climate mitigation behaviour [1]. Werner [2] defined district heating as the use of 'local fuel or heat resources that would otherwise be wasted, in order to satisfy local customer demands for heating, by using a heat distribution network of pipes as a local market place'. The traditionally excess heat resources for district heating networks (DHN) are combined heat and power (CHP), Waste-to-Energy plants and industrial processes. However, there are other local heat resources with a lower thermal level that can be used as potential heat sources for district heating networks, instead of being rejected to the ambient and wasting the available energy [3]. Moreover, the wind and photovoltaics intermittency can be efficiently managed at an affordable cost, using transformative energy technology connected to district heating and cooling networks, like heat pumps and thermal storage. Optimised use of these 
technologies contributes to the management of the intermittent generation in some European countries [4].

Supermarkets are the most energy-intensive commercial buildings, in which the refrigeration system is the largest energy user [5]. The standard $\mathrm{CO}_{2}$ trans-critical booster system has become a wellestablished refrigeration solution in Scandinavian supermarkets as a single compact unit [6]. The critical function of the refrigeration systems is to preserve the food products (fresh or frozen) by absorbing the heat from the cabinets at low temperature levels and rejecting it at a higher temperature level; usually to the ambient. Although part of this rejected heat can be recovered to provide the space heating demand of the supermarket's building [7], between $5 \%$ and $45 \%$ of this heat is still wasted, releasing it to the ambient via a condenser/gas cooler, as represents Fig. 8.1, which is a representation of the results presented by Karampour et al. [8] and Sawalha [7]. However, there is an opportunity to recover this low-grade waste heat through heat pump technology [9].

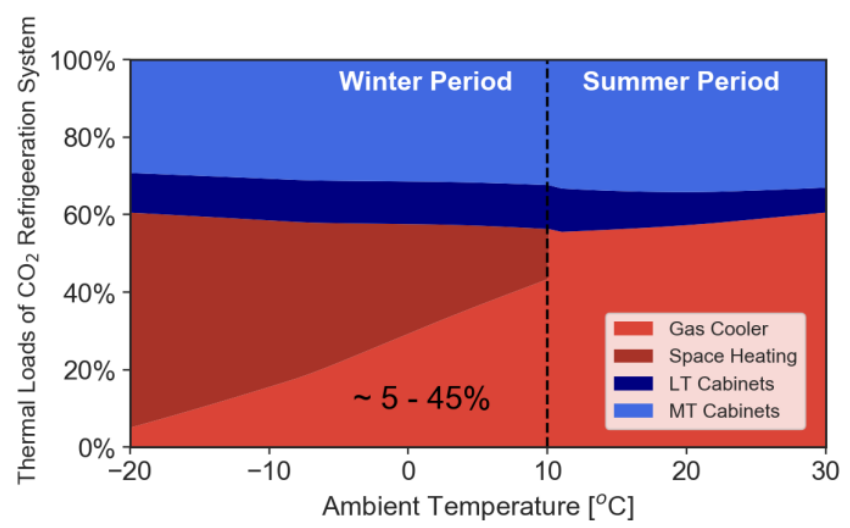

Fig. 8.1. Breakdown of the thermal loads in a $\mathrm{CO} 2$ refrigeration system in average size supermarket based on the modelling proposed by Karampour et al. [8] and Sawalha [7].

Heat pumps are based on a sustainable technology that uses the thermodynamics principles to revalorise heat with a smaller amount of electric energy used [10]. Recent heat pump prototypes have extended the operating ranges (up to $90^{\circ} \mathrm{C}$ ) of this technology efficiently, becoming possible to produce heating at temperatures up to $140{ }^{\circ} \mathrm{C}$ [11]. This technological improvement modified the classification of the heat pumps that operate at high temperature conditions, becoming known as high temperature heat pumps (HTHPs) [11]. Therefore, waste heat rejected by the supermarket refrigeration system can be recovered using the HTHP technology in order to upgrade this heat to useful temperature levels, which will have enough quality to be injected into the local district heating network. The integration of HTHPs into DHN makes the distribution more versatile because HPs are considered as environmental systems to produce heat for DH systems, with proper implementation, design and control [12]. Moreover, the integration of flexible HPs into DHN has been recognised as a significant step to a $100 \%$ renewable energy system, converting excess clean electric energy in heat [13]. In this case, the DHN is used as a heat sink in the HTHP integration, although it can also be used as a heat source for other applications [14].

Another interesting application of the HTHP integration into DHN can be the substitute of natural gas boilers in the industrial sector, using the DHN as a heat source. Approximately, $3200 \mathrm{TWh}$ of the annual EU energy use corresponds to the industrial sector, for which in average, about $30 \%$ represents 
the consumption in the form of electricity, and the remaining $70 \%$ corresponds to the heating consumption. Food, chemical and paper industries are energy-intensive sectors that require heat up to $150^{\circ} \mathrm{C}$ for their industrial processes (e.g. for drying, evaporating, distilling) [15]. The heating demand in these industries is usually satisfied with fossil fuel-fired technology as natural gas boilers. Nevertheless, HTHPs becomes a promising and competitive technology for boiler substitution in delivering the heat of up to $180{ }^{\circ} \mathrm{C}$ [16]. Since the ambient temperature becomes not viable as a potential heat source for energy-efficient industrial HTHPs, DHN can be a potential heat source for this technology [17]. The integration of HTHPs into DHN becomes a promising combination to replace a gas boiler in the industrial sector. A recent potential application proposed by Sartor, et al. [18] is the integration of HTHPs in the low-temperature district heating network. Besides increasing the efficiency and flexibility of the DHN, it reduces the heat losses up to 1,900 MWh per year.

HTHPs, mainly based on vapour compression technology, typically use hydrofluorocarbons (HFCs) as working fluids (refrigerants), which have high values of global warming potential (GWP) [11]. However, in 2014, EU Regulation No. 517/2014 [19] gradually limited the acquisition and utilisation of HFCs, establishing market quotas to their consumption and limiting the maximum GWP in some applications in order to increase the share of low GWP refrigerants. Given this situation, the commonly called fourth generation of refrigerants appeared to replace HFCs [20]. Due to their critical temperature, HFC-134a is used in HTHPs for heating applications until $90{ }^{\circ} \mathrm{C}$ whereas HFC-245fa is considered the reference fluid for high temperature applications up to $140^{\circ} \mathrm{C}$. Therefore, different low GWP alternatives should be found for these two refrigerants if HTHPs expect to get anywhere in the industrial sector.

Regarding the potential alternatives to HFC-134a, Maiorino et al. [21] proposed R-152a as alternative low GWP refrigerant for domestic refrigerators, showing refrigerant charge and energy consumption reductions. Mota-Babiloni et al. [22] performed a drop-in replacement of HFC-134a with HFO$1234 \mathrm{yf}$ and HFO-1234ze(E) in vapour compression liquid chiller, proving that the HFC-134a can be replaced by both very low GWP hydrofluoroolefins (HFOs). Palm [23] realised a comprehensive investigation of the use of hydrocarbons in heat pumps, illustrating that HC-600a and HC-290 become suitable alternatives to HFC-134a. Finally, Mota-Babiloni et al. [24] investigate the bend R-513A as a sustainable alternative to HFC-134a in refrigeration systems, with and without internal heat exchanger. Although these potential low-GWP alternatives to HFC-134a are widely studied for refrigeration systems, more studies are required to analyse and ensure the operation in high temperature conditions.

Then, as low-GWP alternatives to HFC-245fa, HCFO-1233zd(E) and HCFO-1224yd(Z) are considered the most promising candidates to replace HFC-245fa in HTHPs and organic Rankine cycles (ORCs) [25,26]. Moreover, HFO-1336mzz(Z) is widely studied as an alternative to HFC-245fa [27,28], although presents slightly different thermophysical properties to HFC-245fa compared to the previously mentioned alternatives [29]. However, the blend R-514A, composed by HFO-1336mzz(Z) and trans-1,2-dichloroethylene (t-DCE), was developed [30] to reduce the thermodynamic differences between HFO-1336mzz(Z) and HFC-245fa. R-514A was studied by Majurin et al. [31] and showed a great potential to replace HFC-245fa. Natural refrigerants must be named to complete the list of candidates considered to replace HFC-245fa in high temperature applications. The hydrocarbons can be found among this family of refrigerants, specially HC-600 [32,33] and HC-601 [34,35]. 
Based on the above discussed, the integration of HTHP into DHN appears as an innovative and efficient solution to contribute to climate change mitigation in different areas. Moreover, the recent developments in heat pump technology make it possible to operate in higher heat sink and source temperatures with the use of HTHPs. The combination of HTHPs and DHN represents a step forward in the development of sustainable integrated systems. Thus, the purpose of this paper is to investigate the integration of HTHPs into DHN in two different scenarios, using the DHN as a heat sink in one scenario and heat source in the other. When the DHN is acting as the heat sink, the HTHP recovers, revalorises and injects the heat rejected by the refrigeration system of a supermarket. A thermoeconomic optimisation of the refrigeration system and HTHP has been done to maximise the benefits of this system integration. Moreover, the DHN is used as the heat source for HTHPs in the industrial sector to replace the conventional natural gas boilers. Finally, alternative low-GWP refrigerants to HFC-134a and HFC-245fa are evaluated as sustainable candidates in HTHP systems.

The structure of this paper is organised as follows. Section 2 describes the integrated systems, the proposed scenarios and the alternative refrigerants. Section 3 introduces the modelling assumptions and simulation methodology. Section 4 presents the thermo-economic optimisation and results of the systems integration, along with the alternative low-GWP refrigerants evaluation and environmental analysis. Finally, the last section contains the most relevant conclusions of this work. The results of this study provide a comprehensive view of the potential of integrating HTHPs into DHN to decarbonise different urban and industrial environments.

\subsection{System description}

\subsubsection{Research scenarios}

The schematic of both proposed scenarios to integrate HTHPs into DHN is shown in Fig. 8.2. In the first scenario, the DHN is acting as a heat sink, and it is presented in Fig. 8.2a. The scenario in which the DHN is used as a heat source corresponds to Fig. 8.2b.

- $\mathrm{DHN}_{\text {sink }}$ scenario: In order to integrate HTHP system into the standard $\mathrm{CO}_{2}$ trans-critical booster system, a new heat exchanger named waste heat recovery (WHR) is allocated between the gas cooler/condenser exit and the expansion valve inlet, acting as an evaporator of the HTHP. Bypassing the gas cooler/condenser makes the WHR absorb all the waste heat coming from the $\mathrm{CO}_{2}$ refrigeration system. This absorbed heat is upgraded with the compressor to a practical thermal level, which can be injected into the DHN through the HTHP condenser. This scenario requires a thermo-economic optimisation of the $\mathrm{CO}_{2}$ exit temperature from the WHR because a variation of this parameter influences the performance of both systems; i.e. refrigeration and HTHP systems. HTHP system in this scenario provides a heating production temperature up to $90{ }^{\circ} \mathrm{C}$.

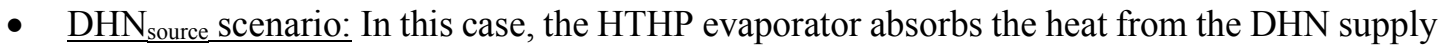
line to revalorise it to thermal levels for which will be useful in the industrial processes (90$130^{\circ} \mathrm{C}$ ). In contrast to the previous scenario, the HTHP system should provide heating production temperatures up to $130^{\circ} \mathrm{C}$ to satisfy the industrial thermal requirements. 
Both HTHP systems include the use of internal heat exchanger (IHX). This component transfers the heat from the condenser outlet to the suction line, increasing the sub-cooling and superheat degree. Numerous studies illustrate that the use of IHX in HTHP systems, improves energy performance, and therefore, its use is highly recommended for high-temperature applications [29,36].

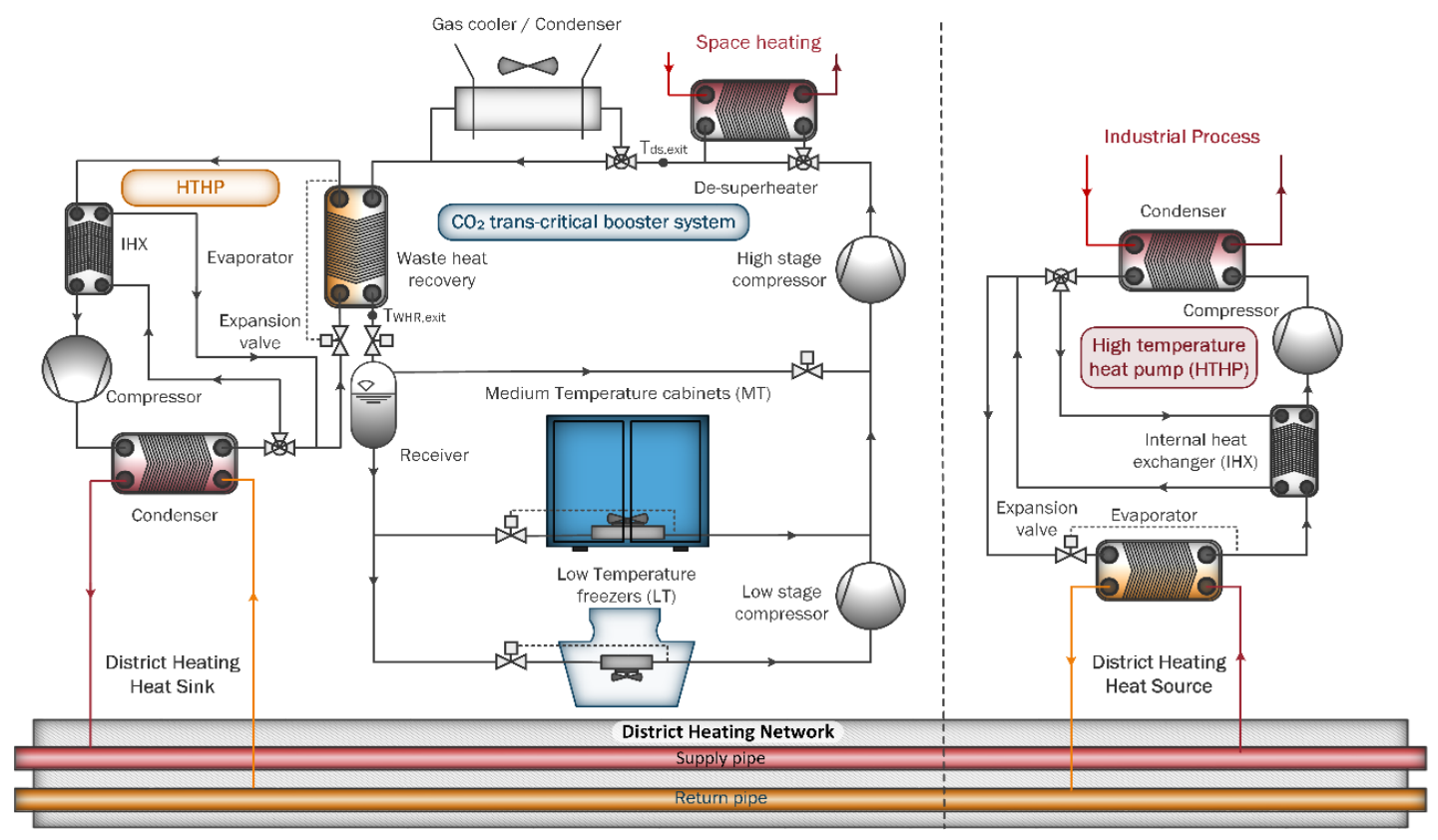

(a)

(b)

Fig. 8.2. Schematic of the integration of HTHPs into DHN: DHNsink a) scenario with an HTHP heating production up to $90{ }^{\circ} \mathrm{C}$ and b) DHNsource scenario with an HTHP heating production up to $130{ }^{\circ} \mathrm{C}$.

\subsubsection{Alternative low-GWP refrigerants}

Although it has been widely discussed the high condensing temperature required for the heating production, HTHP technology also operates with high values of evaporating temperature, between 49-90 ${ }^{\circ} \mathrm{C}$. Moreover, the operating temperature differences of the HTHP systems between both scenarios, distinct reference and alternative refrigerants should be considered for each scenario according to their thermophysical properties. For DHN ${ }_{\text {sink }}$ scenario, HFC-134a becomes the appropriate reference refrigerant to overcome the heating requirements up to $90^{\circ} \mathrm{C}$. Nevertheless, due to its high GWP (1430), different low-GWP refrigerants with GWP lower than 150 are proposed as potential candidates to replace it. These candidates have similar or higher critical temperature than the reference HFC-134a along with GWP values lower than 150. Table 8.1 shows the main thermophysical and transport properties along with the environmental parameters of the reference fluid and the suggested low-GWP alternatives. Although all the alternative refrigerants in this scenario have lower toxicity (ASHRAE class A), there is some difference in the flammability levels. Whereas the hydrocarbons have higher flammability (3), HFC-152a (2) presents lower flammability, becoming even lower for the HFOs (2L). The safety class becomes an important consideration to achieve a proper refrigerant selection. 
Table 8.1. Selected properties of HFC-134a and its suggested low-GWP alternatives [37].

\begin{tabular}{|c|c|c|c|c|c|c|c|c|}
\hline Refrigerant & $\begin{array}{l}\text { Molecular } \\
\text { weight } \\
\left(\mathrm{g} \mathrm{mol}^{-1}\right)\end{array}$ & $\begin{array}{l}\mathrm{T}_{\text {crit }} \\
\left({ }^{\circ} \mathrm{C}\right)\end{array}$ & $\begin{array}{l}\mathbf{P}_{\text {crit }} \\
\text { (MPa) }\end{array}$ & $\begin{array}{l}\text { Saturated } \\
\text { Vapour } \\
\text { density } \\
\left(\mathrm{kg} \mathrm{m}^{-3}\right)^{\mathrm{a}}\end{array}$ & $\begin{array}{l}\text { NBP } \\
\left({ }^{\circ} \mathrm{C}\right)\end{array}$ & ODP & $\begin{array}{l}\text { GWP } 100 \\
{[38]}\end{array}$ & $\begin{array}{l}\text { ASHRAE } \\
\text { Safety } \\
\text { Class [38] }\end{array}$ \\
\hline HFC-134a (Ref.) & 102.0 & 101.1 & 4.05 & 32.4 & -26.0 & 0 & 1430 & A1 \\
\hline HC-600 & 58.1 & 152.0 & 3.8 & 6.2 & -0.5 & 0 & 4 & A3 \\
\hline HC-600a & 58.1 & 134.6 & 3.6 & 9.1 & -11.7 & 0 & 20 & A3 \\
\hline HC-290 & 44.1 & 109.4 & 3.6 & 20.6 & -19.0 & 0 & 3 & A3 \\
\hline HFO-1234yf & 114.0 & 94.7 & 3.4 & 37.9 & -29.5 & 0 & $<1$ & $\mathrm{~A} 2 \mathrm{~L}$ \\
\hline HFO-1234ze(E) & 114.0 & 109.4 & 3.6 & 26.3 & -19.0 & 0 & $<1$ & $\mathrm{~A} 2 \mathrm{~L}$ \\
\hline HFC-152a & 66.0 & 113.3 & 4.5 & 18.5 & -24.0 & 0 & 138 & A2 \\
\hline
\end{tabular}

a At saturated pressure of $25^{\circ} \mathrm{C}$.

On the other hand, $\mathrm{DHN}_{\text {source }}$ scenario has other thermal requirements to overcome the industrial heating demand at high temperature levels. Due to this fact, different refrigerants with a higher critical temperature that the previous presented should be required. In this case, HFC-245fa with a critical temperature of $154^{\circ} \mathrm{C}$ becomes the references fluid in HTHP systems that operates with a heat sink temperature above $100{ }^{\circ} \mathrm{C}$ [11]. Owing to its high GWP (858), different alternative low-GWP refrigerants are proposed as potential candidates to replace this HFC. The thermophysical and transport properties, along with environmental parameters of the potential alternative working fluids to replace HFC-245fa, are presented in Table 8.2. Whereas R-514A is classified with higher toxicity (ASHRAE class B), the rest alternative refrigerants present lower toxicity (ASHRAE class B). About the flammability, the hydrocarbons have higher flammability (3) while HFO-1336mzz(Z), R-514A and the HCFOs shows no flame propagation (1). Thus, the refrigerants with A1 classification will require lower safety measures than the others, becoming an essential consideration to the refrigerant selection.

Table 8.2. Thermophysical properties of HFC-245fa and its alternative low-GWP refrigerants.

\begin{tabular}{|c|c|c|c|c|c|c|c|c|}
\hline Refrigerant & $\begin{array}{l}\text { Molecular } \\
\text { weight } \\
\left(\mathrm{g} \mathrm{mol}^{-1}\right)\end{array}$ & $\begin{array}{l}T_{\text {crit }} \\
\left({ }^{\circ} \mathrm{C}\right)\end{array}$ & $\begin{array}{l}P_{\text {crit }} \\
\text { (MPa) }\end{array}$ & $\begin{array}{l}\text { Saturated } \\
\text { Vapour } \\
\text { density } \\
\left(\mathrm{kg} \mathrm{m}^{-3}\right)^{\mathrm{a}}\end{array}$ & $\begin{array}{l}\text { NBP } \\
\left({ }^{\circ} \mathrm{C}\right)\end{array}$ & ODP & $\mathbf{G W P}_{100}$ & $\begin{array}{l}\text { ASHRAE } \\
\text { Safety } \\
\text { Class }[38\end{array}$ \\
\hline HFC-245fa (Ref.) & 134.0 & 154.0 & 3.65 & 38.68 & 15.1 & 0 & 858 & B1 \\
\hline HC-601 & 72.2 & 196.6 & 3.37 & 8.93 & 36.1 & 0 & 5 & A3 \\
\hline HC-600 & 58.1 & 152.0 & 3.80 & 22.45 & -0.5 & 0 & 4 & A3 \\
\hline R514A & 139.6 & 178.0 & 3.52 & 22.78 & 29.1 & 0 & 2 & B1 \\
\hline HFO-1336mzz(Z) & 164.1 & 171.4 & 2.90 & 24.07 & 33.4 & 0 & 2 & A1 \\
\hline HCFO-1233zd(E) & 130.5 & 166.5 & 3.62 & 30.66 & 18.3 & 0.00034 & 1 & A1 \\
\hline HCFO-1224yd(Z) & 148.5 & 155.5 & 3.33 & 40.18 & 14.6 & 0.00012 & $<1$ & A1 \\
\hline
\end{tabular}

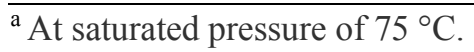

Fig. 8.3 provides a clear view of the reference fluids, and their low-GWP alternative thought a T-s diagram. All the proposed candidates to replace HFC-134a possess similar or even higher critical temperature than the reference fluid, although different T-s curves, as shown in Fig. 8.3a. It should be highlighted that the T-s slope difference in each refrigerant, will provide different interesting behaviours in the performance analysis of these candidates. The T-s diagram of the alternative low- 
GWP refrigerants to replace HFC-245fa are presented in Fig. 8.3b. In this case, HCFOs, HFO and the blend R-514A show similar T-s curve to the reference HFC-245fa, whereas the hydrocarbons present remarkable differences. All the candidates provide interesting results of Coefficient of performance (COP) and Volumetric heating capacity (VHC), which will be presented and discussed in the results section.

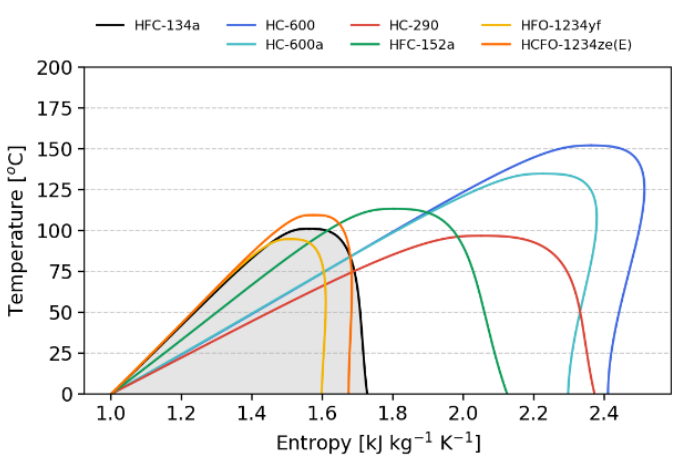

(a)

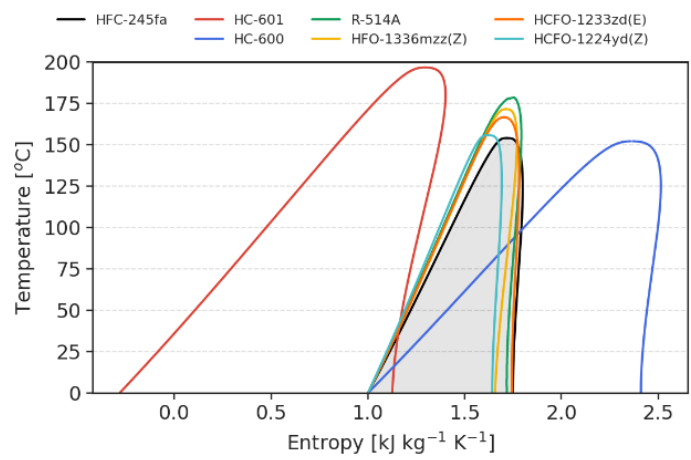

(b)

Fig. 8.3. T-s diagram of the reference refrigerants and its potential low-GWP alternatives for a) DHNsink scenario (Ref. HFC-134a) and b) DHNsource scenario (Ref. HFC-245fa).

\subsection{Methodology and modelling details}

The computer modelling parameters, along with the methodology used in this study, are presented in this section. Stockholm (Sweden) has been selected as the reference case for both the climate conditions and the district heating characteristics. The performance analysis covers the winter period time, in which all ambient temperatures are below $10^{\circ} \mathrm{C}$.

\subsubsection{Calculations procedure}

The simulation results of the integrated systems exposed in this paper are calculated based on the methodology presented in Fig. 8.4. Each scenario configuration and refrigerant, along with the boundary conditions and assumptions are used as input parameters for the model. The modelling is realised with the software Engineering Equation Solver (EES) [39]. This software solves the thermodynamic equations of each configuration and the IHX optimisation. Moreover, both models, $\mathrm{CO}_{2}$ refrigeration model based on Karampour et al. [8] and HTHP, are connected to perform the

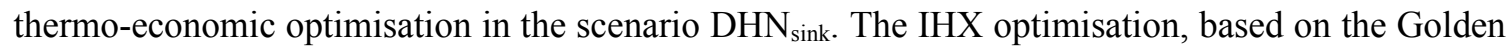
Section Search algorithm implemented in EES, maximises the COP of each scenario and refrigerant, varying the IHX effectiveness without exceeding the maximum discharge temperature of each compressor, depending on the scenario. Finally, the performance parameters become the modelling outputs, which are compared with the reference refrigerant in order to calculate the relative difference of each parameter and therefore, perform the performance and environmental analysis. 
Chapter 8

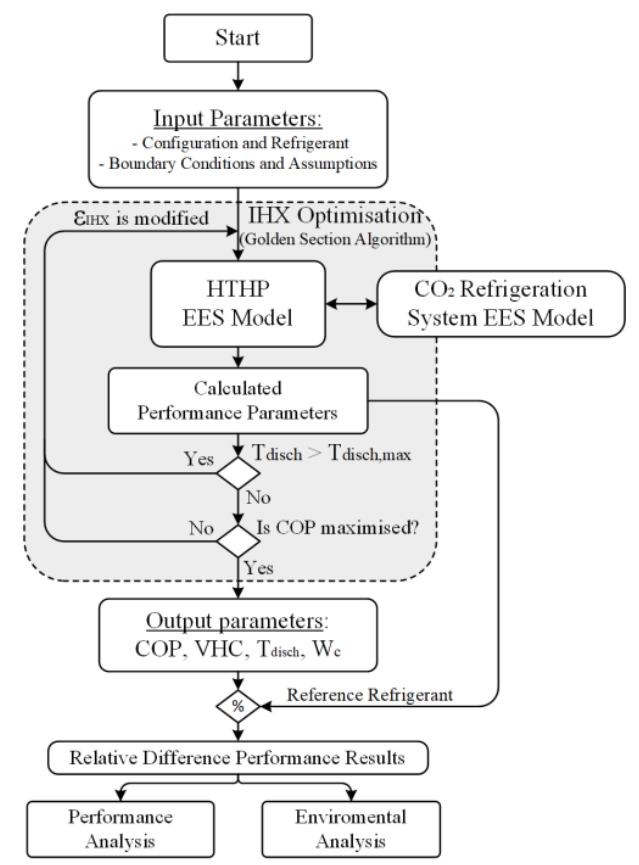

Fig. 8.4. Methodology flow diagram for the modelling scenarios, IHX optimisation and alternative low-GWP refrigerant analysis.

\subsubsection{Boundary conditions and assumptions}

\section{$\mathrm{CO}_{2}$ refrigeration system in $\mathrm{DHN}_{\text {sink }}$ Scenario}

The standard $\mathrm{CO}_{2}$ trans-critical booster system with heat recovery (HR) was modelled using the boundary conditions and assumptions proposed by Karampour et al. [8] for a typical average size supermarket in Sweden. This model has been modified to bypass the gas cooler and to integrate the additional heat exchanger that connects the $\mathrm{CO}_{2}$ refrigeration and the HTHP systems. The thermal loads of the supermarket $\mathrm{CO}_{2}$ refrigeration system for each hour of the year based on Karampour et al. [8] and Sawalha [7] are presented in Fig. 8.5. The medium temperature (MT) cooling and space heating demands are dependent of the ambient temperature, whereas the low temperature cooling demand remains constant throughout the year because glass lids typically cover the low temperature (LT) level freezers. 


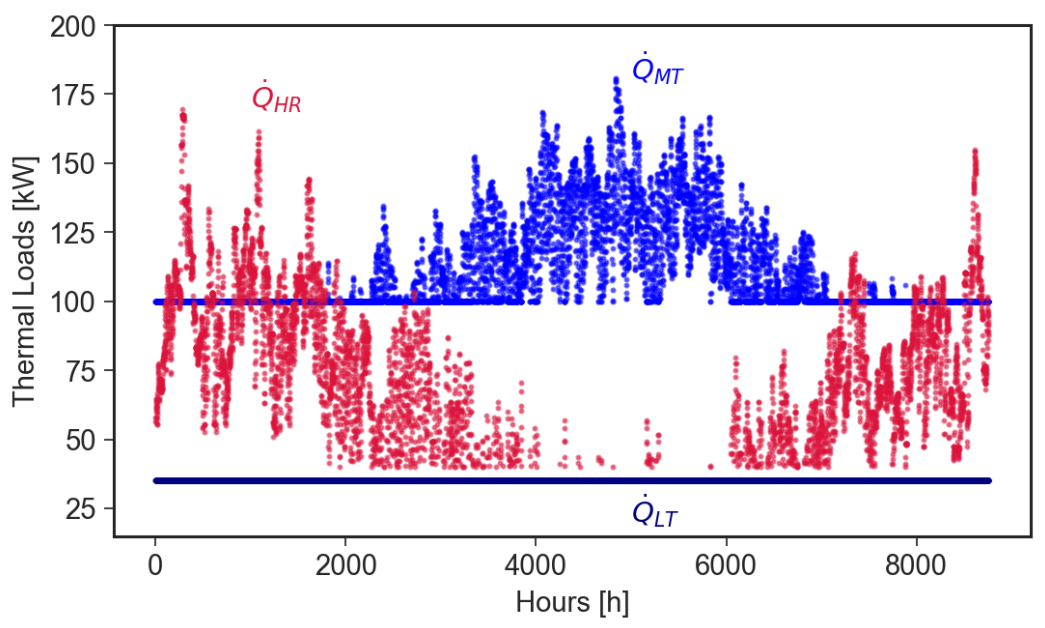

Fig. 8.5. Cooling and space heating thermal load for the $\mathrm{CO} 2$ supermarket refrigeration system during the year.

\section{District heating network}

The temperature profile of DHN has been modelled as a function of the ambient temperature, using the climate data of Stockholm [40] and the selling prices of 2017 for DHN heat injection in this city [41]. The DHN price variation during the year can be observed in Fig. 8.6a. For this study, the analysis zone will consider the winter season for which the ambient temperatures are below $10^{\circ} \mathrm{C}$. The supply and return temperatures of the DHN are presented in Fig. 8.6b, along with the Stockholm BIN hours used to calculate the different energy indicators as COP, VHC along with economic parameters. The BIN method corresponds to a discrete group (BINS) of specific weather condition where, in this case, each bin contains the number of average hours of the occurrence of each specific ambient temperature during a year. The Open District Heating in Stockholm becomes trading market of the excess heat and therefore, a perfect way to inject the excess heat into DHN with two different supply temperature profiles [42]. Two supply temperatures are depending on the DHN generation and the area installed. In this study, the low supply temperature profile is considered in all the calculations.

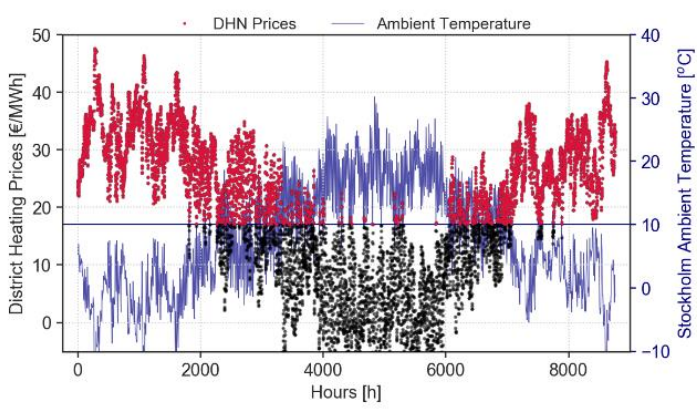

(a)

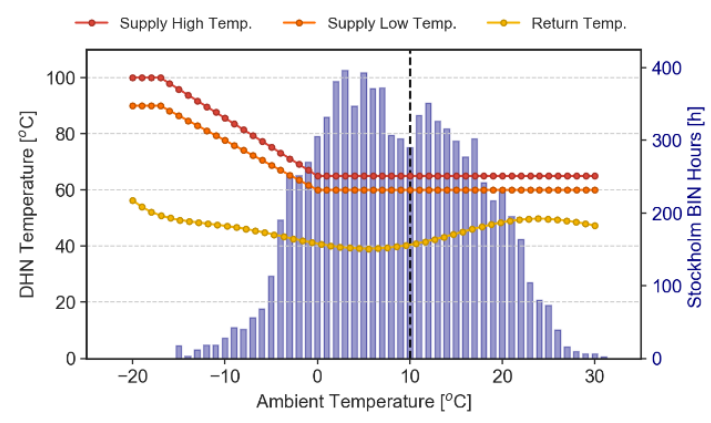

(b)

Fig. 8.6. District heating network modelling assumptions: a) Selling prices and b) supply and return temperatures. 


\section{High temperature heat pumps systems}

The use of an IHX is included in both HTHP models to provide the highest COP of the system in each operating condition. The sub-cooling degree at the condenser outlet is assumed $2 \mathrm{~K}$. In contrast, the superheating degree at the evaporator outlet considered is $5 \mathrm{~K}$. The pitch point or temperature approach in the condensers and evaporator is assumed $5 \mathrm{~K}$. The electro-mechanical efficiency of the compressors is assumed $95 \%$. The isentropic and volumetric efficiencies in this model are calculated using Pierre's correlations (Eq.(8.1) and (8.2)), following the methodology used in previous studies $[29,34]$.

$$
\eta_{v o l}=k_{1} \cdot\left(1+k_{s} \cdot \frac{t_{2 k}-18}{100}\right) \cdot \exp \left(k_{2} \cdot \frac{p_{1}}{p_{2}}\right)
$$

where $t_{2 k}$ is the inlet compressor temperature and $p_{1} / p_{2}$ is the pressure ratio. The remaining symbols $k_{1}, k_{s}$ and $k_{2}$ are constants with the value of $1.04,0.15$, and -0.07 , respectively [43].

$$
\left(\frac{\eta_{v o l}}{\eta_{i s}}\right)=\left(1+k_{e} \cdot \frac{t_{2 k}-18}{100}\right) \cdot \exp \left(a \cdot \frac{T_{1}}{T_{2}}+b\right)
$$

where $T_{1} / T_{2}$ is the ratio between the condensation and evaporation absolute temperatures ratio (in Kelvin). The constants $k_{e}, a$ and $b$ are $-0.1,-2.40$ and 2.88 , respectively.

About the HTHP system in the $\mathrm{DHN}_{\text {sink }}$ scenario, the temperature difference in the WHR heat exchanger from the $\mathrm{CO}_{2}$ part depends on the de-superheater outlet temperature, which depends on the space heating demand, and the WHR outlet temperature, controlled by the HTHP. This difference has a significant influence on both the system performance of the $\mathrm{CO}_{2}$ refrigeration and the HTHP systems. Therefore, a techno-economical optimisation is required to find the optimum value of the inlet temperature to the $\mathrm{CO}_{2}$ expansion valve. The heat absorbed by the evaporator in this scenario depends on the inlet and outlet temperature in the secondary fluid. Whereas the temperature difference between the inlet and outlet in the secondary fluid has been set to $15 \mathrm{~K}$, the inlet temperature of the secondary fluid will follow the temperature profile of the DHN supply line.

On the other hand, the $\mathrm{DHN}_{\text {source }}$ scenario is modelled using the supply DHN temperature profile as the inlet temperature of the secondary fluid in the HTHP evaporator. The temperature difference of the secondary fluid in the evaporator is assumed to be $15 \mathrm{~K}$, whereas this temperature difference becomes $20 \mathrm{~K}$ in the condenser. The heat sink outlet temperature takes into account different values in order to perform a sensitivity analysis of this parameter depending on the thermal requirements of the industrial process. Isentropic and volumetric compressor efficiencies have been implemented in the HTHP model using experimental data from an HTHP prototype with HFC-245fa. The data points of the compressor efficiencies are curve fitted and represented in Eq. (8.3) and (8.4), and both efficiencies have been corrected for each alternative refrigerant following the methodology described by Mateu-Royo et al. [44].

$$
\begin{aligned}
& \eta_{\text {iso }}(P R)=-0.02509 P R^{2}+0.1829 P R+0.4555 \\
& \eta_{v o l}(P R)=-0.02467 P R^{2}+0.2448 P R+0.3650
\end{aligned}
$$




\subsubsection{Energy use analysis}

Two main parameters are used to evaluate the benefit of the studied scenarios with each of the lowGWP alternative refrigerants, which are: the COP and the VHC. The COP for the $\mathrm{CO}_{2}$ refrigeration system is defined by Eq. (8.5), whereas this parameter for the HTHP is defined using Eq. (8.6).

$$
\begin{gathered}
C O P_{C O 2}=\frac{\dot{Q}_{M T}+\dot{Q}_{L T}+\dot{Q}_{H R}}{\dot{W}_{M T}+\dot{W}_{L T}+\dot{W}_{F a n s}} \\
C O P_{H T H P}=\frac{\dot{Q}_{k}}{\dot{W}_{C}}
\end{gathered}
$$

Nevertheless, a new definition of the COP is proposed to evaluate the performance of the $\mathrm{DHN}_{\text {sink }}$ scenario, considering the HTHP compressor electricity consumption and the difference of the electricity consumption in the $\mathrm{CO}_{2}$ refrigeration system $\left(\Delta \dot{W}_{t o t, C_{2}}\right)$. This $\mathrm{COP}$ WHR is defined using Eq. (8.7).

$$
\operatorname{COP}_{W H R}=\frac{\dot{Q}_{k}}{\dot{W}_{C}+\Delta \dot{W}_{t o t, C O_{2}}}
$$

where $\dot{Q}_{k}$ represents the heat rejected in the HTHP condenser, $\dot{W}_{C}$ represents the compressor electric power consumption and $\Delta \dot{W}_{t o t, \mathrm{CO}_{2}}$ represents the compressor electric power consumption difference of the $\mathrm{CO}_{2}$ refrigeration system, operating with and without the integration of HTHP.

On the other hand, the VHC is used to evaluate the difference in heating per unit of volume between the reference working fluid and the low-GWP alternative refrigerants. This parameter is defined by Eq. (8.8).

$$
V H C=\frac{\dot{Q}_{k}}{\dot{V}_{s u c}}
$$

where $\dot{V}_{\text {suc }}$ is the refrigerant volume flow rate $\left(\mathrm{m}^{3} \mathrm{~s}^{-1}\right)$.

The results obtained for the alternative low-GWP refrigerants evaluation are provided as a relative difference, comparing the reference fluid with each candidate refrigerant. Thus, Eq. (8.9) and (8.10) are used to calculate the relative performance difference for both parameters, the $\mathrm{COP}_{\text {нтнр }}$ and VHC.

$$
\% C O P=\frac{C O P_{l o w-G W P}-C O P_{R e f}}{C O P_{R e f}} \cdot 100
$$


Chapter 8

$$
\% V H C=\frac{V H C_{\text {low }-G W P}-V H C_{R e f}}{V H C_{R e f}} \cdot 100
$$

Finally, the relative difference in operating cost is calculated using the Eq. (8.11)

$$
\% O C=\frac{\sum_{i}\left(\dot{W}_{C, i}+\Delta \dot{W}_{t o t, C O_{2}, i}\right) \cdot p_{D H N, i} \cdot R_{p, j}-\sum_{i} \dot{Q}_{k} \cdot p_{D H N, i}}{\sum_{i}\left(\dot{W}_{C O_{2}, i}\right) \cdot p_{D H N, i} \cdot R_{p, j}} \cdot 100
$$

where $p_{D H N}$ is the district heating network price, $R_{p}$ the price ratio between the DHN and electricity, $\dot{W}_{\mathrm{CO}_{2}}$ the power consumption of the $\mathrm{CO}_{2}$ refrigeration system without the integration of $\mathrm{HTHP}, i$ corresponds to the ambient temperature, and $j$ corresponds to different values of price ratios.

\subsubsection{Environmental analysis}

The equivalent $\mathrm{CO}_{2}$ emissions analysis has been realised to provide an environmental perspective of the system integration benefits. Table 8.3 presents a different emission factor.

Table 8.3. Emission factor associated with different system processes.

\begin{tabular}{ll}
\hline Emission factor description & Value $\left(\mathbf{g ~ C O}_{\mathbf{2}} \mathbf{~ k W h} \mathbf{W h}^{-\mathbf{1}}\right)$ \\
\hline Sweden electricity consumption [45] & 13.3 \\
European Union electricity consumption [45] & 295.8 \\
Sweden DHN generation mix [2] & 32.4 \\
Natural gas consumption [46] & 205 \\
\hline
\end{tabular}

For the scenario $\mathrm{DHN}_{\text {sink }}$, the emission factor associated with the electricity consumption is assumed $13.3 \mathrm{~g} \mathrm{CO}_{2} \mathrm{kWh}^{-1}$ based on the European Environment Agency for Sweden [45]. In this case, the equivalent $\mathrm{CO}_{2}$ emissions of the integrated system will be compared with the emission factor of the mix generation in the DHN with a value of $32.4 \mathrm{~g} \mathrm{CO}_{2} \mathrm{kWh}^{-1}$ [2]. For the scenario $\mathrm{DHN}_{\text {source, an }}$ equivalent $\mathrm{CO}_{2}$ emissions comparison has been achieved between the HTHP using DHN as a heat source and a natural gas boiler, providing both systems with the same amount of heat. The emission factor associated with natural gas consumption is considered $205 \mathrm{~g} \mathrm{CO}_{2} \mathrm{kWh}^{-1}$ [46]. In contrast, the electricity emission factor is considered $295.8 \mathrm{~g} \mathrm{CO}_{2} \mathrm{kWh}^{-1}$ [45] for the European Union and the above-stated value for Sweden, in order to compare two different perspectives.

\subsubsection{Total equivalent warming impact (TEWI) evaluation}

In order to evaluate the benefits of the proposed low GWP alternatives, Total Equivalent Warming Impact (TEWI) has been calculated for each refrigerant to quantify the equivalent $\mathrm{CO}_{2}$ emission due to the energy consumption of the HTHP systems (indirect emissions) and to the accidental losses of refrigerant (direct emissions) [47]. TEWI method is calculated based on Eq. (8.12).

$$
T E W I=G W P \cdot L \cdot n+G W P \cdot m_{r}(1-\alpha)+n \cdot E_{a} \cdot \beta
$$


Some necessary assumptions can be considered in order to perform the TEWI analysis. The lifespan of the system $(n)$ is considered 15 years and the recycling factor of the refrigerant $(\alpha)$ is omitted for this evaluation. Considering HTHPs systems will be contained in the machinery room, an annual leakage rate of $5 \%$ of the total refrigerant charge is considered [48]. Finally, the indirect emission factor $(\beta)$ considered is the electricity emission factor for the European Union. Using the Sweden electricity emission factor will provide the same relative results of each refrigerant evaluation with lower absolute values.

\subsection{Results and discussion}

This section includes the results and discussion of the HTHP integration into the DHN, dividing this section between the two proposed scenarios: $\mathrm{DHN}_{\text {sink }}$ and $\mathrm{DHN}_{\text {source }}$.

\subsubsection{DHNsink Scenario}

\section{- Thermo-economic optimisation}

In this scenario, a thermo-economic optimisation of the WHR exit temperature is required in order to maximise the benefits of the systems integration. Low temperature at $\mathrm{CO}_{2}$ expansion valve inlet of the refrigeration system results in higher $\mathrm{COP}_{\mathrm{CO} 2}$; however, it means that the evaporation temperature

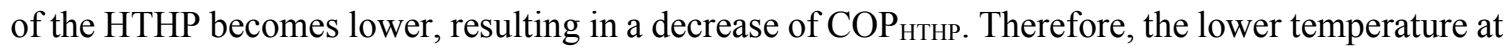
the expansion valve inlet of the refrigeration system results in more heat recovery in WHR heat exchanger.

Fig. 8.7 presents the economic benefits per operating hour, depending on the WHR exit temperature, the ambient temperature and the price ratio between electricity consumption and selling heat to DHN prices. Based on the results obtained, an increase of the WHR exit temperature increases the economic benefits of the integrated system. Moreover, the thermal loads, DHN prices and energy consumption are highly influenced by the ambient temperature, and therefore, the economic benefits become affected by the ambient variable. Nevertheless, there is a clear tendency to obtain the maximum economic benefits, which will be located operating in ambient temperatures between 0 to $10{ }^{\circ} \mathrm{C}$ and fixing the WHR temperature at the highest level. The space heating demand of the supermarket's building is influenced by the ambient temperature, becoming lower with high ambient temperatures. Hence, the maximum economic benefit will be located operating in higher ambient temperatures where there is more waste heat available. 


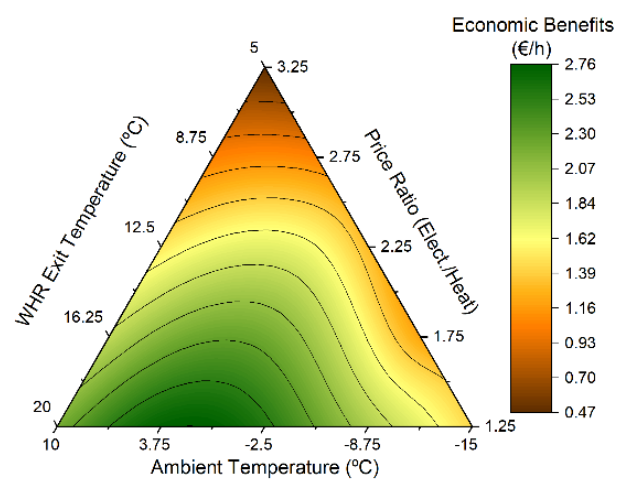

Fig. 8.7. Thermo-economic optimisation and economic benefits per operating hour of the HTHP integration into DHN as a heat source.

Nevertheless, the WHR exit temperature influences the energy performance of both systems, as shown in Fig. 8.8. Whereas the COP of the $\mathrm{CO}_{2}$ refrigeration system decreases with an augment of the WHR exit temperature, the COP of the HTHP is positively affected. It is essential to highlight that the condensing temperature is a function of the ambient temperature due to the connection with the DHN. As the $\mathrm{COP}_{\mathrm{CO} 2}$ reduction is less influenced than the $\mathrm{COP}_{\mathrm{HTHP}}$, the $\mathrm{COP}_{\mathrm{WHR}}$ increases with an increase of the WHR exit temperature. It is essential to remark that the $\mathrm{CO}_{2}$ refrigeration system is assumed to recover the same heat to overcome the building heating demand with or without HTHP integration. As a result of the thermo-economic optimisation, the WHR exit temperature is set to 20 ${ }^{\circ} \mathrm{C}$ for the performance evaluation and the alternative low-GWP refrigerant evaluation.

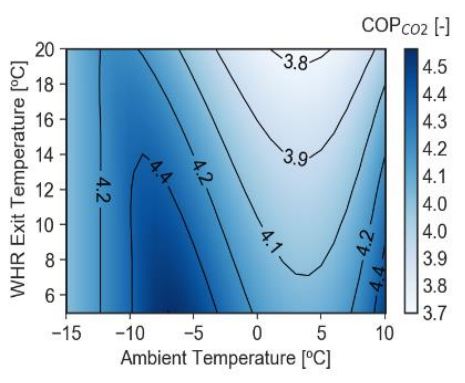

(a)

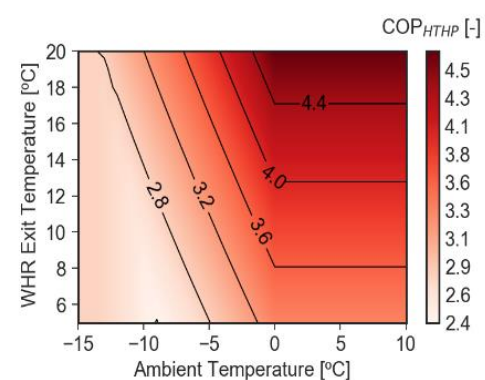

(b)

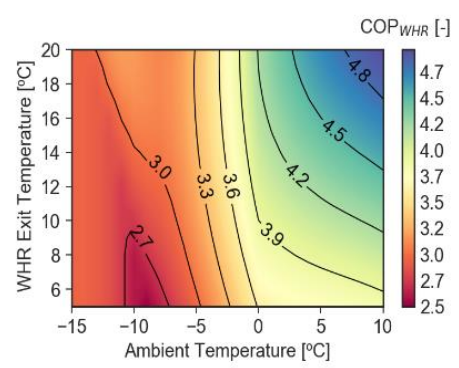

(c)

Fig. 8.8. COP of the different integrated system depending on the WHR exit and the ambient temperatures for a) $\mathrm{CO} 2$ refrigeration system, b) HTHP and c) Total integrated solution.

Fig. 8.9 illustrates that the HP heating capacity can be slightly modified with a variation of the WHR exit temperature. This variable heating capacity provides flexibility to the integrated HTHP to overcome a specific heating requirement only with a variation in the WHR exit temperature.

At ambient temperatures between 0 to $10^{\circ} \mathrm{C}$, there is located most of the operating hours in this study, and it becomes the region where this system provides the highest flexibility. For low ambient temperatures, the supermarket building requires a high amount of heat to overcome the space heating demand. Thus, $\mathrm{CO}_{2}$ refrigeration system control reduces the heat rejected to the ambient in order to provide the required heating demand. It causes a decrease in the available waste heat and therefore, the HTHP system becomes less flexible at low ambient temperatures. 


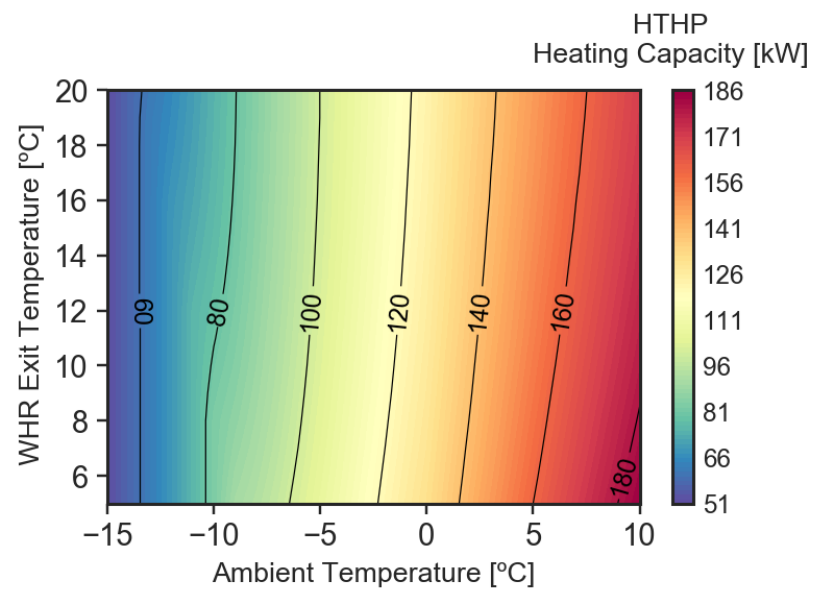

Fig. 8.9. Heating capacity of the HTHP system depending on the WHR exit and the ambient temperatures.

\section{- Performance evaluation}

The evaluation of the integrated system has been carried out from two perspectives: analysing the performance of the refrigeration system, HTHP and WHR system along with the relative operating cost of the full integration. Fig. 8.10a presents the three different COP analysed, corresponding to the $\mathrm{CO}_{2}$ refrigeration system, the HTHP and the integrated system as waste heat recovery solution. The $\mathrm{COP}_{\mathrm{CO} 2}$ has some variations with the ambient temperature due to the strategy control implemented in the system to recover the heating demand of the supermarket building [7]. As the ambient temperature decreases, the system is forced to run in transcritical conditions in order to generate more heat to fulfil the heating requirements.

Until a specific ambient temperature, the system changes the control strategy continue being able to provide the necessary heat. More details of the control strategy implemented are explained by Sawalha [7]. About the HTHP, the $\mathrm{COP}_{\text {HTHP }}$ remains constant until a specific ambient temperature, where this performance parameter starts to decrease. This behaviour is caused by the DHN profile temperature, which remains constant in $60^{\circ} \mathrm{C}$ in the supply line until approximately $90{ }^{\circ} \mathrm{C}$ in the lowest ambient temperatures. This increase in the thermal supply levels increases the temperature lift of the HTHP and therefore, produces a drop in the performance. Finally, the $\mathrm{COP}_{\mathrm{WHR}}$ presents higher values than the $\mathrm{COP}_{\text {нтнР }}$ operating in warm ambient temperatures caused by the energy consumption reduction of the gas cooler fans in the $\mathrm{CO}_{2}$ refrigeration system compared with the reference. The integration of HTHP requires the gas cooler bypass, and therefore, the fans in this component become disabled in the integrated system. Then, $\mathrm{COP}_{\mathrm{WHR}}$ is being influenced by the drop of both $\mathrm{CO}_{2}$ refrigeration and HTHP systems, until specific ambient temperature where the $\mathrm{CO}_{2}$ requires high heating demand and the WHR system becomes benefited by this strategy control.

The majority of the operating hours in Stockholm are located in the high-efficiency zone of the WHR integrated system. Due to this fact, it is expected a potential benefit of this system integration in terms of operating costs. Fig. $8.10 \mathrm{~b}$ illustrates the potential operating costs savings comparing the integrated system with the standard $\mathrm{CO}_{2}$ refrigeration system without integration. 
This study is focused on the operating cost because the investment cost does not become representative to illustrate the potential of this technology due to the novelty of HTHP technology in the market.

The principal operating hours are located between ambient temperatures of -5 to $10^{\circ} \mathrm{C}$ as can observe in Fig. 8.10a. The relative difference in operating cost has been calculated using Eq. (8.11), where the DHN price dependency with the ambient temperature provides only one possible DHN price for each ambient temperature. However, there are multiple price ratios for each temperature, and therefore, multiple electricity prices can be considered in a single ambient temperature. Hence, a price ratio range between 1.2 and 2.7 is considered in this analysis in order to limit the possible solutions and provide a realistic result. Therefore, operating savings between $50 \%$ and $100 \%$ should be expected for an average price ratio of 2.25 . Therefore, this system integration shows an excellent potential to be implemented in most of the supermarkets that already have a DHN connection in order to obtain higher economic operating benefits. A correct heat selling price to DHN will promote the application of this WHR technology due to the higher benefit for the prosumers.

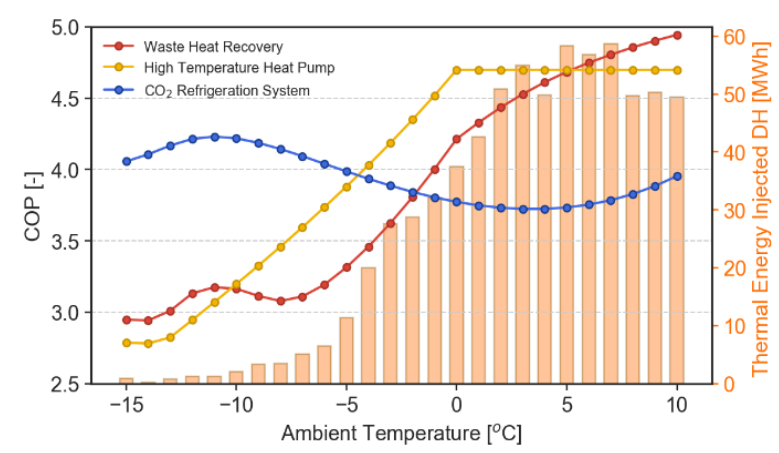

(a)

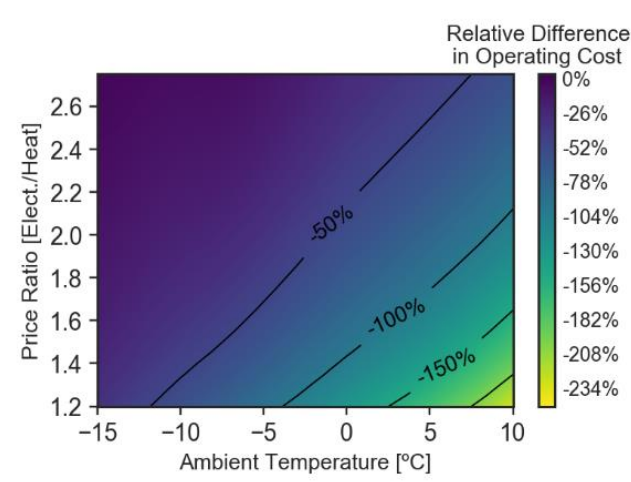

(b)

Fig. 8.10. Performance evaluation of the integrated system with the ambient temperature, using DHN as a heat source: a) COPs and b) relative difference in the operating cost.

\section{- Alternative refrigerants to HFC-134a}

This section presents the results of the potential candidates from two perspectives: looking at the performance (i.e. COP from Eq. (8.6)) and the installation and components size (i.e. VHC in Eq. (8.8)). The calculations are performed with the same operating conditions of the $\mathrm{DHN}_{\text {sink }}$ scenario. These results are plotted in Fig. 8.11 as a relative difference between the reference fluid and each alternative; using Eq. (8.9) for \%COP and Eq. (8.10) for \%VHC. HC-600a and HC-600 present the highest performance improvements with a $\% \mathrm{COP}$ increase between $9 \%$ to $17 \%$, depending on the ambient temperature. However, both refrigerants have lower VHC; around 40\% for HC-600a and $60 \%$ for HC-600, and therefore, greater compressor size is required to provide similar heating capacities owing to their lower suction density, shown in Table 8.1. In contrast, HC-290 provides a slight increase of COP along with the highest $\mathrm{VHC}$ increase of about $38 \%$, requiring a smaller compressor for the same heating demand. 
It can be observed from Fig. 8.11 that HFC-152a has equal or slightly lower VHC, but this is the only refrigerant analysed that presents a reduction of the COP, but only about $1 \%$. The hydrofloroolefins (HFOs) on the other hand, both refrigerants have an increase of the COP without being highly influenced by the ambient temperature. HFO-1234yf has slightly similar or even higher VHC, while HFO-1234ze(E) has a reduction of $20 \%$, which can be significant in the refrigerant selection.

HC-290 can be a proper candidate to replace HFC-134a in new design installations, providing a slight increase in efficiency and providing the required heating with a smaller compressor. Contrary, HC600a can provide a significant COP increase but at the expense of larger compressors for the same heating demand. All these refrigerants have a greater or lesser degree of flammability, and therefore, it is required special security measures to operate with these refrigerants.

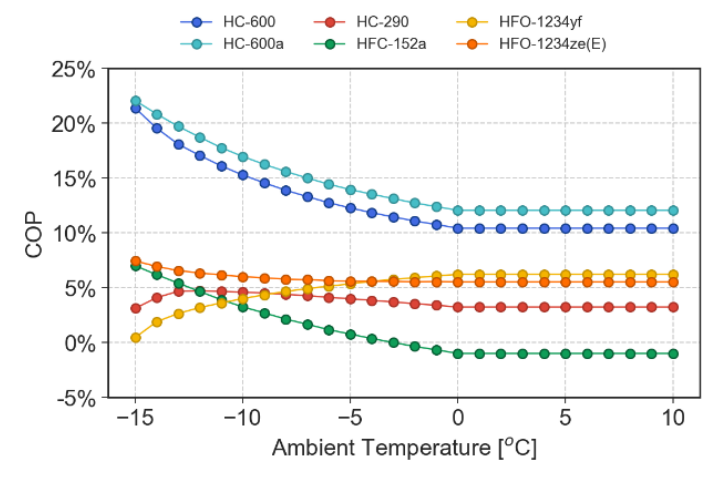

(a)

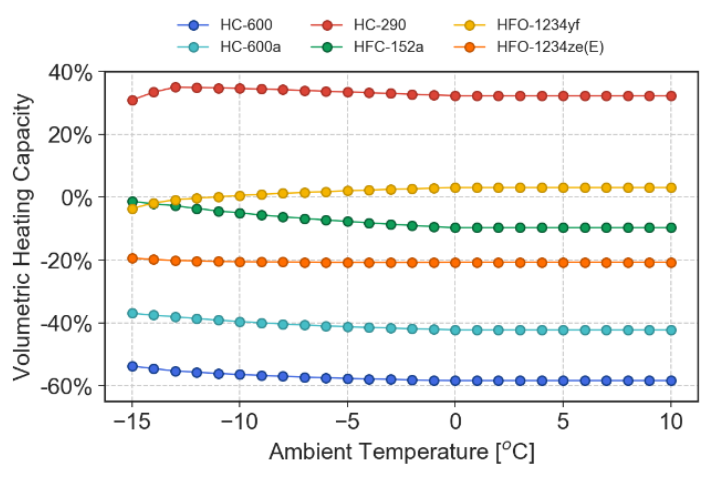

(b)

Fig. 8.11. Alternative low-GWP refrigerants comparison to replace HFC-134a: a) COP and b) VHC.

The discussion in this section looks only at the efficiency and the size of the compressor; however, other factors should be taken into account in choosing the suitable refrigerant for the application, such as availability of components, safety requirements, and installation cost.

\subsection{2 $\mathrm{DHN}_{\text {source }}$ Scenario}

\section{- Performance evaluation}

In this scenario, DHN is used as a heat source, and the interest becomes in the heating production to overcome the thermal requirements of the industrial process. Thus, the results in this section are the COP and heating capacity of the HTHP system integrated into DHN as a function of the ambient and the heat sink temperatures (Fig. 8.12), using HFC-245fa as reference fluid. The calculated performance parameters are obtained for the same evaporator capacity. In this case, the heat sink temperature becomes limited by the temperature lift, which is defined as the temperature difference between the inlet heat source and outlet heat sink. Until an ambient temperature of $0{ }^{\circ} \mathrm{C}$, the supply line of the DHN has a temperature of $60{ }^{\circ} \mathrm{C}$, and therefore, the heat sink is being limited to $113^{\circ} \mathrm{C}$. As the DHN supplies temperature increase as a function of the ambient temperature, the HTHP system can provide higher heat sink temperatures to overcome a significant range of industrial processes. Although the HTHP system has some limitations, the integration concept can provide heat sink 
temperatures above $100{ }^{\circ} \mathrm{C}$ with high efficiency. Thus, the integration of HTHPs into DHNs becomes a sustainable alternative to replace the natural gas boiler in the industry, overcoming the industrial thermal requirements with high efficiency and low-carbon emissions. Moreover, HTHPs have high operating flexibility, being able to modulate the heating capacity and therefore, provide the precise amount of heat required in each instant, as shown in Fig. 8.12b. This solution represents a sustainable low-carbon alternative to decarbonise the industrial sector and therefore, contribute to climate change mitigation.

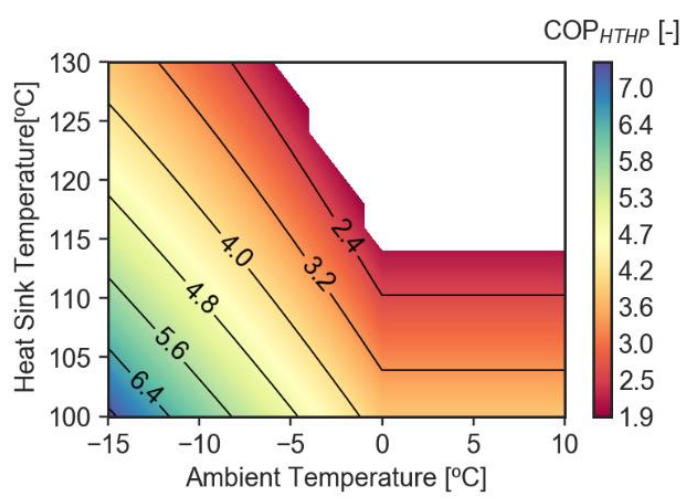

(a)

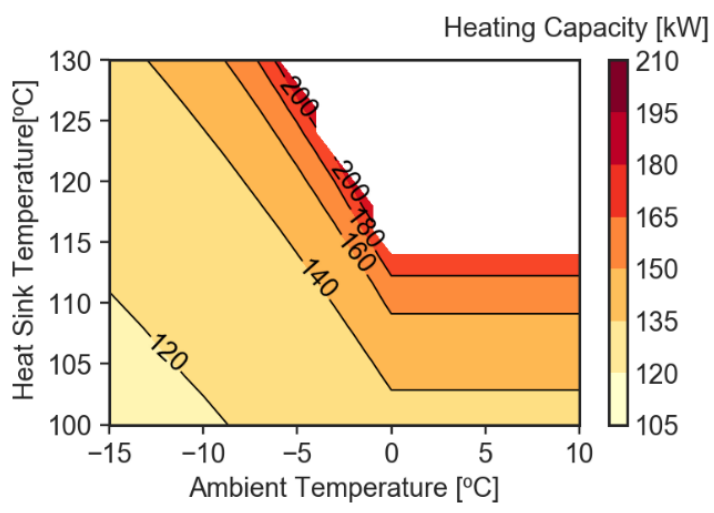

(b)

Fig. 8.12. Performance analysis of integrating HTHP into DHN (scenario DHNsource): a) COPHTHP and b) heating capacity.

\section{- Alternative refrigerants to HFC-245fa}

Similarly to the other scenario, the refrigerant HFC-245fa is used in the majority of the HTHPs and ORC system with the problematic of having high GWP of 858 . Thus, it is necessary to analyse the alternative refrigerants available that have low-GWP and can be a proper substitute for the reference fluid HFC-245fa. Equal to the previous low-GWP refrigerant assessment, COP and VHC parameters are used as critical indicators of the performance and installation size of each candidate, presented in Fig. 8.13.

HC-601, HFO-1336mzz(Z) and R-514A have the most remarkable COP improvements. However, these refrigerants exhibit the highest VHC reduction, and therefore, bigger compressors are required to provide the same amount of heat. Contrary to the previous scenario, HC-600 manifests similar efficiency to HFC-245fa, but also, in this case, the highest increase of VHC, requiring a smaller compressor size than HFC-245fa. Finally, the HCFOs exhibit a balance between the COP and VHC indicators, being potential drop-in replacements in this application, specially HCFO-1224yd(Z). 


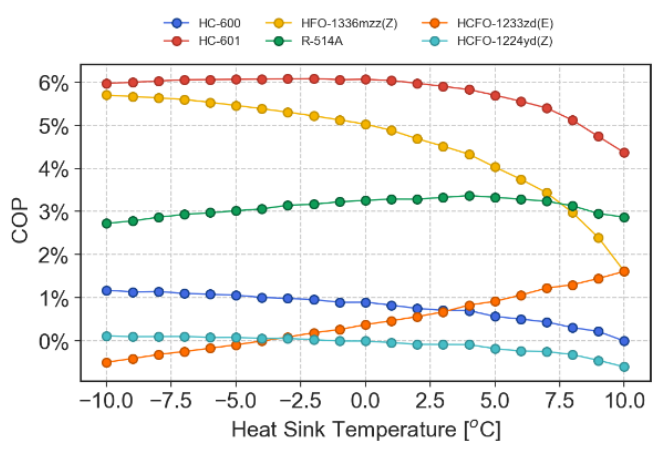

(a)

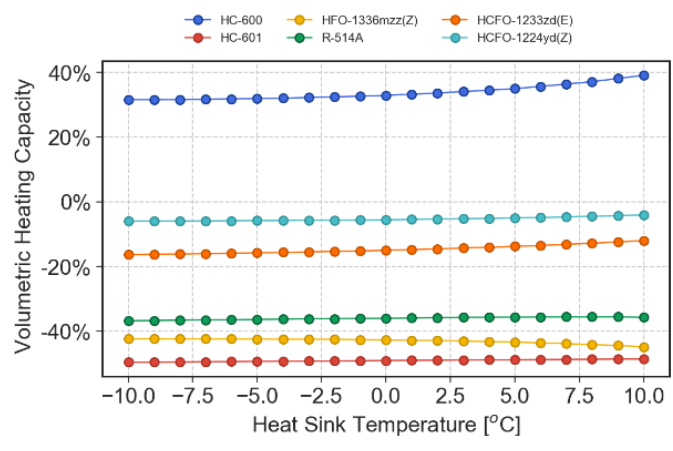

(b)

Fig. 8.13. Assessment for alternative low-GWP refrigerants to replace HFC-134a: a) COP and b) VHC.

\subsubsection{Environmental analysis}

One of the main aspects of integrating HTHPs into DHNs is the potential to reduce the equivalent $\mathrm{CO}_{2}$ emissions, becoming an additional resource in decarbonisation and climate change mitigation. Fig. 8.14a presents the $\mathrm{CO}_{2}$ emissions of the DHN and the integrated system for $\mathrm{DHN}_{\text {sink }}$ scenario. In this figure, the $\mathrm{CO}_{2}$ emissions of both systems are compared, providing the same amount of heat as a function of the ambient temperature. Significant $\mathrm{CO}_{2}$ emission reductions of the integrated system compared to DHN can be appreciated in Fig. 8.15a, quantified at about $60 \%$ over the winter period.

On the other hand, Fig. 8.14b illustrates the environmental analysis concerning $\mathrm{DHN}_{\text {source }}$ scenario. In this case, the integrated system is compared with a natural gas boiler with an efficiency of $95 \%$ to overcome the same heating demand in the industrial processes, using two different electricity emissions factors. During the winter period, the integrated system can reduce the equivalent $\mathrm{CO}_{2}$ emissions up to $98 \%$ for Sweden. In contrast, this reduction can up to $47 \%$ using the EU emission factor in order to have an average view. For the mentioned results, this industrial integrated solution can contribute to achieving the environmental targets of the European Union, aiming at decarbonisation of the industrial sector.

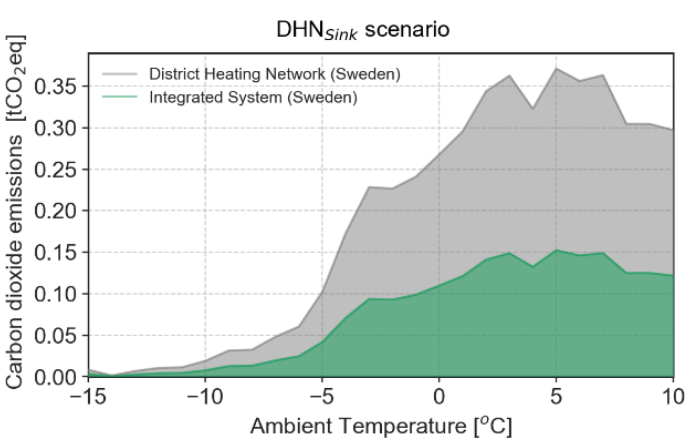

(a)

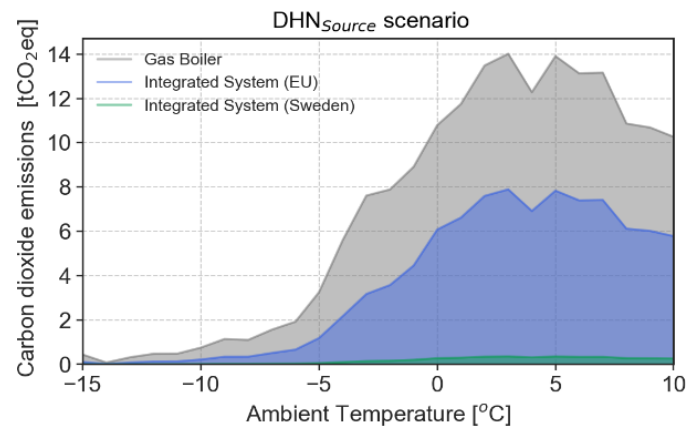

(b)

Fig. 8.14. Environmental analysis of the $\mathrm{CO} 2$ equivalent emissions for the: a) DHNsink scenario and b) DHNsource scenario. 


\subsubsection{TEWI evaluation}

The use of alternative low-GWP refrigerants in HTHP systems can get better equivalent $\mathrm{CO}_{2}$ emissions reductions due to the performance improve and lower GWP values compared to the reference refrigerants HFC-134a and HFC-245fa. Hence, TEWI evaluation illustrates the equivalent $\mathrm{CO}_{2}$ emissions of each refrigerant, including the energy consumption and leakages. Fig. 8.15 presents the TEWI comparison for both scenarios, $\mathrm{DHN}_{\text {sink }}$ and $\mathrm{DHN}_{\text {sink. }}$. Since most of the alternatives have low-GWP, TEWI analysis becomes more sensitive to the energy performance improvements of each refrigerant. HFC-152a shows lower equivalent $\mathrm{CO}_{2}$ emissions than the other alternatives owing to its slightly high GWP value compared to the other low-GWP refrigerants. The rest low-GWP alternatives in both scenarios present similar equivalent $\mathrm{CO}_{2}$ emissions reduction, and therefore, there is not a clear candidate only based on TEWI evaluation.

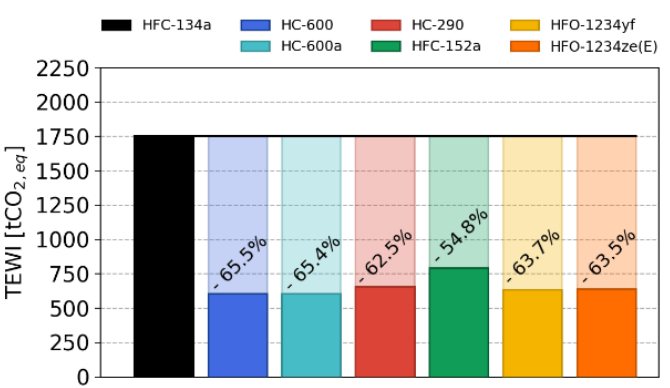

(a)

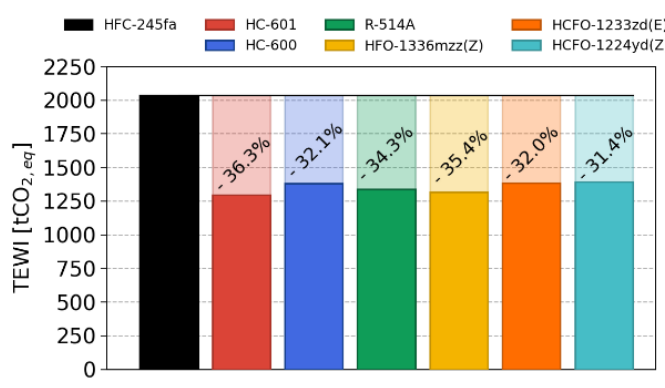

(b)

Fig. 8.15. Total equivalent warming impact (TEWI) evaluation for the: a) $D H N_{\text {sink }}$ scenario and b) $D H N_{\text {source }}$ scenario.

\subsection{Conclusions}

This work presented the integration of HTHP into DHN in two different situations, using the DHN as a heat sink and heat source. The target was to investigate the potential of this technology as an innovative and efficient solution to contribute to climate change mitigation. Thus, a twofold approach was followed:

1. Using the DHN as a heat sink, an integrated system solution was modelled in order to recover the waste heat from $\mathrm{CO}_{2}$ refrigeration systems, upgrade and inject it into the DHN. A thermoeconomic optimisation of the proper WHR exit temperature was achieved to maximise the economic benefits of this integration. Moreover, alternative low-GWP refrigerants were assessed to replace the reference HTHP working fluid, HFC-134a. Finally, an environmental analysis was provided to illustrate the potential equivalent $\mathrm{CO}_{2}$ emission reduction in the DHN generation mix, adopting this solution.

2. Using the DHN as a heat source, HTHP modelling was based on experimental compressor data from an HTHP prototype in a wide range of heat sink temperatures. System parameters, such as COP and heating capacity, were calculated to provide a comprehensive performance evaluation of the HTHP integration. Besides, potential candidates with low-GWP to replace HFC-245fa were investigated as an environmental-friendly refrigerants alternative. Finally, 
an environmental analysis of this integration system was presented to illustrate its potential in the decarbonisation of the energy-intensive industry sector.

The following conclusions can be drawn from the results of this study:

- The integration of HTHPs into DHNs provides significant environmental and performance improvements, being an innovative and profitable system solution to decarbonise different sectors.

- Using the DHN as a heat sink, the $\mathrm{COP}_{\mathrm{WHR}}$ results between 3.2 and 5.4, reducing the operating cost between $50 \%$ and $100 \%$ with an average price ratio of 2.25 compared with the standard $\mathrm{CO}_{2}$ refrigeration system. With the DHN as the heat source, the integrated system provides a COP from 2.8 to 5.7 for a heat sink of $110^{\circ} \mathrm{C}$. A reasonable heat selling price to DHN will promote the application of this WHR technology due to the higher benefit for the prosumers

- HC-290, HFO-1234ze(E) and HFO-1234yf were considered the ideal alternative low-GWP refrigerants to replace the HFC-134a in new design installations. Moreover, HCFO$1233 \mathrm{zd}(\mathrm{E})$ and $\mathrm{HCFO}-1224 \mathrm{yd}(\mathrm{Z})$ were the most promising low-GWP refrigerants to replace the reference working fluid, HFC-245fa.

- The environmental results, using the $\mathrm{DHN}_{\text {sink }}$ scenario, showed that the integrated system solution produces about $60 \%$ lower equivalent $\mathrm{CO}_{2}$ emissions than the DHN generation mix over the winter period. Moreover, the $\mathrm{DHN}_{\text {source }}$ scenario can reduce the equivalent $\mathrm{CO}_{2}$ emissions up to $47 \%$ using the EU carbon emission factor, whereas this reduction can be about $98 \%$ for Sweden. Therefore, this integrated system becomes a potential solution to replace the conventional natural gas boilers and reduce the greenhouses gas emission in the industrial sector.

\section{References}

[1] IPCC. Global Warming of $1.5^{\circ}$ C.An IPCC Special Report on the impacts of global warming of $1.5^{\circ} \mathrm{C}$ above pre-industrial levels and related global greenhouse gas emission pathways, in the context of strengthening the global response to the threat of climate change, 2018.

[2] Werner S. District heating and cooling in Sweden. Energy 2017;126:419-29. doi:10.1016/J.ENERGY.2017.03.052.

[3] Pieper H, Ommen T, Elmegaard B, Brix Markussen W. Assessment of a combination of three heat sources for heat pumps to supply district heating. Energy 2019;176:156-70. doi:10.1016/J.ENERGY.2019.03.165.

[4] Galindo Fernández M, Roger-Lacan C, Gährs U, Aumaitre V. Efficient district heating and cooling systems in the EU - Case studies analysis, replicable key success factors and potential policy implications. European Union. 2016. doi:10.2760/371045.

[5] Karampour M, Sawalha S, Arias J. D2.2 Eco-Friendly Supermarkets - An Overview, H2020 Project SuperSmart, Grant Agreement No 696076, Retrieved 11.11.2016 from: http://www.supersmart-supermarket.info/downloads/. 2016. 
Chapter 8

[6] Sawalha S, Karampour M, Rogstam J. Field measurements of supermarket refrigeration systems. Part I: Analysis of $\mathrm{CO} 2$ trans-critical refrigeration systems. Appl Therm Eng 2015;87:633-47. doi:10.1016/J.APPLTHERMALENG.2015.05.052.

[7] Sawalha S. Investigation of heat recovery in $\mathrm{CO} 2$ trans-critical solution for supermarket refrigeration. Int J Refrig 2013;36:145-56. doi:10.1016/J.IJREFRIG.2012.10.020.

[8] Karampour M, Sawalha S. State-of-the-art integrated CO2 refrigeration system for supermarkets: A comparative analysis. Int J Refrig 2018;86:239-57. doi:10.1016/J.IJREFRIG.2017.11.006.

[9] Ahmadisedigh H, Gosselin L. Combined heating and cooling networks with waste heat recovery based on energy hub concept. Appl Energy 2019;253:113495. doi:10.1016/J.APENERGY.2019.113495.

[10] Arpagaus C, Bless F, Schiffmann J, Bertsch SS. Multi-temperature heat pumps: A literature review. Int J Refrig 2016;69:437-65. doi:10.1016/j.jirefrig.2016.05.014.

[11] Arpagaus C, Bless F, Uhlmann M, Schiffmann J, Bertsch SS. High temperature heat pumps: Market overview, state of the art, research status, refrigerants, and application potentials. Energy 2018;152:985-1010. doi:10.1016/J.ENERGY.2018.03.166.

[12] Sayegh MA, Jadwiszczak P, Axcell BP, Niemierka E, Bryś K, Jouhara H. Heat pump placement, connection and operational modes in European district heating. Energy Build 2018;166:122-44. doi:10.1016/J.ENBUILD.2018.02.006.

[13] Wang Z. Heat pumps with district heating for the UK's domestic heating: individual versus district level. Energy Procedia 2018;149:354-62. doi:10.1016/J.EGYPRO.2018.08.199.

[14] Ommen T, Thorsen JE, Markussen WB, Elmegaard B. Performance of ultra low temperature district heating systems with utility plant and booster heat pumps. Energy 2017;137:544-55. doi:10.1016/J.ENERGY.2017.05.165.

[15] Kosmadakis G. Estimating the potential of industrial (high-temperature) heat pumps for exploiting waste heat in EU industries. Appl Therm Eng 2019;156:287-98. doi:10.1016/J.APPLTHERMALENG.2019.04.082.

[16] Bergamini R, Jensen JK, Elmegaard B. Thermodynamic competitiveness of high temperature vapor compression heat pumps for boiler substitution. Energy 2019;182:110-21. doi:10.1016/J.ENERGY.2019.05.187.

[17] Kontu K, Rinne S, Junnila S. Introducing modern heat pumps to existing district heating systems - Global lessons from viable decarbonizing of district heating in Finland. Energy 2019. doi:10.1016/j.energy.2018.10.077.

[18] Sartor K, Lemort V, Dewallef P. Improved district heating network operation by the integration of high-temperature heat pumps. Int J Sustain Energy 2018;37:842-56. doi:10.1080/14786451.2017.1383409.

[19] The European Parliament and the Council of the European, Union. Regulation (EU) No 517/2014 of the European Parliament and the Council of 16 April 2014 on fluorinated greenhouse gases and repealing Regulation (EC). No 842/2006 Off J Eur Union 150, 195-230 2014.

[20] Calm JM. The next generation of refrigerants - Historical review, considerations, and outlook. Int J Refrig 2008;31:1123-33. doi:10.1016/j.ijrefrig.2008.01.013. 
[21] Maiorino A, Aprea C, Del Duca MG, Llopis R, Sánchez D, Cabello R. R-152a as an alternative refrigerant to R-134a in domestic refrigerators: An experimental analysis. Int J Refrig 2018;96:106-16. doi:10.1016/J.IJREFRIG.2018.09.020.

[22] Mota-Babiloni A, Navarro-Esbrí J, Barragán Á, Molés F, Peris B. Drop-in energy performance evaluation of R1234yf and R1234ze(E) in a vapor compression system as R134a replacements. Appl Therm Eng 2014;71:259-65. doi:10.1016/j.applthermaleng.2014.06.056.

[23] Palm B. Hydrocarbons as refrigerants in small heat pump and refrigeration systems - A review. Int J Refrig 2008;31:552-63. doi:10.1016/J.IJREFRIG.2007.11.016.

[24] Mota-Babiloni A, Belman-Flores JM, Makhnatch P, Navarro-Esbrí J, Barroso-Maldonado JM. Experimental exergy analysis of R513A to replace R134a in a small capacity refrigeration system. Energy 2018;162:99-110. doi:10.1016/J.ENERGY.2018.08.028.

[25] Eyerer S, Dawo F, Kaindl J, Wieland C, Spliethoff H. Experimental investigation of modern ORC working fluids R1224yd(Z) and R1233zd(E) as replacements for R245fa. Appl Energy 2019;240:946-63. doi:10.1016/J.APENERGY.2019.02.086.

[26] Molés F, Navarro-Esbrí J, Peris B, Mota-Babiloni A. Experimental evaluation of HCFO1233zd-E as HFC-245fa replacement in an Organic Rankine Cycle system for low temperature heat sources. Appl Therm Eng 2016;98:954-61. doi:10.1016/j.applthermaleng.2016.01.011.

[27] Juhasz JR. Novel Working Fluid , HFO-1336mzz ( E ), for Use in Waste Heat Recovery Application. 12th IEA Heat Pump Conf 2017, Rotterdam 2017.

[28] Navarro-Esbrí J, Molés F, Peris B, Mota-Babiloni A, Kontomaris K. Experimental study of an Organic Rankine Cycle with HFO-1336mzz-Z as a low global warming potential working fluid for micro-scale low temperature applications. Energy 2017;133. doi:10.1016/j.energy.2017.05.092.

[29] Mateu-Royo C, Navarro-Esbrí J, Mota-Babiloni A, Amat-Albuixech M, Molés F. Thermodynamic analysis of low GWP alternatives to HFC-245fa in high-temperature heat pumps: HCFO-1224yd(Z), HCFO-1233zd(E) and HFO-1336mzz(Z). Appl Therm Eng 2019. doi:10.1016/j.applthermaleng.2019.02.047.

[30] Chemours. Opteon ${ }^{\mathrm{TM}}$ XP30 (R-514A), Technical information 2019:1-16.

[31] Majurin J, Sorenson E, Steinke D, Herried M. Chemical Stability Assessments of R-514A and R-1233zd(E). ASHRAE Winter Conf Las Vegas, NV 2017.

[32] Moisi H, Rieberer R. Refrigerant Selection and Cycle Development for a High Temperature Vapor Compression Heat Pump. 12th IEA Heat Pump Conf 2017, Rotterdam 2017:1-10.

[33] Bamigbetan $\mathrm{O}$, Eikevik TM, Nekså $\mathrm{P}$, Bantle M, Schlemminger C. Experimental investigation of a prototype R-600 compressor for high temperature heat pump. Energy 2019;169:730-8. doi:10.1016/J.ENERGY.2018.12.020.

[34] Mateu-Royo C, Navarro-Esbrí J, Mota-Babiloni A, Amat-Albuixech M, Molés F. Theoretical evaluation of different high-temperature heat pump configurations for low-grade waste heat recovery. Int J Refrig 2018. doi:10.1016/j.ijrefrig.2018.04.017.

[35] Frate GF, Ferrari L, Desideri U. Analysis of suitability ranges of high temperature heat pump working fluids. Appl Therm Eng 2019;150:628-40. doi:10.1016/J.APPLTHERMALENG.2019.01.034. 
[36] Arpagaus C, Kuster R, Prinzing M, Bless F, Uhlmann M, Büchel E, et al. High temperature heat pump using HFO and HCFO refrigerants - System design and experimental results. 25th IIR Int. Congr. Refrig. (ICR 2019). Montréal, Québec, Canada., 2019. doi:10.18462/iir.icr.2019.242.

[37] Lemmon EW, Bell IH, Huber ML, McLinden MO. NIST Standard Reference Database: Reference Fluid Thermodynamic and Transport Properties-REFPROP, Version 10. Natl Inst Stand Technol Stand Ref Data Program, Boulder, CO 2018.

[38] ASHRAE. ASHRAE Handbook Fundamentals. Am Soc Heating, Refrig Air-Conditioning Eng 2017.

[39] Klein S. Engineering Equation Solver (EES) V10.6. Fchart Software, Madison, USA WwwFchartCom 2006.

[40] Meteotest 2016. Meteonorm Software V7. Bern, Switzerland, n.d.

[41] Adrianto LR, Grandjean P-A, Sawalha S. Heat Recovery from CO2 Refrigeration System in Supermarkets to District Heating Network. 13th IIR Gustav Lorentzen Conf IIR/IIF, Val Spain 2019.

[42] Stockholm Exergi. Öppen Fjärrvärme 2019. https://www.oppenfjarrvarme.se/dagens-priser/.

[43] Granryd E, Ekroth I, Lundqvist P, Melinder A, Palm B, Rohlin P. Refrigeration Engineering. K Tek Högskolan 1999.

[44] Mateu-Royo C, Navarro-Esbrí J, Mota-Babiloni A, Molés F, Amat-Albuixech M. Experimental exergy and energy analysis of a novel high-temperature heat pump with scroll compressor for waste heat recovery. Appl Energy 2019;253:113504. doi:10.1016/J.APENERGY.2019.113504.

[45] EEA. Overview of electricity production and use in Europe. Eur Enviroment Agency 2018.

[46] Scoccia R, Toppi T, Aprile M, Motta M. Absorption and compression heat pump systems for space heating and DHW in European buildings: Energy, environmental and economic analysis. J Build Eng 2018;16:94-105. doi:10.1016/J.JOBE.2017.12.006.

[47] Makhnatch P, Khodabandeh R. The role of environmental metrics (GWP, TEWI, LCCP) in the selection of low GWP refrigerant. Energy Procedia 2014;61:2460-3. doi:10.1016/j.egypro.2014.12.023.

[48] IPCC. IPCC/TEAP special report on safeguarding the ozone layer and the global climate system: Issues related to hydrofluorocarbons and perfluorocarbons. Cambridge Publ Intergov Panel Clim Chang [by] Cambridge Univ Press 2005. 


\section{Chapter 9 Conclusions and Future Work}

\subsection{General discussion and conclusions}

This thesis deals with different challenges that enable the development of high temperature heat pumps for industrial waste heat recovery. A literature review determined the state-of-the-art and the future trends, paying particular attention to refrigerants, components, configurations, research developed projects and market situation. Based on this literature review, multiple configurations and refrigerants have been theoretically analysed in order to provide knowledge about the most appropriate configuration and refrigerant for each application. Moreover, a prototype of high temperature heat pump was built to prove the viability of this technology and provide the operation of these systems at high temperature applications. Finally, a reversible organic Rankine cycle - high temperature heat pump system was studied to extend the applications of these systems and then, the integration of high temperature heat pump with district heating networks was studied to promote the utilisation of heat pumps in other waste heat recovery scenarios. Therefore, the development of high temperature heat pumps for waste heat recovery can replace the conventional fossil fuel heating technology and reduce the waste heat rejected to the ambient. Both achievements represent an advance in the integration of sustainable technology in the industrial sector and contribute to climate change mitigation.

This work consists of a compendium of different articles that covers four required elements in the technology development: state-of-the-art, theoretical analysis, experimental/semi-empirical evaluation along with advanced applications and system integration. As a result of the conducted investigation, several conclusions increase the practical knowledge about this technology and contribute to the development and integration of high temperature heat pumps as sustainable waste heat recovery and heating technology.

From the literature review, the comprehensive overview of the high temperature heat pump technology results in the following conclusions:

- HFC-245fa becomes the most used refrigerant in HTHPs and the reference working fluid, but due to its high GWP, it is necessary to find an alternative refrigerant. Sustainability, commercial availability, safety and similar thermodynamic properties are the main criteria for the refrigerant selection.

- HC-601 (Pentane), HC-600 (Butane), R-514A, HFO-1336mzz(Z), HCFO-1233zd(E) and HCFO-1224yd(Z) becomes potential alternative low GWP refrigerants to replace HFC- 
Chapter 9

245fa, being the last three refrigerants the most promising candidates. These candidates present material compatibility with the most common elastomers and oil lubricants (POE).

- Single-stage and two-stage configurations are the most common architectures in commercial, research and development systems, including the use of internal heat exchanger (IHX) in most of the configurations.

- Reciprocating and screw compressors are the most used technologies in these systems, becoming scroll compressors an interesting research gap to be studied for small scale applications.

- From the overview of commercial and research developments, the future trend of this technology lies in the development of an HTHP capable of increasing the current supply temperature with higher heat source temperatures.

From the theoretical analysis of different system configurations and potential low GWP refrigerants in high temperature heat pumps, the achievements are presented:

- The difference between the heat sink and source temperature, known as temperature lift, becomes a sensitive parameter in evaluating vapour compression systems, especially for high temperature applications.

- For a temperature lift around $40 \mathrm{~K}$, the single-stage configuration with IHX becomes the most appropriate architecture, but as the temperature lift increases, a two-stage cycle with IHX becomes the most convenient configuration.

- The refrigerant evaluation illustrates that there is a trend between COP and volumetric heating capacity. The most efficient refrigerants that provide the highest COP have the lowest volumetric heating capacity and vice versa. Thus, the refrigerant selection will be highly dependent on the application, along with the installation and energy cost.

- HC-601, R-514A and HFO-1336mzz(Z) require a significant superheat degree (around $20 \mathrm{~K}$ ) to ensure the dry compression, whereas this requirement results between 7 to $4 \mathrm{~K}$ for HCFO$1233 z d(E)$ and HCFO-1224yd(Z). Hence, an IHX becomes an essential component in HTHPs systems to be included in order to ensure dry compression.

- HCFO-1224yd(Z) and HCFO-1233zd(E) are the most promising low GWP alternative refrigerants for drop-in replacement of HFC-245fa, obtaining a potential COP improvement of $21 \%$ and $17 \%$, respectively, with similar values of volumetric heating capacity to the reference working fluid.

- The TEWI analysis illustrates a potential decrease of equivalent $\mathrm{CO}_{2}$ emissions up to $60 \%$ with the use of low GWP refrigerants instead of HFC-245fa. 
From the experimental and semi-empirical evaluation of the HTHP prototype, the main outcomes obtained are the following:

- The HTHP prototype with scroll compressor provides significant performance improvements for low-grade waste heat recovery. At a heat source temperature of $80{ }^{\circ} \mathrm{C}$ and heat sink temperature of $140{ }^{\circ} \mathrm{C}$, the COP was 2.23 . The highest COP was 3.41 , which was achieved at heat source and heat sink temperatures of 80 and $110^{\circ} \mathrm{C}$, respectively.

- The exergy analysis illustrated the areas of potential performance improvements. The compressor is the component with the highest irreversibility and therefore, appears as the highest source for improvement. Mechanical design and lubrication improvements in this component could increase the overall system efficiency. The expansion valve is the component with the second highest irreversibility of the system. Its replacement with ejector could improve the performance of the installation.

- The potential of HTHP as a waste heat recovery system was demonstrated with the integration of this technology in a CHP installation. The environmental results showed that the HTHP system could reduce the equivalent $\mathrm{CO}_{2}$ emission up to $57.3 \%$ compared to conventional heating technologies, in this case, a natural gas boiler.

- The semi-empirical computational evaluation showed that either HCFO-1233zd(E) or HCFO-1224yd(Z) could be used as a possible drop-in replacement for HFC-245fa in hightemperature heat pumps. Although HFO-1336mzz(Z) presents a higher COP than the other refrigerants, it requires a greater compressor size to provide similar heating capacities owing to its lower suction density.

- The volumetric heating capacity of HCFO- $1224 \mathrm{yd}(\mathrm{Z})$ is about $8.5 \%$ lower than HFC-245fa used as a drop-in in replacement in an HFC-245fa experimental setup. This difference is strongly related to heating capacity reduction, operating with the same volumetric flow rate.

- The COP values obtained with HCFO-1224yd(Z) are comparable or even $4.5 \%$ higher than those obtained with HFC-245fa. At the maximum heat sink temperature of $140{ }^{\circ} \mathrm{C}, \mathrm{HCFO}-$ $1224 \mathrm{yd}(\mathrm{Z})$ provides a COP of 2.33, whereas HFC-245fa shows a value of 2.23.

- The energy performance parameters of HCFO-1224yd(Z) in a drop-in replacement are close to those obtained with HFC-245fa in high temperature heat pumps. Hence, HCFO-1224yd(Z) becomes a potential low-GWP alternative to replace the reference working fluid HFC-245fa.

From the advanced configuration and integration, the main results corresponding to this section are presented in detail as follows:

- The proposed reversible HTHP-ORC system provides a significant performance improvement for low-grade waste heat recovery. At the middle evaporating temperature of $85^{\circ} \mathrm{C}$, a COP of 2.22 is achieved condensing at $140{ }^{\circ} \mathrm{C}$, working as HTHP mode, whereas the ORC mode achieves a net electrical efficiency of $7.25 \%$ at a condensing temperature of $40{ }^{\circ} \mathrm{C}$. The highest performance results are a COP of 2.44 and a net electric efficiency of $8.75 \%$, both considering an evaporating temperature of $100{ }^{\circ} \mathrm{C}$. 
Chapter 9

- About the system architecture, different power capacities for the electric motor and generator are required. Therefore, a single component can be used as a compressor or expander, but the electric motor and generator should be different.

- The integration of HTHPs into DHNs provides significant environmental and performance improvements, being an innovative and profitable system solution to decarbonise different sectors.

- Using the DHN as a heat sink, the $\mathrm{COP}_{\mathrm{WHR}}$ results between 3.2 and 5.4, reducing the operating cost between $50 \%$ and $100 \%$ with an average price ratio of 2.25 compared with the standard $\mathrm{CO}_{2}$ refrigeration system. With the DHN as the heat source, the integrated system provides a COP from 2.8 to 5.7 for a heat sink of $110^{\circ} \mathrm{C}$. A reasonable heat selling price to DHN will promote the application of this WHR technology due to the higher benefit for the prosumers

- HC-290, HFO-1234ze(E) and HFO-1234yf were considered the ideal alternative low-GWP refrigerants to replace the HFC-134a in new design installations. Moreover, HCFO$1233 \mathrm{zd}(\mathrm{E})$ and HCFO-1224yd(Z) were the most promising low-GWP refrigerants to replace the reference working fluid, HFC-245fa.

- The environmental results, using the $\mathrm{DHN}_{\text {sink }}$ scenario, showed that the integrated system solution produces about $60 \%$ lower equivalent $\mathrm{CO}_{2}$ emissions than the DHN generation mix over the winter period. Moreover, the $\mathrm{DHN}_{\text {source }}$ scenario can reduce the equivalent $\mathrm{CO}_{2}$ emissions up to $47 \%$ using the EU carbon emission factor, whereas this reduction can be about $98 \%$ for Sweden. Therefore, this integrated system becomes a potential solution to replace the conventional natural gas boilers and reduce the greenhouses gas emission in the industrial sector.

Overall, high temperature heat pumps offer an opportunity to improve the energy efficiency in the industrial sector, contributing to climate change mitigation due to the equivalent $\mathrm{CO}_{2}$ emissions reduction. Operating at high temperatures require improvements in the materials and components to facilitate the implementation of this technology. Novel compressors developments will extend the actual temperature limits of high temperature heat pumps, increasing the opportunities as waste heat recovery technology. The use of low GWP refrigerants contributes to reducing greenhouse gasses emissions, obtaining a technology that will promote sustainable development. Advanced configurations and the integration with other technologies as district heating networks improve the utility and flexibility, extending the applications of this technology. All in all, high temperature heat pumps appears as a promising technology that could boost sustainable development, increasing energy efficiency and decarbonising the world.

\subsection{Future work suggestions}

High temperature heat pump technology is situated in the early development stage, which means that there is still a long way of progress and improvements. Although vapour compression systems, especially heat pumps, are a mature technology with long haul, the operation at high temperature conditions requires significant developments. This thesis aimed to throw light on this field, but much needs to be done. Hence, some suggested research lines for the future are as follows: 
- Developing and improving compressors that allow higher suction and discharge temperatures than the current designs along with the comprehensive evaluation of the lubrication at high temperature conditions.

- Analysing experimentally low GWP alternative refrigerants that will replace the actual HFCs, looking for potential drop-in replacements that can be used with the actual designs. Moreover, the evaluation of potential mixtures that improve the thermodynamic properties of the pure fluids used in HTHPs.

- Testing an HTHP prototype in existing industrial installations in order to illustrate the real potential of this technology in several types of applications, quantifying the energy, economic and environmental savings.

- Combining this technology with others as solar, district heating networks, CHP, etc., to evaluate the advantage or disadvantage in terms of performance, flexibility and stability.

- Evaluating the scalability of this technology in order to be integrated into other industries with heat sources of higher thermal capacity, and therefore, extending this possibility of energy efficiency enhancement to other installations.

- Developing smart communication and control to optimise the HTHP operation, improving its energy efficiency and facilitating its integration to Industry 4.0. 
Chapter 9 


\section{Chapter 10 Scientific Production}

\subsection{Journal contribution}

1. Mateu-Royo, C., Mota-Babiloni, A., Navarro-Esbrí, J., Barragán-Cervera, A. Experimental comparison of HFO-1234ze(E) and R-515B to replace HFC-134a in heat pump water heaters and moderately high temperature heat pumps. Applied Thermal Engineering (2020). (Submitted paper)

2. Mateu-Royo, C., Mota-Babiloni, A., Navarro-Esbrí, J. Semi-empirical and environmental assessment of the low GWP refrigerant HCFO-1224yd(Z) to replace HFC-245fa in high temperature heat pumps. International Journal of Refrigeration (2021). DOI: $\underline{10.1016 / j . i j r e f r i g .2021 .02 .018}$

3. Mateu-Royo, C., Mota-Babiloni, A., Navarro-Esbrí, J., Barragán-Cervera, A. Comparative analysis of HFO-1234ze(E) and R-515B as low GWP alternatives to HFC-134a in moderately high temperature heat pumps. International Journal of Refrigeration 124, 197-206 (2021). DOI: doi.org/10.1016/j.ijrefrig.2020.12.023

4. Mateu-Royo, C., Arpagaus, C., Mota-Babiloni, A., Navarro-Esbrí, J., Bertsch, S. S. Advanced high temperature heat pump configurations using low GWP refrigerants for industrial waste heat recovery: A comprehensive study. Energy Conversion and Management 229, 113752 (2021). DOI: doi.org/10.1016/j.enconman.2020.113752

5. Mateu-Royo, C., Navarro-Esbrí, J., Mota-Babiloni, A., Barragán-Cervera, A. Theoretical performance evaluation of ejector and economizer with parallel compression configurations in high temperature heat pumps. International Journal of Refrigeration 119, 356 - 365 (2020). DOI: $10.1016 /$ j.ijrefrig.2020.07.016

6. Mateu-Royo, C., Sawalha, S., Mota-Babiloni, A., Navarro-Esbrí, J. High temperature heat pump integration into district heating network. Energy Conversion and Management 210, 112719 (2020). DOI: $\underline{10.1016 / j . e n c o n m a n .2020 .112719}$

7. Mota-Babiloni, A., Navarro-Esbrí, J., Molés, F., Mateu-Royo, C. A practical approach for teaching the organic Rankine cycles (ORC) in an advanced thermodynamics course. DYNA Journal 95, 154 - 157 (2020). DOI: 10.6036/9211 
8. Mota-Babiloni, A., Joybari, M. M., Navarro-Esbrí, J., Mateu-Royo, C., Barragán-Cervera, A., Amat-Albuixech, M., Molés, F. Ultralow-temperature refrigeration systems: Configurations and refrigerants to reduce the environmental impact. International Journal of Refrigeration 111, 147 - 158 (2020). DOI: 10.1016/j.ijrefrig.2019.11.016

9. Navarro-Esbrí, J., Amat-Albuixech, M., Molés, F., Mateu-Royo, C., Mota-Babiloni, Collado, R. HCFO-1224yd(Z) as HFC-245fa drop-in alternative in low temperature ORC systems: Experimental analysis in a waste heat recovery real facility. Energy 193, 116701 (2020). DOI: 10.1016/j.energy.2019.116701

10. Mateu-Royo, C., Navarro-Esbrí, J., Mota-Babiloni, A., Molés, F., Amat-Albuixech, M. Experimental exergy and energy analysis of a novel high-temperature heat pump with scroll compressor for waste heat recovery. Applied Energy 253, 113504 (2019). DOI: $\underline{10.1016 / \text { j.apenergy.2019.113504 }}$

11. Karampour, M,. Mateu-Royo, C., Rogstam, J., Sawalha, S. Geothermal storage integration into a supermarket's CO2 refrigeration system. International Journal of Refrigeration 106, $492-505$ (2019). DOI: $10.1016 /$ j.ijrefrig.2019.05.026

12. Mateu-Royo, C., Mota-Babiloni, A., Navarro-Esbrí, J., Peris, B., Molés, F., Amat-Albuixech, M. Multi-objective optimization of a novel reversible High-Temperature Heat Pump-Organic Rankine Cycle (HTHP-ORC) for industrial low-grade waste heat recovery. Energy Conversion and Management 197, 111908 (2019). DOI: 10.1016/j.enconman.2019.111908

13. Mateu-Royo, C., Navarro-Esbrí, J., Mota-Babiloni, A., Amat-Albuixech, M., Molés, F. Thermodynamic analysis of low GWP alternatives to HFC-245fa in high-temperature heat pumps: HCFO-1224yd(Z), HCFO-1233zd(E) and HFO-1336mzz(Z). Applied Thermal Engineering 152, 762 - 777 (2019). DOI: 10.1016/j.applthermaleng.2019.02.047

14. Mota-Babiloni, A., Mateu-Royo, C., Navarro-Esbrí, J., Molés, F., Amat-Albuixech, M., Barragán-Cervera, A. Optimisation of high-temperature heat pump cascades with internal heat exchangers using refrigerants with low global warming potential. Energy 165B, 1248 1258 (2018). DOI: 10.1016/j.energy.2018.09.188

15. Mateu-Royo, C., Navarro-Esbrí, J., Mota-Babiloni, A., Amat-Albuixech, M., Molés, F. Theoretical evaluation of different high-temperature heat pump configurations for low-grade waste heat recovery. International Journal of Refrigeration 90, 229 - 237 (2018). DOI: 10.1016/j.ijrefrig.2018.04.017

16. Molés, F., Navarro-Esbrí, J., Peris, B., Mota-Babiloni, A., Mateu-Royo, C. R1234yf and R1234ze as alternatives to R134a in Organic Rankine Cycles for low temperature heat sources. Energy Procedia 142, 1192 - 1198 (2017). DOI: 10.1016/j.egypro.2017.12.380 


\subsection{International conferences contribution}

1. Mateu-Royo, C., Navarro-Esbrí, J., Mota-Babiloni, A., Molés, F., Amat-Albuixech, M. Semiempirical evaluation of HCFO-1224yd(z) as a replacement for HFC-245fa in high temperature heat pumps*. IIR International Rankine 2020 Conference-Heating, Cooling and Power Generation -, Glasgow, UK, $26^{\text {th }}-29^{\text {th }}$ July 2020.

2. Amat-Albuixech, M., Navarro-Esbrí, J., Molés, F., Mota-Babiloni, A., Mateu-Royo, C. Experimental drop-in replacement of HFC-245fa by HCFO- 1224yd(Z), a low-GWP working fluid candidate for low- temperature organic Rankine cycles. IIR International Rankine 2020 Conference -Heating, Cooling and Power Generation, Glasgow, UK, $26^{\text {th }}-29^{\text {th }}$ July 2020.

3. Navarro-Esbrí, J., Amat-Albuixech, M., Mota-Babiloni, A., Molés, F., Mateu-Royo, C. Small-scale organic Rankine cycle for domestic biomass fueled Combined Heat and Power applications. $5^{\text {th }}$ International Seminar on ORC Power Systems, Atenas, Greece, $9^{\text {th }}-11^{\text {th }}$ September 2019. ISBN 9789090320380.

4. Molés, F., Navarro-Esbrí, J., Amat-Albuixech, M., Mota-Babiloni, A., Mateu-Royo, C. Analysis of low global warming potential alternatives to HFC-245fa in micro scale low temperature organic Rankine cycles. $5^{\text {th }}$ International Seminar on ORC Power Systems, Atenas, Greece, $9^{\text {th }}-11^{\text {th }}$ September 2019. ISBN 9789090320380.

5. Mateu-Royo, C., Mota-Babiloni, A., Navarro-Esbrí, J., Molés, F., Amat-Albuixech, M. Development of a high-temperature heat pump prototype with scroll compressor for industrial waste heat recovery. $2^{\text {nd }}$ Symposium on High-Temperature Heat Pumps. Copenhagen, Denmark, $9^{\text {th }}$ September 2019. ISBN 9788259437815.

6. Mateu-Royo, C., Navarro-Esbrí, J., Mota-Babiloni, A., Molés, F., Amat-Albuixech, M. Thermodynamic analysis of a novel high-temperature heat pump for low-grade waste heat recovery. $25^{\text {th }}$ IIR International Congress of Refrigeration. Montreal, Canada, $25^{\text {th }}-28^{\text {th }}$ August 2019. ISBN 9782362150357.

7. Mota-Babiloni, A., Navarro-Esbrí, J., Mateu-Royo, C., Molés, F., Barragán-Cervera, A., Amat-Albuixech, M. Liquid-to-suction heat exchanger assessment using new synthetic refrigerants to replace R-134a. 25 th IIR International Congress of Refrigeration. Montreal, Canada, $25^{\text {th }}-28^{\text {th }}$ August 2019. ISBN 9782362150357.

8. Karampour, M., Mateu-Royo, C., Rogstam, J., Sawalha, S. Integration of supermarket's $\mathrm{CO}_{2}$ refrigeration system and geothermal storage. $25^{\text {th }}$ IIR International Congress of Refrigeration. Montreal, Canada, 25 ${ }^{\text {th }}-28^{\text {th }}$ August 2019. ISBN 9782362150357.

\footnotetext{
* Winner of the Best Paper by a Student Author on the Theme of Working Fluids
} 
9. Mateu-Royo, C., Navarro-Esbrí, J., Mota-Babiloni, A., Amat-Albuixech, M., Molés, F. Stateof-the-art of high-temperature heat pumps for low-grade waste heat recovery. $11^{\text {th }}$ National and $2^{\text {nd }}$ International Engineering Thermodynamics Congress (11CNIT), Albacete, Spain, $12^{\text {th }}-14^{\text {th }}$ June 2019. ISBN 9788409116355.

10. Mateu-Royo, C., Navarro-Esbrí, J., Mota-Babiloni, A., Amat-Albuixech, M., Molés, F. Theoretical analysis of two-stage vapour compression cycle in high temperature heat pumps for low-grade waste heat recovery. 11th National and 2nd International Engineering Thermodynamics Congress (11CNIT), Albacete, Spain, $12^{\text {th }}-14^{\text {th }}$ June 2019. ISBN 9788409116355 .

11. Amat-Albuixech, M., Navarro-Esbrí, J., Molés, F., Mota-Babiloni, A., Mateu-Royo, C., Barragán-Cervera, A. Theoretical analysis of a small-scale and low-temperature Organic Rankine Cycle for a domestic Combined Heat and Power application. $11^{\text {th }}$ National and $2^{\text {nd }}$ International Engineering Thermodynamics Congress (11CNIT), Albacete, Spain, $12^{\text {th }}-14^{\text {th }}$ June 2019. ISBN 9788409116355.

12. Navarro-Esbrí, J., Molés, F., Amat-Albuixech, M., Mota-Babiloni, A., Mateu-Royo, C., HFO-1336mzz (Z) and HCFO-1233zd(E) as alternatives to HFC-245fa in organic Rankine cycles for micro-scale low-temperature applications. $I^{\text {st }}$ IIR International Conference on the Application of HFO Refrigerants. Birmingham, UK, $2^{\text {nd }}-5^{\text {th }}$ June 2019. ISSN 0151-1637.

13. Peris, B., Navarro-Esbrí, J., Molés, F., Amat-Albuixech, M., Mota-Babiloni, A., MateuRoyo, C., Low GWP working fluids for reversible systems of high temperature heat pump and organic Rankine cycle (HTHP/ORC). $13^{\text {th }}$ IIR Gustav Lorentzen Conference on Natural Refrigerants: Natural Refrigerant Solutions for Warm Climate Countries (GL 2018). Valencia, Spain, $18^{\text {th }}-20^{\text {th }}$ June 2018. ISSN 0151-1637

14. Mateu-Royo, C., Karampour, M., Rogstam, J., Sawalha, S. Integration of geothermal storage in $\mathrm{CO}_{2}$ refrigeration systems of supermarkets. $13^{\text {th }}$ IIR Gustav Lorentzen Conference on Natural Refrigerants: Natural Refrigerant Solutions for Warm Climate Countries (GL 2018). Valencia, Spain, $18^{\text {th }}-20^{\text {th }}$ June 2018. ISSN 0151-1637

15. Molés, F., Navarro-Esbrí, J., Peris, B., Mota-Babiloni, A., Mateu-Royo, C. R1234yf and R1234ze as alternatives to R134a in Organic Rankine Cycles for low temperature heat sources. $9^{\text {th }}$ International Conference on Applied Energy, ICAE2017. Cardiff, UK, $21^{s t}-24^{\text {th }}$ June 2018. ISSN 1876-6102 


\subsection{National conferences contribution}

1. Mateu-Royo, C., Navarro-Esbrí, J., Mota-Babiloni, A., Moles, F., González-Piquer, M., Barragán-Cervera, A. Desarrollo experimental de un prototipo de bomba de calor de alta temperatura para la recuperación de calor residual industrial. X Congreso Ibérico y VIII Congreso Iberoamericano de Ciencias y Técnicas del Frío. Pamplona, Spain, $11^{\text {th }}-12^{\text {th }}$ November 2020. ISBN 9782362150432.

2. Mateu-Royo, C., Mota-Babiloni, A., Navarro-Esbrí, J., Moscardó-Boscá, R., Moles, F., Barragán-Cervera, A. Evaluación teórica de compresión en paralelo y eyector como configuraciones para bombas de calor de alta temperatura. X Congreso Ibérico y VIII Congreso Iberoamericano de Ciencias y Técnicas del Frio. Pamplona, Spain, $11^{\text {th }}-12^{\text {th }}$ November 2020. ISBN 9782362150432.

3. Mota-Babiloni, A., Navarro-Esbrí, J., Barragán-Cervera, A., Martínez-Micó, A., Mateu-

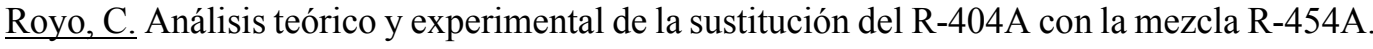
$X$ Congreso Ibérico y VIII Congreso Iberoamericano de Ciencias y Técnicas del Frío. Pamplona, Spain, $11^{\text {th }}-12^{\text {th }}$ November 2020. ISBN 9782362150432.

4. Mota-Babiloni, A., Navarro-Esbrí, J., Barragán-Cervera, A., Gómez-Macián, C., MolésRibera, F., Mateu-Royo, C. Análisis de R-452A como alternativa al R-404A en sistemas de compresión de vapor. X Congreso Ibérico y VIII Congreso Iberoamericano de Ciencias y Técnicas del Frío. Pamplona, Spain, $11^{\text {th }}-12^{\text {th }}$ November 2020. ISBN 9782362150432.

5. Karampour, M., Sawalha, S., Mateu-Royo, C., Rogstam, J. Geothermal Storage Integration into Supermarket's $\mathrm{CO}_{2}$ Refrigeration System. International Ground Source Heat Pump Association (IGSHPA) Research Track, Stockholm, Sweden, $18^{\text {th }}-20^{\text {th }}$ September 2018.

6. Mota-Babiloni, A., Navarro-Esbrí, J., Mateu-Royo, C., Molés, F., Amat-Albuixech, M., Barragán-Cervera, A. Propuesta De Simulador De Bomba De Calor De Alta Temperatura Para Uso Educativo. VII Congreso Internacional Multidisciplinar de Investigación Educativa: La marcha de las ciencias de la educación (CIMIE 2018). Zaragoza, Spain, $5^{\text {th }}$ $6^{\text {th }}$ July 2018. ISBN 9788409084593.

7. Mota-Babiloni, A., Navarro-Esbrí, J., Mateu-Royo, C., Barragán-Cervera, A. Sostenibilidad medioambiental en las aulas universitarias a través de refrigerantes de bajo PCA. IX Congreso Ibérico y VII Congreso Iberoamericano de Ciencias y Técnicas del Frío. Valencia, Spain, $19^{\text {th }}-21^{\text {st }}$ June 2018. ISBN 9788409016198.

8. Navarro-Esbrí, J., Mateu-Royo, C., Amat-Albuixech, M., Molés, F., Mota-Babiloni, A. Bombas de calor de alta temperatura y fluidos de trabajo alternativos de bajo PCA. $I X$ Congreso Ibérico y VII Congreso Iberoamericano de Ciencias y Técnicas del Frío. Valencia, Spain, $19^{\text {th }}-21^{\text {st }}$ June 2018. ISBN 9788409016198. 
9. Mateu-Royo, C., Karampour, M., Sawalha, S. Mota-Babiloni, A., Navarro-Esbrí, J. Soluciones para reducir el consumo energético de supermercados en climas fríos. IX Congreso Ibérico y VII Congreso Iberoamericano de Ciencias y Técnicas del Frío. Valencia, Spain, $19^{\text {th }}-21^{\text {st }}$ June 2018. ISBN 9788409016198.

10. Mateu-Royo, C., Navarro-Esbrí, J., Molés, F., Mota-Babiloni, A., Barragán-Cervera, A. Simulador de ciclo de refrigeración para la implementación educativa de la sostenibilidad ambiental. First International Conference on Engineering Education for the XXI Century ICEE21C, Castellón de la Plana, Spain, $6^{\text {th }}-7^{\text {th }}$ July 2017. ISBN 9788490826423.

11. Peris, B., Navarro-Esbrí, J., Mateu-Royo, C., Molés, F., Mota-Babiloni, A. Banco de pruebas virtual de ciclos de potencia. First International Conference on Engineering Education for the XXI Century - ICEE21C, Castellón de la Plana, Spain, $6^{\text {th }}-7^{\text {th }}$ July 2017. ISBN 9788490826423.

12. Mota-Babiloni, A., Navarro-Esbrí, J., Barragán-Cervera, A., Pérez-Belis, V., Mateu-Royo, C.Utilización de un refrigerante de menor PCA en sistemas de compresión de vapor de R134a. First International Conference on Engineering Education for the XXI Century ICEE21C, Castellón de la Plana, Spain, $6^{\text {th }}-7^{\text {th }}$ July 2017. ISBN 9788490826423.

13. Barragán-Cervera, A., Navarro-Esbrí, J., Peris, B., Mateu-Royo, C., Molés, F._Utilización de un refrigerante de menor PCA en sistemas de compresión de vapor de R134a. First International Conference on Engineering Education for the XXI Century - ICEE21C, Castellón de la Plana, Spain, $6^{\text {th }}-7^{\text {th }}$ July 2017. ISBN 9788490826423.

\subsection{Book chapters}

Mota-Babiloni, A., Mateu-Royo, C., Navarro-Esbrí, J. Chapter 17: High-Temperature Heat Pumps for a Sustainable Industry. In book: Emerging Research in Sustainable Energy and Buildings for a Low-Carbon Future (Editors: Howlett, R. J., Littlewood, J. R., Jain, L. C.), 364 pages (2021). Springer Nature Singapore, Singapore. 